US Army Corps

of Engineers ${ }_{\circledast}$

Engineer Research and

Development Center

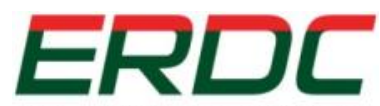

INNOVATIVE SOLUTIONS for a safer, better world

Environmental Security Technology Certification Program (ESTCP)

\title{
Demonstration of the Energy Component of the Installation Master Plan Using the "Net Zero Energy Planner" Tool
}

Alexander M. Zhivov, Michael. P. Case, Richard Liesen,

October 2015 and Matthew Swanson

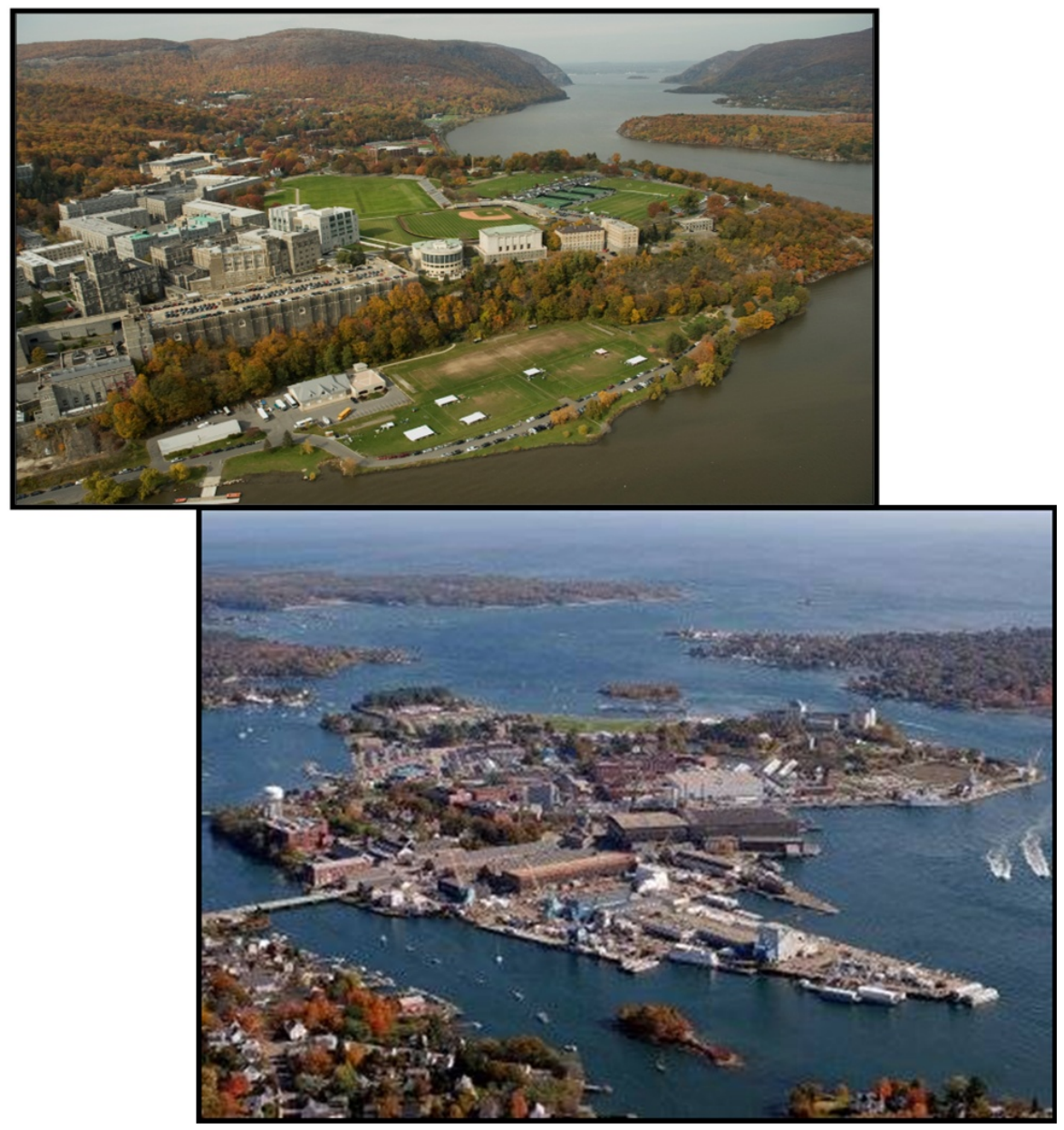


The U.S. Army Engineer Research and Development Center (ERDC) solves the nation's toughest engineering and environmental challenges. ERDC develops innovative solutions in civil and military engineering, geospatial sciences, water resources, and environmental sciences for the Army, the Department of Defense, civilian agencies, and our nation's public good. Find out more at www.erdc.usace.army.mil.

To search for other technical reports published by ERDC, visit the ERDC online library at http://acwc.sdp.sirsi.net/client/default. 


\section{Demonstration of the Energy Component of the Installation Master Plan Using the "Net Zero Energy Planner" Tool}

Alexander M. Zhivov, Michael. P. Case, Richard Liesen, and Matthew Swanson

U.S. Army Engineer Research and Development Center (ERDC)

Construction Engineering Research Laboratory (CERL)

2902 Newmark Dr.

Champaign, IL 61822

Final Report

Approved for public release; distribution is unlimited.

Prepared for Headquarters, U.S. Army Corps of Engineers

Washington, DC 20314-1000 


\section{Abstract}

This work demonstrated the energy master planning (EMP) concept and automated Net Zero Planner tool (NZP) developed by the Army Engineer Research and Development Center (ERDC) at two U.S. Department of Defense (DoD) installations: United States Military Academy, West Point (USMA) and Portsmouth Navy Shipyard (PNSY). The NZP Tool incorporates the concept and various automated modules to integrate optimization across buildings, distribution, and generation systems. Results demonstrated that use of the NZP Tool reduces the time required for the analysis and the analysis cost to $\sim 35 \%$ of the time required by the alternative current best practice. Lessons learned from the project were used to make many user interface changes were made throughout the program to facilitate the process, to ease data entry, and to help determine the information required to produce useful, relevant output reports. Funding for this demonstration was provided by the Environmental Security Technology Certification Program (ESTCP) - Energy and Water Project \# EW201240.

DISCLAIMER: The contents of this report are not to be used for advertising, publication, or promotional purposes. Citation of trade names does not constitute an official endorsement or approval of the use of such commercial products. All product names and trademarks cited are the property of their respective owners. The findings of this report are not to be construed as an official Department of the Army position unless so designated by other authorized documents. 


\section{Executive Summary}

\section{Technology description}

The U.S. Army Engineer Research and Development Center (ERDC) has developed an energy master planning (EMP) concept and the automated Net Zero Planner tool to support U.S. Department of Defense (DoD) energy policy. The energy concept minimizes energy use at the building level, improves the efficiency of energy conversion and distribution, and uses energy from renewable sources to balance fossil fuel based energy to achieve a net zero fossil fuel energy status. Energy goals are achieved through synergy among energy use reduction in building-related systems, energy supply, and distribution systems. The NZP Tool incorporates the concept and various automated modules to integrate optimization across buildings, and their energy generation and distribution systems

\section{Objectives of the demonstration}

The objective of this project was to demonstrate a holistic energy EMP concept and NZP at two defense installations, the U.S. Military Academy (USMA) at West Point, NY and the Portsmouth Naval Shipyard (PNSY), Kittery, ME. The demonstration was designed to test whether the implementation of this concept and tool together would reduce the time and cost of conducting an energy planning process in pursuit of DoD energy goals compared to working without the tool. Such goals may include achieving Net Zero Energy in a way that meets or exceeds EPAct (2005) and EISA (2007) criteria for energy intensity, that meets energy security requirements at a lower cost, and that controls electrical capacity growth requirements. If the tool could be demonstrated to reduce the time and cost of planning, then deployment of such a tool, together with a dissemination of lessons learned through pilot Energy Master Plans, would support achievement of DoD's mid- and long-term energy goals.

Two separate teams of experts with relevant experiences from the United States and around the world conducted the demonstrations at both sites. ERDC and Subject Matter Expert (SME) teams performed data collection and analysis and established the Baseline and Base Cases using typical EMP approaches. They conducted further analysis using the Net Zero Planner (NZP) Tool and SME calculation methods. 


\section{Demonstration results}

Several alternative scenarios were analyzed, including building energy efficiency improvements, decentralization of energy conversion systems, conversion from steam to hot water distribution systems, trigeneration, and energy supply from renewable sources. Analyses conducted for the USMA showed that, in spite of additional loads due to new construction and a new requirement for cooling in barracks, all analyzed scenarios, the Base Case, and four alternatives would significantly reduce energy use. Compared to the Baseline, the alternatives reduce energy use from 31 to $51 \%$ for site energy and from 27 to $84 \%$ for source energy, and they reduce energy costs from 27 to $84 \%$. NZE status for the selected area can be achieved by switching from natural gas to syngas in the future if its cost becomes comparable with that of natural gas.

For PNSY, the reduction of building and process loads with energy efficiency measures (EEMs) and the reduction of distribution and conversion losses were not enough to cost effectively meet the installation's energy goals. Navy installations can purchase renewable energy credits (RECs), but PNSY leadership expressed a preference for not exercising that option to attain the targets. At both installations, the NZP Tool method and SME manual method showed very similar modeling results at the building loads step of the process, and they also showed the same trends in life cycle cost (LCC) when conversion alternatives were compared.

The investment cost and energy usage results for both methods were generally within $10-20 \%$ of each other for all of the scenarios, despite the differences in the process used in each method. Furthermore, the energy usage and investment cost rankings, which were the same for both groups, ultimately resulted in the same recommendations for both installations.

A comparison of a budget allocated to conduct the energy analysis manually (using the two groups of SMEs and time and labor cost of ERDC researchers) with a budget to conduct a similar analysis using the NZE Planner Tool, showed that the application of the NZP Tool costs about $20 \%$ of the cost of the alternative (manual) method.

During application of the NZP, several modifications to the tool were made based on real life experiences gained by ERDC researchers. The current version of NZP was modified to increase the speed and efficiency of the 
EMP process significantly by simplifying repeated tasks to reduce the likelihood of human error in the tedious data entry tasks required in the process. Moreover, since these new features are easily accessible to both the experienced and less skilled users, new users with a broad range of skill sets can quickly be trained to use the system, typically under the guidance of SMEs.

The NZP team noted several additional benefits that result from using the tool. First, the speed of calculations and rollup was much better in the tool than in the process employed by the SMEs. Chapter 8 includes a detailed discussion of the relative labor costs of the SME approach vs. the NZP approach. For instance, during demonstration at USMA, the NZP Tool took $\sim 3$ weeks to set up and run the models while the SMEs took about 3 months. Second, once the models were created, it was considerably easier and less costly to make changes to the model and examine the results. The SME team required a good deal of time to coordinate results by passing spreadsheets back and forth. By contrast, NZP's ability to maintain, organize, and roll up the data made a change in the model relatively painless.

NZP also allows users to creatively customize the tool to adapt it to the intricacies of an individual installation by customizing building models to match construction types and vintage, and also to match energy supply configurations with in-depth parameters or smart inputs. This feature was designed to make the analytical process accessible to users with a broad range of skills by exposing a simple set of parameters to novices, and more detailed parameters to expert users. The simplification of repeated tasks makes it easy for users to dynamically change and rerun analyses as well as to easily set up and test alternative scenarios.

\section{Implementation issues}

The EMP concept and the NZP Tool were refined during the project, including the introduction of a "Baseline" (current situation) and a "Base Case" (future situation under a business as usual scenario). These concepts are defined in the body of this report. It also became clear that procedures for calibration of the Baseline and Base Case using utility bills and data from energy meters became an important step in the beginning of the study. During the projects, it also became clear that there was a need to define installation-specific energy goals, which establish the type of study that needs to be performed, i.e., a planning or pre-engineering analysis. 
The role of energy goals in establishing the type of study became clear during at the USMA and PNSY demonstrations as SME groups from separate disciplines, each of which emphasized different energy goals, took distinct approaches in performing the comparative validating analyses. This step helped to define who the customer is and who at the installation would be the users of the program. Two groups of users were determined, each with different output requirements. Installation master planners have a need for NZP, which helps to provide a Sustainability Component Plan to overlay their Master Plans. The Sustainability Component Plan is a new concept that Corps of Engineers have begun using to add energy implications to Master Plans. The other identified user is the installation energy manager; whose need is for help in identifying and sequencing coordination of projects, which requires a pre-engineering assessment. There were innumerable other technical changes that were incorporated throughout the Tool that were defined by the user's needs and requirements.

Another area of the analysis directly affected by the ESTCP project was the reporting for buildings, and for supply and distribution sections. One of the reports that was added was the Multi-Criteria Decision Analysis report, which helps rank alternative solutions. This report was related to the energy goals described in the Study details tab and was directly associated with the decision model for the study.

The U.S. Army Corps of Engineers (USACE) or Directorate of Public Works (DPW) typically either develops Installation Master Plans in-house, or subcontracts the development to private sector companies. NZP can be used either by in-house personnel or by contractors. The limited number of USACE energy master planners can easily be trained to apply EMP concepts and to use the NZP Tool. However, all potential contractors involved in EMP would require training to make effective use of NZP. An initial training course, which was developed and delivered to the PNSY planners and energy manager in November 2014, was instrumental in creating a course for USACE personnel that was offered in J anuary 2015. NZP course material derived from these courses had been integrated into the USACE PROSPECT Sustainability Course. 


\section{Contents}

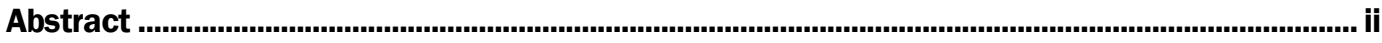

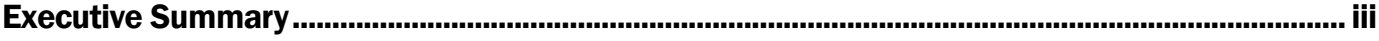

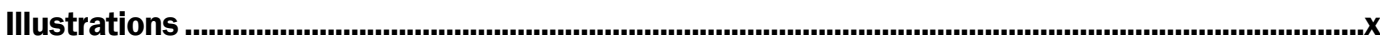

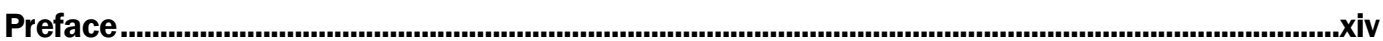

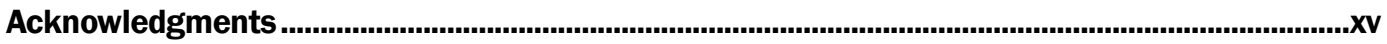

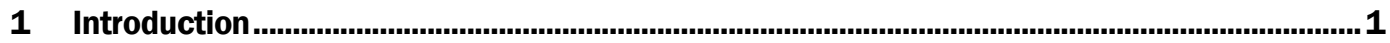

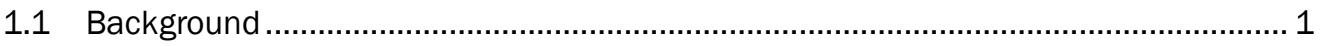

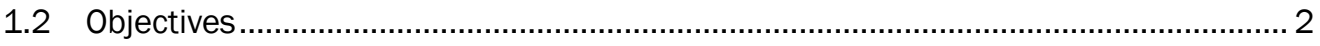

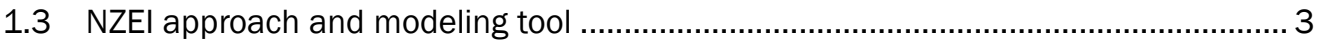

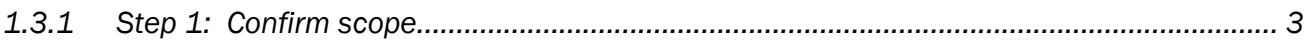

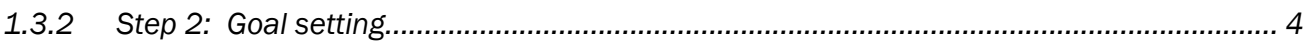

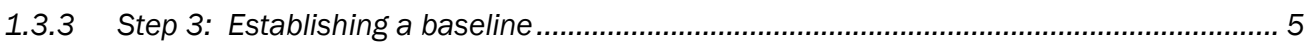

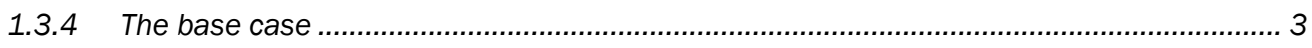

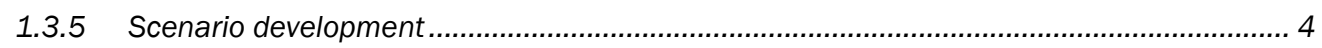

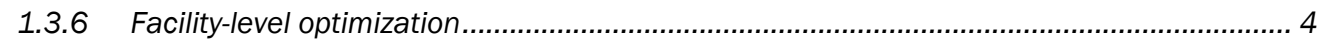

1.3.7 Supply and distribution system optimization ............................................................... 5

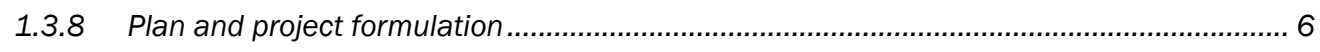

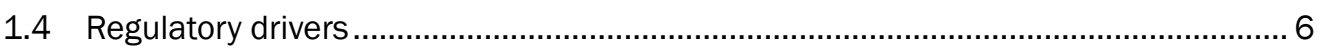

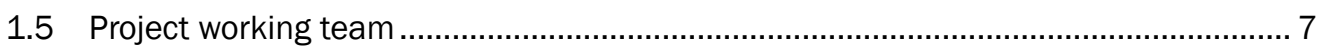

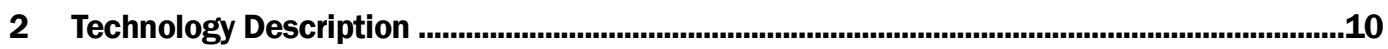

2.1 Technology overview .................................................................................. 10

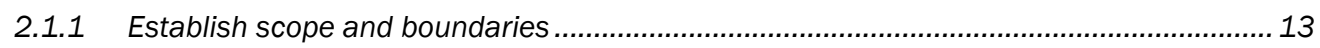

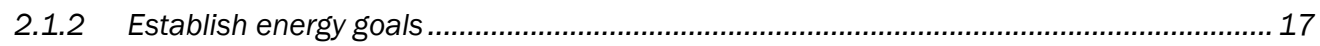

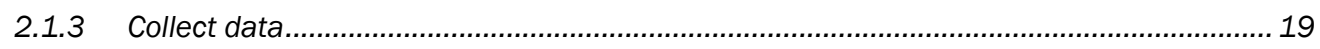

2.1.4 Establish baseline models and calibrate against metered data ......................................20

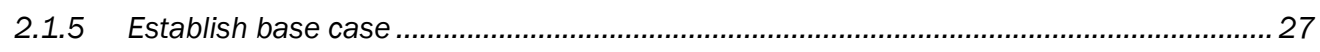

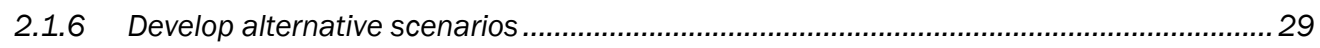

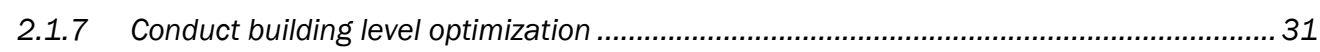

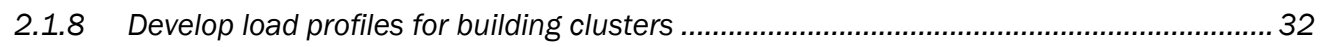

2.1.9 Optimize installation conversion, distribution, and storage architecture ..........................36

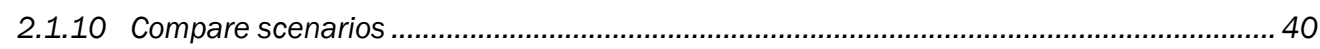

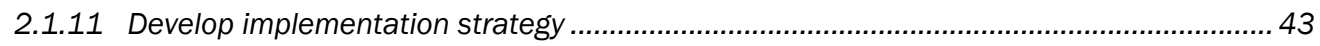

2.1.12 Complementary goals (spin-offs, co-benefits) ............................................................4 44

2.1.13 Implementation strategy: Backcasting and forecasting ............................................. 44

2.2 Technology development .....................................................................................46

2.3 Advantages and limitations of the technology ................................................. 48

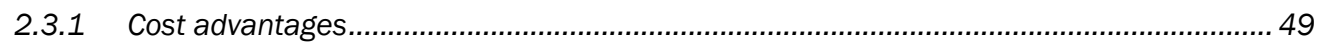

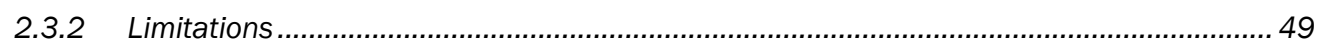


3 Performance Objectives ...................................................................................................50

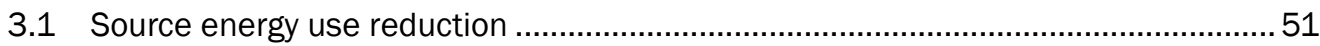

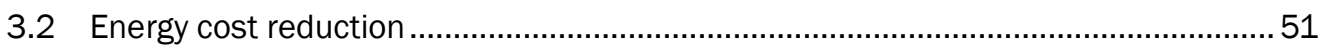

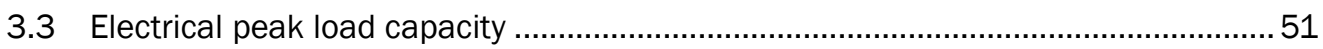

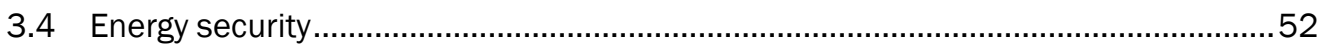

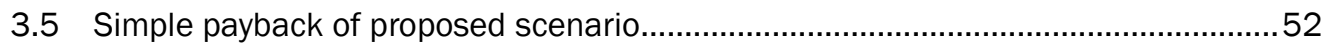

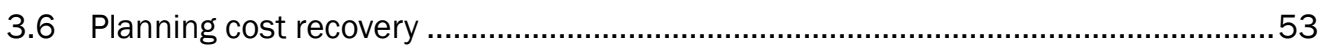

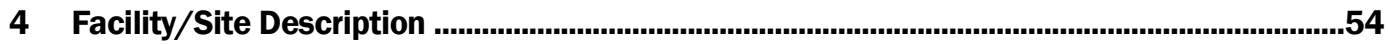

4.1 The U.S. Military Academy (USMA), West Point.....................................................5 54

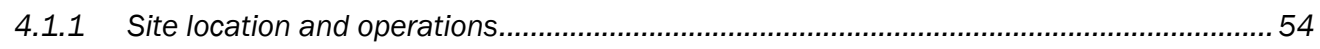

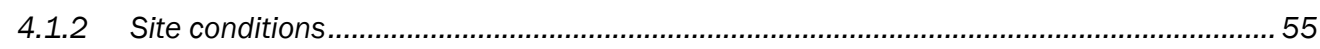

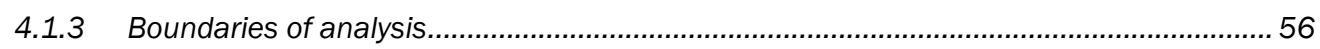

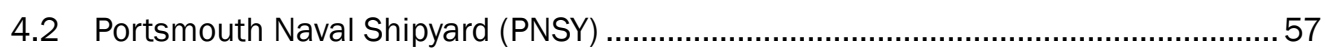

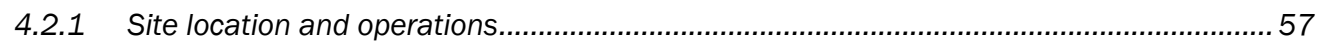

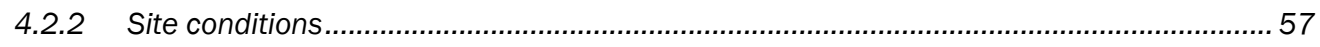

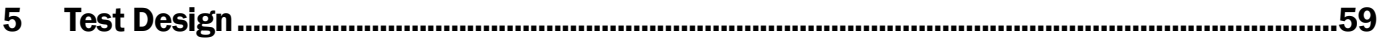

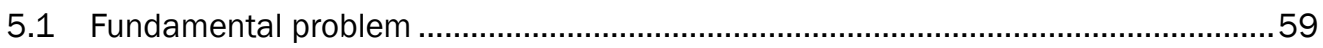

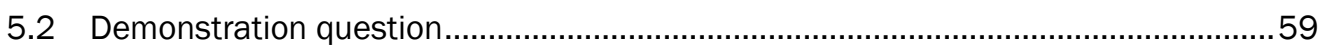

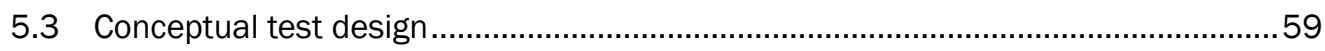

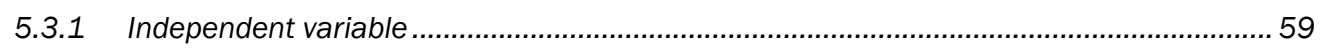

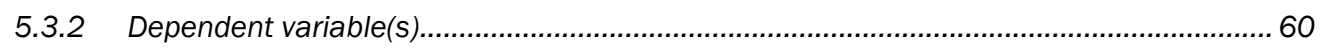

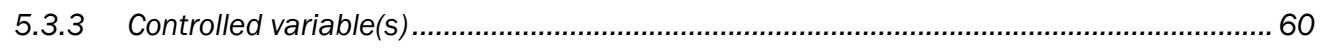

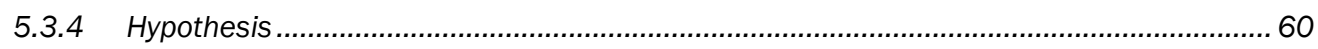

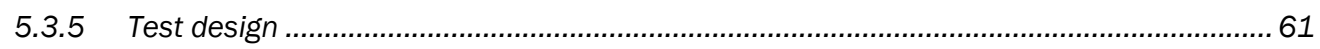

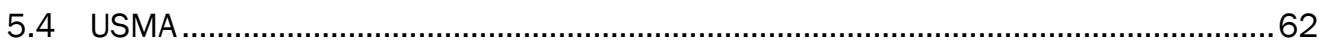

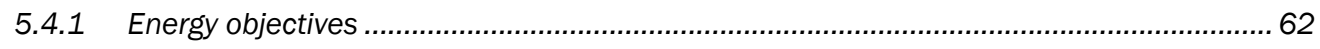

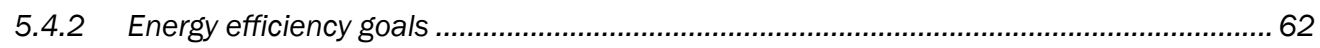

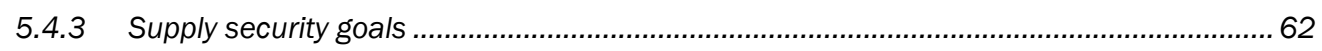

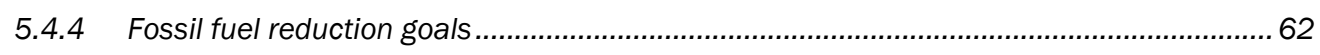

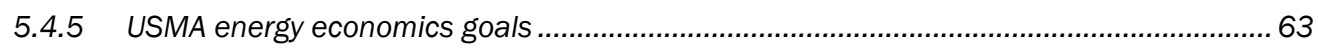

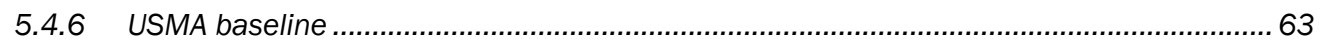

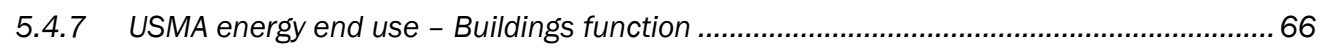

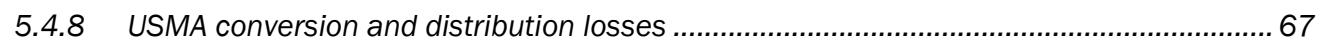

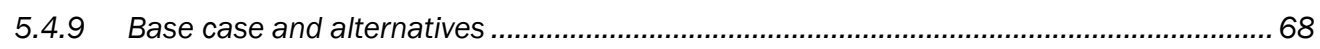

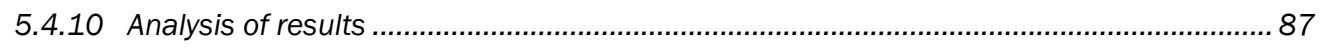

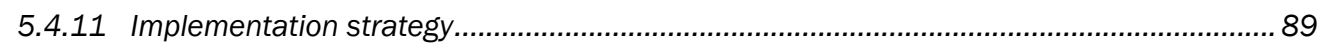

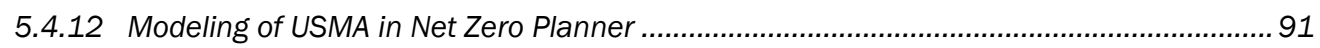

5.5 Portsmouth Naval Shipyard (PNSY) .............................................................100

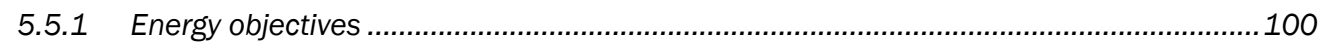

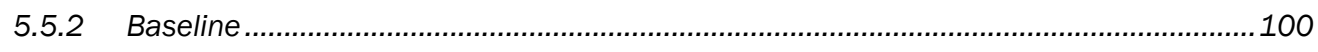

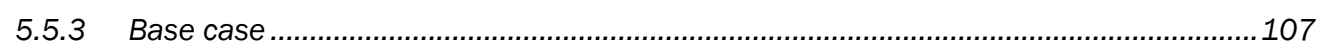

5.6 Discussion ................................................................................................. 118 
6 Performance Assessment ............................................................................................120

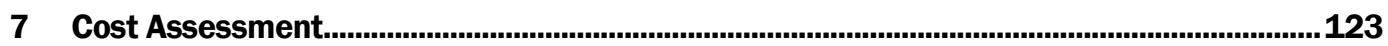

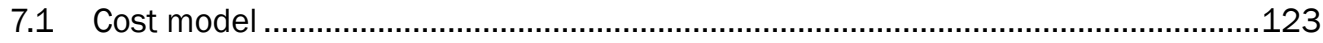

7.2 Cost drivers ................................................................................................. 125

7.3 Cost analysis and comparison .......................................................................125

8 Net Zero Planner (NZP) Tool Enhancement.................................................................129

9 Conclusions and Lessons Learned ........................................................................................136

9.1 Conclusions .......................................................................................................... 136

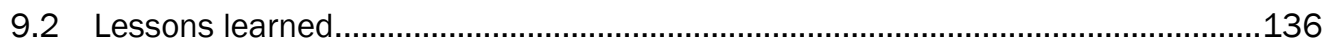

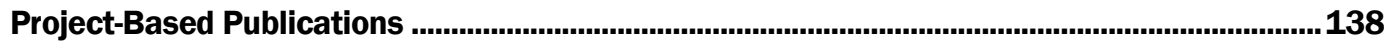

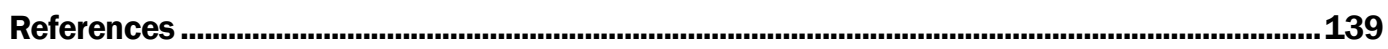

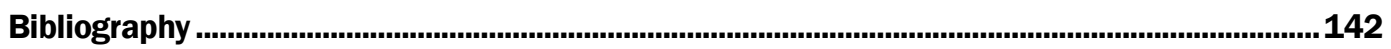

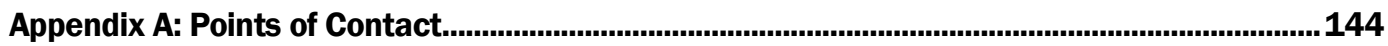

Appendix B: Energy Efficiency Measures for Building Renovations and New Cadet

Barracks.......................................................................................................................... 147

Appendix C: USMA, West Point New Cadet Barracks Energy Analysis ....................................188

Appendix D: Preliminary Information Required for Baseline Characterization for NZE

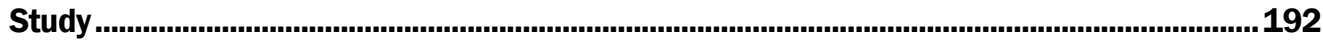

Report Documentation Page (SF 298) .................................................................................. 197 


\section{Illustrations}

\section{Figures}

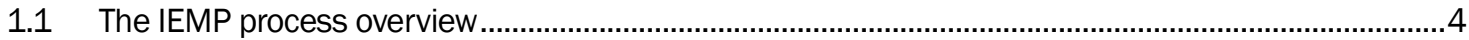

1.2 Using the Net Zero Planner to select buildings to be included in the scope of the USMA

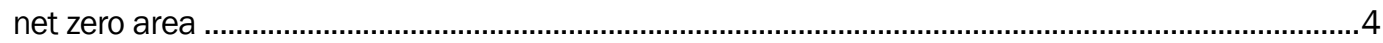

1.3 Source energy to site energy conversion is about $30 \%$ efficient .......................................................

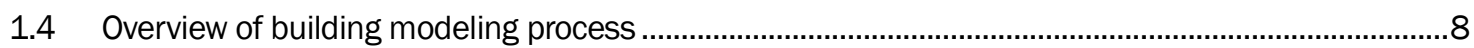

2-1 Energy Planning exists on a continuum, increasing in the required level of detail from left

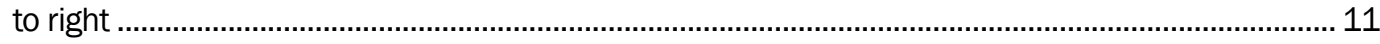

2-2 Diagram of the RPMP process as documented in UFC 2-100-01 ….......................................... 12

2-3 Detailed EMP Process using the NZP Tool ........................................................................................ 14

2-4 Examples of community boundaries: a- defined by building clusters; b- defined by

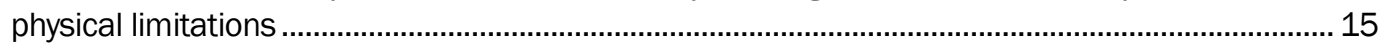

2-5 NZP is a web-based system. This screen shows a list of studies to which the user has

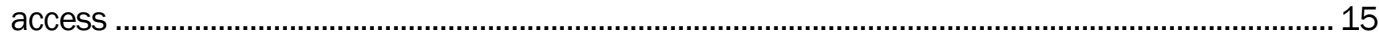

2-6 Select geographic scope of the study

2-7 The user selects facilities to include in the study..........................................................................

2-8 Energy goals are defined at the start of a study, in consultation with the installation decision makers. Metrics related to these goals are defined later in the decision support screens.

2-9 Buildings are categorized as existing, planned, or demolish. This annotation is used to display and analyze the Baseline (present day) against the Base Case and other future alternatives. Existing and demolish categories are shown on the left, while existing and planned categories are shown on the right

2-10 Example of energy use and cost for a military community..

2-11 Facilities are grouped into "Facility Groups" based on their type of construction, era, usage type, and other factors

2-12 Baseline: Overview of a complex building modeling process ..................................................... 24

2-13 NZP building level simulations on server .................................................................................. 26

2-14 Load profiles derived for individual buildings can be summed up for a building cluster analysis

2-15 Example of community level baseline: Building and process energy end use broken down by function

2-16 NZP automatically creates an EnergyPlus input for file for every Facility Group and combination of packages specified in its database. Here, the HVAC package is specified for a barracks. The baseline model is modified to reflect better HVAC equipment. In addition, the popup shows that the HVAC package includes the Lighting Package .

2-17 Energy supply chain from primary energy to its use inside a building 30

2-18 The user uses the Package Selection screen to examine the cumulative effects of EEMs for each facility type.

2-19 Generalized superstructure representation of the model. The lines indicate matter and energy flows between the sources, conversion options, and loads 


\section{Figures}

2-20 Example superstructure with sample flows and technology options ................................................ 35

2-21 Facilities can be grouped into "clusters." The resulting building loads and energy densities are calculated for each cluster .....

2-22 Mixed-Integer Linear Programming (MILP) is used to find the lowest cost combination of supply, distribution, and storage technologies that meet the installation's goals..............................38

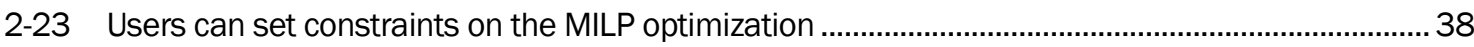

2-24 Device selections from the MILP optimization ................................................................................ 39

2-25 The cluster optimization analysis page. Here, the District Hot Water alternative is expanded to show results for each cluster

2-26 NZP Decision Matrix that shows all of the alternatives with associated energy performance and costs

2-27 Value function for Source Energy

2-28 NZP includes a MCDA module that allows the user to construct and compare weighted decision models that relate back to the study goals.

2-29 Sensitivity analysis can be conducted on the criteria weights by moving the slider bar

2-30 Backcasting: Defining milestones and determining necessary steps to reach the final goal

2-31 Forecasting: Formulating concrete actions and planning projects in a holistic way that is geared to meeting each milestone

4-1 Site map with existing heating grids and rough cluster boundaries .................................................55

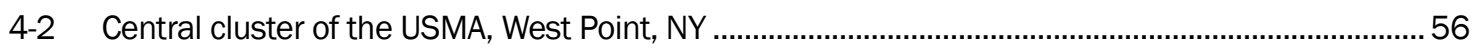

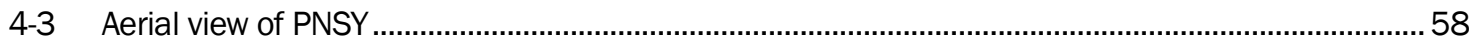

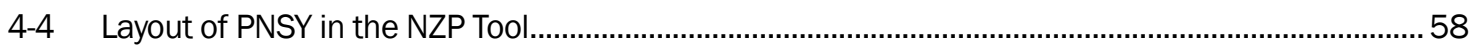

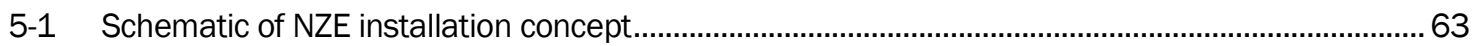

5-2 Schematic of baseline energy uses and wastes at NZE Area .......................................................... 65

5-3 NZE Area baseline energy uses and losses ..............................................................................6 66

5-4 Breakdown of distribution losses (MMBtu/yr) ............................................................................ 68

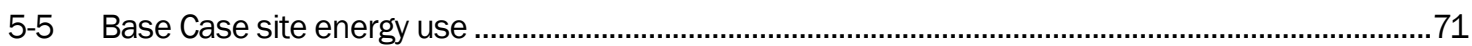

5-6 Layout of TriGen at CEP with reciprocating engines..................................................................... 81

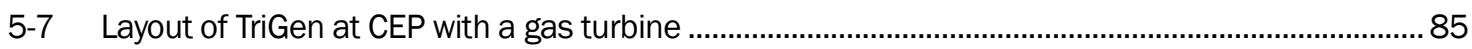

5-8 Comparison of all alternatives to the baseline: (a) site, source, and costs as a percentage, (b) types of energy used...................................................................................................................... 88

5-9 Implementation schedule for Trigeneration Scenario (Alternative 3) ..............................................90

5-10 Implementation phases for Trigeneration Scenario (Alternative 3) ................................................ 90

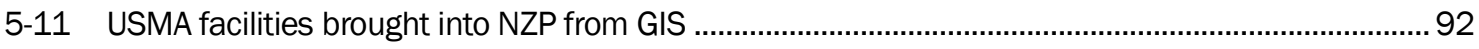

5-12 The baseline includes 45 facilities in nine groups. See text for explanation of the use of the status column (Existing, Demolished, and Planned) to represent planned DERs..................... 92

5-13 The Base Case includes 46 buildings in 10 groups....................................................................93

5-14 Baseline load duration curve (heating).....................................................................................94

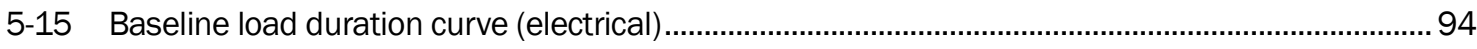

5-16 Base Case load duration curve (heating) ……...............................................................................95 


\section{Figures}

5-17 Base Case load duration curve (electrical)

5-18 The USMA central area was modeled as a single cluster. NZP automatically aggregates the building loads and calculates the energy Density

5-19 The MCDA Decision Model is constructed from the NZP model output data. The user has access to all metrics in the final report and uses them to construct a weighted model in the tool. Weights are set in consultation with installation decision makers (note: these weights are for demonstration purposes only and do not reflect policy decisions by USMA leadership)

5-20 The MCDA decision model results in a ranked ordering of alternatives. An interesting result of the weights used for demonstration purpose is that some of the options turn out to score much lower than the status quo.

5-21 Heating, cooling, and electric load duration curves for the baseline

5-22 Technology transfer - Net Zero Planner user training ................................................................119

5-23 Net Zero Planner installation onsite training ...........................................................................119

B-1 HW radiator within office of Mahan Hall...................................................................................... 181

B-2 Kitchen hood that is good candidate for variable air flow.........................................................183

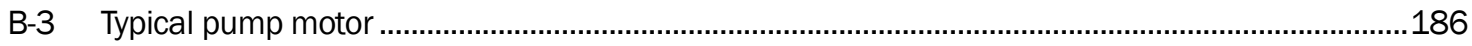

C-1 USMA, West Point New Cadet Barracks ......................................................................................188

C-2 Annual EUI for each EEM Package................................................................................................. 191

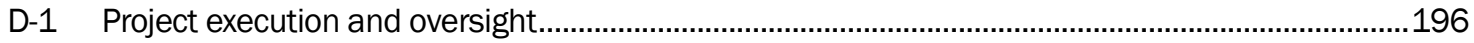

\section{Tables}

1.1 National average source - Site ratios for selected primary fuels ......................................................

2-1 NZP calculates site and source energy. These data indicate the aggregated values, broken down by building type.

3-1 Summary of quantitative performance objectives......................................................................... 50

3-2 Comparison of demonstration projects performance parameters against performance objectives 53

5-1 Baseline energy use for NZE Area buildings connected to CEP ....................................................64

5-2 Baseline distribution of energy within the NZE Area......................................................................65

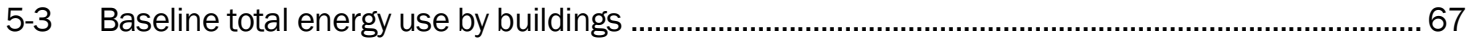

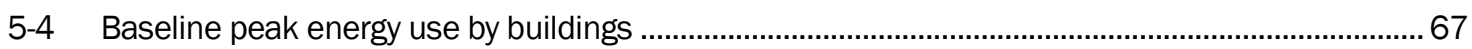

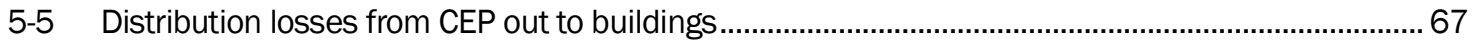

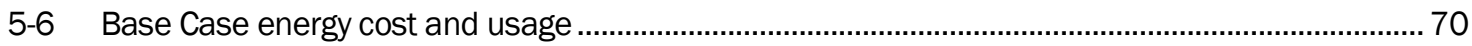

5-7 Base Case energy purchases by distribution within the NZE Area ................................................... 70

5-8 Summary of the Decentralized Systems conversion alternative ..................................................... 73

5-9 Summary of the Central Steam-to-HW System conversion alternative.............................................. 77

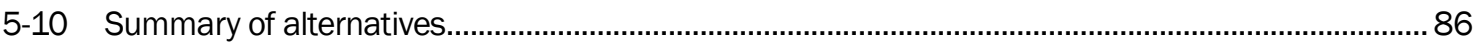

5-11 For USMA, the baseline was modeled and calibrated. Next, the Base Case was modeled to include what was considered a realistic set of EEMs ..................................................................... 94

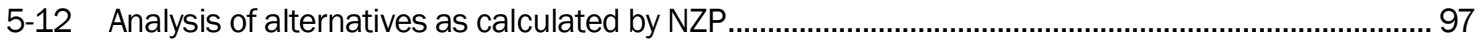




\section{Tables}

5-13 Baseline: Total energy footprint for 2010/2011 and energy purchases .......................................102

5-14 Baseline: Summary of categorization of shipyard buildings by age and function ..........................105

5-15 Baseline: Comparison of SME calculations to NZP Tool calculations …………............................. 107

5-16 Building Results: EEMs calculated from the SME method and the NZP Tool ................................109

5-17 Summary of the energy supply equipment used for each alternative ...........................................112

5-18 Summary of the energy supply equipment used for each alternative ...........................................112

5-19 Energy comparison between SME analysis and the NZP Tool results by scenario ........................116

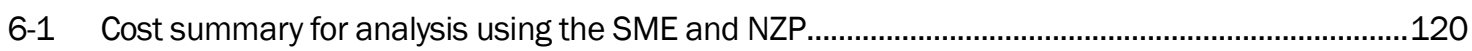

7-1 Cost Model for use of the NZP Tool on an Installation ..............................................................124

B-1 EnergyPlus model results for energy use in renovated barracks...............................................150

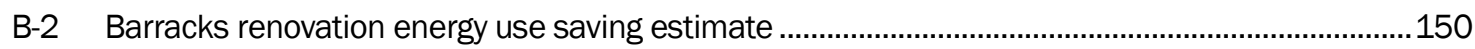

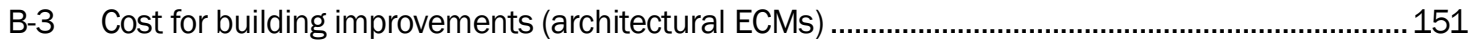

B-4 Costs to replace existing windows with blast resistant aluminum casement windows...................152

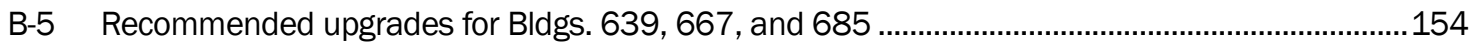

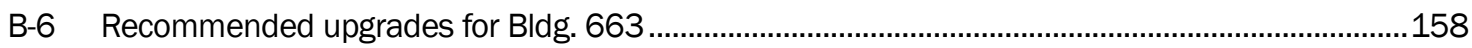

B-7 Recommended upgrades for Bldg. 609 ……..............................................................................160

B-8 Recommended upgrades for Bldg. 635 .......................................................................................163

B-9 Recommended upgrades for Bldg. 726 ……........................................................................

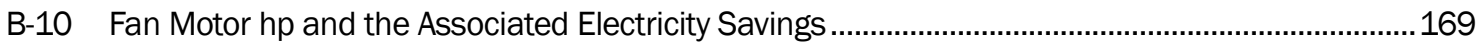

B-11 Annual savings, heating, and cooling of HR efficiencies from 20 to 50\% ....................................173

B-12 Annual savings, heating, and cooling by installing an HR with an efficiency of 50\% ......................173

B-13 Savings associated with reduced exhaust hood operation in Bldg. 602 ........................................184

B-14 Savings associated with reduced exhaust hood operation in Bldg. 603 …....................................184

B-15 Savings associated with reduced exhaust hood operation in Bldg. 603.....................................186

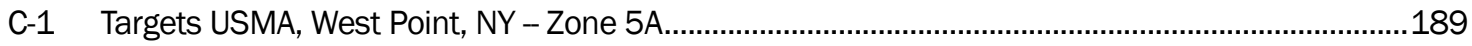

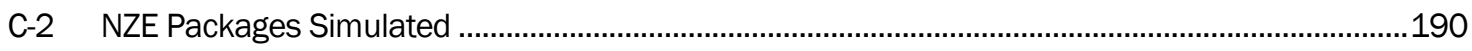

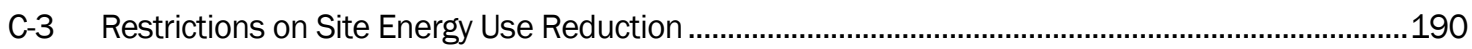

C-4 Building Site Energy....................................................................................................................190

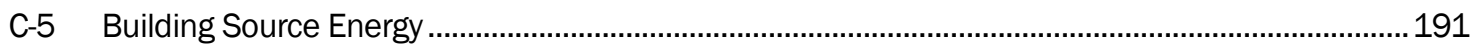




\section{Preface}

Funding for this demonstration was provided by the Environmental Security Technology Certification Program (ESTCP) - Energy and Water Project \# EW-201240. Additional funding to analyze exiting steam system and contribute to new cadet barracks design and exiting barracks renovation concepts was provided by the U.S. Army Corps of Engineers (USACE) New York District, U.S. Military Academy (USMA) West Point Directorate of Public Works (DPW), and by the Office of the Assistant Secretary of the Army (Installations, Energy and Environment) (ASA[IE\&E]).

The work was managed and executed by the Energy Branch (CF-E) of the Facilities Division (CF), Construction Engineering Research Laboratory (CERL). The CERL principal investigator was Dr. Alexander Zhivov. The Project Working Team acknowledges with appreciation the support and advice provided by the ESTCP review board through the process of development of the demonstration plan; the cooperation from the USMA personnel team members and USACE New York District engineers; and the ideas and information generously shared by researchers and engineers from the National Renewable Energy Laboratory (NREL), Sandia National Laboratory, and NORESCO Company. The partners from the International Energy Agency (IEA) Energy Conservation in Buildings and Community Systems (ECBCS) Program Annex 51 "Energy Efficient Communities” also contributed a wealth of knowledge and information throughout development of this project. At the time of publication, Andrew Nelson was Chief, CEERD-CF-E, and Donald K. Hicks was Chief, CEERD-CF. The associated Acting Technical Director was Kurt Kinnevan, CEERD-CV-T. The Director of ERDC-CERL is Dr. Ilker R. Adiguzel.

COL Bryan S. Green was Commander of ERDC, and Dr. J effery P. Holland was the Director. 


\section{Acknowledgments}

Funding for this demonstration was provided by the Environmental Security Technology Certification Program (ESTCP) - Energy and Water Project \# EW-201240. The project team would like to thank and gratefully acknowledge technical guidance provided by the ESTCP Office, led by Dr. Jim Galvin.

Additional funding to analyze the existing steam system at the USMA, West Point and to contribute to a new cadet barracks design and existing barracks renovation concepts have been funded by the USACE New York District, USMA, West Point DPW and by the Office of the Assistant Secretary of the Army ( Installations, Energy \& Environment).

The Project Working Team (PWT) appreciates the support and advice provided by the ESTCP review board through the process of development of the demonstration plan; cooperation from the USMA and Portsmouth Navy Shipyard (PNSY) personnel team members and USACE New York District engineers, ideas and information shared by researchers and engineers from the National Renewable Energy Laboratory, Sandia National Laboratory, and NORESCO company. A wealth of knowledge and information was provided by the partners from the International Energy Agency Energy Conservation in Buildings and Community Systems (ECBCS) Program Annex 51 “Energy Efficient Communities” throughout development of this project.

The project team is also thankful for the support provided by the following individuals:

\begin{tabular}{|l|l|}
\hline Name & Affiliation \\
\hline Mr. Paul Volkman, NZE Program Manager & $\begin{array}{l}\text { Office of the Assistant Secretary of the Army (Energy and } \\
\text { Sustainability) }\end{array}$ \\
\hline Commander Glenn Hubbard, Energy Branch Head & $\begin{array}{l}\text { Headquarters, Naval Facilities Engineering Command (HQ } \\
\text { NAVFAC) }\end{array}$ \\
\hline $\begin{array}{l}\text { Commander Tabitha Pierzchala, Energy \& American } \\
\text { Recovery and Reinvestment Act (ARRA) Action Officer }\end{array}$ & HQ NAVFAC \\
\hline Mr. Matthew Talaber, Director of Public Works & USMA \\
\hline Mr. Frank Bloomer, Deputy Director of Public Works & USMA \\
\hline Mr. Paul Simihtis, Energy Manager, DPW & USMA \\
\hline Mr. Husain Shehreyar, Energy Engineer, DPW & USMA \\
\hline Mr. Peter Mcgaughran, Chief O\&M, DPW & USMA \\
\hline Mr. Carl Meyer, Master Planner, DPW & USMA \\
\hline
\end{tabular}




\begin{tabular}{|l|l|}
\hline Name & Affiliation \\
\hline COL. Russell Lachance, Acting Deputy Head Dean & USMA \\
\hline Mr. Jeffrey Friese, Project Manager & USACE, NY District \\
\hline Mr. Andrew Zuzulock, Project Manager & USACE, NY District \\
\hline Commander Brian Weinstein, Public Works Commander & PNSY \\
\hline Mr. John Wyeth, Deputy Public Works Officer & PNSY \\
\hline Lt David Dreyer, Installation Energy Manager & PNSY \\
\hline Ms. Melissa Kalicin, Project Manager & PNSY \\
\hline Ms. Melanie Spreen, Community Planner & PNSY \\
\hline Mr. Steve Dakin, Utilities Energy Manager & PNSY \\
\hline Mr. Lance Mahar, Mechanical Engineer & PNSY \\
\hline Mr. Adam Gray, Industrial Engineer, continuous \\
improvement/Lean manufacturing & PNSY \\
\hline Mr. Tom Harris, Project Leader & National Renewable Energy Laboratory (NREL) \\
\hline Mr. Samuel Booth, Project Leader & NREL \\
\hline
\end{tabular}




\section{Introduction}

\subsection{Background}

Until very recently, defense installation planners addressed energy systems for new facilities on an "individual facility" basis, without consideration of energy sources, renewables, storage, or future generation needs. Building retrofits under Sustainment, Restoration, and Modernization (SRM) projects typically do not address energy conservation. Energy Savings Performance Contract (ESPC) projects that address only "low hanging fruit" (improved efficiency of lighting, electrical, heating, ventilating, and air-conditioning [HVAC] systems, controls, and Building Energy Management Systems [BEMSs]) will fail to maintain the current rate of energy reduction, and cannot meet the rate required by the U.S. Energy Independence and Security Act of 2007 (EISA 2007), and will thereby become less economically attractive.

There is a lack of tools and case studies that address dynamics of energy systems at the community scale. Development and rapid deployment of such tools with dissemination of lessons learned through pilot energy master plans is essential in achieving the DoD medium- and long-term energy goals.

Most national and international research and policy energy-related efforts in the built environment focus on renewable energy sources and energy efficiency in single buildings. Organizations that have made first efforts to evaluate and analyze international experiences on planning and implementation of low energy communities include: the International Energy Agency (IEA) Energy Conservation in Buildings and Community Systems (ECBCS) Annex 51, the German funded project EnEff Stadt (a comprehensive approach to urban areas with local and district heating networks), the World Bank Energy Sector Management Assistance Program (ESMAP) Energy efficient cities initiative, and the Clinton Climate Initiative C40 program. The U.S. Army is pioneering a "Net Zero Installations" program for selected installations, which goes beyond zero energy and includes zero waste and zero water initiatives.

In community-wide energy planning, it is important to consider the integration of supply and demand, which leads to optimized solutions. The objective is to apply principles of a holistic approach to community energy 
planning and to provide the necessary methods and instruments to master planners, decision makers, and stakeholders. Such comprehensive decision-making and modeling tools are currently not available.

The U.S. Army Engineer Research and Development Center (ERDC) has developed an energy optimization concept and automated tool to support DoD energy policy. The energy concept minimizes energy use at the building level, improves the efficiency of energy generation and distribution, and finally uses energy from renewable sources to balance fossil-generated energy to achieve a net zero fossil energy status. Energy goals will be achieved through synergy between energy use reduction in building-related systems, and energy supply and distribution systems. The Net Zero Planner integrates optimization across buildings, distribution, and generation systems.

\subsection{Objectives}

The U.S. Department of Defense (DoD) has established challenging goals to increase energy efficiency and reduce greenhouse gas (GHG) emissions of their installations in all five services with an ultimate goal of Net Zero Energy (NZE) installations. These objectives are similar to those of some U.S. communities and college and university campuses. The Engineer Research and Development Center, Construction Engineering Research Laboratory (ERDC-CERL) has developed an NZE installation concept and tool, the "Net Zero Planner," to support NZE planning for DoD installations.

The primary research objective for this ERDC-CERL led Environmental Security Technology Certification Program (ESTCP) project is to test and demonstrate the development of holistic NZE plans using the Net Zero Planner at two large, complex military (Army and Navy) installations, with the possibility to proliferate the approach to multiple DoD installations. The U.S. Army has named the U.S. Military Academy (USMA) at West Point as one of eight pilot net zero installations for energy use, as a part of the Army's overall effort to conserve resources. The NZEI concept and Net Zero Planner tool will be tested at USMA (the focus of this report), and the results of this work will be used in the development of the Installation Energy Master Plan (IEMP). The second defense installation selected to participate in this project (a Navy base), is the Portsmouth Naval Shipyard (PNSY) located near Kittery, ME, on Seavey's Island in the Piscataqua River close to its outlet to the Atlantic Ocean. The results of the PNSY part of this work will be addressed in a separate report. 
The Net Zero Planner will provide energy planners at installations a capability to create optimized plans to meet their energy goals (including NZE), by reducing overall energy use, using renewable energy sources, reducing GHG emissions, estimating costs, and evaluating risks. In addition to development of a roadmap for meeting site and source energy goals, the project will also address other important DoD objectives, e.g., on-site uninterruptable energy generation to meet or exceed mission critical electrical and thermal needs; electrical peak reduction, use of solar thermal energy or waste heat from the cogeneration process, etc. This project will provide support for short-, medium-, and long-term investment and operational energy management decisions.

\subsection{NZEI approach and modeling tool}

The project team uses a collaborative and highly integrated planning process based on best practices from around the globe and best-in-class tools. Figure 1.1 shows this process. A variety of automated tools are typically used by most teams, including spreadsheets, standalone building energy simulations, and the Net Zero Planner being demonstrated by this project. This section will discuss the approach used by the team, including discussion of how the Net Zero Planner is used to support the process.

\subsubsection{Step 1: Confirm scope.}

The initial step in an IEMP process is to determine the scope of the installation's facilities and operations to be included in the study. This step begins with conversations with stakeholders and data from sources such as maps, geographic information systems (GISs), and spreadsheets obtained in a pre-visit. During the kickoff meeting, the team discusses which facilities, distribution networks, and energy conversion facilities to include.

At this point, a geographical boundary (study area) is often established as well. Tenant facilities such as family housing, commissaries, and exchanges are generally included as an energy load to be met by the installation, but excluded for the purpose of recommended efficiency improvements if the installation does not have control of them. In the Net Zero Planner, the included facilities are selected by the Study Manager when the project is created (Figure 1.2). A list of these facilities is also kept in a master spreadsheet for reference by the team. 
Figure 1.1. The IEMP process overview.

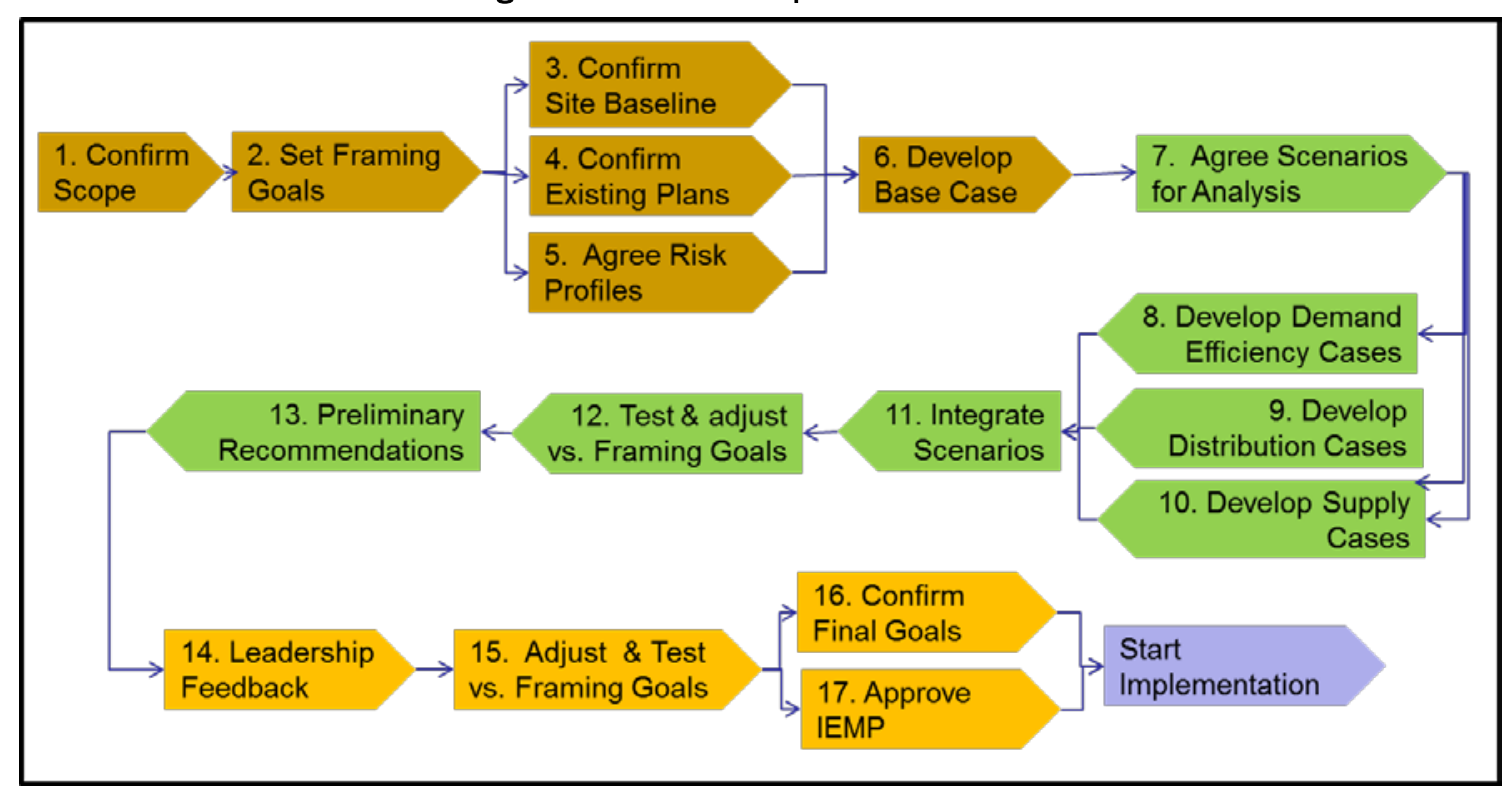

Figure 1.2. Using the Net Zero Planner to select buildings to be included in the scope of the USMA net zero area.

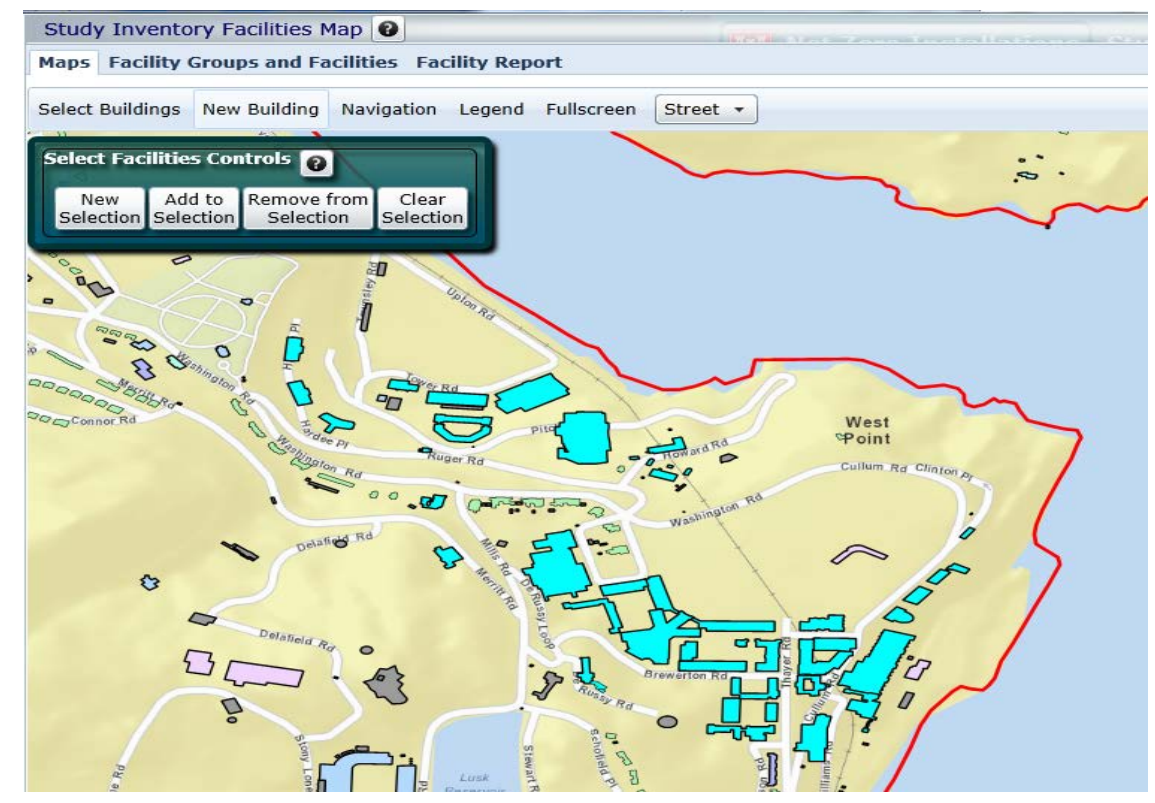

\subsubsection{Step 2: Goal setting}

The team works with the installation stakeholders to develop energy goals early on, typically at the kickoff meeting. The goals serve to focus the study team and to engage in a serious discussion from the outset about what the installation would like to see accomplished. The goals should be challenging, but should remain within the realm of possibility and informed by 
benchmarks such as Energy Use Intensities (EUIs) of best-in-class buildings around the world. Typical examples include increasing energy efficiency across the board or achieving zero fossil energy use. Energy goals are not a firm commitment, but rather represent quantitative (number) values to use when comparing alternative scenarios against a baseline. To be effective, energy goals should meet the following criteria:

- They must encompass the entire study area.

- They must balance often conflicting outcomes.

- They may exceed existing targets in some aspects.

- The pathway to achieve them may not be clear at the start of the IEMP process.

- Their quantitative indicators should be easily derived from available data.

- Non-quantitative goals should be core to final recommendations.

- If achieved, they would clearly be a success.

The goals are recorded in the Net Zero Planner and referred to frequently over the course of the study to remind the team what they are trying to achieve. The tool also has an optional Multi-Criteria Decision Analysis (MCDA) module that permits weights to be assigned to decision criteria that reflect their importance to the stakeholders. Once scenarios were identified and the analysis was done, the scenarios will be compared against the energy goals. If the goals turn out not to have been feasible, then the team and installation stakeholders can engage in discussion about how to adjust them.

\subsubsection{Step 3: Establishing a baseline}

Before one decides on the path to reach a goal, it helps to know the starting point. The importance of establishing the baseline energy usage cannot be over-emphasized. In this case, the baseline is defined as the current energy consumption profile and is a snapshot of an installation's typical annual energy profile. Climatic variation is normal from year to year, so mean values taken over a number of years should be used. Energy use should be broken down into categories relevant to the installation, such as:

- end-uses

- building functions

- industrial processes

- central services - compressed air / water / sewer

- distribution losses 
- steam, hot water, cooling water, compressed air networks

- on-site electrical

- on-site conversion losses

- gas turbines

- reciprocating engines

- boilers

- chillers

- off-site conversion and distribution losses

- purchased natural gas

- purchased electricity.

\subsubsection{Site vs. source energy}

When discussing energy use, one should always be clear about whether one is discussing site energy or source energy. Site energy represents electrical, thermal, and chemical energy that is directly consumed at the point of use (e.g., for heating, cooling, lights, or plug loads). Source energy refers to the primary fuel (coal, natural gas, diesel fuel, uranium, etc.) consumed in conversion from one type of energy to another secondary type of energy (i.e., coal to electricity) and in transmission of this energy to the site. Figure 1.3 shows how source energy is converted to electricity, transmitted to the site, and consumed as site energy at a building. Most experts estimate the average site/ source efficiency of the U.S. commercial grid at about $30 \%$. This means that, for instance, a building that consumes about 1 million Btu/yr of electrical energy on site will require the power plant to produce 3.33 million Btu/yr of source energy. Other primary fuels, such as natural gas, propane, and fuel oil incur losses in distribution as well and so have their own site-source conversion factors. The U.S. Environmental Protection Agency's (USEPA's) Energy Star program publishes source-site ratios for each of the primary and secondary fuels listed in its Portfolio Manager system (USEPA 2013). The USEPA ENERGY STAR program uses national average conversion factors to avoid penalizing manufacturers for locally less efficient energy producers. Table 1.1 lists typical source-site ratios. For a given region, source-site ratios may be significantly different if there is exists a large amount of hydropower, solar power, or wind power in the mix, so it can be useful to also look at regional conversion ratios. The Net Zero Planner defaults to national average source-site ratios, but permits the users to substitute regional values. Regional values can be obtained from Deru (2007). The Net Zero Planner always reports both site and source energy consumption to decision makers. 
Figure 1.3. Source energy to site energy conversion is about $30 \%$ efficient.

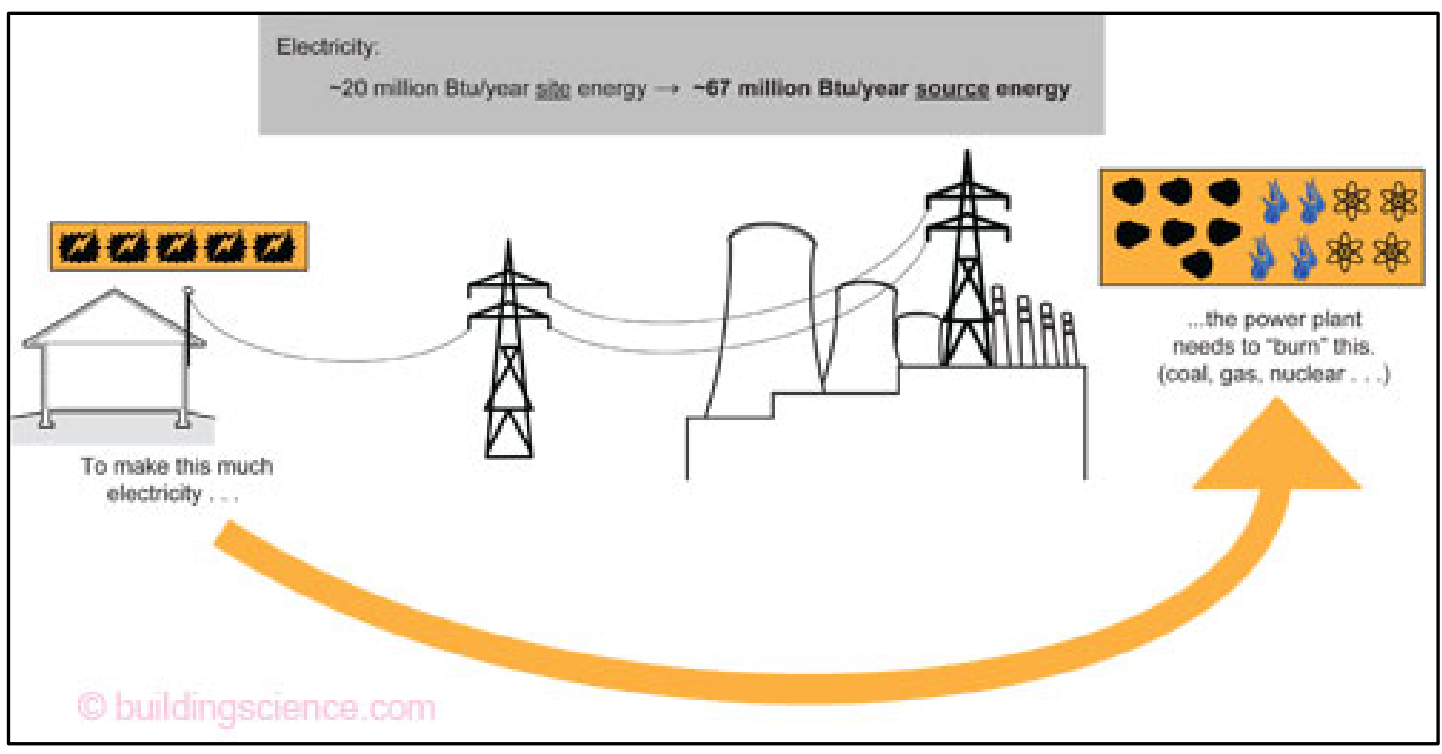

Graphic used courtesy of Building Science Corp.

Table 1.1. National average source - Site ratios for selected primary fuels.

\begin{tabular}{|l|c|}
\hline Fuel Type & Source-Site Ratio \\
\hline Electricity (Grid Purchase) & 3.34 \\
\hline Natural Gas & 1.047 \\
\hline Fuel Oil & 1.01 \\
\hline Propane & 1.01 \\
\hline
\end{tabular}

\subsubsection{Estimating building energy loads and other end-uses}

In many cases, the lack of metered energy consumption data for individual buildings requires that a modeling process be used to estimate the makeup of an installation's energy use "by building." This process allows estimates of the community energy end-use to be meaningfully developed for complex, diverse sites with hundreds, or even thousands of buildings, quickly and with an acceptable allocation of resources. Figure 1.4 shows the energy modeling process used by the team.

The first step of baseline building-level modeling characterizes the community as a whole in terms of the range of buildings it contains. Using all available information and observation from field visits, the total building inventory of the community is broken into main building categories (typically residential, non-residential, and industrial). 
Figure 1.4. Overview of building modeling process.

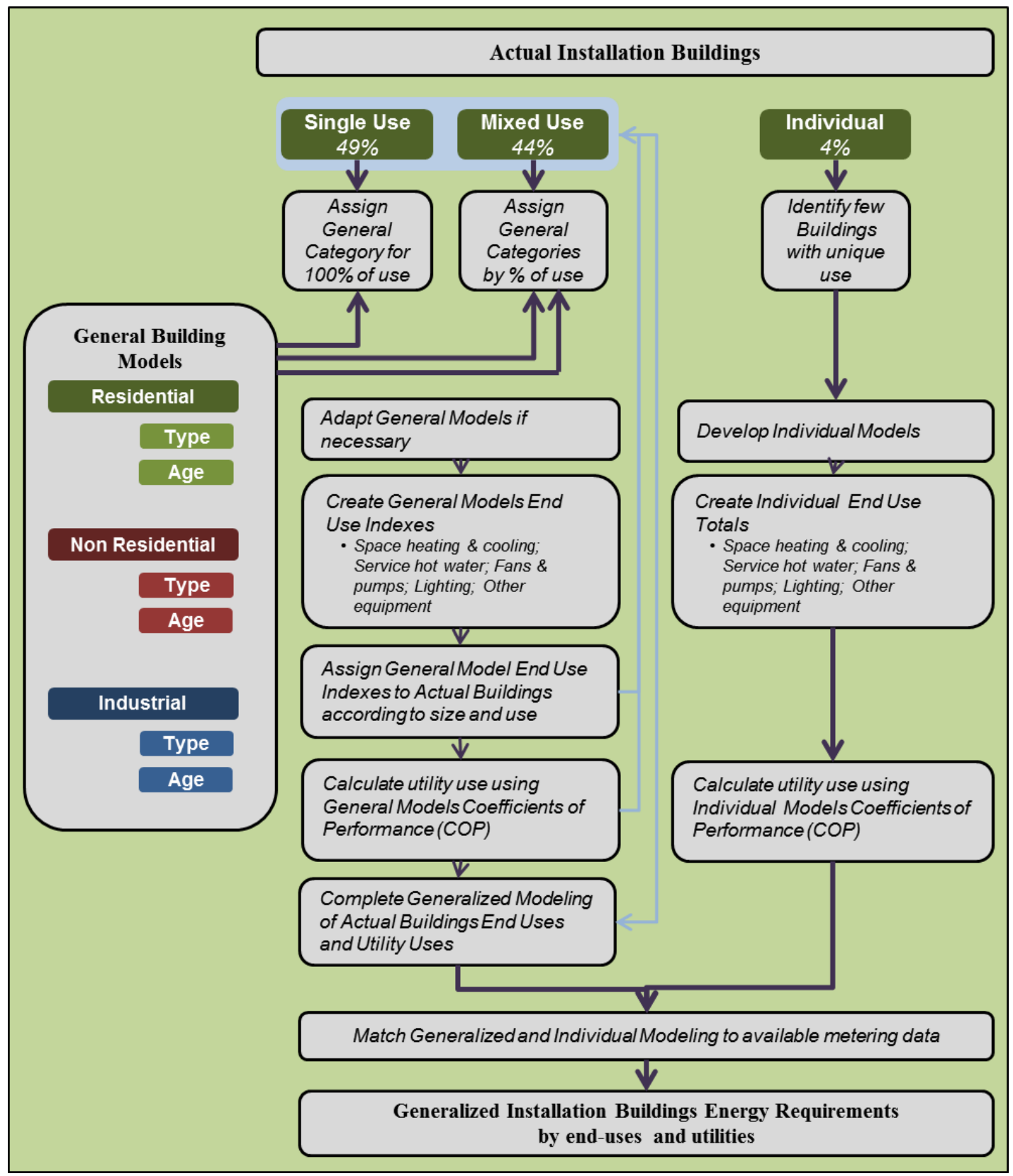

Within each of these categories, the main types of buildings or building use are identified. Non-residential buildings, for example, could be offices, retail structures, hospitals, etc. Examples of residential buildings would include barracks, single family homes, attached housing, multi-family homes, etc. Example of industrial buildings would include structures that house low-, medium- and high-energy processes. The broad range of ages of construction within each building type are estimated; buildings are typically grouping by chronological age, or by relevant changes in building codes or market practice that significant impact energy performance. 
The Net Zero Planner tool has facilitated this process by providing a "Iibrary" of Army specific EnergyPlus-based energy models for each building use, type, and vintage that most closely matches the mix in the specific community. The models available in the Net Zero Planner were developed from common facility types built to U.S. Army Corps of Engineers (USACE) Center of Standardization (COS) building standards. The models include: Army Reserve Center (ARC), Brigade Headquarters (BdeHQ) admin with moderate process loads, Battalion Headquarters (BnHQ) admin with low process loads, Child Development Center (CDC), Company Operations Facility (COF) admin with soldier readiness bays, Dining Faculty (DFAC), General Instruction Building or School (GIB), General Purpose Warehouse (GPW), Information Systems Facility (InfoSys), Outpatient Healthcare Center (OHC), Tactical Equipment Maintenance Facility (TEMF), and Unaccompanied Enlisted Personnel Housing (UEPH) barracks.

In any community, some buildings have mixed use, e.g., buildings that combine offices and warehousing, etc. To address these facility types, the Net Zero Planner includes a capability to specify a Custom Facility using defined space types. The "Custom" facility type automatically generates the geometry and zoning of the facility given a set of user inputs. All buildings are rectangular with a perimeter/ core zone configuration, with perimeter zones $15 \mathrm{ft}$ deep; buildings can be specified with the following space types:

- active storage

- assembly area; auditorium

- attic

- bulk storage

- cafeteria

- classroom

- cold storage

- commons

- conference room

- corridor; hallway

- data center; server room

- dining area

- fine storage

- fitness

- kitchen
- laundry room

- lockers

- mechanical room

- office

- readi-bay

- rectifier room

- residential; barracks room

- restroom

- workshop

- stairwell

- storage

- telecommunications room

- uninterruptable power supply room

- utility closet.

These space types have set schedules and loads that are typical for that activity. 
The remaining structures typically have characteristics that cannot be reasonably generalized. For these "individual buildings" a specific energy model is assembled and the specific end-uses by building function calculated. The Net Zero Planner has the capability to take energy simulation results from programs like eQuest or EnergyPlus simulated outside of the tool and then upload the resultant data into the Net Zero Planner for use as a facility type. The estimated utility use of each individual building is calculated using the appropriate individual models' COPs and efficiencies for natural gas and electricity.

For the USMA project, the buildings were categorized into eight models, seven standard and one custom uploaded simulation results. Each of these representative models had their parameters modified to match the observed characteristics of the representative group of facilities and to match their vintage. Typical examples of modification could be the number of stories, insulation, windows specification, temperature setpoint, etc. It must be emphasized that any community-specific modifications apply to the generalized model, not to any specific actual building. Each of the seven facility types were simulated by the energy parametric engine in the Net Zero Planner, which is simply called "Params." The last facility type, for "Religious," was created to accommodate a custom upload to address the unique schedule of this facility type; in hind sight this separate category was probably not necessary since the number of facilities of this type addressed in the study was under 50,000 sq ft (only about $1 \%$ of the building area).

Each of these energy models was run in Params using EnergyPlus Version 7 to create energy end-use indexes in Btu/ sq ft and $\mathrm{kWh} / \mathrm{m}^{2}$ for the building functions of space heating and cooling, service hot water, fans, pumps, lighting, and other electrically operated equipment. These building facility types were assigned to all of the buildings in the USMA study area

The generalized energy end-uses by building function is estimated by assigning the appropriate energy end-use indexes to each actual building based solely on their size (floor area.) The estimated utility use of each actual building is calculated using the appropriate models' Coefficients of Performance (COPs) or efficiencies for natural gas and electricity. 


\subsubsection{Calibration of building models}

The total estimated utility needs from the general and individual modeling process described above are rolled up by the study building inventory and compared to any available baseline metered gas, electricity, or other utility data. If necessary, any significant discrepancies between metered and modeled data are resolved by adjusting models using the team's experience and selected repeat site visits and data review.

After the previous calibration step, the model results are reliable enough to identify the breakdown of energy use and cost by general building types, by groupings of actual buildings, and by specific functional end-uses. They are also the basis for prioritizing potential energy efficiency and energy productivity opportunities within similar groupings.

It is important to note that the modeling process described above is not a substitute for the detailed modeling of a single building. This detailed modeling would typically be done on selected buildings during subsequent implementation of the energy master planning recommendations for specific renovation projects to fine tune the strategic recommendations.

\subsubsection{The base case}

The Base Case includes the baseline and factors in projected changes to the facility inventory or process loads to calculate projected energy consumption over the entire study period. Alternatives considering portfolios of Energy Efficiency Measures (EEMs), distribution, and supply measures may be compared against both the Baseline and Base Case.

The baseline is a snapshot of USMA's current energy performance, based on the average of fiscal year 2010 (FY10) and FY11. The Base Case extrapolates a view of the future energy use, cost, and emissions by taking a "Businessas-Usual" view of the future and by assuming that existing situation described in the baseline will be changed only due to already planned projects, e.g., new construction, major renovation (Operations and Maintenance, Army [OMA] and SRM funded), and improvements conducted through the ESPC program. The Base Case acts as a reference for judging various alternative energy strategies. It also gives valuable perspectives into the potential energy-related risk that may need to be considered. 


\subsubsection{Scenario development}

Energy master planning requires a comprehensive analysis of potential EEMs, with calculations carried through from final end-use through distribution, conversion, and finally to source fuel. There are a potential unwieldy number of scenarios that could be analyzed. A limited number of integrated scenarios are selected for detailed analysis in the next phase of developing the IEMP.

The process to select the alternative scenarios begins after the Baseline and Base Case are largely complete. These inform the team of the relative scale of each part of the energy value chain, of its performance, and of potential risks and opportunities. Each alternative takes a distinctly different approach to potentially improving the overall energy efficiency and may have specific options that can be included or not included. The results of analyzing each alternative are assessed relative to the key energy goals (i.e., economic returns, efficiency, and supply security and emission reduction). The final recommendations are based on the alternative and options that most closely meet all energy goals.

The Net Zero Planner includes an optimization algorithm that automatically selects the best combination of energy conversion and storage devices to meet a particular set of building and industrial loads for each alternative. In addition to the Baseline and Base Case, a thermally distributed alternative is usually considered (i.e., boilers and chillers located in each building). In addition, existing district energy systems are analyzed for equipment changes, including conversion of steam to hot water. Other devices considered include cogeneration, thermal storage, electrical storage, and renewables such as solar photovoltaics and wind energy. The goal during scenario development is to set up alternatives that reflect broad constraints to be considered during the optimization phases that follow.

\subsubsection{Facility-level optimization}

Improving efficiency and reducing facility loads is almost always less expensive than making changes to distribution or supply systems. Thus, it makes sense to consider measures such as insulation, lighting, low flow fixtures, etc., before adding expensive renewable energy devices, e.g., photovoltaic (PV) solar panels, or other supply measures. Generically, any change done to a facility to improve efficiency or reduce load is referred to 
as an "EEM." Facility-level optimization refers to selecting the best set of EEMs for facilities on the installation to meet the installation's goals at the lowest cost.

The Net Zero Planner supports facility-level optimization by automatically applying packages of complimentary EEMs to the facility types specified during Baseline and Base Case development. The tool applies anywhere from six to 12 different packages to each facility type model, simulating the performances and cost of the EEM package using EnergyPlus on the Net Zero Planner server farm. The team then examines the output of the different EEM simulations and selects the most cost effective package for each facility type. Human judgment is important as well. The team assesses realistically available resources and makes a judgment regarding the number of EEMs that are reasonably likely to be implements. For instance, the most cost effective time to add many EEMs to a building is during a major retrofit. Thus, the anticipated schedule of major retrofits places a major role in the pace of EEM implementation.

\subsubsection{Supply and distribution system optimization}

Many installations began with centralized electrical and heating plants, usually using steam, and were then slowly converted to hot (and sometimes chilled) water distribution systems, or to completely decentralized systems using natural gas as a fuel and commercial power from the grid. Because of maintenance issues, steam distribution systems are almost never economically viable as new or recapitalized systems compared to modern hot water distribution systems, or even to completely decentralized systems. With a renewed emphasis on energy savings traced back to the source fuel, however, modern district systems may be the only way to meet policy goals economically. (Typical electrical generation, transmission, and distribution systems waste up to $70 \%$ of the source fuel compared to cogeneration electrical/ heat/ cooling plants.) The Net Zero Planner uses a module called "NZI-Opt" to perform calculations and optimization in this step to determine whether some form of centralized cogeneration or decentralization best meets the energy goals at the lowest cost. Industrial scale supply solutions such as solar photovoltaics, solar thermal, wind energy, bio-mass (wood chips, etc.), bio-gas, or synthetic gas are considered as part of the mix during distribution and supply optimization. They are almost always more expensive than making efficiency 
improvements or implementing cogeneration using natural gas as a fuel, but there may be other policy goals driving the use of these alternative technologies (e.g., net zero [NZ] fossil fuel, support for a nascent industry, or energy security).

\subsubsection{Plan and project formulation}

The final integrated plan is produced by comparing the baseline, Base Case, and alternatives using the criteria defined as part of the energy goals. MCDA methods may be used to support traceable decision processes and to integrate quantitative and qualitative factors selecting a preferred alternative. The Net Zero Planner presents results as a decision table, with the baseline, Base Case, and alternatives down one axis and decision criteria across the other axis for so that all alternatives can be compared easily. A sensitivity analysis should be conducted using the alternatives and risk factors such as price volatility (what happens if natural gas prices double), availability (is there a domestic supply?), and maintenance costs (e.g., relative risks of decentralized versus centralized equipment). The integrated plan contains a phased implementation strategy over the study period, showing investment costs (public or private), predicted energy, water, and waste reductions, and return on investment.

\subsection{Regulatory drivers}

Federal government agencies are required by law to eliminate fossil fuel use in new and renovated facilities by 2030 and to reduce overall facility energy usage by $30 \%$ by 2015 (EISA 2007). New buildings and buildings undergoing major renovations are required to reduce consumption of fossil fuel-generated energy, both off- and onsite, as compared with energy consumption by a similar building in fiscal year 2003 (FY03) (as measured by Commercial Buildings Energy Consumption Survey (CBECS 2003) or Residential Energy Consumption Survey (RECS 2003) data from the Energy Information Agency) - by 55\% in 2010, $80 \%$ by 2020, and $100 \%$ by 2030.

The 2005 Energy Policy Act requires that Federal facilities be built to achieve at least a 30\% energy savings over the 2004 International Energy Code or American Society of Heating, Refrigerating, and Air-Conditioning Engineers (ASHRAE) Standard 90.1-2004 (ASHRAE 2004), as appropriate, and that energy efficient designs must be LCC effective. In April 2011, 
the U.S. Army selected eight pilot installations to achieve NZE by 2020 (EISA 2007). In J anuary 2014, the Secretary of the Army issued the Net Zero Installations Directive, which expanded the Net Zero Initiative beyond the pilot installations to all permanent Army installations. The U.S. Navy is also selecting several installations to achieve NZE goals.

Other significant drivers relevant to energy efficiency in DoD and other Federal buildings include:

- Federal Leadership in High Performance and Sustainable Buildings. Memorandum of Understanding of 2006

- Executive Order 13423 Strengthening Federal Environmental, Energy, and Transportation Management of 2007

- Unified Facilities Criteria (UFC) 3-400-01 Energy Conservation, with changes of 2008

- Army Energy Security Implementation Strategy of 2009

- Executive Order Executive Order 13514-Federal Leadership in Environmental, Energy, and Economic Performance of 2009

- Office of the Assistant Secretary of the Army (OASA) Memorandum: Sustainable Design and Development Policy Update (Environmental and Energy performance) of October 2010.

To become low/ net zero energy, installations must implement aggressive conservation and efficiency efforts with new construction and exiting building stock, reduce waste and inefficiency in energy generation and distribution systems, and meet the balance of energy needs from renewable energy sources. Such an approach requires integrated Energy Master Planning. DoD Instruction 4165.70 (Real Property Management) establishes the requirement for Installation Master Plans. Unified Facilities Criteria (UFC) 2-100-01 (HQUSACE, NAVFAC, and AFCESA 2012) prescribes minimum DoD requirements for Master Planning, with integrated EMP being a part of the Area Development Plan (ADP) process.

\subsection{Project working team}

This project was executed by a team that included subject matter experts (SMEs) from ERDC-CERL, the PERTAN Group and USMA. This team worked in close collaboration with various other governmental and private organizations. The project manager and principal investigator of the project is Dr. Alexander Zhivov from ERDC-CERL. The ERDC-CERL team 
also included Dr. Michael Case, Dr. Richard Liesen, Dr. Matt Swanson, Mr. Dale Herron, Mr. Benjamin Barnes, Mr. J ames Miller (contract officer), and Mr. William Brown; USACE New York District team members are Mr. J effrey Friese, and Mr. Andrew Zuzulock.

The Directorate of Public Works (DPW) of the USMA at West Point was an important member of the team, providing information for the analysis, project support and coordination during site visits, inputs in development of energy goals, analysis of feasibility of different scenarios and their phased implementation. The core U.S. Military Academy Directorate of Public Works (USMA-DPW) team members are: Mr. Paul M. Simihtis, Mr. Shehreyar Husain, Mr. Randy McMurtrie, Mr. Carl Meyer, Mr. Nick Gorsky, Mr. J oey Fahey, and Mr. Mahendra Girdhard, with support from USMA COL LaChance.

The PERTAN Group contracted with the following SMEs who participated in the data collection and development of the master plan:

- Ventilation/Energy Applications, PLLC Engineering Consultants: Mr. Alfred Woody, Dr. Curt Björk, and Mr. Ray Patenaude; whom were responsible for HVAC investigations of the campus, analysis of HVAC considerations of heating, cooling, electric loads; as well as the economic considerations of combined building envelope and HVAC EEM packages. Also provided support regarding grid and generation systems.

- TKDA, GEF (Germany) and Linkoping University (Sweden) partnership: Mr. Lon Fiedler and Mr. Peter Steitz (TKDA); Dr. Stephan Richer and Mr. Simon Schad (GEF) and Dr Bahram Moshfegh (Linkoping University). These firms are responsible for the analysis as it pertains to heating and cooling generation systems, supply, fuels, distributions, and cogeneration systems.

- Building Science Corporation (BSC): Dr. J oe Lstiburek, Christopher Schumacher, Alex Lukachko, Aaron Grin and Robert Lepage, analyzed current building envelope and enclosure systems and developed retrofit solutions for USMA building stock as high performance building envelope concept for the new barracks building.

- RKS (Germany): Dr. Alfred Kerschberger provided input and general concepts related to master planning, analyzed the current building inventory, and performed preliminary development of building envelope 
EEMs. Dr. Kerschberger left the project in December 2012 due to health constraints.

- The PERTAN Group: Mr. Anthony R. Latino and Mrs. Sharie CarterBane, who were responsible for administering and coordinating of the SME team members, also contributed to this report.

The following organizations provided additional support to the project:

- National Renewable Energy Laboratory (NREL): Mr. J erry Davis, Tom Harris - results of renewable energy options study

- Sandia National Laboratory: Mr. Ben Schenkman and Mr. Mike Hightower - energy security requirements

- NORESCO: Mr. J ohn Saams - results of feasibility studies for different EEMs contributing to development of the Base Case, extensive Energy Services Company (ESCO) experience working at USMA

Several joint meetings were conducted between the team, NORESCO, SANDIA, and NREL to exchange information, coordinate efforts, optimize results, and support specific projects to be implemented at USMA West Point.

With global best practices in mind, the team experience and skill mix includes energy expertise in military and commercial buildings, industrial processes, electrical and thermal distribution, and multiple energy supply approaches in the United States and internationally. The team has extensive familiarity in developing Community Energy Master Plans for U.S. Army installations as well as for small- and medium-sized communities and campuses in the United States and in Europe. 


\section{Technology Description}

\subsection{Technology overview}

Development of the technology tested in this project was funded as an Army applied research program. It includes both an EMP process and the NZP Tool (Case et al. 2014). The EMP process draws from lessons learned during studies conducted at Fort Carson, CO, Fort Bragg, NC, Camp Humphreys, South Korea, Fort Irwin, CA, and many other installations (e.g., Kimman, Rovers, and Ravesloot 2010; Zhivov et al. 2006; and Annex 46 2009). Although the EMP process could be executed using non-integrated existing analysis technologies, the goal of NZP is to execute the process quickly, efficiently, at lower cost, and with a high level of repeatability in an integrated single program structure. Both the process and the technology can be taught to energy Subject Matter Experts (SME) and once a study is completed, it will leave behind an installation energy model that can be modified and maintained by the installation with relatively little effort. Unlike a paper report, study models can be copied and updated as circumstances change. This section contains an overview of EMP and NZP sufficient to understand the major concepts and capabilities. Chapter 4 includes examples of their application and results. The tool has also been applied to EMP processes at Fort Leonard Wood, MO, Fort Hunter Liggett, CA, Schofield Barracks, HI, and the Presidio of Monterey, CA.

Energy planning may be conducted at varying levels of detail, depending on the purpose of the planning exercise. Figure 2-1 shows the level of detail used at various installations. Traditional engineering studies, which require more in-depth analysis and costing, reside on the right hand side. The least amount of detail falls to the left, in Sustainability Component Plans (SCP), which are conducted as a part of Real Property Master Planning process. Historically, these studies used rules-of-thumb for energy performance and did not perform any costing, although costing would help to identify more feasible alternatives (Annex 46 2009). The studies conducted for this project fall somewhere in the middle, with more detailed analysis and costing. NZP is intended to be used at the planning level, where a holistic-integrated plan is needed. The use of NZP to support SCPs is a recent development that resulted from presenting case studies to Headquarters, U.S. Army Corps of Engineers (HQUSACE) Master 
Planners. This use demonstrates the emergent versatility of the tool. Traditionally, architects and engineers focus on individual buildings, while Sustainability Planners and Master Planner focus on long-term plans and zoning. Some types of decisions, however, such as district energy system (which could include cogeneration, district solar, or wind) require efficient buildings operating within higher order energy frameworks-for example, decisions about whether to connect buildings to a district system that takes advantage of solar-thermal energy and large scale thermal energy storage.

Understanding the NZP technology and process requires some familiarity with the Master Planning process. Figure 2-2 shows the Real Property Master Planning (RPMP) process as documented in Unified Facility Criteria (UFC) 2-100-01 (HQUSACE, NAVFAC, and AFCESA 2012).

Figure 2-1. Energy Planning exists on a continuum, increasing in the required level of detail from left to right.

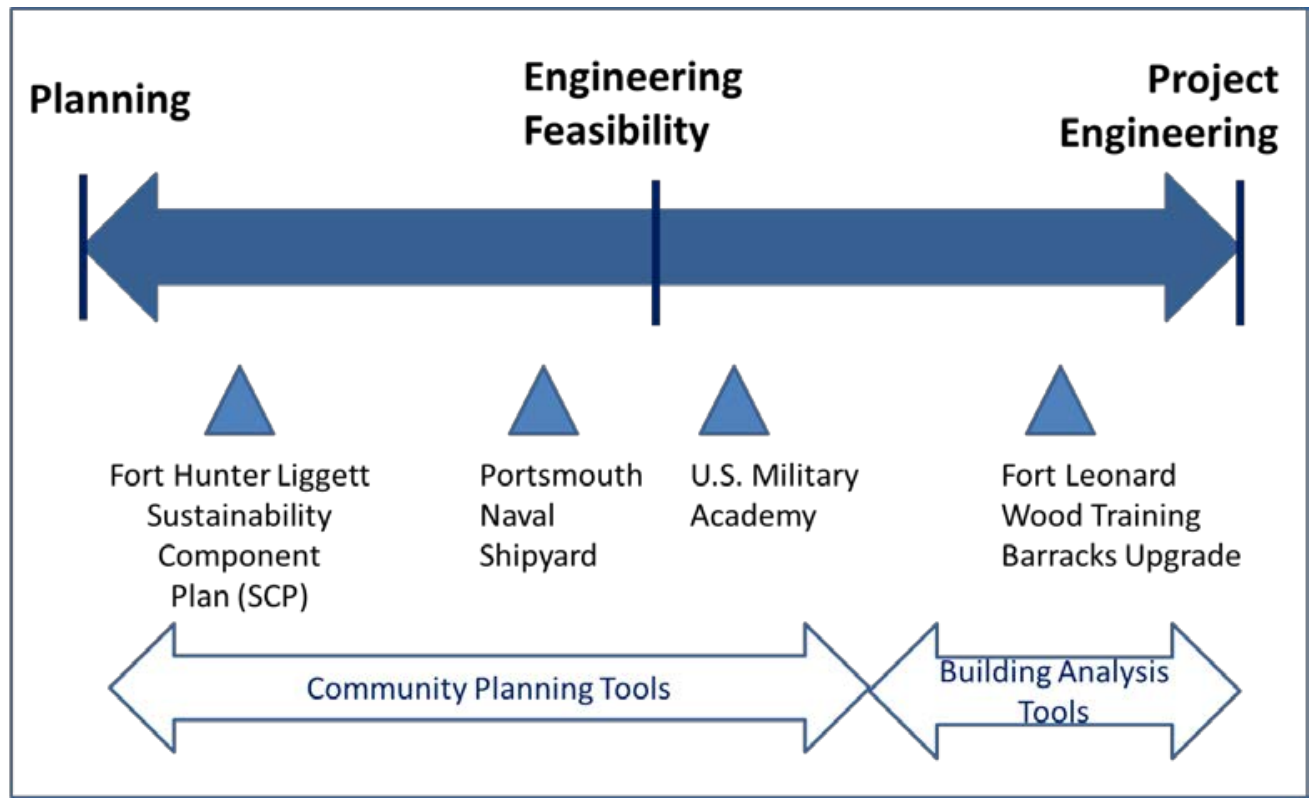


Figure 2-2. Diagram of the RPMP process as documented in UFC 2-100-01.

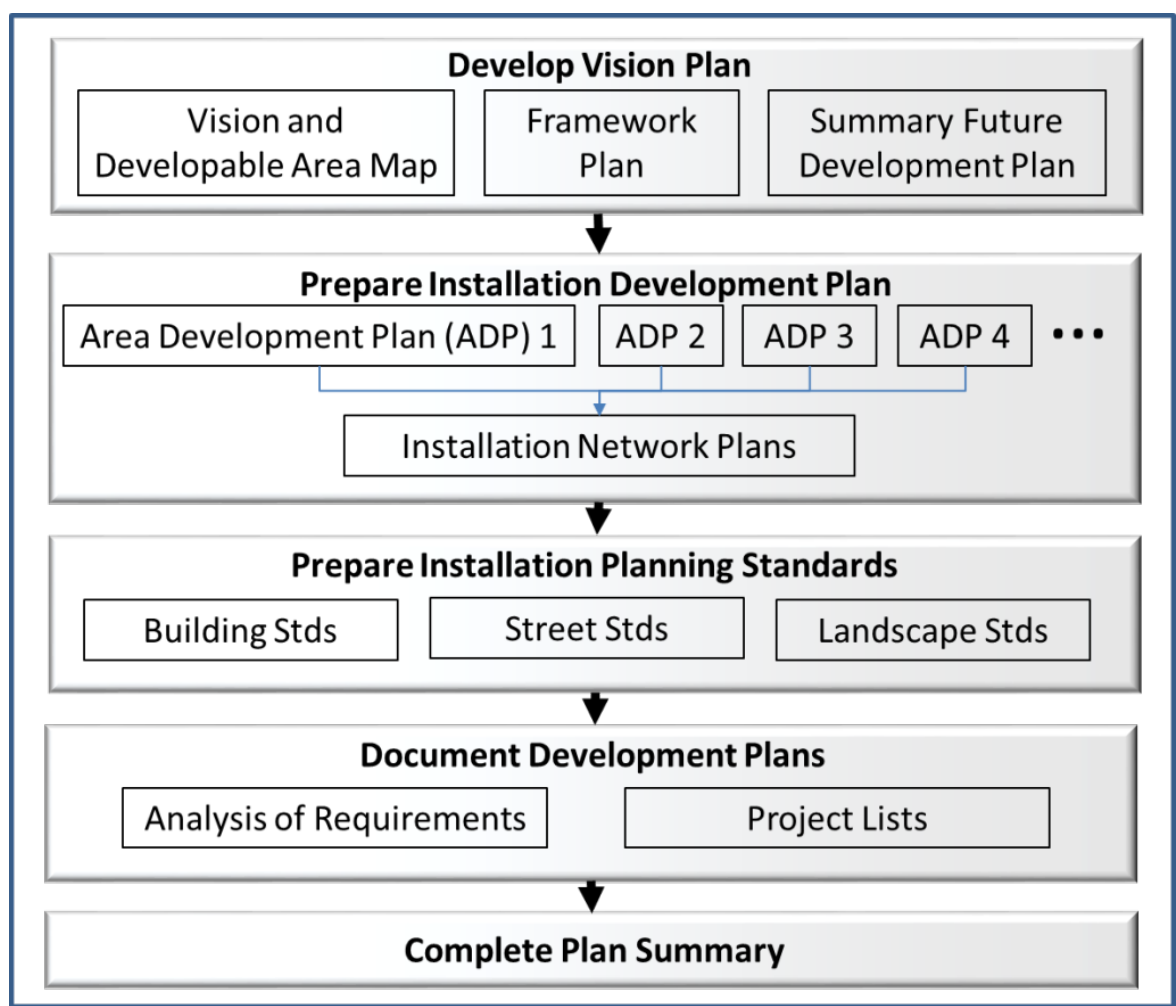

The RPMP process differs from typical building architecture and engineering in that it looks beyond the " 5 foot boundary" and has an explicit process for creating a vision and establishing goals. Installations also frequently have a "Sustainability Plan" that sets goals for conservation/reduction of energy, water, waste, and other factors, although the Sustainability Plan will not be discussed in detail here. Specifically, the Vision section of the RPMP, with the Sustainability Plan, should set installation-wide energy goals that guide the Energy Master Plan. It documents assumptions for environmental conditions over at least 50 years and conceivably over 100 years. The Installation ADP breaks the overall installation into areas, each of which is planned separately. Planning Standards and an associated Installation Design Guide contain explicit instructions about design requirements and criteria for new construction, and for major and minor renovation projects. The Sustainability Component Plan has emerged as an overlay to the ADP that explicitly addresses the sustainability of the plan. Results of analysis using NZP directly inform energy budgets (Energy Use Intensities) and installationwide strategies. 
Figure 2-3 illustrates the major steps in the EMP process. The rest of this section gives a brief description of each step with a screen capture showing how that step is implemented in the tool. Transition to a Low Energy or Net Zero Energy Installation requires a disciplined planning and implementation process. The following sections discuss the definitions of goals and objectives, the identification of system boundaries, and the creation of a road map for implementation. They also provide a brief description of each step with a screen capture showing how that step is implemented in the tool.

\subsubsection{Establish scope and boundaries}

The scope of the energy minimization effort can include residential, commercial, and public buildings; community-based infrastructure; industrial energy users; community-owned and transit transportation; agriculture and other energy-consuming users; or any combination of those.

A community can have fixed boundaries defined either by physical limitations (e.g., an island-based community) or political or administrative boundaries. For example, a military installation or university campus may be a contiguous area, or may be comprised of separate areas (Figure 2-4). Such community boundaries define its real estate, but may also suggest the possibility for interface with other communities via electrical or thermal (district heating/ cooling) networks. An analysis of community boundaries may also reveal how communities can best meet their energy needs (e.g., by purchasing power, hot water, steam, chilled water, or other utilities from networks, and/ or by capturing waste heat from processes). The same analysis can determine the feasibility of exporting power, heat, and cooling energy from cogeneration to other buildings within the community.

The Net Zero Planner is web-based. Important information for all military installations can be found on a centralized database and Geographic Information System (GIS) server. The system is currently only accessible to users accessing it through a *.mil domain address. Analysis starts with selection of the military installation using the initial screen (Figure 2-5). 


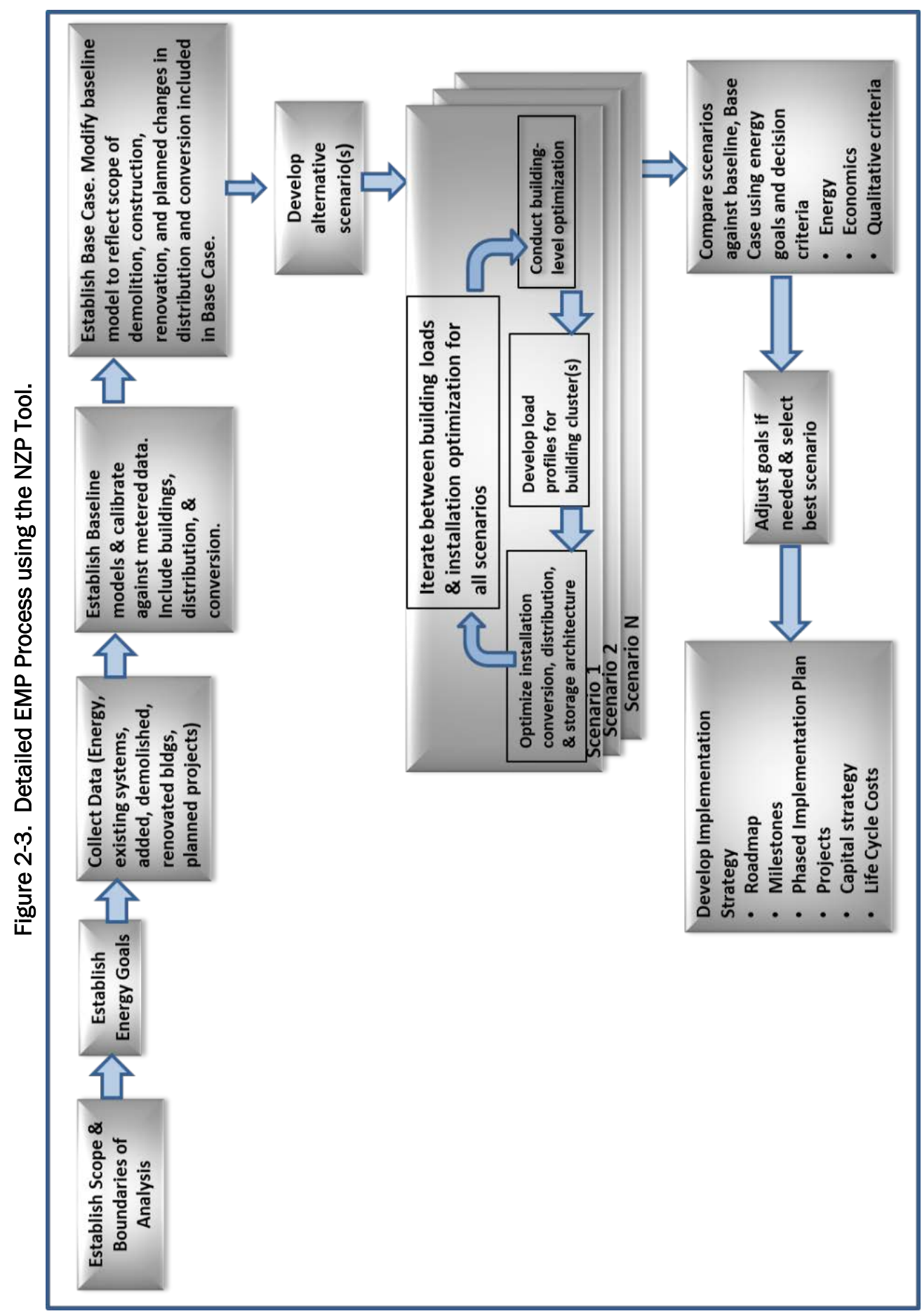


Figure 2-4. Examples of community boundaries: a- defined by building clusters; b- defined by physical limitations.

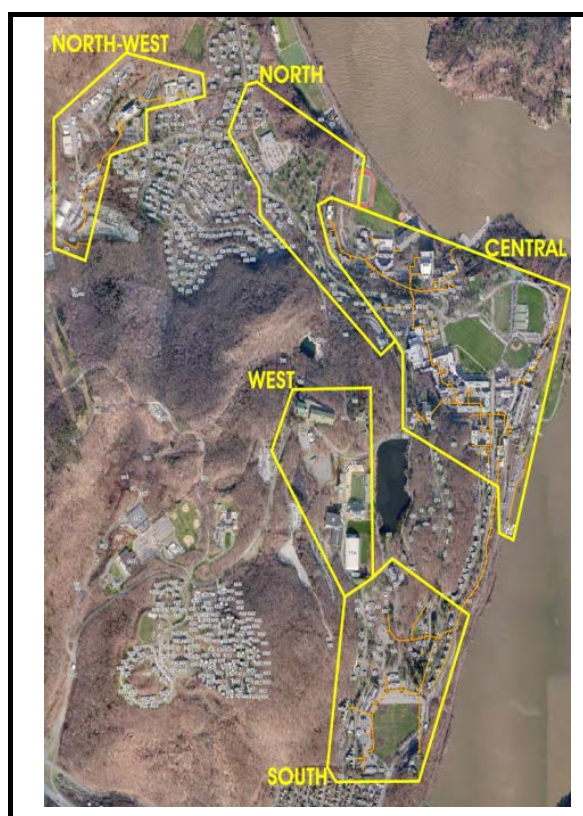

a.

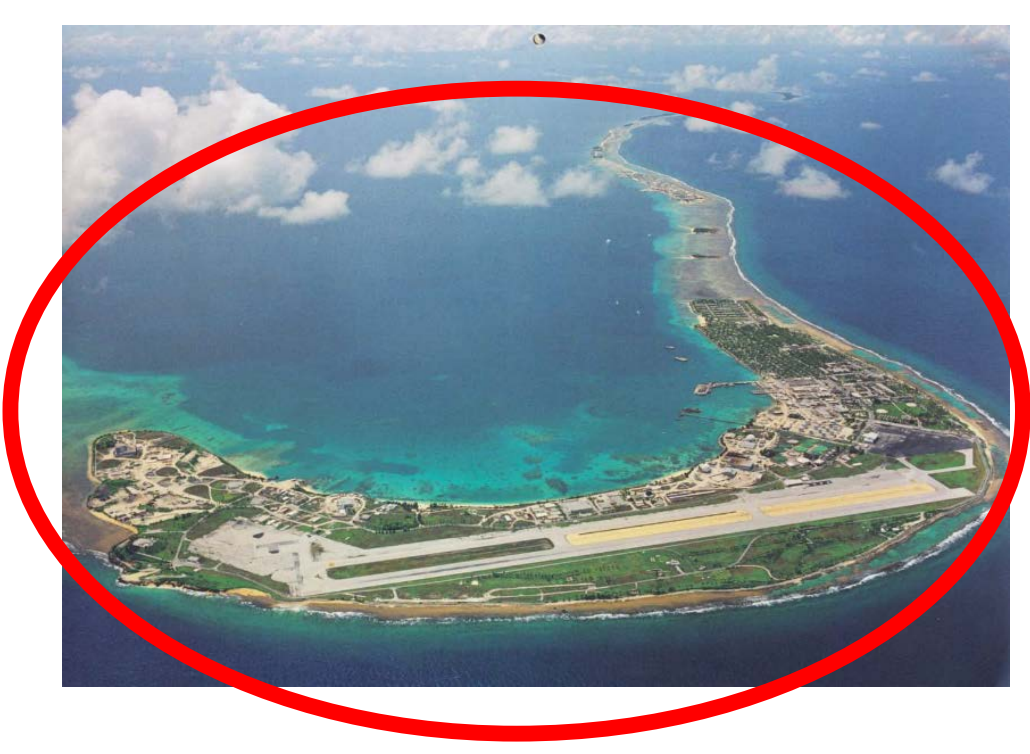

b.

Figure 2-5. NZP is a web-based system. This screen shows a list of studies to which the user has access.

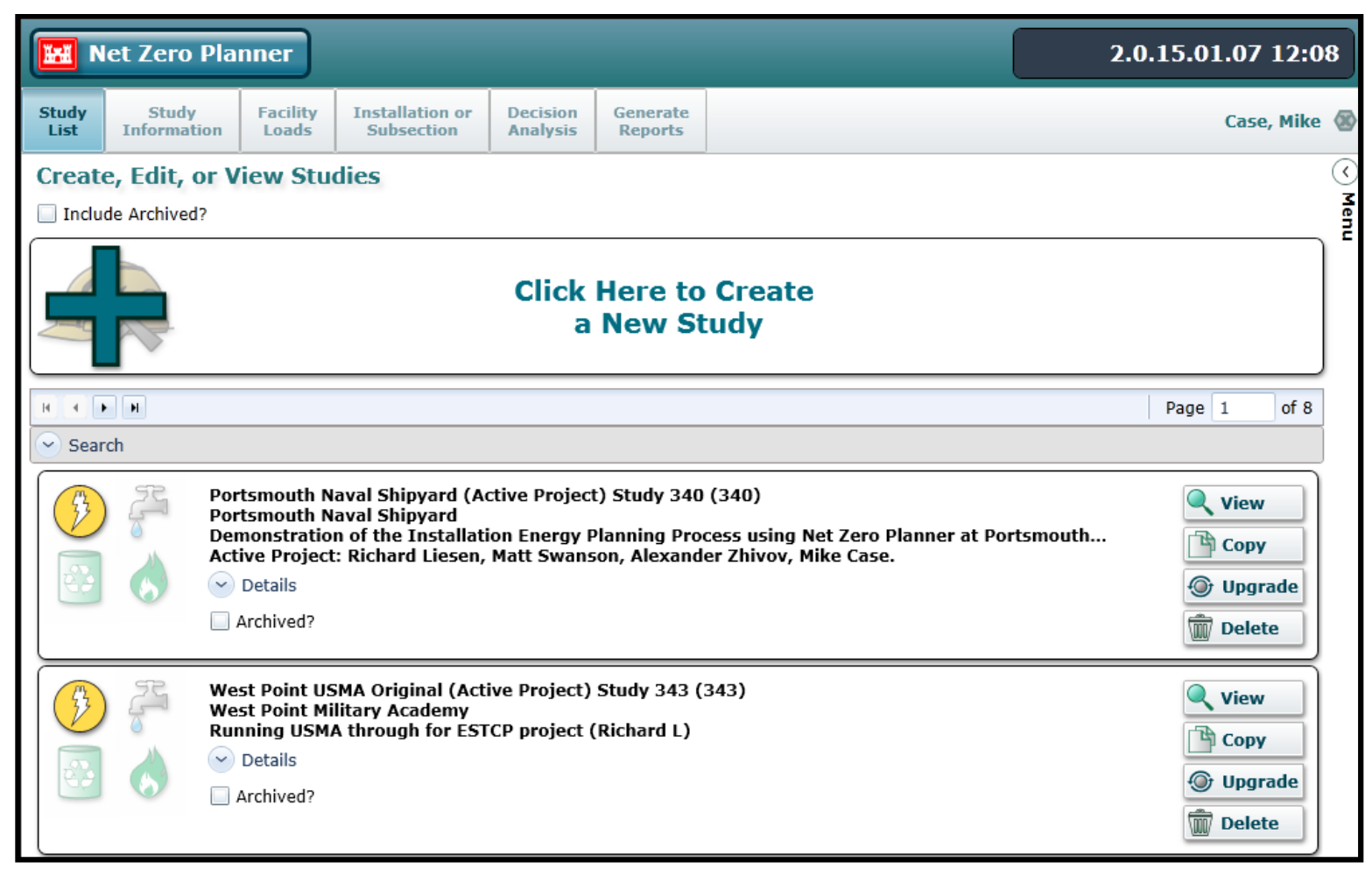


Users select the geographic scope of the analyzed installation or its part by choosing the area within an installation boundary (Figure 2-6). NZP has boundaries for all Army installations and a number of Navy and Air Force installations. When defining the scope, it is important to understand which energy users the community can control. The most common net zero definition is limited to source-based energy targets for community building stock, industrial processes, and community-based infrastructure; such targets sometimes extend to community-owned private and public vehicles.

Figure 2-6. Select geographic scope of the study.

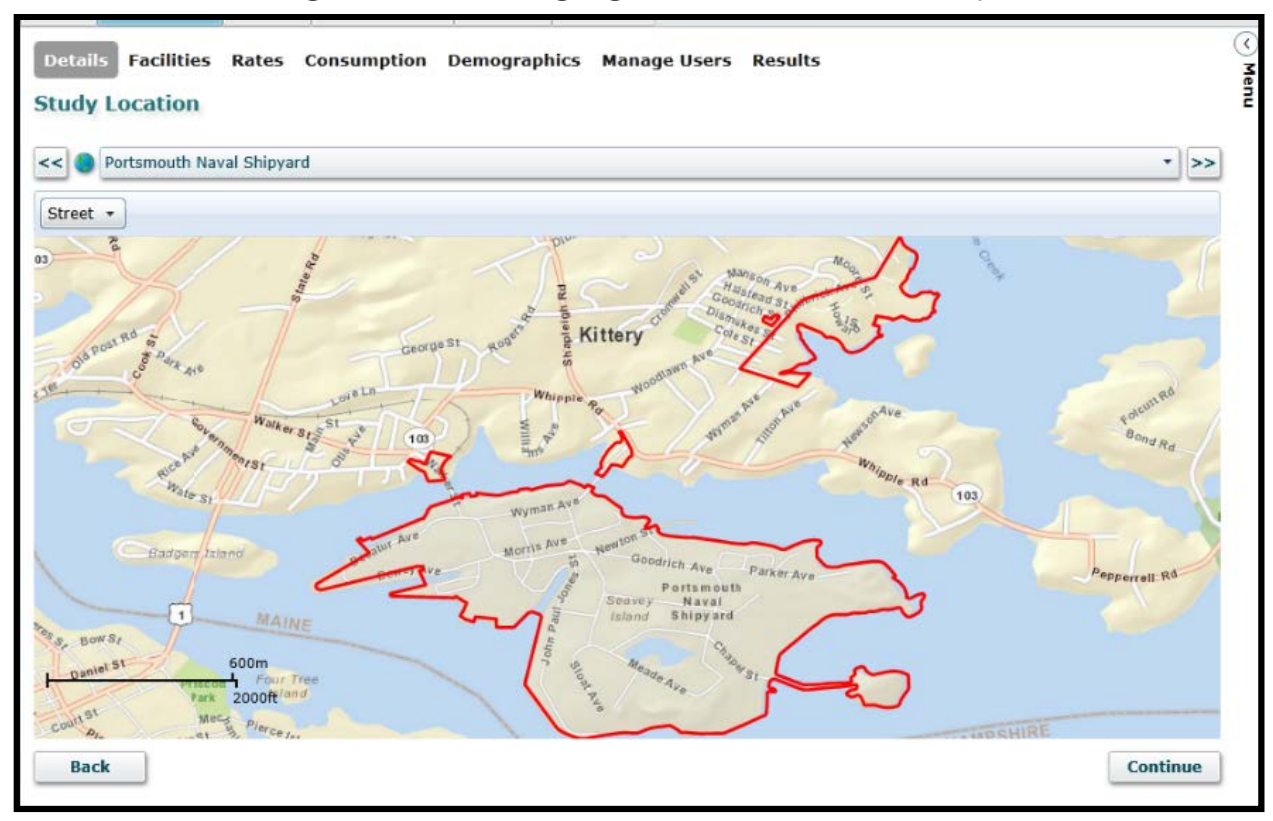

Once the installation boundary has been selected, the user chooses the facilities that will be included in the study. These data come from Spatial Data Standards for Facilities, Infrastructure, and Environment (SDSFIE) compliant GIS, usually obtained from the installation itself. NZP also includes an appropriate weather file for the location selected, using the closest ASHRAE TMY3 weather file. TMY3 (Typical Meteorological Year) is the format used by the EnergyPlus whole building simulation program. Figure 2-7 shows the selection screen for including buildings and existing infrastructure in a study. 
Figure 2-7. The user selects facilities to include in the study.

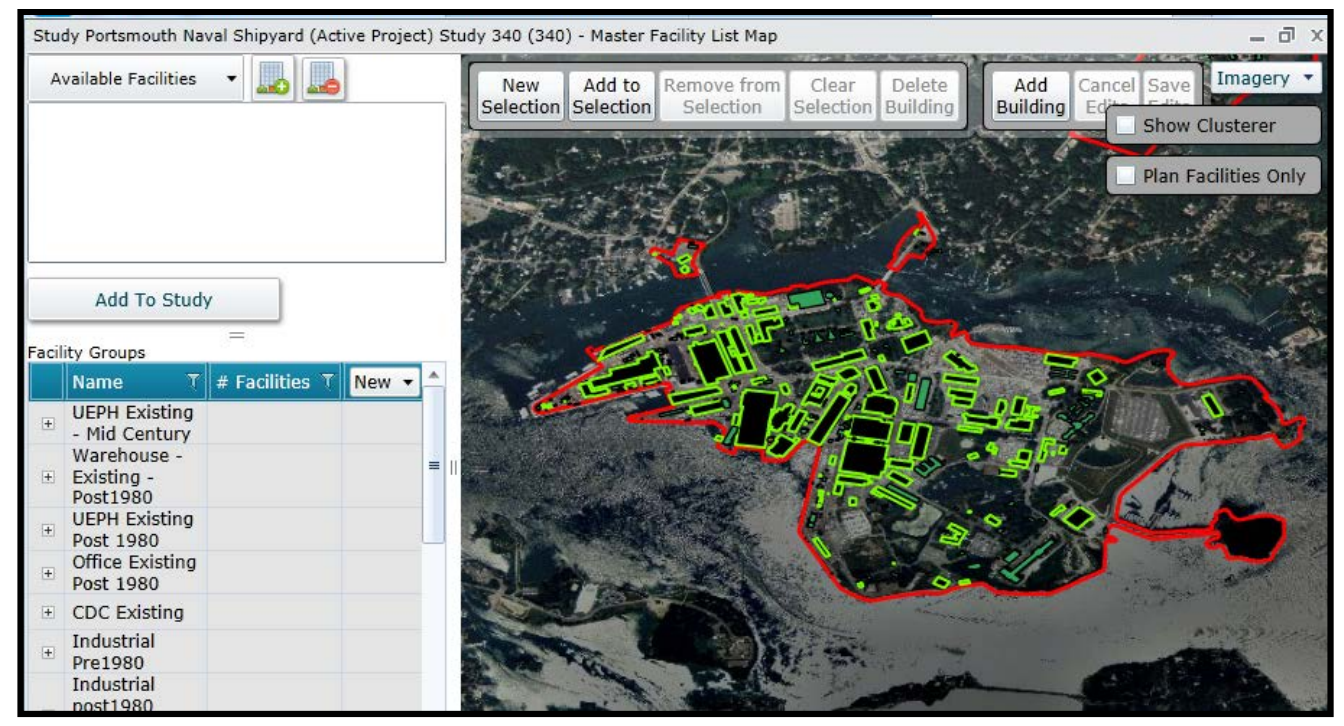

\subsubsection{Establish energy goals}

It is important to clearly define long- and short-term energy goals at the beginning of a study, as well as important limitations and other priorities, e.g., energy efficiency, energy supply security, peak power loads, carbon footprint, water availability and conservation goals, etc. Long-term energy goals can be expressed as the reduction by a desired percentage of site or source energy use against a baseline in a given year, or the achievement of a net zero site/ source energy community within a given timeframe. These goals lead to decision metrics that will be used to decide between alternative solutions, which will be described later in this report. They help to focus the study and define "success." It is entirely possible that the goals will turn out not to be feasible, in which case the goals can be adjusted once quantitative data are available. Figure 2-8 shows how goals are captured in NZP.

There is often confusion between site and source energy in the definition of NZE community. This difference influences technical approaches used to achieve this status. When the goal is to minimize community site energy, the emphasis is made on energy efficiency of systems located inside community boundaries. The amount of thermal or electrical energy supplied to the community is treated equally without any consideration of the inefficiency of electricity generation or distribution losses in thermal and power networks. Such an approach may result in preferences for such technologies that consume electricity for heating and cooling as electrical 
heating, electrical cooling, or ground-coupled heat pumps. Given the inefficiency of power generation, such an approach will result in increased fossil fuels usage and GHG emissions.

Figure 2-8. Energy goals are defined at the start of a study, in consultation with the installation decision makers. Metrics related to these goals are defined later in the decision support screens.

\begin{tabular}{|c|c|c|c|c|c|c|}
\hline \multicolumn{7}{|c|}{ Study Goals } \\
\hline $2:$ & Goal-Criteria & 2011 Baseline Value $T$ & 2041 Target Value $T$ & Comment & $T$ & $\mathrm{mid}^{*}$ \\
\hline \multirow[t]{4}{*}{ F } & \multicolumn{6}{|c|}{ Click here to add new item } \\
\hline & Internal Rate of Return & N/A & $5 \%$ & Higher than 30 year T-Bills & & (aid \\
\hline & GHG Reduction & $65,210 \mathrm{mt}$ & Net Zero & Green power purchase is $\mathrm{OK}$ & & (aidi \\
\hline & Site Energy Use & $296,030 \mathrm{MWh}$ & Derived & Depends on scenario & & (aidi \\
\hline \multirow[t]{2}{*}{$>$} & Source Energy Use & $368,530 \mathrm{MWh}$ & $\begin{array}{c}40 \% \\
221,118 \mathrm{MWh}\end{array}$ & Based on draft baseline & & (aid \\
\hline & Back & & & & Conti & nue \\
\hline
\end{tabular}

When the source energy or fossil fuel based energy is considered as a minimization parameter, energy efficiency of the community systems may become of less importance. Communities connected to hydropower stations or to nuclear reactors will become fossil fuel neutral without any effort given to improvement of community energy systems. However, when electricity provided to the community is primarily based on fossil fuel, which is the case for most communities connected to large power grids, the goal of "net zero fossil fuel" is more challenging in that it requires improvements in the efficiency of the community energy system and reduced energy waste in the power generation and distribution systems.

After defining the community energy goals, it is important to connect these goals to the existing community's "core values" and energy-related constraints which may include:

- Enhancing energy security

- Requirements to energy systems' reliability

- Power peak reduction

- Gas supply limitations

- Environmental limitations (carbon footprint), etc.

- Energy projects economics (e.g., the net investments aimed at achieving energy goals will achieve an Internal Rate of Return of at least 5\%). 
Installation/ community leaders, decision makers, and end users and businesses can help to define these core area values and to connect them with the planned installation/ community development.

\subsubsection{Collect data}

In addition to GIS data on facilities, additional information is needed. This includes existing facilities, planned facilities, and those planned for demolition. $\mathrm{ADPs}$ contain these data. If an $\mathrm{ADP}$ is not available, then the Installation Master Planner is interviewed. The installation also provides utility data (including rate schedules), annual to monthly consumption, and meter data at the building level, if possible. Existing infrastructure information such as composition and capacity of central plants, location and size of heating and cooling loops, and configuration of the electrical grid (capacity of large transformers and limitations on power delivery from the grid) is required as well. There is usually a "data cleaning" step to ensure that the GIS data entered into NZP is complete and accurate. Trained SMEs are required for this step. They will conduct a walkthrough of representative existing facilities and may need to look at building plans to determine methods and materials of construction, HVAC equipment, as well as other energy-related parameters. The amount of information needed depends greatly on the level of analysis, as described previously. Detailed information is needed for a pre-engineering study and more general information is sufficient for a planning study. Figure 2-9 shows how information about existing, planned, and to-be-demolished buildings is used to compare the Baseline against all future alternatives. The screen shots are from a different installation that better shows how different the current and future configurations might look.

The Baseline consists of existing buildings and those marked for demolition. The Base Case (future) consists of existing and planned buildings, with no buildings marked for demolition. Other alternatives begin with the Base Case and represent other possible futures. 
Figure 2-9. Buildings are categorized as existing, planned, or demolish. This annotation is used to display and analyze the Baseline (present day) against the Base Case and other future alternatives. Existing and demolish categories are shown on the left, while existing and planned categories are shown on the right.

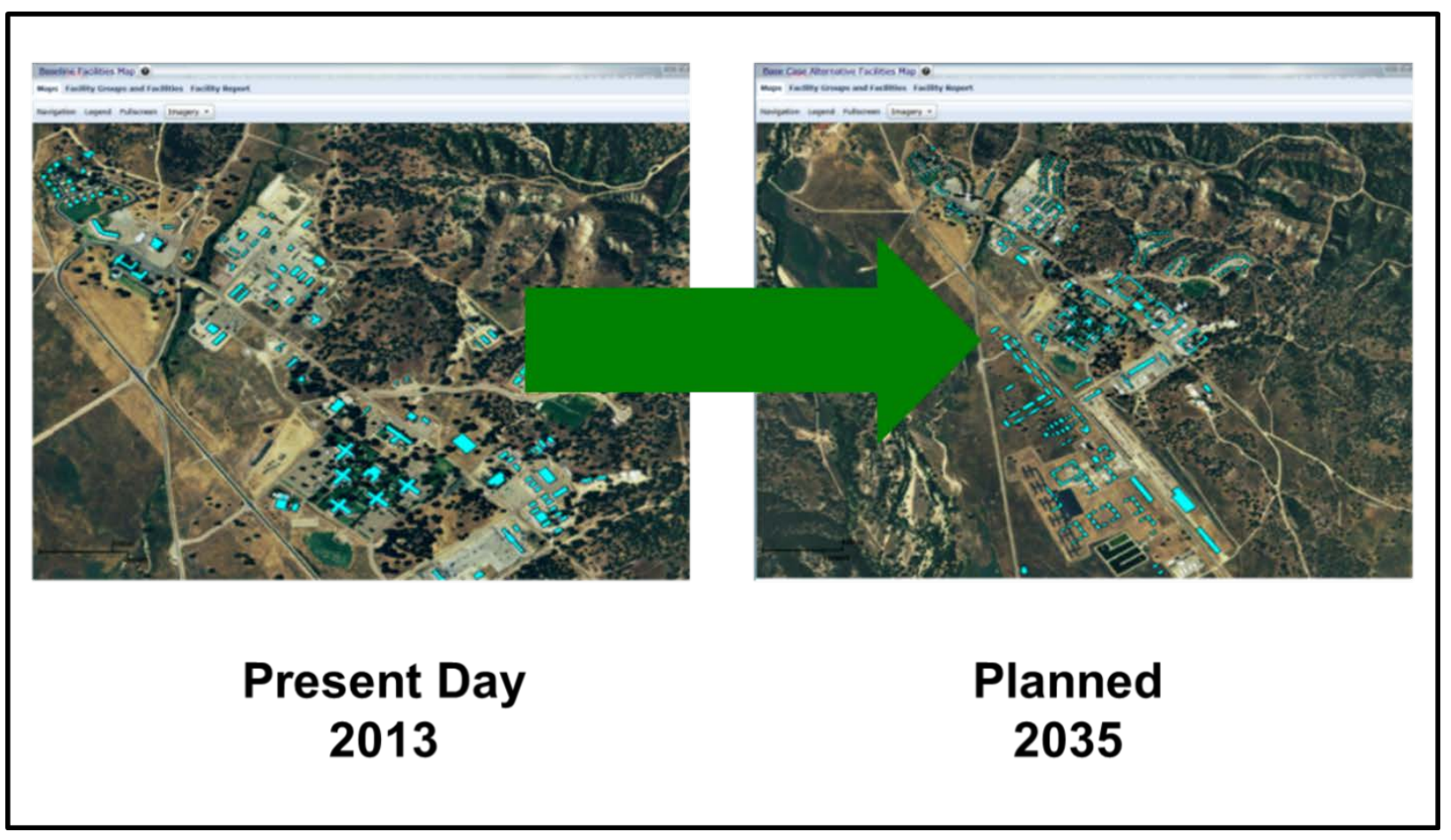

\subsubsection{Establish baseline models and calibrate against metered data}

The importance of the most difficult part of doing an analysis - establishing the Baseline energy usage - cannot be over emphasized. The Baseline (site and source energy usage and energy cost) is defined as the current energy consumption profile. It is essential that the Baseline energy use profile capture the quantity and type of energy used (converted by the installation at the central energy plant [CEP] or at individual buildings) such as grid electricity, natural gas, propane, and energy generated from renewable sources (e.g., solar, wind, hydro, etc.). It is also important to understand how the energy is used, whether for heating, cooling, plug loads, or industrial processes. The Baseline is a snapshot of a point in time and can be derived from a reference year or from consumption data averaged over a number of years to even out climatic variations. 
The total energy use in the community can be broken into different users, losses in generation, conversion, and transmission, using the following categories:

1. End uses:

o Building Functions

o Industrial Processes

o Central Services - Compressed Air / Water / Sewer

2. Distribution losses:

o Hot water, chilled water, and steam network

o Onsite electrical

3. Onsite conversion losses:

o Turbines

o Boilers

o Engines

4. Off-site conversion and distribution losses:

o Purchased natural gas

o Purchased electricity.

Site energy use is comprised of energy uses and losses under Categories 1 , 2 and 3. The source energy use is derived from the energy uses and losses under Categories 1 to 4 . Different data sources and estimation approaches can be used in this analysis.

The best sources of such information are energy bills, metered energy logs, targeted measurements of energy losses in distribution systems, and modeling results. Military installations often only have meter data for the entire installation or district heating/ cooling/ power plants. In this case, energy use of the facilities is apportioned by comparing the aggregate modeled usage against the installation-wide usage. More and more, however, individual metered data are available that can be used to more accurately calibrate the models. Users must use their experience and judgment. For planning purposes, the user is not trying to get an exact model of every single building. Rather, the user needs to get an idea of the relative importance of each building in the overall energy usage of the installation and its potential for improvement. Thus, if the models can be calibrated 
within about $10 \%$ of the overall energy usage, the potential for change (improvement or otherwise) in energy use by applying energy efficiency measures (EEMs) can be estimated with a reasonable level of accuracy.

Figure 2-10 shows an example of energy use and cost for one military community.

Figure 2-10. Example of energy use and cost for a military community.
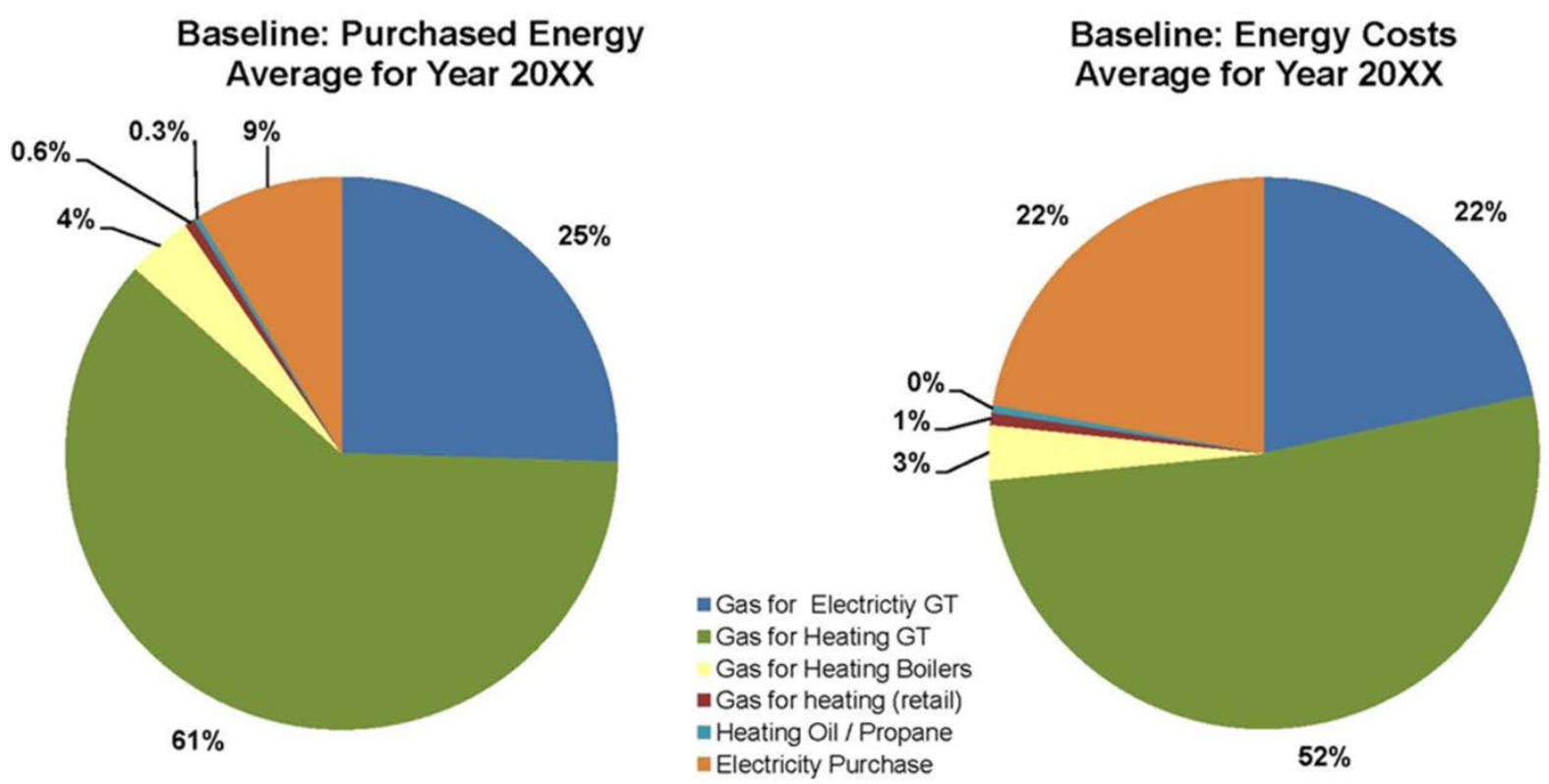

1,010,140 MMBtu / 296,030 MWh

$\$ 11,032,900$

The total energy use in the community should be broken down into consumption between different users; and losses in generation, conversion, and transmission. This information provides a good starting point for identification of energy wastes and inefficiencies along the chain between the energy sources and energy use. The energy distribution profiles should be shown for groups of buildings and individual buildings as well.

To describe baseline end uses, computer simulation whole building energy models are usually developed for individual facilities included in the analysis or for facilities with similar physical features that can be modeled as one facility group (Case et al. 2014). The models are calibrated by comparing the calculated Energy Use Intensities (EUIs) against measured data. 
The energy performance of the facilities is modeled using a process described in detail in Case et al. (2014) and summarized here. The facilities included in the study are divided into representative "Facility Groups" using their similarities for energy modeling purposes. For example, a group of barracks that was built about the same time with similar physical features would be modeled as one facility group. Figure 2-11 shows a partial list of Facility Groups. NZP has models for over 30 types of buildings, based on DoD standards and on the U.S. Energy Information Administration (EIA) CBECS categories. The models are further divided by eras/ standards of construction: Pre-1900, Mid-Century, Pre-1980, and Post-1980 (ASHRAE 90.1 (2004, 2007, 2010, etc.), and ASHRAE climate zones.

Figure 2-11. Facilities are grouped into “Facility Groups" based on their type of construction, era, usage type, and other factors.

\begin{tabular}{|c|c|c|c|c|c|c|c|}
\hline \multicolumn{8}{|c|}{$(3)$ Map } \\
\hline \multicolumn{8}{|c|}{ Facility Group Summary Facilities Summary } \\
\hline \multicolumn{8}{|c|}{ Drag a column header and drop it here to group by that column } \\
\hline & Name & \begin{tabular}{|ll} 
Facility & \\
Type & $T$
\end{tabular} & Status T & $\begin{array}{l}\text { Facilities } \\
(\#)\end{array}$ & $T$ & $\begin{array}{l}\text { Plan Area } \quad T \\
(\%)\end{array}$ & $\begin{array}{l}\text { Cond. Area } \\
\left(\mathrm{ft}^{\wedge} 2\right)\end{array}$ \\
\hline \pm & CDC Existing & $\mathrm{CDC}$ & Existing & & 1 & 0.18 & 6,496 \\
\hline \pm & Navy Exchange and Commissary & DFAC & Existing & & 2 & 1.22 & 43,790 \\
\hline \pm & Training Black Box & GIB & Existing & & 1 & 0.83 & 30,082 \\
\hline \pm & Commissary Warehouse & GPW & Existing & & 1 & 0.21 & 7,721 \\
\hline$\oplus$ & Industrial - Demolish - Mid Century & GPW & Demolished & & 4 & 4.75 & 171,253 \\
\hline \pm & Industrial - Existing - Post 1980 - Low Process Loads & GPW & Existing & & 5 & 1.45 & 52,346 \\
\hline \pm & Industrial post1980 Medium Process Loads & GPW & Existing & & 13 & 12.66 & 456,056 \\
\hline$\oplus$ & Industrial Pre1980 & GPW & Existing & & 21 & 27.14 & 977,869 \\
\hline \pm & Warehouse - Existing - Post1980 & GPW & Existing & & 10 & 1.28 & 46,102 \\
\hline 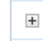 & Warehouse Existing Mid Century & GPW & Existing & & 22 & 7.93 & 285,773 \\
\hline 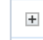 & Warehouse Existing Pre 1900 & GPW & Existing & & 11 & 13.38 & 482,114 \\
\hline$\oplus$ & Office - Existing - Modern & Office-Medium & Existing & & 2 & 0.83 & 29,807 \\
\hline 甲 & Office - Existing - Pre 1900 & Office-Medium & Existing & & 11 & 5.08 & 183,063 \\
\hline
\end{tabular}

Any community will have a few buildings that house a mix of two or three uses, each of which fits into one of the model categories. Examples could be Company Operations Facilities (COFs) or Army Reserves that combine offices and warehousing, etc. The project team assigns percentages of the appropriate models to these mixed use buildings. Figure 2-12 shows an overview of the complex building modeling process. 
Figure 2-12. Baseline: Overview of a complex building modeling process.

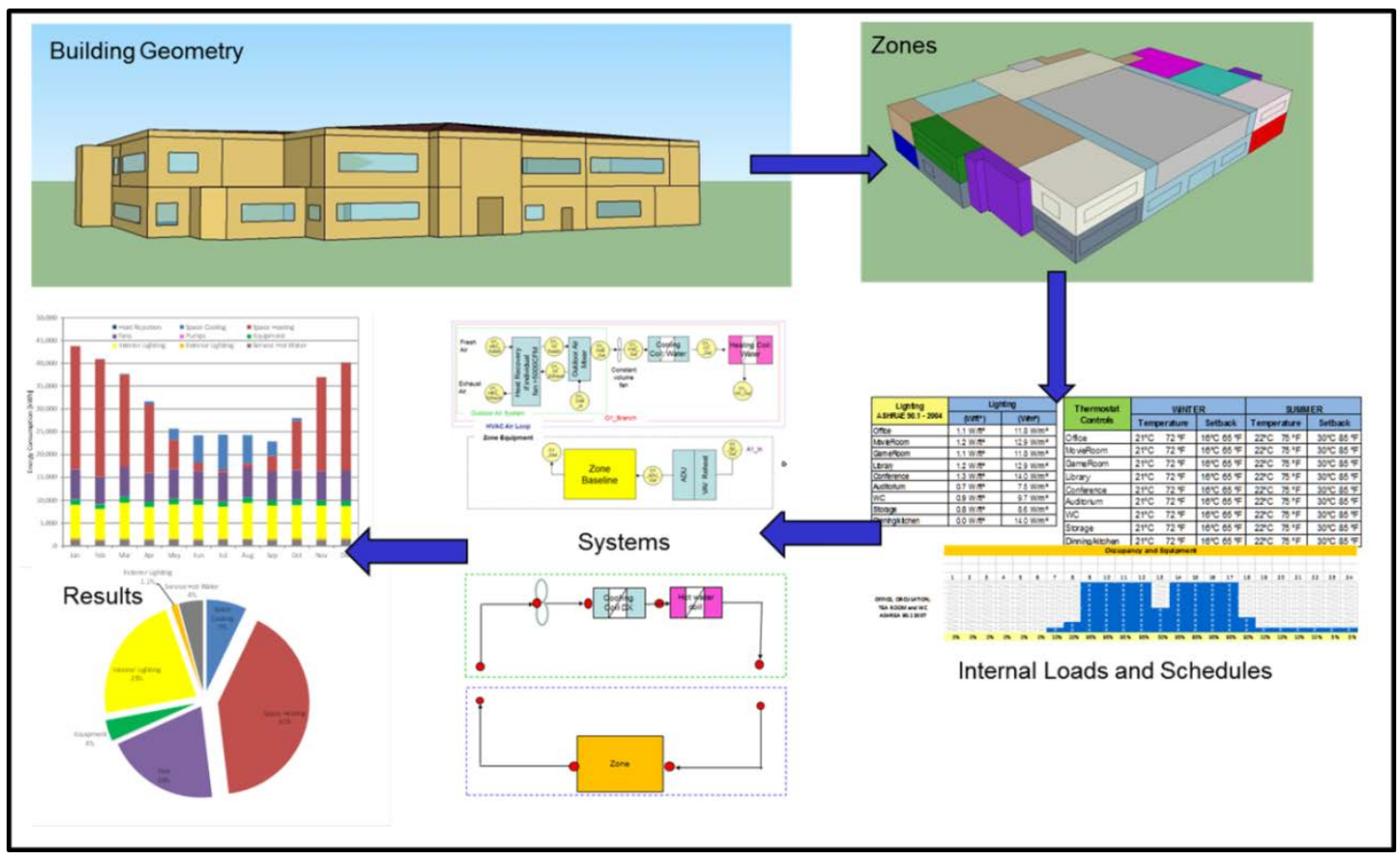

The generalized energy end uses by building function is estimated by assigning the appropriate energy end use indexes to each Actual Building based solely on its size (floor area). The estimated utility use of each Actual Building is calculated using the appropriate Model's Coefficients of Performance (COPs) for gas and electricity.

The remaining structures typically have characteristics that cannot be reasonably generalized. For these "individual buildings," a specific EnergyPlus model is assembled and the specific end uses by building function are calculated. The estimated utility use of each individual building is calculated using the appropriate Individual Model's COPs for gas and electricity.

The total estimated utility needs from the total of the general and individual modeling process described above are then compared to any available baseline metered gas, electricity, or other utility data. If necessary, any significant discrepancies between metered and modeled data are resolved by adjusting models using the modeling team experience and selected repeat site visits and data review. NZP can run over 1000 simulations at a time (100 in parallel) (Figure 2-13) 
The results of such modeling are reliable enough to identify the splits of energy use and cost by general building types, by groupings of actual buildings, and by specific functional end uses. They are also the basis for prioritizing potential energy efficiency and energy productivity opportunities within similar grouping.

When this process has been completed for each building, the results from all of the individual buildings are integrated and summed into energy demand profiles. These curves are derived from hourly load data to show all possible variations to the system, and are generated from the hourly building energy simulation program. Due to the diversity of energy use in buildings comprising the cluster (community), the peak of the resulting load curve is much smaller than the sum of peaks of individual buildings so that the needed generation and backup capacity is much smaller. The modeling approach described above allows derivation of the seasonal energy use and annual total by major building function for each building and for the site as a whole (Figure 2-14). The hourly data from the energy simulation models can also be used to calculate energy end use by function (Figure 2-15).

Note that the modeling process described above is not a substitute for the detailed modeling of a single building. This detailed modeling would typically be done on selected buildings for project engineering during subsequent implementation of the EMP recommendations for specific renovation projects to fine-tune the strategic recommendations. 
Figure 2-13. NZP building level simulations on server.

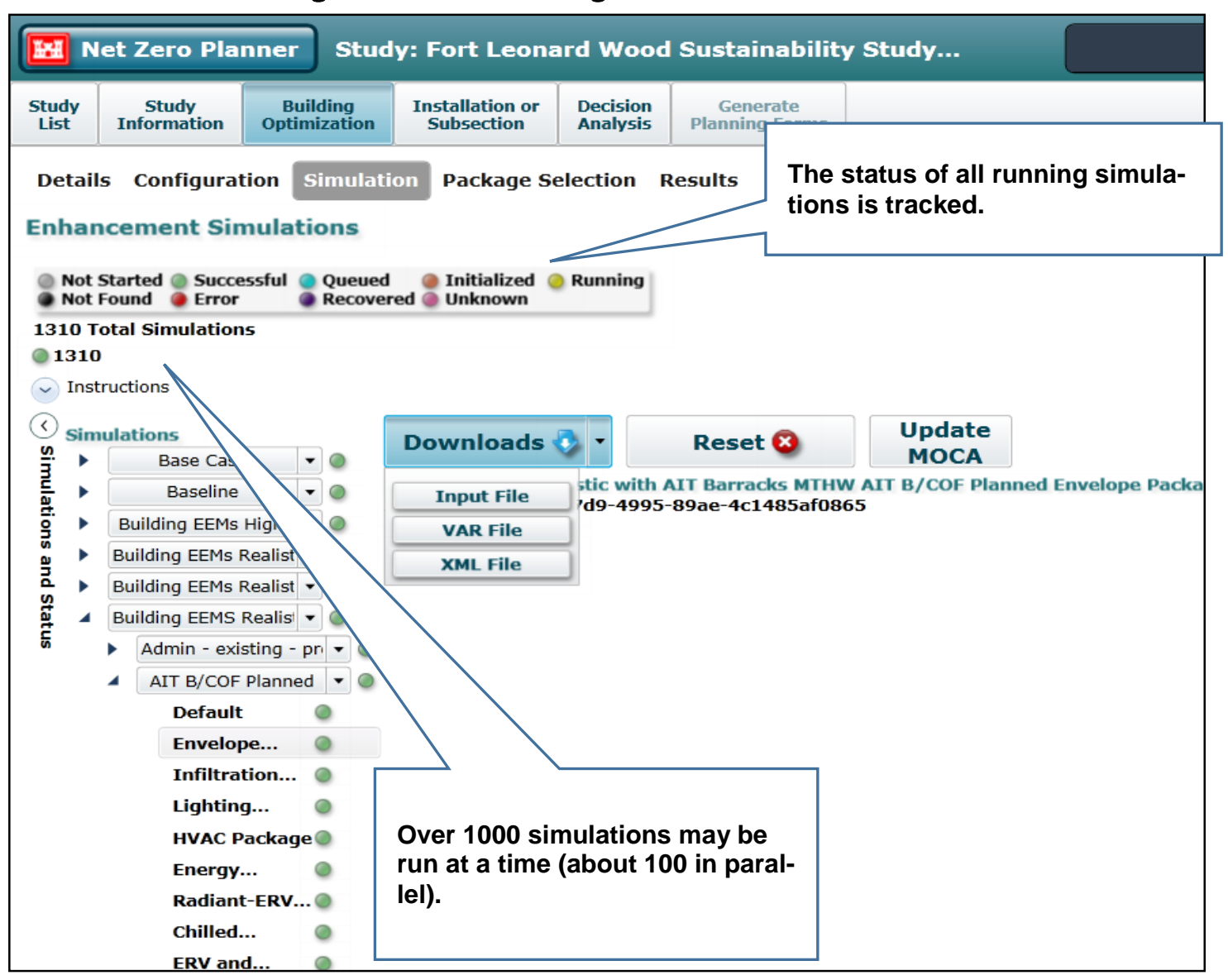

Figure 2-14. Load profiles derived for individual buildings can be summed up for a building cluster analysis.
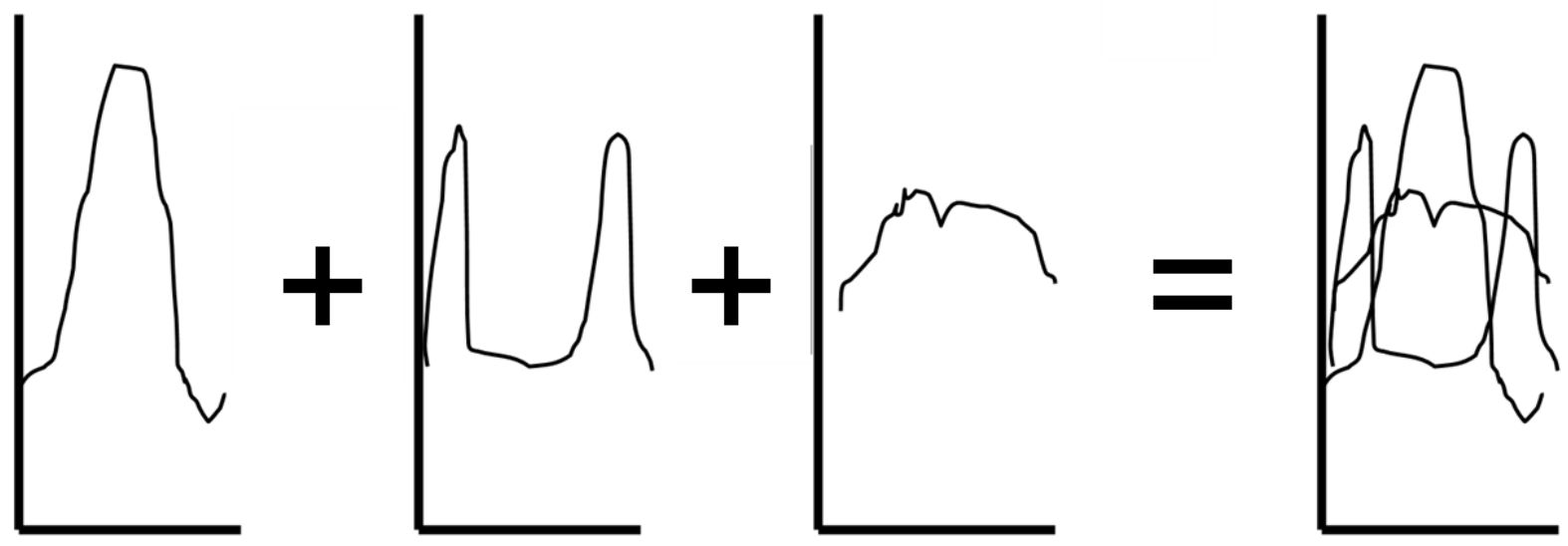
Figure 2-15. Example of community level baseline: Building and process energy end use broken down by function.

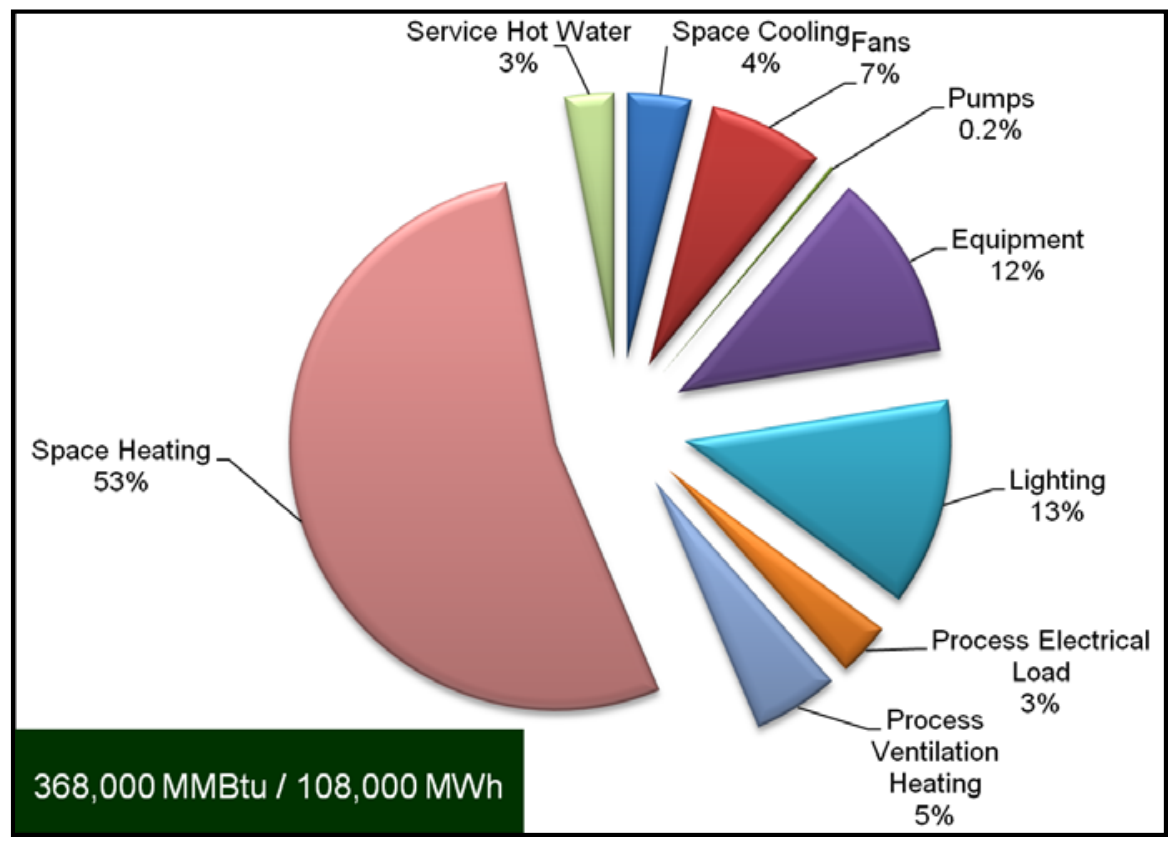

Table 2-1 summarizes example baseline site and source energy.

Table 2-1. NZP calculates site and source energy. These data indicate the aggregated values, broken down by building type.

\begin{tabular}{|c|c|c|c|c|c|c|c|c|c|}
\hline Alternative & Facilities & Total Area $\left(\mathrm{ft}^{\wedge} 2\right)$ & $\begin{array}{l}\text { Site Electricity } \\
\text { (kBtu) }\end{array}$ & \begin{tabular}{|l|} 
Source \\
Electricity (kBtu)
\end{tabular} & $\begin{array}{l}\text { Site Gas } \\
\text { (kBtu) }\end{array}$ & $\begin{array}{l}\text { Source Gas } \\
(\mathrm{kBtu})\end{array}$ & $\begin{array}{l}\text { Source Gas } \\
\text { Intensity } \\
\left(\mathrm{kBtu} / \mathrm{ft}^{\wedge} 2\right) \\
\end{array}$ & \begin{tabular}{|l|} 
Site Total \\
Energy \\
Intensity \\
(kBtu/ft2) \\
\end{tabular} & \begin{tabular}{|l} 
Source Total \\
Energy (kBtu)
\end{tabular} \\
\hline Baseline & 124 & $3,503,449$ & $300,071,296$ & $1,002,238,080$ & $203,585,168$ & $213,153,792$ & 60.84 & 143.76 & $1,215,391,872$ \\
\hline
\end{tabular}

\subsubsection{Establish base case}

The baseline data described above can be used to project a Base Case scenario for energy use given the availability of information on an increase or decrease of energy use due to: new construction; consolidation and demolishing processes; buildings repurposing and change of mission; use of new and existing utility contracts; and the dates when known contracts will expire. Any planned and programmed measures for energy use reduction through efficiency measures should be included in the Base Case scenario (Case et al. 2014).

The Base Case is defined as a future "business as usual" alternative that includes all existing and already planned facilities. Facilities marked for 
demolition in the baseline are not included. The baseline models of buildings and energy systems shall be adjusted to reflect all planned modifications. The Base Case includes the data on site energy use along with primary energy use and energy cost, broken into categories similar to those used for the Baseline. It is important to present the data showing the cost of implementation of the Base Case as well as changes in site, and source energy use, energy cost, and GHG compared to the Baseline.

The Base Case is created in NZP by creating an alternative and labeling it "Base Case." It also generates a custom set of EEM packages for each facility group based on the facility model (type of building), era/ standard of construction, and climate zone. Packages include such measures as air sealing (infiltration), insulation, better windows, better HVAC equipment, daylighting, cool roofs, and a number of other typical measures that can improve the energy efficiency of a building. Generally, more packages are available to new construction buildings than to existing buildings, due to the difficulty and expense of retrofit. The packages are cumulative in that each package may depend on the one listed before it in the interface, although the user can change this as well. There is also a cost of applying the measure. This cost reflects the typical "delta" cost of applying the measure during a building retrofit. For example, the expense of applying R20 insulation instead of R13 includes the cost of the additional insulation, not the entire cost of removing drywall, etc. This number can be changed, but delta costs are used because energy projects are most cost effective when performed as an add-on to other building renovation projects. For the Base Case, the user selects the package that best reflects the "business as usual" scenario. Typically, this is one that does not apply many EEM packages. In the case of older buildings, this may mean that no packages are selected. Figure 2-16 shows the parameters for a barracks (Unaccompanied Enlisted Personnel Housing [UEPH]) model, with the packages listed on the left. The popup menu shows that the HVAC package is based on the Lighting Package. The parameters shown to the right indicate that the HVAC package includes a high efficiency, condensing boiler. 
Figure 2-16. NZP automatically creates an EnergyPlus input for file for every Facility Group and combination of packages specified in its database. Here, the HVAC package is specified for a barracks. The baseline model is modified to reflect better HVAC equipment. In addition, the popup shows that the HVAC package includes the Lighting Package.

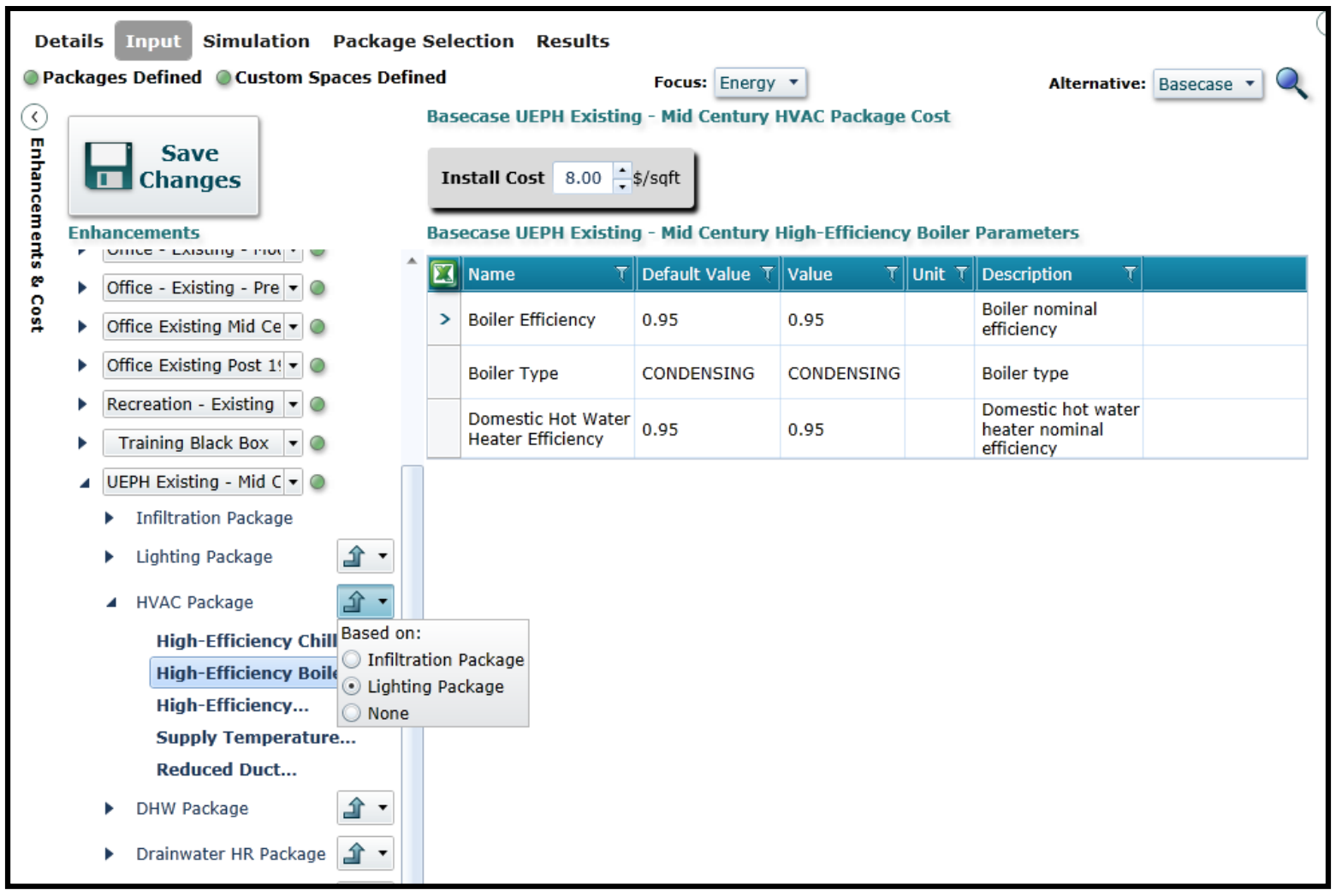

\subsubsection{Develop alternative scenarios}

Once the Baseline and Base Case have been established, energy planners can start exploring options or alternative scenarios. A handful of alternative scenarios shall be selected that will be analyzed in depth. Electric and thermal energy systems consist of three major elements: energy generation, energy distribution, and energy demand (Figure 2-17) (Güssing 2011). 
Figure 2-17. Energy supply chain from primary energy to its use inside a building.

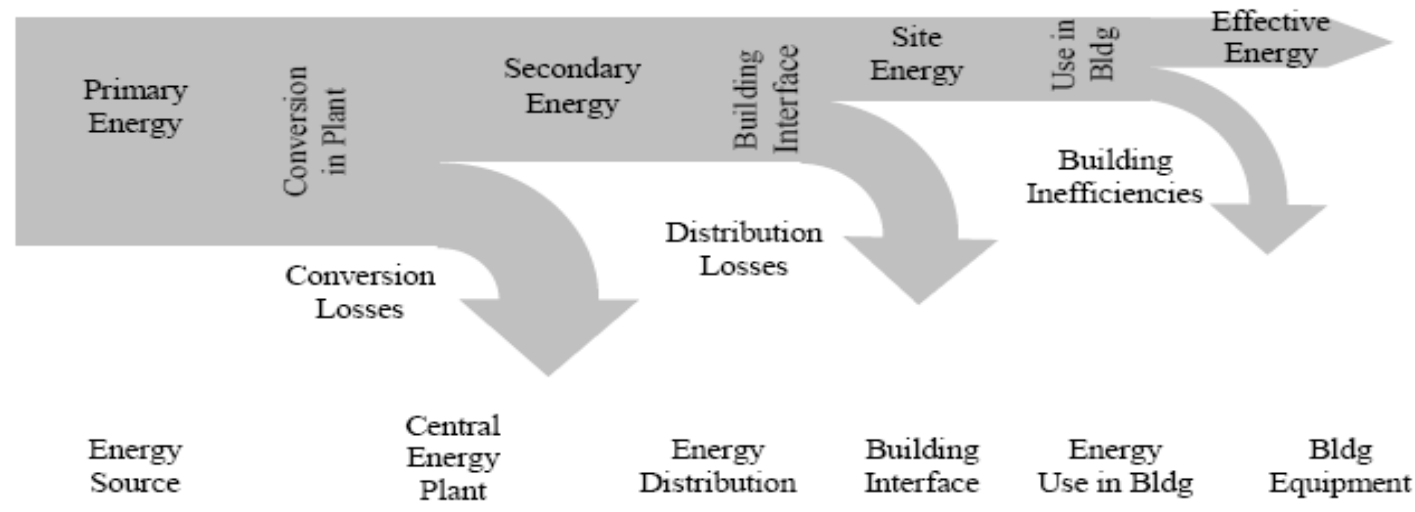

The goal is to find the optimum balance of these three elements for the entire energy system, where each element is considered in the calculation of the amount of energy delivered and lost, in various forms, by the energy systems (Loorbach 2007). Alternative scenarios can explore different levels and scopes of building stock renovation and energy supply strategies. Renovation scenarios can range from renovation of the whole building stock included in the boundaries of analysis; to renovation to different energy efficiency levels, which can vary from light renovation using only cost effective measures to a deep energy renovation of all buildings within the study boundaries (Zhivov et al. 2015, described in Chapter 6); to a deep energy renovation of only buildings with a potential to undergo major renovation during the timeline of the study. When building packages are selected, they are treated cumulatively, e.g., when the envelope is applied after the HVAC, it is integrated with all values and is sized appropriately. Supply strategies can include, but are not limited to, decentralized energy supply, steam-to-hot-water district systems conversion, energy supply using only renewable energy sources, etc. Distribution strategies can include $100 \%$ centralized energy supply solutions, completely decentralized solutions or a combination of clusters of buildings connected to several CEPs (heating, cooling, and cogeneration) and buildings having individual (decentralized) energy systems. Since energy and cost analysis of each scenario is a time consuming process that depends on the tools and expertise used, it is recommended to preselect and agree on alternative scenarios during the initial steps of the project. 
In NZP, these options are called "alternatives," short for "Alternative Scenario." Typically, the user will copy the Base Case to create one or more alternatives that focus on building optimization. Once satisfied that buildings have been optimized to the desired degree, the user can create new alternatives to explore supply and distribution options. Although, as shown in Figure 2-3 (p 14), alternative capabilities to create, copy, modify, and delete occur at this stage of the process, these alternatives can actually be exercised at any time. This flexibility makes it a very powerful tool for trade-space analysis. These alternatives will be further illustrated throughout the remainder of this report.

\subsubsection{Conduct building level optimization}

It is generally accepted that it is most cost effective to reduce facility loads before exploring distribution and supply options. However, highly efficient central or district plants may change the economics of facility EEMs. Thus, Figure 2-3 showed an analysis iteration loop that can be used to achieve a balance between energy efficiency of end users and waste heat available at the CEP under the certain supply alternative. To minimize facility energy loads, the user examines the results of applying EEM packages to each facility group. Generally, copies of the Base Case take into account the estimated amount of new construction and deep retrofit rate to select the likely level of penetration of EEMs into the building stock. This will give an indication of the most likely reduction in facility loads for the installation. Sometimes, several alternatives may be created that explore a high, medium, and low option for building load reduction. Figure 2-18 shows the NZP Package Selection screen. The EEM packages are ordered with cumulative energy reductions, based on a strategy that progresses from light renovation to deep energy retrofit. For example, the envelope package, which would be considered as a deep retrofit option, includes the previous packages and is considered last. Although it is considered last, the envelope package will still result in a change to the mechanical system sizing in the simulation. Here, the user has selected the Envelope Package, as indicated by the checked box on the left. 
Figure 2-18. The user uses the Package Selection screen to examine the cumulative effects of EEMs for each facility type.

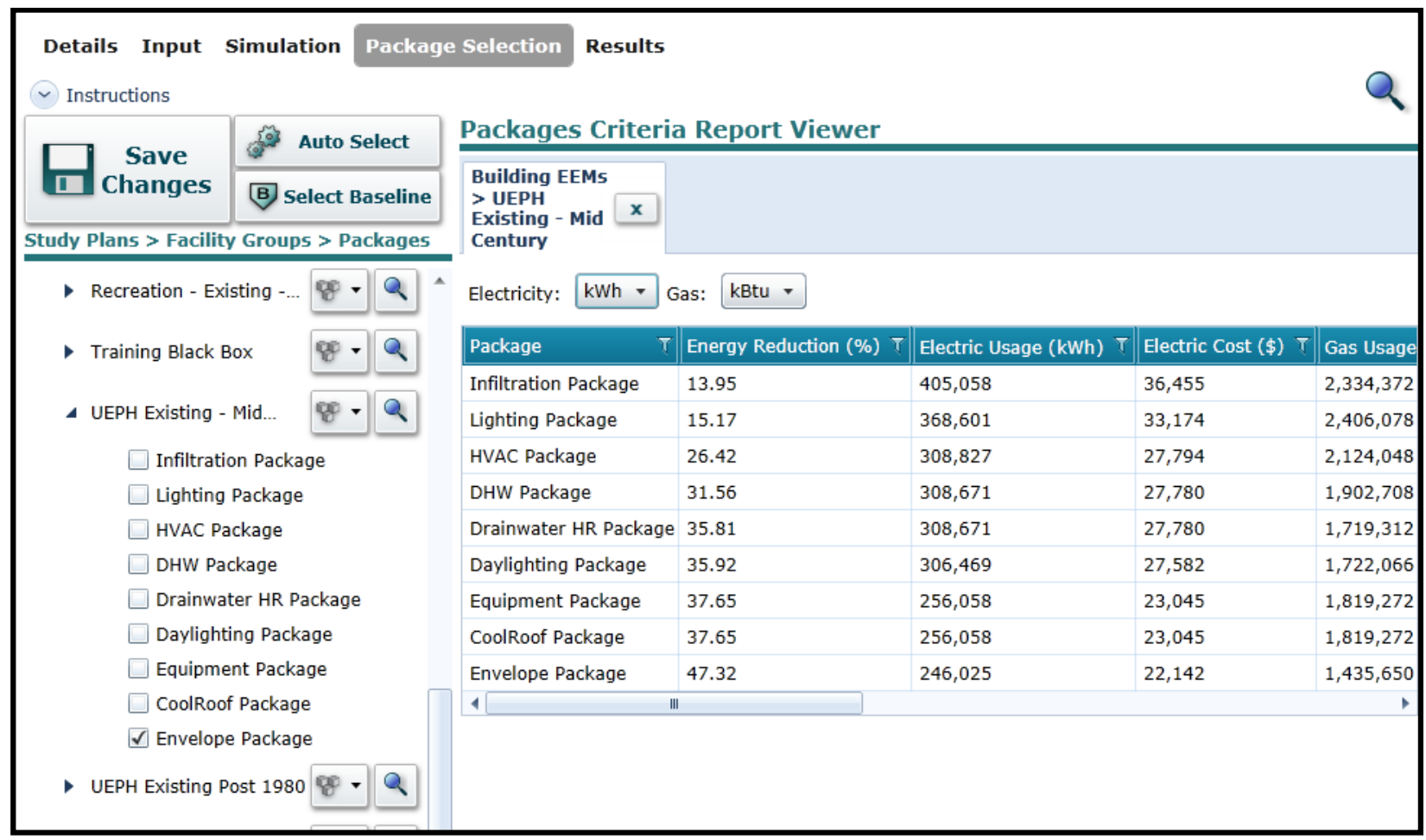

\subsubsection{Develop load profiles for building clusters}

After the LCC efficiency bundles of energy efficient measures have been applied to decrease load as much as possible, the analysis continues with distribution and supply systems optimization. Many installations began with centralized electrical and heating plants, usually using steam, and were then slowly converted to hot (and sometimes chilled) water distribution systems, or to completely decentralized systems using natural gas to supply local facility boilers and commercial power from the grid. Because of maintenance issues, steam distribution systems are almost never economically viable as new or recapitalized systems compared to modern hot water distribution systems, or even to completely decentralized systems. With a renewed emphasis on energy savings traced back to the source fuel, however, modern district systems may be the only way to meet policy goals economically. (Typical electrical generation, transmission, and distribution systems waste up to $70 \%$ of the source fuel compared to cogeneration electrical/ heat/ cooling plants.) Once the user is satisfied that feasible alternatives have been identified to minimize facility loads, they can begin to 
explore supply and distribution options, including centralized and decentralized heating and cooling, or combinations of the two systems.

The supply system optimization process determines the lowest LCC suite of equipment and ensures that the demands for heat, cooling, and electric energy are satisfied during each of the 8760 hours of the year, and that additional user-specified constraints are also satisfied. The design of community-scale energy supply and distribution systems requires consideration of the potential energy flows between many different devices and loads. Descriptions of the common design include: meeting the heating, cooling, and/ or electric loads at all times while sizing baseload and peaking equipment; minimizing source or site fossil fuel energy; and providing energy security and redundancy. However, the energy generation and distribution systems used on military installations are subject to two additional sets of requirements that may not be present when addressing non-military community-scale problems. These include:

1. Energy infrastructure redundancy to ensure continuous operations (potentially including both thermal and electric loads).

2. Legislative requirements on total installation-wide renewable energy production, energy reduction, and green house gas emissions and DoD NZE goals.

In any acceptable solution, redundancy and legislative requirements, which vary between DoD installations, must also be met.

Figure 2-19 shows a generalized "superstructure representation" of the energy generation/ conversion model. The model consists primarily of matter and energy flows that originate at the sources, experience some conversion by the selected options, and finally satisfy the load requirements. These sources can be on demand (such as natural gas or grid electricity usage), or intermittent (such as wind power or solar irradiation). The conversion options currently fall into three groups: (1) direct conversion options, (2) intermittent renewable options, and (3) storage conversion options. Direct conversion options take in one of the flows and convert that flow into one or more other flows within a single time-step (e.g., boiler, chiller, reciprocating engine). Intermittent renewable options make use of predicted power or heat output data for each option considered (e.g., photovoltaic system, wind turbine, solar-thermal system). Storage conversion options can convert be tween different flow types as well, but have the additional ability to store the 
output for use in a later time-step, e.g., hot and cold water storage tanks, batteries, and hot and cold water distribution networks. The separation of conversion options into three distinct classes allows greater model flexibility without a great sacrifice to the computation time. This distinction is further discussed in the mathematical model section. The loads can represent almost any quantity that is relevant to community planning as long as the flows are carefully defined, the units are consistent, and sufficient options are presented to meet the loads. Example loads include: heating, cooling, electric, potable water, sewage, solid waste, etc.

Figure 2-19. Generalized superstructure representation of the model. The lines indicate matter and energy flows between the sources, conversion options, and loads.

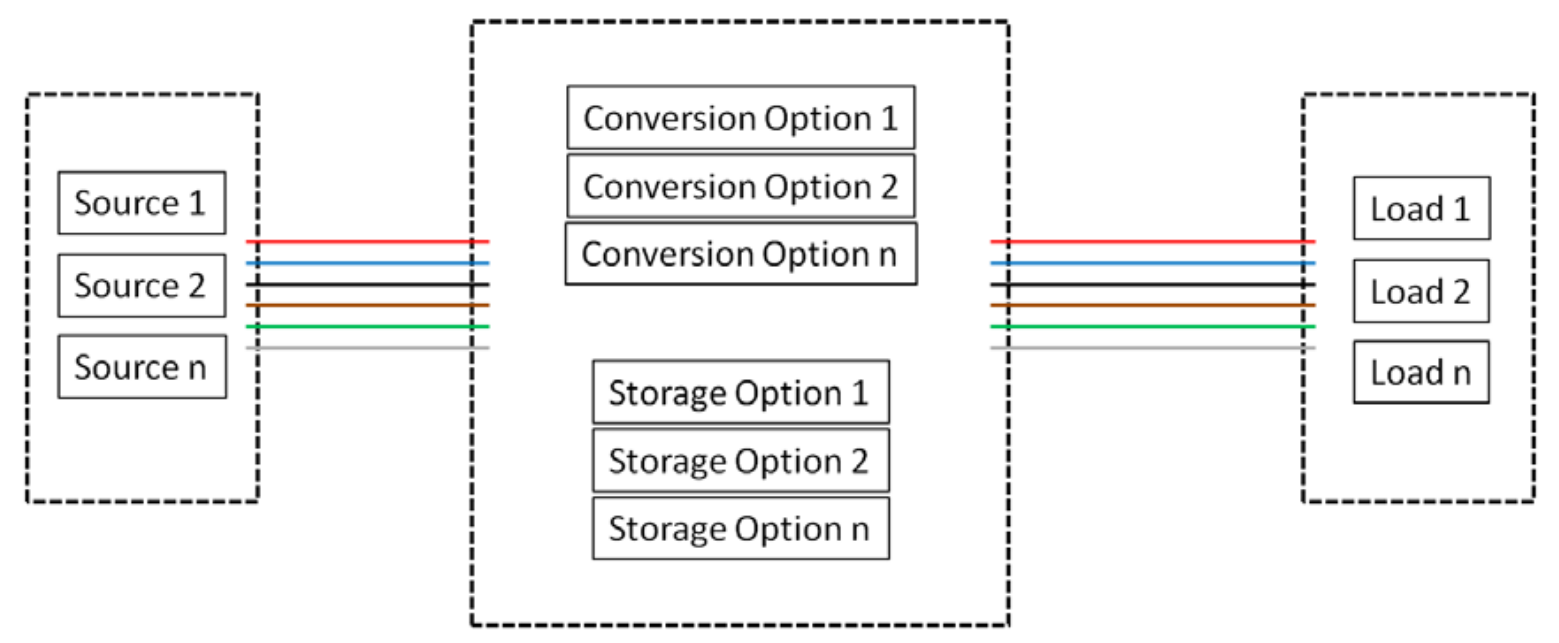

Figure 2-20 shows an example superstructure that describes the model in a more concrete way. This superstructure shows a snapshot of some of the technologies and flows that the model currently considers. In this example, a single central plant is shown with the capability to serve the heating, cooling, and electric loads of a single building cluster through either new or existing utility networks. Alternately, the loads can be met by distributed equipment that would be present at the building level. This superstructure allows the selection of a fully centralized, fully distributed, or hybrid system. Although this example presents a relatively simple superstructure, the generality of the model allows for any number of conversion options, central plants, utility networks, and loads. Furthermore, the conversion options and networks considered can consist of both existing and new proposed infrastructure. The only requirement is that each of the options be fully defined with parameters that are described in the mathematical model section. 
The user first identifies "clusters" of facilities that appear to be good candidates for district solutions such as cogeneration or utility scale renewables. NZP supports this with a tool that allows the user to select facilities to include in a cluster. Any facility that is not included in a district heating or cooling cluster is put into a special "decentralized" cluster so that it can be analyzed using distributed boilers and chillers (i.e., a boiler and chiller in each facility). Figure 2-21 shows the cluster tool as used to explore cogeneration. The cluster shown includes all of the facilities that are on the Current Steam Network. NZP calculates load information for the cluster, including the heating and cooling load density. Generally, denser clusters are more suitable for district solutions as they require shorter runs of pipe and hence suffer lower energy losses. The user can add and subtract facilities while examining the cluster characteristics to find a configuration that best suits their needs. Each alternative can have as many clusters as deemed necessary and the number of clusters can be different for each alternative. Each facility can belong to at most one cluster in an alternative. NZP does the book-keeping to calculate loads for the cluster, based on modeling results completed in earlier steps.

Figure 2-20. Example superstructure with sample flows and technology options.

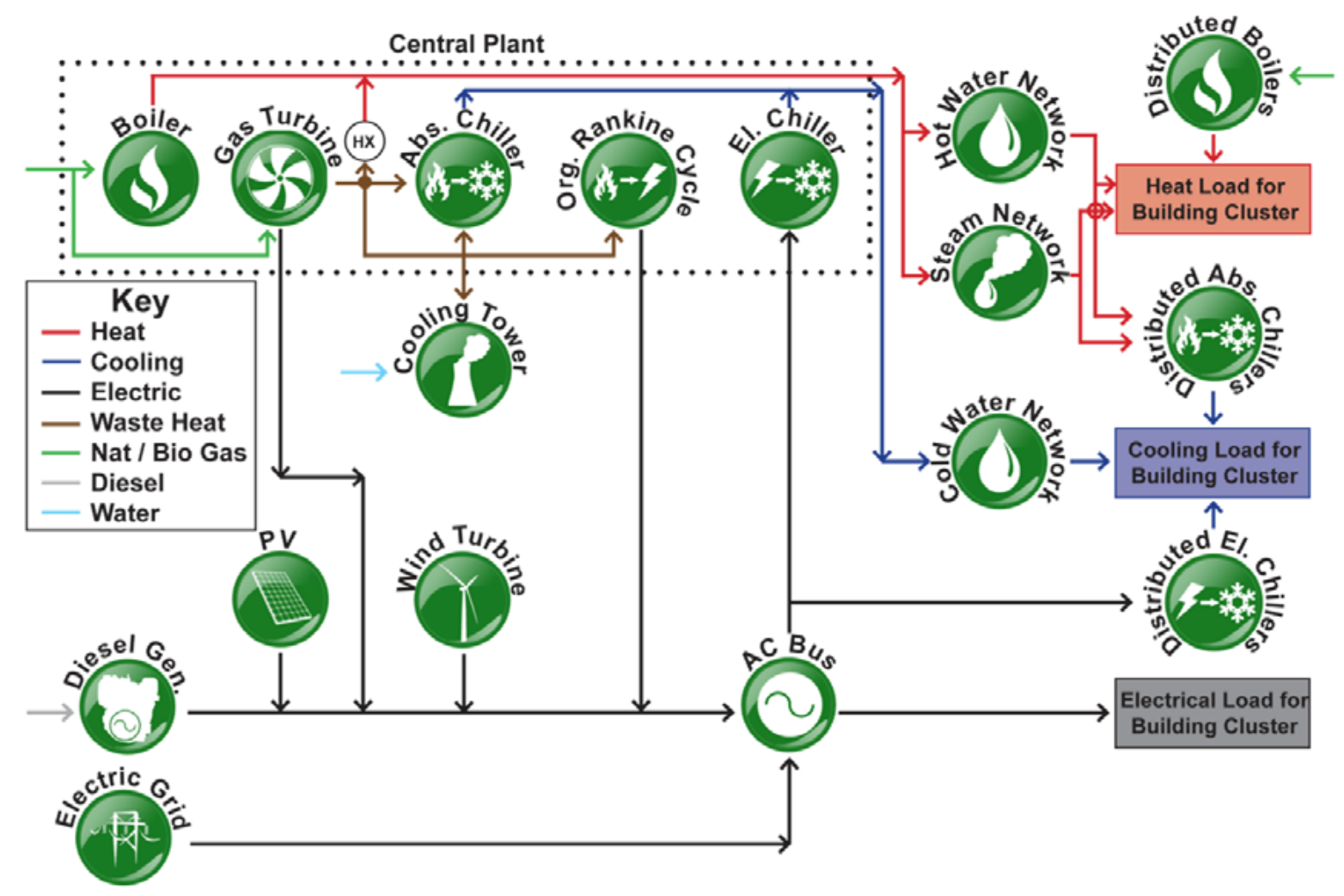


Figure 2-21. Facilities can be grouped into "clusters." The resulting building loads and energy densities are calculated for each cluster.

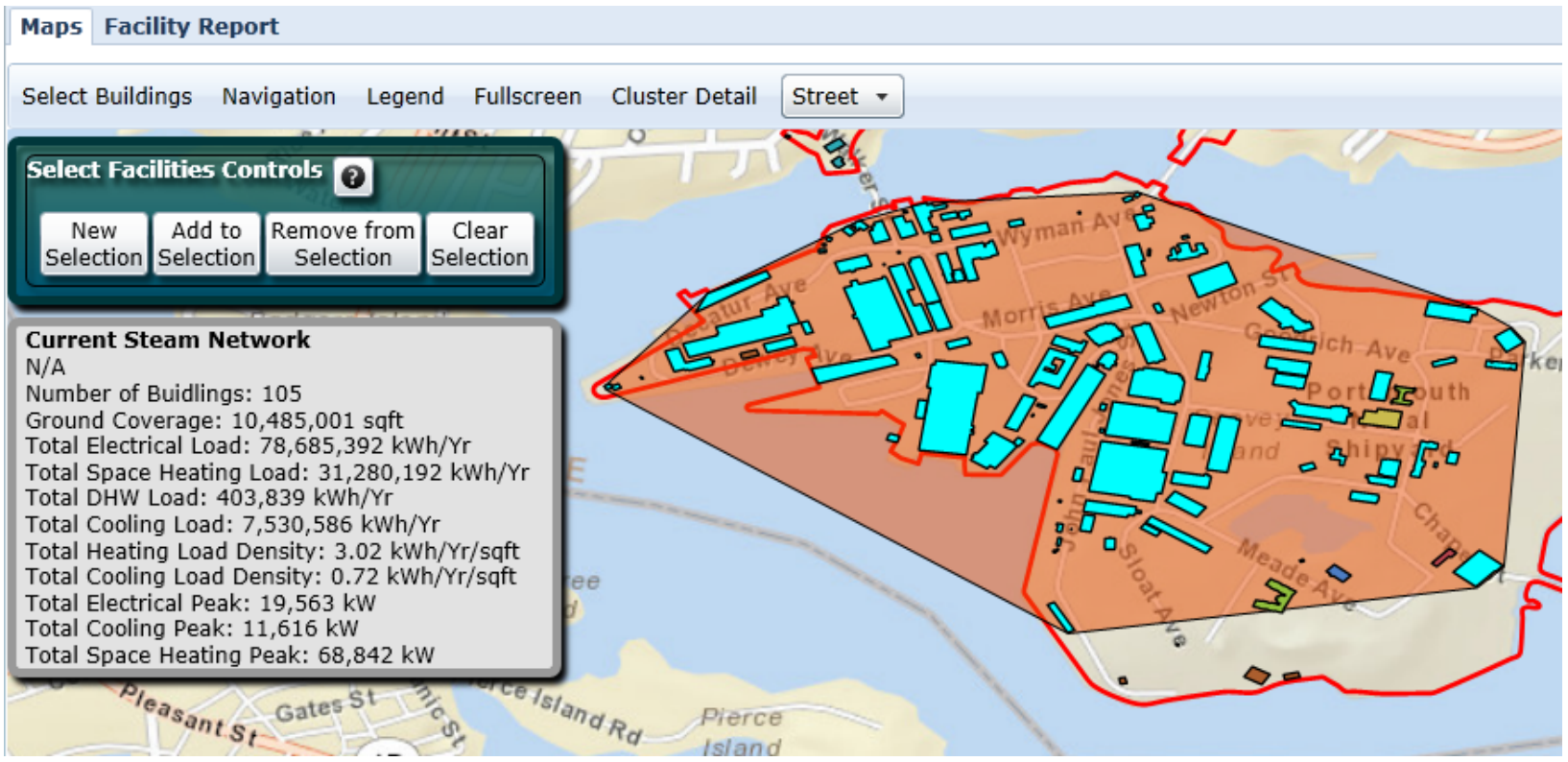

\subsubsection{Optimize installation conversion, distribution, and storage architecture}

Given a set of heating, cooling, and electrical power needs for each cluster, NZP uses mixed-integer linear programming (Swanson et al. 2014) to determine the optimal mix of generation (energy conversion), distribution, and energy storage that meets the installation goals at the lowest cost. Industrial scale supply solutions such as solar photovoltaics, solar-thermal, wind energy, biomass (wood chips, etc.), biogas, or synthetic gas need to be considered as part of the mix during distribution and supply optimization. They are almost always more expensive than making efficiency improvements or implementing cogeneration using natural gas as a fuel, but there may be other policy goals driving the use of these alternative technologies (e.g., NZ fossil fuel, support for a nascent industry, or energy security). NZP contains efficiency, installation cost, and maintenance data for most forms of energy generation, including renewables, as well as data on typical distribution systems and storage options. Users can substitute their own data for the defaults if they have better information. In some cases, such as photovoltaics, users can obtain data from an online system and enter it into NZP. In this case, users can access NREL's photovoltaic (PV) Watts to find the expected performance of solar PV panels for their installation, which will be considered during the installation. 
Figure 2-22 shows the NZP screen that is used to select the devices that will be considered in the optimization. For example, this screen shows that a natural gas turbine with combined heat and power is an option (NGT_CHP). If all of the defaults are left in place, then all of the options in the database of devices will be considered. If the user is trying to match a specific scenario, such as the baseline for an installation with an existing central plant, then devices can be removed from the list or the maximum number can be set to zero. The list of clusters in this alternative is shown on the left (Current Steam Network, Distributed Natural Gas, Fuel Oil, and Propane). The device list can be tailored for each alternative and each cluster. Clusters in different alternatives can have different devices considered as well.

Figure 2-23 shows the constraints screen. Here, users can specify parameters such as critical loads, maximum carbon emissions, fraction of renewable energy required, economic parameters, redundancy, maximum initial investment cost, and allowable source energy. In this case, $16 \mathrm{MW}$ of energy generation was required to be on the installation and a very high budget was entered to prevent the optimization from being initial investment-constrained. Remember that the optimization will still attempt to find the solution with the lowest LCC to meet the specified goals.

Once devices and constraints have been set, MILP optimizations are run for every cluster in every alternative. Like the EnergyPlus runs, these optimizations are run on a server farm capable of running many simulations simultaneously. NZP writes an input file in the AMPL language, producing a system of thousands of equations and constraints. The CPLEX solver is used to solve the system of equations. The more devices considered in a single run, the longer it will take. For the optimizations conducted under this project, typical run times took between 5 and 15 minutes. The optimization goes through every solution combination without technical or experience bias. 
Figure 2-22. Mixed-Integer Linear Programming (MILP) is used to find the lowest cost combination of supply, distribution, and storage technologies that meet the installation's goals.

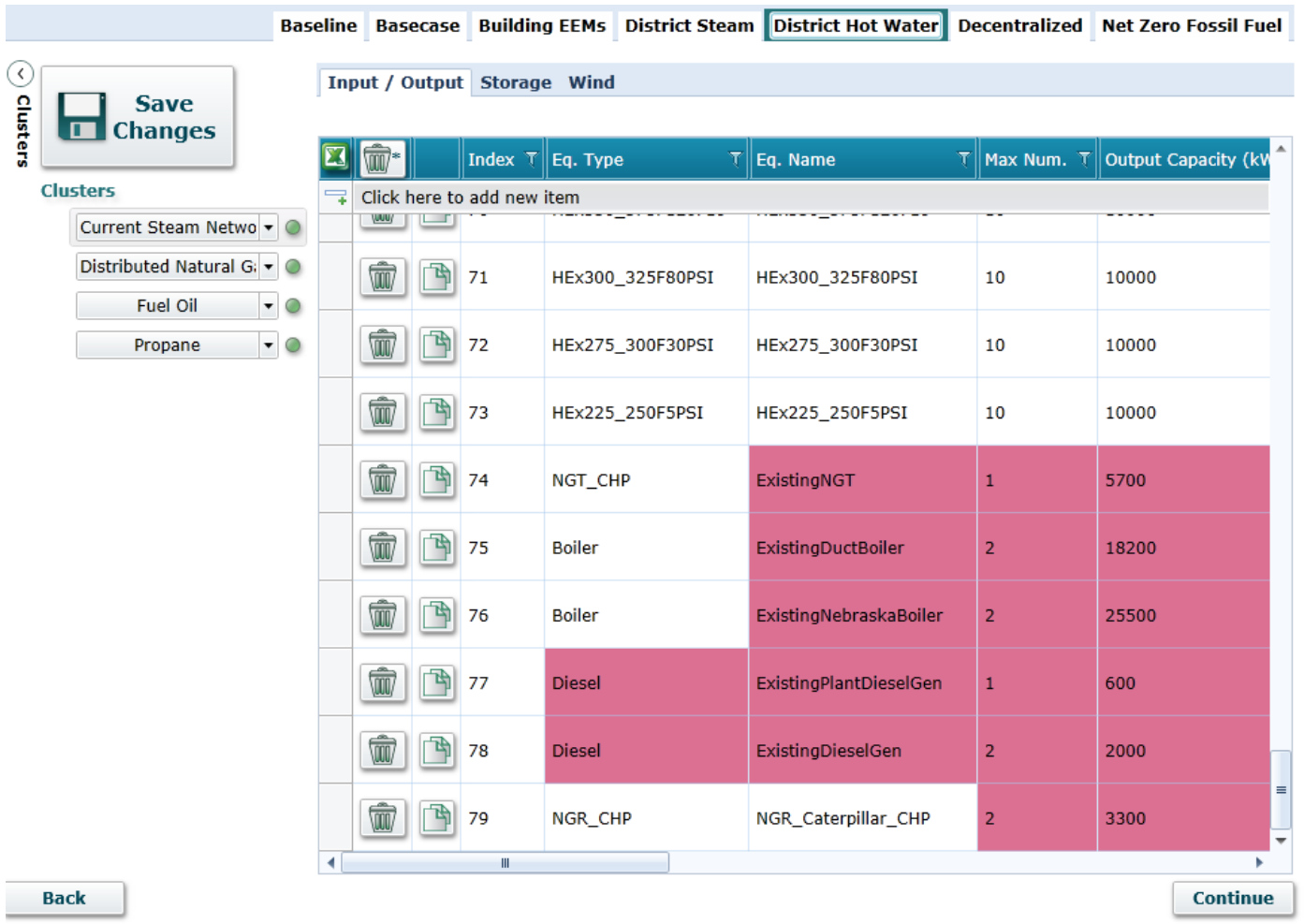

Figure 2-23. Users can set constraints on the MILP optimization.

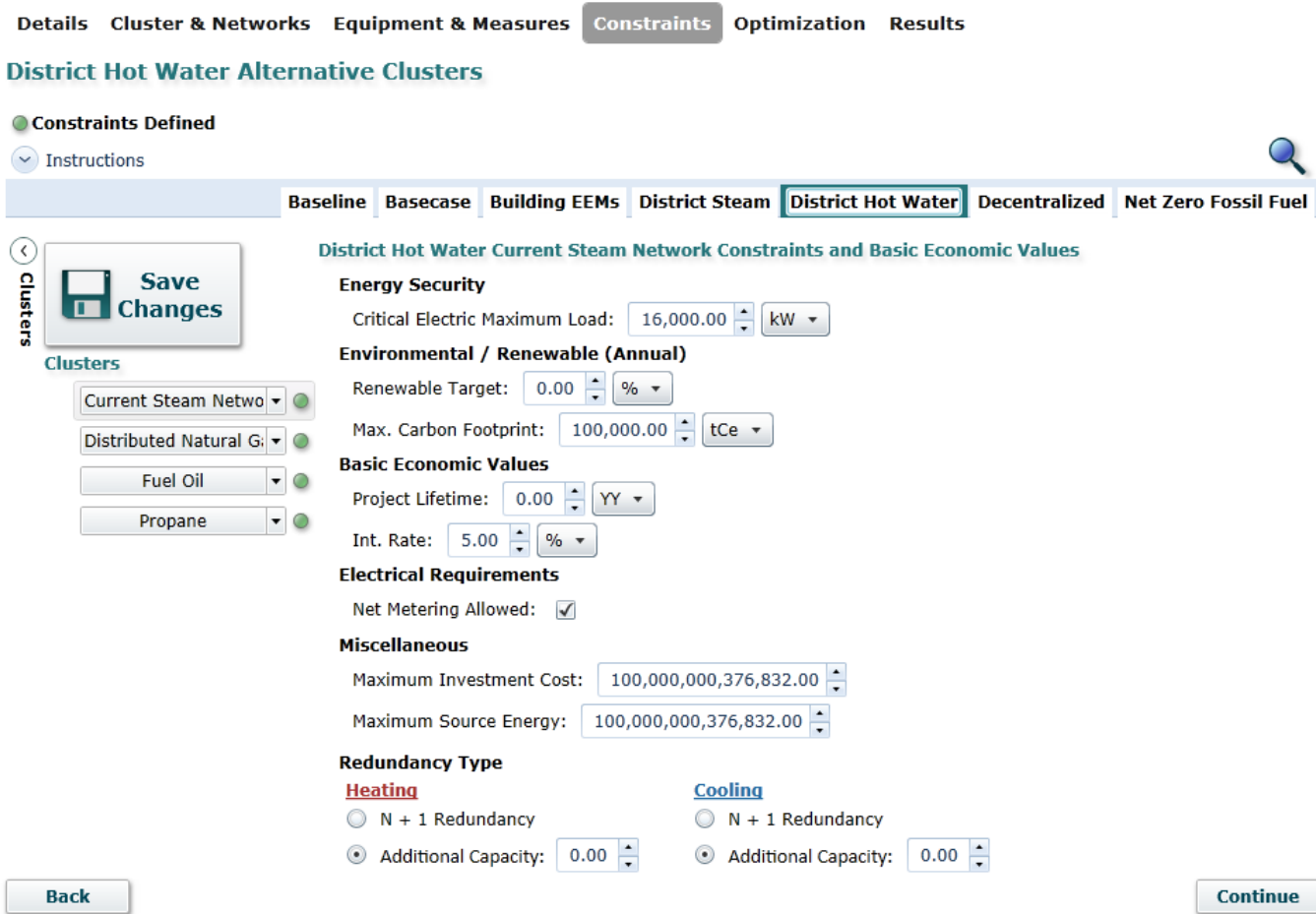


Figure 2-24 shows the devices selected for the "Current Steam Network" cluster as part of the "District Hot Water" alternative. These results will be discussed later in the report, but in this case, the optimization chose to keep some existing equipment ( 0 investment cost), but add a natural gas reciprocating engine with combined heat and power (NGR_Caterpillar_CHP). It also replaces the existing steam network with a Low Temperature Hot Water network (LHotWaterNetwork). The devices that have names staring with " $\mathrm{HEx}$ " are heat exchangers.

Figure 2-25 shows a summary of all alternatives an all clusters, with the clusters for the "District Hot Water" expanded. This allows the user to explore and compare the performance of each optimization. At this point (refer to the process diagram shown in Figure 2-3), the user might want to conduct a sensitivity analysis on the level of facility optimization to see if that would change the recommended cluster optimization. The user can make copies of any alternative and change the selected EEM packages, which would in turn change the underlying facility loads, requiring re-optimization. This step normally takes on the order of 30 minutes per alternative.

Figure 2-24. Device selections from the MILP optimization.

\begin{tabular}{|c|c|c|c|c|}
\hline Cluster & T Devices T & & & \\
\hline \multicolumn{2}{|c|}{ Current Steam Network 25} & & & \\
\hline Type & Equipment & Max Power T & Unit & Devices \\
\hline Input $\backslash$ Output & ACBus1 & 20,000 & $\mathrm{~kW} \cdot$ & 2 \\
\hline Input $\backslash$ Output & DistElec_Chills & 999,999 & $k W \cdot$ & 1 \\
\hline Input $\backslash$ Output & ExistingDieselGen & 2,000 & $k W \rightarrow$ & 2 \\
\hline Input $\backslash$ Output & ExistingNebraskaBoiler & 25,500 & $\mathrm{~kW} \cdot$ & 2 \\
\hline Input $\backslash$ Output & ExistingNGT & 5,700 & $k W>$ & 1 \\
\hline Input\Output & HEx300_325F80PSI & 10,000 & $\mathrm{~kW} \cdot$ & 7 \\
\hline Input $\backslash$ Output & HEx350_375F120PSI & 10,000 & $\mathrm{~kW} \cdot$ & 7 \\
\hline Storage & LTHotWaterNetwork & 900,000 & $k W \cdot$ & 1 \\
\hline Input\Output & NGR_Caterpillar_CHP & 3,300 & $\mathrm{~kW} \cdot$ & 2 \\
\hline
\end{tabular}


Figure 2-25. The cluster optimization analysis page. Here, the District Hot Water alternative is expanded to show results for each cluster.

\begin{tabular}{|c|c|c|c|c|c|c|c|c|c|c|c|c|c|c|c|}
\hline \multicolumn{16}{|c|}{ 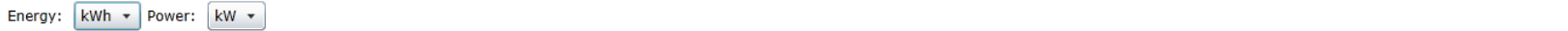 } \\
\hline \multicolumn{3}{|c|}{ Alternative } & \multicolumn{2}{|l|}{ Natural Gas (kWh) } & \multicolumn{2}{|c|}{ Peak Natural Gas (kW) T } & Electricity (kWh) & \multicolumn{2}{|c|}{\begin{tabular}{l|l}
$\mathrm{T}$ & Peak Electricity (kW) \\
\end{tabular}} & $T$ & \multicolumn{2}{|c|}{ Total Site Energy (kWh) T } & \multicolumn{3}{|c|}{ Total Source Energy (kWh) T } \\
\hline \pm & \multicolumn{2}{|c|}{ Baseline } & \multicolumn{2}{|l|}{$320,390,400$} & \multicolumn{2}{|l|}{117,551} & $90,569,128$ & \multicolumn{3}{|l|}{12,558} & \multicolumn{2}{|l|}{$324,585,824$} & \multicolumn{2}{|l|}{$349,456,544$} & \\
\hline \pm & \multicolumn{2}{|c|}{ Basecase } & \multicolumn{2}{|l|}{$256,372,160$} & \multicolumn{2}{|l|}{107,684} & $101,163,544$ & \multicolumn{3}{|l|}{26,734} & \multicolumn{2}{|l|}{$293,941,728$} & \multicolumn{2}{|l|}{$393,899,104$} & \\
\hline \pm & \multicolumn{2}{|c|}{ Building EEMs } & \multicolumn{2}{|l|}{$229,887,904$} & \multicolumn{2}{|l|}{113,392} & $86,002,472$ & \multicolumn{3}{|l|}{17,733} & \multicolumn{2}{|l|}{$258,508,864$} & \multicolumn{2}{|l|}{$336,284,000$} & \\
\hline \pm & \multicolumn{2}{|c|}{ District Steam } & $191,314,320$ & & \multicolumn{2}{|l|}{107,596} & $86,102,728$ & 16,354 & & & $213,730,528$ & & $275,173,568$ & & \\
\hline$\square$ & Distr & rict Hot Water & $183,567,200$ & & 107,445 & & $86,082,576$ & 16,354 & & & $207,743,872$ & & $272,942,336$ & & \\
\hline & etail & ils Site Use & & & & & & & & & & & & & \\
\hline & & Cluster & $T$ & & tural Gas (kWh) T & Peak $\mathrm{N} z$ & atural Gas (kW) T & Electricity (kWh) & $T \quad P$ & Peak E & Electricity $(\mathrm{kW})$ & T Total Sit & ite Energy (kWh) T & Total Sourc & rce Energy (kWh) \\
\hline & \pm 0 & Current Steam Network & & & , 021,520 & 105,520 & & $83,766,832$ & & 15,684 & & 202,882 & 2,176 & $262,544,128$ & \\
\hline & \pm & Distributed Natural Gas & & & 27,583 & 1,327 & & $1,096,286$ & & 322.00 & & $3,023,86$ & & $5,679,772$ & \\
\hline & (t) $\mathrm{F}$ & Fuel Oil & & 42,4 & 431 & 471.00 & & 824,257 & & 224.00 & & 866,688 & & $2,797,444$ & \\
\hline & I $\mathrm{P}$ & Propane & & 319 & 865 & 0 & & 232,595 & & 35.00 & & 552,461 & & $1,109,528$ & \\
\hline & +5 & Decentralized - District Hot W & Nater & & $; 802$ & 127.00 & & 162,606 & & 39.00 & & 418,687 & & 811,470 & \\
\hline
\end{tabular}

\subsubsection{Compare scenarios}

Ultimately, the purpose of the analysis using NZP is to support the client installation in making decisions that, in turn, leads to a well formulated EMP. NZP supports this goal with reports that allow comparing the Baseline, Base Case, and Alternatives using the criteria defined as part of the energy goals. There is also a Multi-Criteria Decision Analysis (MCDA) tool that can be used to create weighted decision models and support traceable decision processes that integrate quantitative and qualitative factor. Figure 2-26 illustrates the decision matrix for the study. It summarizes costs, energy performance, and $\mathrm{CO}_{2}$ reduction. Wherever there is a " + " sign, the columns can be expanded to show more detailed breakdowns. Each alternative can also be expanded to show cluster data.

Figure 2-26. NZP Decision Matrix that shows all of the alternatives with associated energy performance and costs.

\begin{tabular}{|c|c|c|c|c|c|c|c|}
\hline \multirow{3}{*}{\begin{tabular}{|r|} 
Iternative + \\
$T$ \\
Baseline
\end{tabular}} & \multirow{2}{*}{ Investment +} & \multirow{2}{*}{$\begin{array}{c}\text { Total Equivalent } \\
\text { Annual Cost } \\
\text { (Dollars/Year) }\end{array}$} & Total Source Energy & Total Site Energy + & \multicolumn{2}{|c|}{ Energy Savings + } & \multirow{2}{*}{\begin{tabular}{|c|c|} 
& C02 Reduction \\
$T$ & $\%$ reduction \\
\end{tabular}} \\
\hline & & & MWhs/Year & MWhs/Year & \multicolumn{2}{|c|}{ 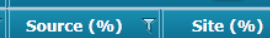 } & \\
\hline & 0 & $22,664,838$ & 347,996 & 323,788 & 0 & 0 & 0 \\
\hline Basecase & 0 & $21,544,808$ & 392,433 & 293,141 & -12.77 & 9.47 & -20.99 \\
\hline Building EEMs & $41,797,240$ & $20,374,818$ & 335,473 & 258,090 & 3.60 & 20.29 & -2.57 \\
\hline District Steam & $96,377,240$ & $17,858,212$ & 274,362 & 213,312 & 21.16 & 34.12 & 16.37 \\
\hline $\begin{array}{l}\text { District Hot } \\
\text { Water }\end{array}$ & $88,427,240$ & $16,875,866$ & 272,131 & 207,325 & 21.80 & 35.97 & 16.56 \\
\hline Decentralized & $82,397,240$ & $18,569,192$ & 332,344 & 129,668 & 4.50 & 59.95 & -16.00 \\
\hline $\begin{array}{l}\text { Net Zero Fossil } \\
\text { Fuel }\end{array}$ & $280,063,904$ & $23,080,810$ & 29,213 & 85,210 & 91.61 & 73.68 & 93.11 \\
\hline
\end{tabular}

At the beginning of the EMP process, the users entered energy goals into NZP. Once the models and optimizations have been run, producing quantitative data, results can be matched up against the energy goals to determine how close the users were able to come to achieving their goals. This 
is done in the MCDA module (Figure 2-27). Users can select from the energy goals shown in Figure 2-8 and create criteria that capture how closely the results come to meeting the goals. The MCDA module shows a value function for source energy. Since the goal was to reduce source energy by $40 \%$, the value function assigns a value of 1 to $221,118 \mathrm{MWhrs} / \mathrm{yr}$, which is $60 \%$ of the Base Case 368,530 MWhrs/yr. The Base Case is assigned a value of 0 , with a linear function between them. Note that in this case, no "extra" credit is given for reducing source energy further. If more credit for source energy reduction were desired, the value function could be changed.

It is usually the case that the decision criteria are not equally important to each other. To support the installation's decision process, the users need to elicit weights for the different criteria from installation decision makers. This is not always an easy process, but it does encourage decision makers to reflect on how they make their decisions. Figure 2-28 shows graphically how the decision model is constructed, the weights on each of the criteria, and the resulting ranking of alternatives. Note that the criteria can be grouped as well. Site and source energy are grouped under Energy, although they are not weighted equally. The MCDA model also documents how the decision was made, which can be important when public comment or NEPA (National Environmental Policy Act) analysis is required.

Figure 2-27. Value function for Source Energy.

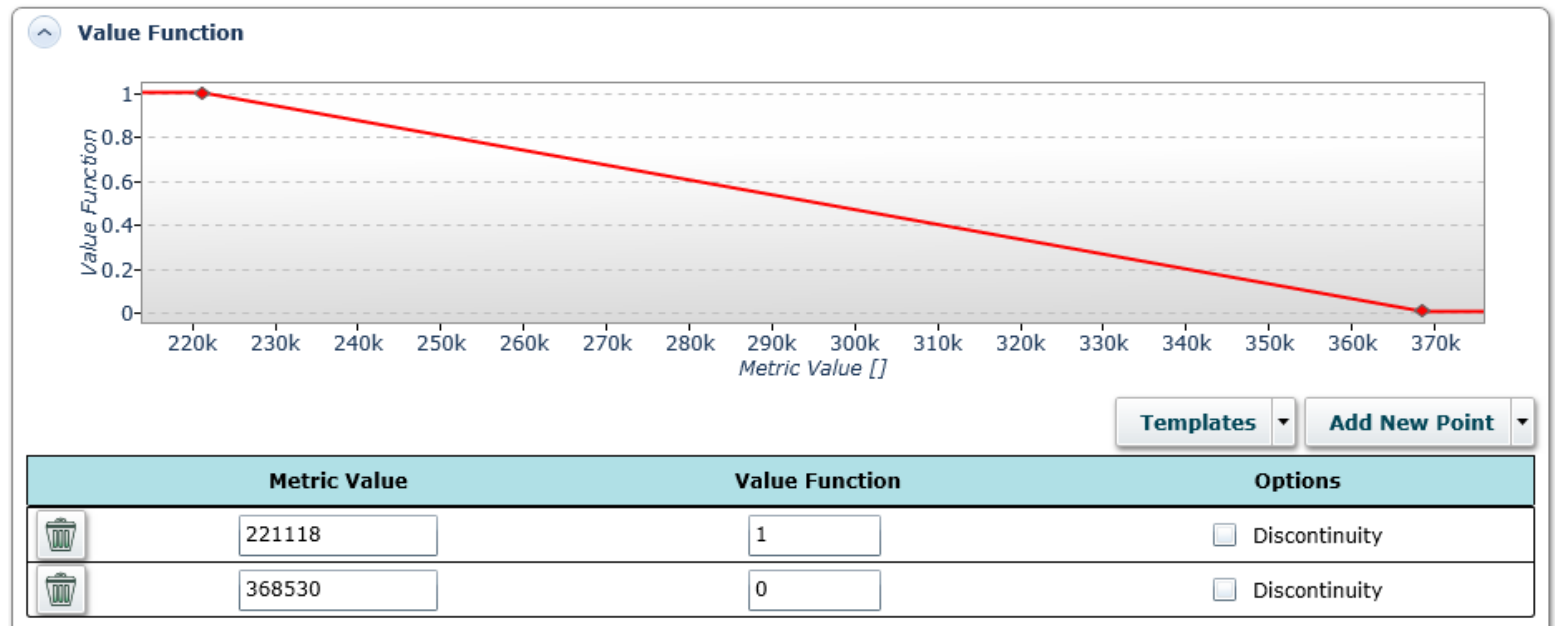


Figure 2-28. NZP includes a MCDA module that allows the user to construct and compare weighted decision models that relate back to the study goals.

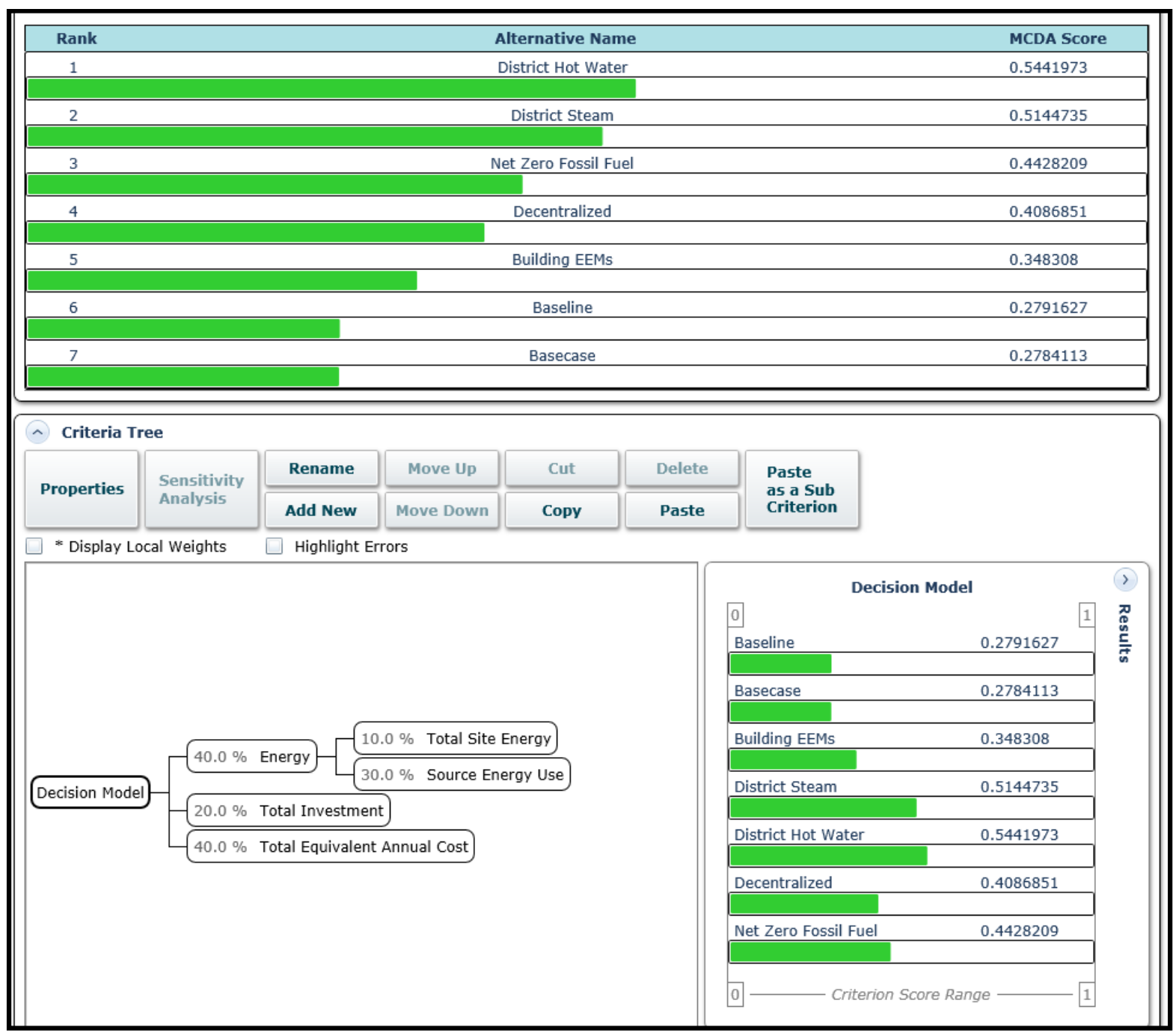

There is also a tool to support sensitivity analysis on the weighting of the criteria. In Figure 2-29, the weight attributed to the energy group criteria is $40 \%$, resulting in the District Hot Water alternative achieving the highest score. If greater weight were given to energy reduction over cost, say above $60 \%$, for example, the Net Zero Fossil Fuel alternative would achieve a higher score. It is also clear that the decision between the District Hot Water and District Steam alternatives is NOT sensitive to weighting, as the lines do not cross. 
Figure 2-29. Sensitivity analysis can be conducted on the criteria weights by moving the slider bar.

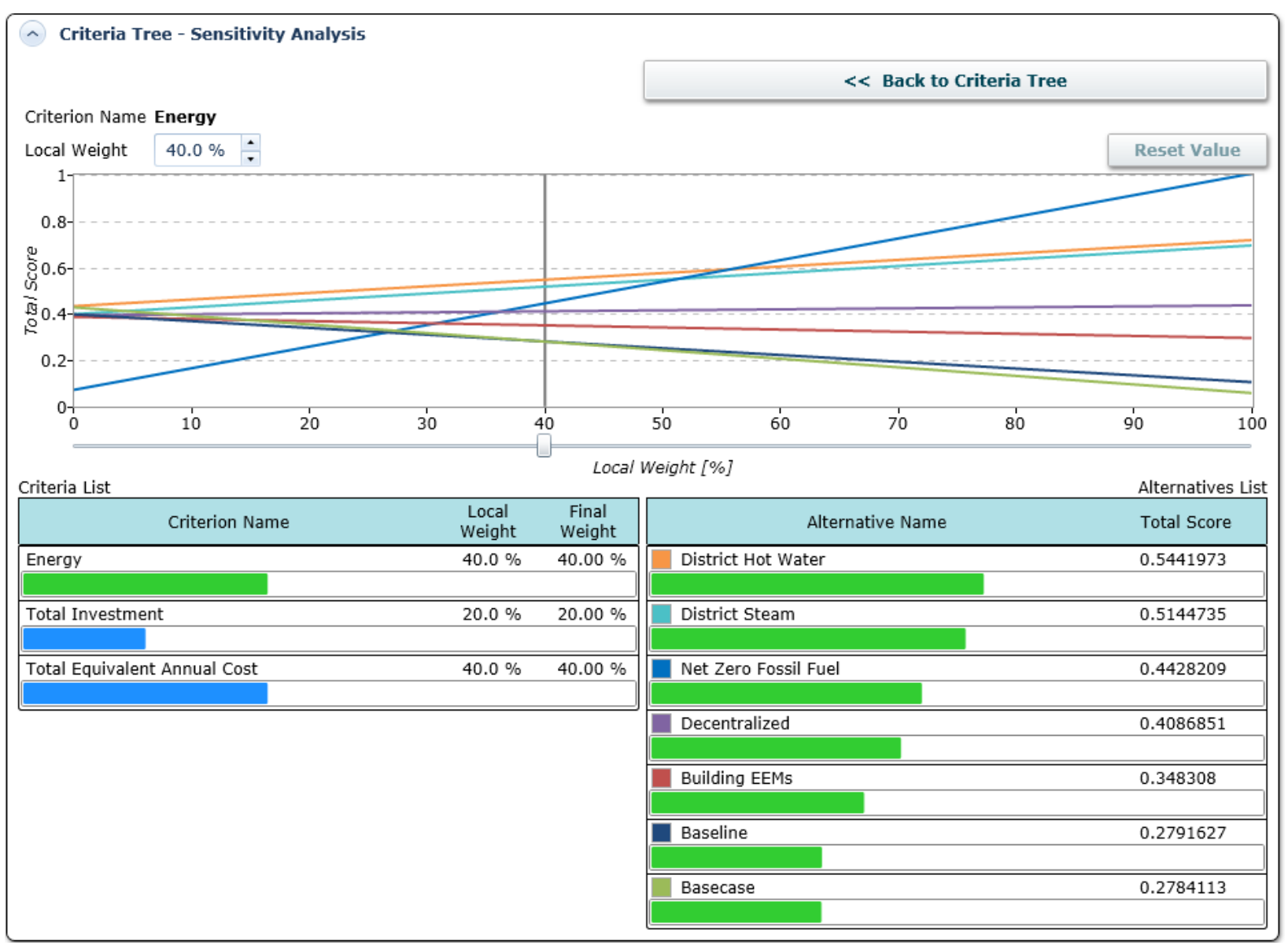

\subsubsection{Develop implementation strategy}

After the installation has decided on a preferred alternative, an implementation strategy is important. Although NZP can provide data to support the strategy, such as a listing of EEM upgrades by facility type as well as supply and distribution equipment, the tool does not currently provide automation support to generate an implementation strategy. Nonetheless, this is an important follow-on to the EMP process.

The transition process is described in terms of the definition and implementation of a roadmap to NZE communities. As soon as the long-term goal is set, one can apply backcasting and forecasting techniques (described in Section 0 ) to define the process leading toward energy neutrality. 


\subsubsection{Complementary goals (spin-offs, co-benefits)}

Different innovative NZE projects around the world have shown that energy efficient projects will be more successful if they can be linked to other key issues, which are of an economic, social (quality of life), health, and environmental character. In the United States, one can profit from regional credits. These "spin-off" effects are usually not taken into account when making a business case for an energy efficient urban development. When the spin-off effects are taken into account and valued, the whole effort will become more feasible and easier to motivate. However, a complication often arises from the fact that co-benefits arise from different departments and/or disciplines.

For military campuses in particular, but for local communities as well, energy security and indoor environmental quality (especially in hot and humid climates) become increasingly important spin-offs (Zhivov et al. 2014b; Kimman, Rovers, and Ravesloot 2010). In a business case, it is hard to quantify the value of this spin-off. However, if one begins to consider the effects of blackouts (e.g., losing data, losing defense shields, etc.) or mold remediation in buildings, the cost advantages of becoming net zero become more apparent. When possible to quantify the value of particular spin-offs, their impact on LCC of alternatives can be added to the energy-related component.

\subsubsection{Implementation strategy: Backcasting and forecasting}

As a part of an implementation strategy, long-term goals are transitioned into medium-term goals (milestones) and short-term projects, which must have tangible results. It is important to recognize that many decision makers (e.g., installation commanders, etc.) have limited-term assignments or duties and will more likely commit to projects that can be realized during their tenure. Furthermore, short-term projects satisfy the short-term (1 to 5 years) planning process. It is important to get commitment from both decision makers and funding agencies since they play key roles in achieving the long-term goal. The main restriction is that $100 \%$ of the short-term projects fit on the roadmap toward the long-term goals.

The transition process is described in terms of the definition and implementation of a roadmap to net zero energy communities. As soon as the long- 
term goal is set, one can apply backcasting and forecasting techniques to define the process leading toward energy neutrality (Annex 512013; Zhivov et al. 2014b; Kimman, Rovers, and Ravesloot 2010). Figure 2-30 illustrates the process of defining milestones (mid-term goals) and determining the necessary steps to reach the final goal.

Backcasting answers the fundamental question: "If we want to attain a certain goal, what actions must be taken to get there?" Using backcasting, concrete actions in the short term can be formulated from the long-term goals. For example, a goal of an energy neutral built environment in 2050 could be supported by requiring that all new houses built after 2015 (for instance) be energy neutral.

Forecasting (Figure 2-31) refers to planning projects to meet milestones defined through the backcasting process: setting project requirements, and optimizing and designing projects and sets of projects in a holistic way that is geared to meeting each milestone. The feasibility of the projects can be learned from the best practices and the frontrunners.

Figure 2-30. Backcasting: Defining milestones and determining necessary steps to reach the final goal.

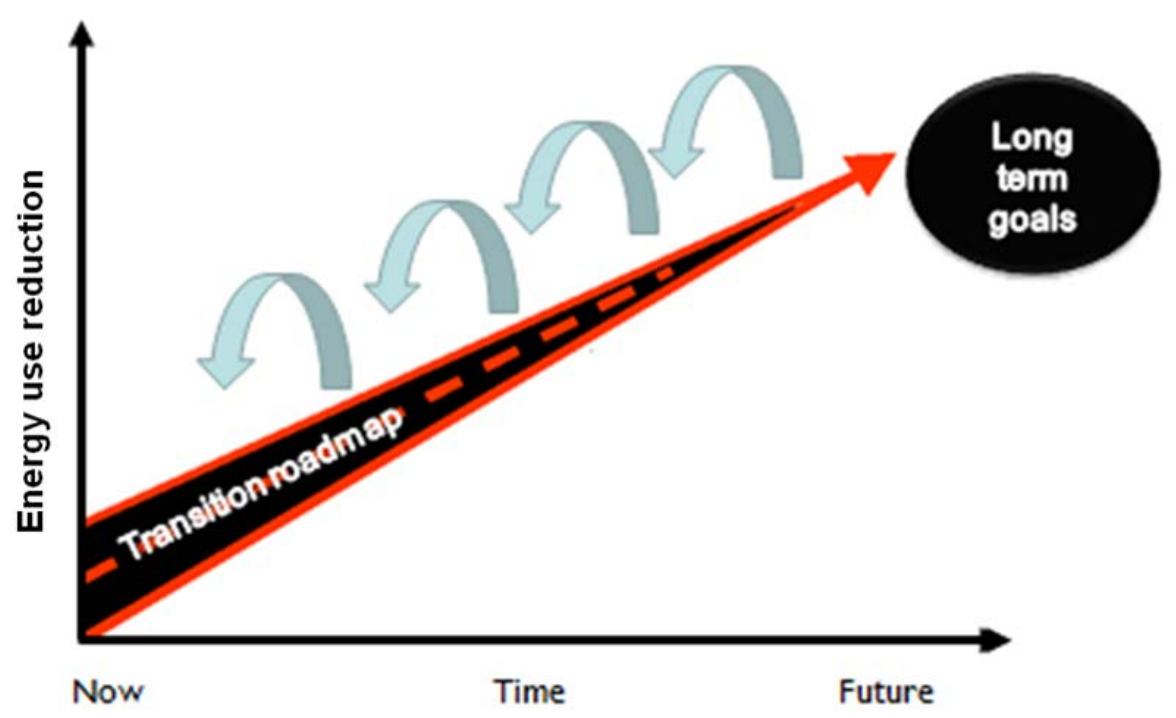


Figure 2-31. Forecasting: Formulating concrete actions and planning projects in a holistic way that is geared to meeting each milestone.

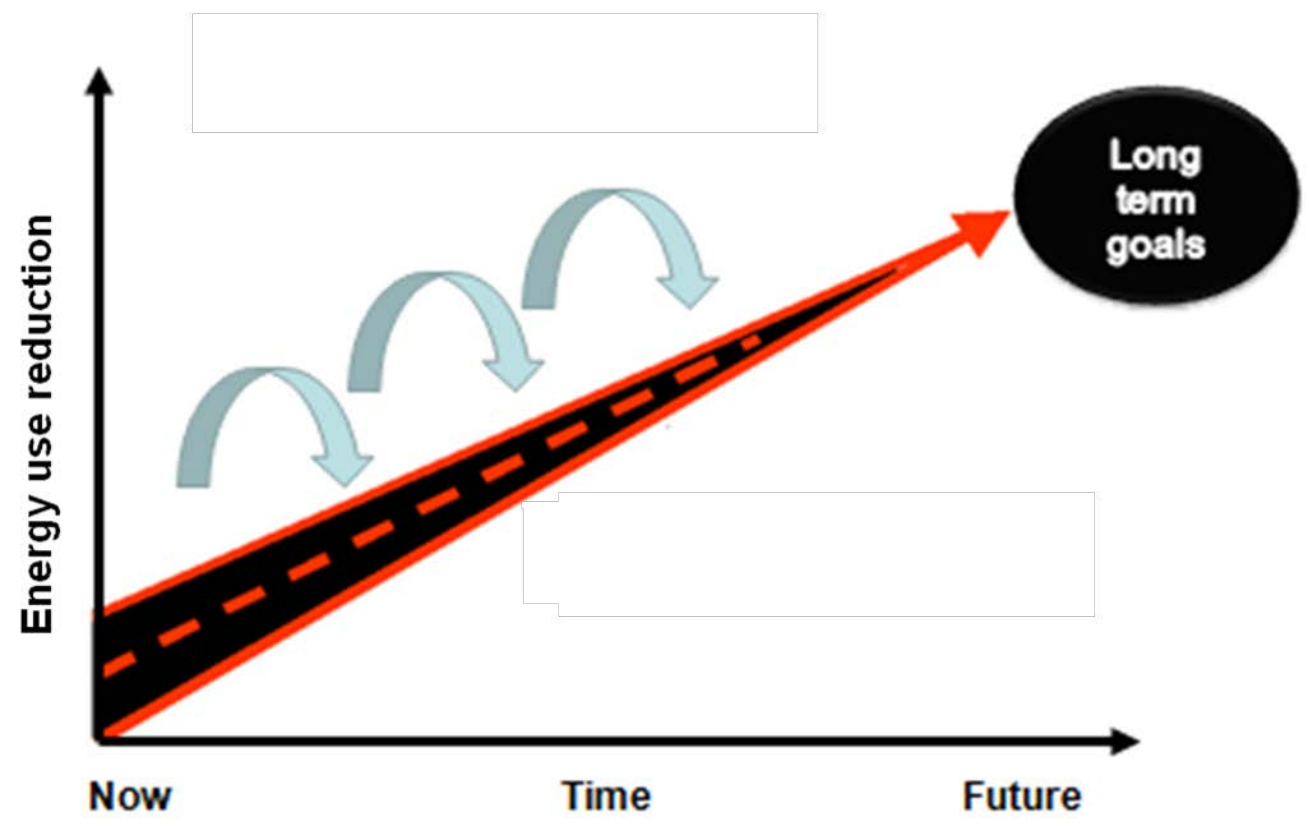

Both backcasting and forecasting approach the challenge of discussing the future from opposite directions. Backcasting and forecasting processes are both necessary to determine the transition path and to make the roadmap as concrete as possible. Both backcasting and forecasting can be used for monitoring the transition process to the long-term goals.

\subsection{Technology development}

As a result of 6.2. R\&D project started in 2011, the U.S. Army Engineer Research and Development Center (ERDC) has developed an Energy Master Planning concept (Zhivov et al. 2014) and an automated Net Zero Planner Tool (NZP) (Case et al. 2014) to support U.S. Department of Defense (DoD) energy policy. The energy concept minimizes energy use at the building level, improves the efficiency of energy generation and distribution, and uses energy from renewable sources to balance fossil fuel based energy to achieve a net zero fossil fuel energy status. Energy goals will be achieved through synergy among energy use reduction in building-related systems, energy supply, and distribution systems. NZP incorporates the concept and various automated tools to integrate optimization across buildings, distribution, and generation systems. 
NZI-Opt sets up a superstructure of many possible devices. This, along with information about existing distribution and storage networks and mixed-integer linear programming, is used to select the optimal set of devices and control schedule to include in the system to meet a given set of loads. The common elements of most of these optimization approaches are that they require a specified electrical and thermal load (typically hourly data for a year), fuel and electricity rates, a set of devices to consider, and information about distribution and storage networks.

NZI Planner is a web-based tool that uses a commercial web browser plugin (Silverlight) to provide a near desktop experience in the user interface, connected to the NZI core, which acts as a web-based application server. Many of the essential computation tasks are provided as Internet web services, which supply flexibility in scaling the service or in changing to new service providers. A web service is an application that is accessible via the Internet and can respond to requests for tasks or data following a specified protocol.

Between 2013 and 2015, this research was expanded to include Net Zero Water and Net Zero Waste components.

The ESTCP funded project \# EW-201240 conducted at both installations allowed both the process and the NZP Tool to be refined. The energy planning process was refined and several steps were added, e.g., the introduction of the Baseline and the Base Case, which are now clearly defined and integrated into the process and the Tool. During the projects, it became apparent that there was a need to determine how to calibrate the Baseline; thus, inputting data from energy meters became an important step in the beginning of the study. During the projects, (especially while executing USMA and PNSY projects, and reviewing the different approaches taken by each SME group that did the comparative validating analysis), it became clear that there was a need to frame goals that establish the type of study that needs to be done, i.e., a planning or pre-engineering analysis.

The process alignment also helped define the customer for the NZP Tool, and who at the installation would be the user of the program. Two groups of users were determined each with different output requirements. The Installation Master Planner is a group that has a need to use the NZP Tool to quantify and provide a Sustainability Component Plan to overlay their 
building Energy Master Plans. The other identified user is the installation energy manager, who has a need for help in identifying and coordinating the sequence of energy projects, which requires a pre-engineering assessment.

Many user interface changes were made throughout the program to facilitate the process, to make it easier for the user to enter data, and to help determine what information must be provided for output reports. Specific information on changes made in the tool which resulted from this project is listed in Chapter 8 of this report.

\subsection{Advantages and limitations of the technology}

Performance Advantages. The EMP concept and NZP Tool allows for a holistic approach to community EMP. The demonstrated tool is a unique highly automated software package that can be used for community/ or buildings cluster level of energy analysis.

Grouping buildings by categories and era of construction can be done more quickly using the tool since it has a database with pre-set packages of technologies and different building types' EUI. This feature comes handy with selection of packages of EEMs for different levels of building energy renovation.

One of NZP's unique features allows calculation of 8760 hour heating, cooling, and power load profiles for all buildings included in the selected building cluster that can account for coincident and non-coincident loads. The load diversification factor varies depending on composition of building types included in the cluster and can reach 0.7 or even be lower. This feature allows for the selection of more accurate energy generation and conversion equipment and for operation based on realistic peaks and more accurate cost estimates for scenarios under consideration.

Another unique feature of the tool is its ability to provide both building level energy consumption modeling and a cluster level energy generation and distribution modeling and equipment selection with an easy iteration of building models. For example, if optimization of cogeneration process results in excessive waste heat, energy building level of energy efficiency can be adjusted. 


\subsubsection{Cost advantages}

Development of an Energy Master Plan requires upfront investment in long-term planning, which can cost up to several hundred thousand dollars. However these investments can be paid back from savings resulting from implementation of one or few projects implemented under the holistic energy roadmap.

\subsubsection{Limitations}

Application of the developed energy master planning concept and NZP Tool require training and experience in EMP. Experience gained through this project shows, that such training is required both for better understanding the energy master planning process and familiarization with its application using the tool.

The main barriers/ bottlenecks to development of energy efficient installations/ communities planning and implementation that must be addressed include:

1. Defining vision and energy targets

2. Process and organization

3. Management support and involvement

4. Skills and know-how

5. Understanding of technical concepts

6. Monitoring of the progress

7. Tools and methods for analysis

8. Project financing

9. Legal issues.

Bottlenecks most commonly occur in the areas of large projects financing, holistic projects design, and installations' buy-in for deep energy retrofits, procurement, quality assurance, and collaboration between different trades. Bottlenecks are often characterized by short-term thinking, separation of implementation and operation, lack of incentives to achieve energy goals (including a lack of negative consequences for energy inefficiency), segmentation of organizations, lack of coordination between different projects executed within the same organization, etc. 


\section{Performance Objectives}

The goal of this project was to demonstrate the EMP concept and the NZP Tool at two DoD installations, and through that demonstration, to show that their use enables a streamlined energy planning process that results in a roadmap to meet or exceed the installations' energy goals at a lifecycle cost below that resulting from implementation of the Base Case. The Base Case was developed using the current Master Planning process. The project goal was considered to be met if the six objectives listed in Table 3-1 were achieved.

Table 3-1. Summary of quantitative performance objectives.

\begin{tabular}{|c|c|c|c|c|}
\hline Performance Objective & Metric & $\begin{array}{l}\text { Data } \\
\text { Requirements }\end{array}$ & Success Criteria & $\begin{array}{l}\text { Success } \\
\text { Criteria Met? }\end{array}$ \\
\hline $\begin{array}{l}\text { 1. Installation/campus- } \\
\text { wide source energy use } \\
\text { reduction compared to } \\
\text { the Base Case }\end{array}$ & $\begin{array}{l}\text { Annual } \\
\text { energy } \\
\text { use } \\
\text { (MMBtu } \\
\text { or kWh) }\end{array}$ & $\begin{array}{l}\text { Installation } \\
\text { provides } \\
\text { electrical and fuel } \\
\text { bills }\end{array}$ & $55 \%$ & $\begin{array}{l}\text { Met at } \\
\text { USMA, not } \\
\text { met at PNSY }\end{array}$ \\
\hline $\begin{array}{l}\text { 2. Installation/campus- } \\
\text { wide energy cost } \\
\text { reduction compared to } \\
\text { the Base Case }\end{array}$ & $\$$ & $\begin{array}{l}\text { Installation } \\
\text { provides } \\
\text { electrical and } \\
\text { thermal energy } \\
\text { bills }\end{array}$ & $60 \%$ & $\begin{array}{l}\text { Met at } \\
\text { USMA }\end{array}$ \\
\hline $\begin{array}{l}\text { 3. Electrical peak load } \\
\text { capacity }\end{array}$ & $\begin{array}{l}\text { Peak } \\
\text { electrical } \\
\text { load } \\
(\mathrm{MW})\end{array}$ & $\begin{array}{l}\text { Installation } \\
\text { provides } \\
\text { projected } \\
\text { electrical capacity } \\
\text { requirements and } \\
\text { contract } \\
\text { limitations }\end{array}$ & $\begin{array}{l}\text { Proposed solution does } \\
\text { not exceed capacity } \\
\text { limitation including future } \\
\text { growth }\end{array}$ & $\begin{array}{l}\text { Met at both } \\
\text { locations }\end{array}$ \\
\hline $\begin{array}{l}\text { 4. Energy Security - cost to } \\
\text { achieve uninterruptable } \\
\text { onsite energy } \\
\text { generation }\end{array}$ & $\$$ & $\begin{array}{l}\text { Installation } \\
\text { provides estimate } \\
\text { for onsite } \\
\text { demand }\end{array}$ & $\begin{array}{l}\text { Generated roadmap } \\
\text { allows for } 100 \% \text { onsite } \\
\text { uninterruptable power } \\
\text { generation for critical } \\
\text { facilities at no additional } \\
\text { cost }\end{array}$ & $\begin{array}{l}\text { Met at both } \\
\text { locations }\end{array}$ \\
\hline $\begin{array}{l}\text { 5. Simple Payback (SPB) of } \\
\text { proposed scenario } \\
\text { compared to the Base } \\
\text { Case }\end{array}$ & Years & & 15 & $\begin{array}{l}\text { Met at } \\
\text { USMA, Not } \\
\text { met at PNSY }\end{array}$ \\
\hline 6. Planning cost SPB & Years & $\begin{array}{l}\text { Projected energy } \\
\text { cost savings and } \\
\text { the ESTCP project } \\
\text { budget }\end{array}$ & $\begin{array}{l}\text { Roadmap planning costs } \\
\text { will be recovered from } \\
\text { energy savings within } \\
1 \text { year }\end{array}$ & $\begin{array}{l}\text { Met at both } \\
\text { locations }\end{array}$ \\
\hline
\end{tabular}




\subsection{Source energy use reduction}

This objective is critical in the development of an executable roadmap for a net zero energy installation or a selected cluster of buildings. The same concept and NZP tool can be applied to less stringent installation energy goals, such as meeting the minimum legal requirements under EISA 2007. In addition, it is important to demonstrate approaches that reduce source energy. Modeling using the tool allows prediction of source energy for the Base Case and scenarios. EISA 2007 was chosen as a minimum success criterion because it sets the legal requirement for all government owned portfolios of buildings. As installations attempt to move closer to NZE goals, the technologies required become more expensive and therefore the concept and tool can be used to find economically feasible solutions.

\subsection{Energy cost reduction}

This objective is important since energy cost reduction is one of the main drivers for energy-related projects funded using public funding (Military Construction for new construction and some renovation projects or Sustainment, Restoration and Maintenance programs) or using private sector money through Energy Performance Contracting.

\subsection{Electrical peak load capacity}

Often, the installation contracts with utilities for electrical power delivery, which creates a limitation on peak electrical demand capacities available to the installation. This limitation affects the amount of electrical power that can be purchased or sold to the grid, as well as constraining installations' ability to meet increased mission demands. The tool is capable of optimizing demand reduction as well as integrating interruptible/ non-interruptible power solutions and thermal and electrical storage to permit installations to meet growing mission demands while not exceeding their grid limitations. Peak electrical loads are calculated as part of the hourly simulations used throughout the tool, including coincident and non-coincident loads (diversity factor). The success criteria of not exceeding contracted peak load capacities was selected as an economic consideration due to the high cost of upgrading the commercial grid infrastructure. 


\subsection{Energy security}

Energy efficiency and energy security are often planned for separately, despite being mutually interdependent. Energy security in this case is defined as the ability to meet critical mission-related electrical and thermal loads when power supply from the grid is interrupted. The purpose of including energy security as an objective is to demonstrate how the EMP concept and the NZP Tool allow the selection of an energy generation and distribution system architecture that meets mission critical loads at a lower cost, compared to procuring individual backup generators. Critical load is an input parameter for NZP and is used to establish a constraint on the amount of onsite generation that must be considered in a feasible solution. Distributed generation options are automatically compared against the cost of procuring dedicated backup generators. The success criterion of $100 \%$ was selected based on the reasoning that the critical load must be met.

\subsection{Simple payback of proposed scenario}

This simple payback combines energy efficiency achieved (compared to the Base Case) with the financial investments required to implement this scenario by calculating the amount of time it will take to recover initial investments. While it is easy to compute, it fails to account for the time value of money, does not consider the possibility of changing energy costs over time, inflation, and some other factors, which can be accounted for using a comprehensive LCC analysis.

For the project demonstration, "Objective 6 - Planning Cost Recovery," is the most critical. The success criterion for this objective was that the roadmap planning costs could be recovered from 1 year's energy savings. The first step in assessing success is to determine the annual energy savings for the recommended scenario as compared to the Base Case scenario (business as usual), for USMA, West Point and Portsmouth. The annual energy savings was $\$ 3,918,948(\$ 5,190,838$ - $\$ 1,271,890)$ for USMA, West Point and \$2,300,536 (\$10,152,027 - \$7,851,491) for Portsmouth. Collectively this represents an annual energy savings of $\$ 6,219,484$, well above the planning costs associated with the two studies (approximately $300 \mathrm{k}$ each). Therefore, this objective was successfully met. Chapter 8 includes more detailed information on the costs associated with performing an Energy Master Plan, including the reductions due to the streamlining work developed through this project. 
Table 3-2 lists the results of an analysis of the demonstration projects alongside the first five performance objectives, for comparison. These data show that performance parameters at the USMA NZE Area exceed the stated goals, while source energy and energy cost reduction and SPB goals at PNSY have not been met. The main reason for not meeting these goals is that PNSY is the Navy industrial site and most of energy use is based on mission-related processes. Though process-related energy consumption can be reduced (e.g., by installation of energy efficient scaffolding and other process-related measures), the level of energy use reduction is limited.

Table 3-2. Comparison of demonstration projects performance parameters against performance objectives.

\begin{tabular}{|l|c|c|l|l|l|}
\hline Installation & $\begin{array}{l}\text { Source energy } \\
\text { reduction, \% }\end{array}$ & $\begin{array}{l}\text { Energy Cost } \\
\text { reduction, \% }\end{array}$ & Peak load & $\begin{array}{l}\text { Energy security } \\
\text { through uninterruptable } \\
\text { onsite power generation }\end{array}$ & SPB \\
\hline USMA & 75 & 75 & $\begin{array}{l}\text { Satisfied and 28\% } \\
\text { below compared to } \\
\text { Base Case }\end{array}$ & 100 & 10 \\
\hline PNSY & 33 & 31 & $\begin{array}{l}\text { Satisfied and 17\% } \\
\text { below compared to } \\
\text { the Base Case }\end{array}$ & $\begin{array}{l}100 \\
\text { Satisfied and 5\% above } \\
\text { the Base Case }\end{array}$ & 21 \\
\hline Goal & 55 & 60 & $\begin{array}{l}\text { Below capacity } \\
\text { limitation }\end{array}$ & 100 & 15 \\
\hline
\end{tabular}

\subsection{Planning cost recovery}

For the project demonstration, "Objective 6 - Planning Cost Recovery," is the most critical. The success criterion for this objective was that the roadmap planning costs could be recovered from 1year's energy savings. The first step in assessing success is to determine the annual energy savings for the recommended scenario as compared to the Base Case scenario (business as usual), for USMA, West Point and Portsmouth. The annual energy savings was $\$ 3,918,948(\$ 5,190,838$ - $\$ 1,271,890)$ for USMA, West Point and \$2,300,536 (\$10,152,027 - \$7,851,491) for Portsmouth. Collectively this represents an annual energy savings of $\$ 6,219,484$, well above the planning costs associated with the two studies (approximately $300 \mathrm{k}$ each). Therefore, this objective was successfully met. Chapter 7 includes more detailed information on the costs associated with performing an Energy Master Plan, including the reductions due to the streamlining work developed through this project. 


\section{Facility/Site Description}

NZP was demonstrated at two defense installations, the U.S. Military Academy (USMA) at West Point, NY, and the Portsmouth Naval Shipyard (PNSY), Kittery, ME.

\subsection{The U.S. Military Academy (USMA), West Point}

\subsubsection{Site location and operations}

The U.S. Military Academy (USMA), the oldest U.S. military installation in continuous use, has trained many of this country's most prominent military figures, as well as many of the civil engineers who designed and built the networks of railroad, canal, and port facilities that were essential to the development of America's resources during the $19^{\text {th }}$ and early $20^{\text {th }}$ centuries.

USMA's location on the west bank of the Hudson River had a defensive and strategic importance throughout the history and birth of the United States. Both the British and Continental Armies realized the strategic importance of commanding the plateau of the west bank of the Hudson River. The military reservation is located about 50 miles $(80 \mathrm{~km})$ north of New York City. The site is dominated by hills and small mountains, especially in the northern and western part of the campus, which are part of a region known as Hudson Highlands. The main campus and central installation area (cantonment area) total 1,800 acres ( $728 \mathrm{ha}$ ), only a portion of the nearly 16,000 acres (6,475 ha) reservation (Figure $4-1)$. The campus is composed of approximately 700 buildings that occupy nearly 10 million sq $\mathrm{ft}\left(930,000 \mathrm{~m}^{2}\right)$ of gross floor area, more than $50 \%$ of which is concentrated in the central region. The campus has a central steam plant that operates year round and that provides heating and domestic hot water (DHW) for the core campus area via a steam distribution system. From the 5.7 million sq $\mathrm{ft}\left(530,100 \mathrm{~m}^{2}\right)$ gross floor area in the central campus area and the south loop; about 5 million sq $\mathrm{ft}\left(465,000 \mathrm{~m}^{2}\right)$ are connected to the steam grid. The central plant has a steam generating capacity of 250,000 lb/ hr (250 Btu/ min). 
Figure 4-1. Site map with existing heating grids and rough cluster boundaries.

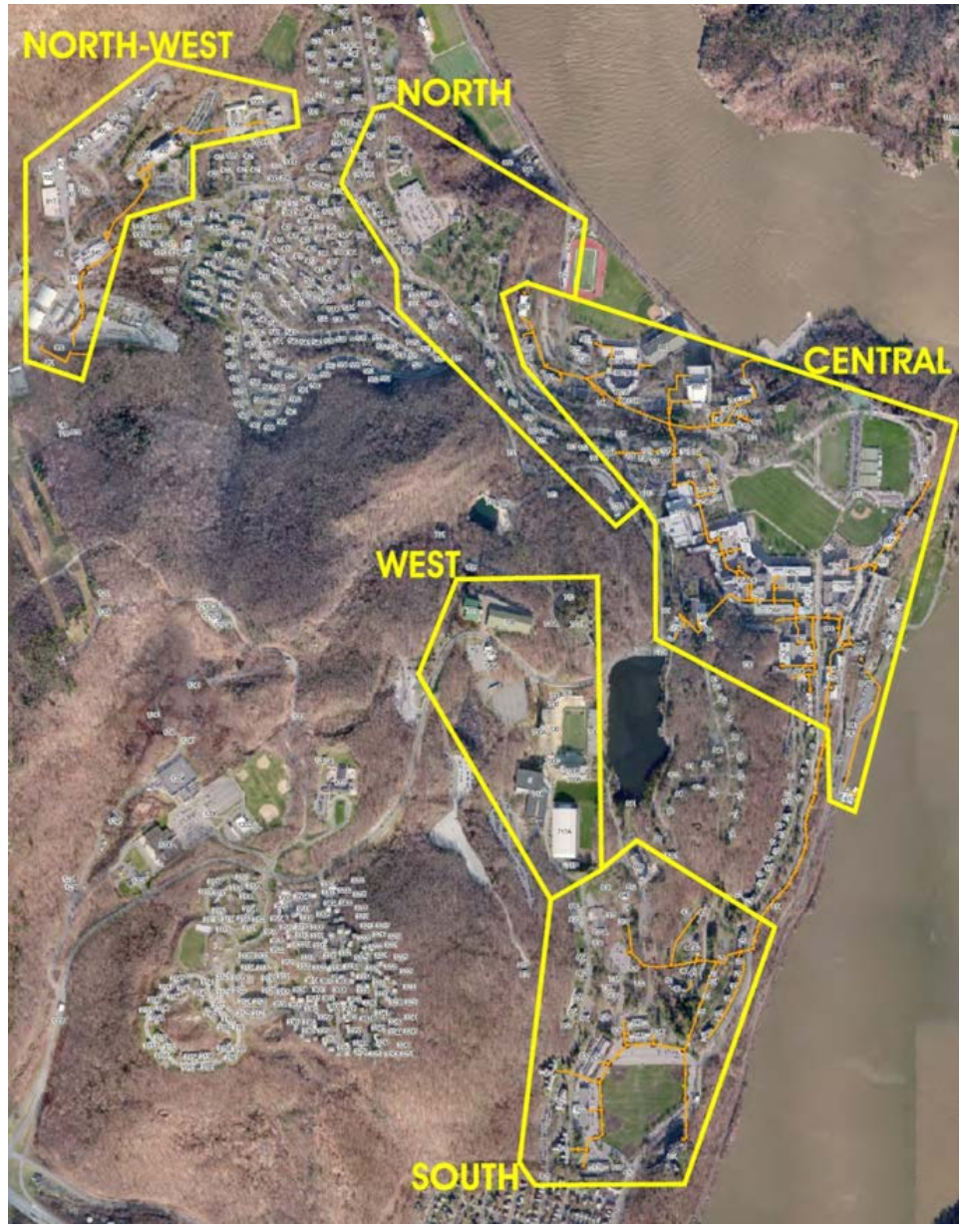

\subsubsection{Site conditions}

By its nature, an installation EMP for a large installation like USMA can become very complex. Clarity and alignment over scope is essential, and the scope of the USMA NZE analysis was agreed on and determined at the beginning of the project. The selected annual baseline was an average between 2010 and 2011 with the planning horizon from 2013 to 2020. Using a mean value as a synthetic baseline helps to prevent an unusually hot or cold year from skewing the results of a study.

From the beginning of the project, it became clear that it would not be technically and financially feasible to meet the 2020 NZE goal on the entire installation. Therefore, reasonable boundaries for an NZE Area were 
established so that the goal would be achievable. The following criteria and logic were used in defining the preliminary NZE boundary:

- Density of Buildings. Selection of a densely populated area with a high energy demand would allow for lower costs in distribution modernization and lower distribution heat and cooling losses.

- Grid Connection. Buildings will be clustered by their connection to the thermal grid.

- USMA will maintain control over building energy use.

- USMA will set priorities for building stock modernization.

\subsubsection{Boundaries of analysis}

In the process of defining NZE boundaries, the USMA community was divided into five clusters using the two heating grids and their possible enlargements as well as the density and usage of buildings as criteria for boundaries (Figure 4-1). Based on the above criteria, the PWT agreed during the kickoff meeting with the USMA management to select the central cluster of buildings as the NZE study area (Figure 4-2). The central cluster of buildings comprises USMA's core campus/ academic area, with its 44 highly visible and significant educational and training buildings and barracks, which is the heart of the installation. All buildings within this cluster are connected to the CEP and represent the major part of the installation's energy use. In the near future, an additional barracks building will be constructed within this area and connected to the central plant, increasing the total number of buildings in this area to 45 . Furthermore, most of potential funding for building modernization is planned for buildings located in this area.

Figure 4-2. Central cluster of the USMA, West Point, NY.

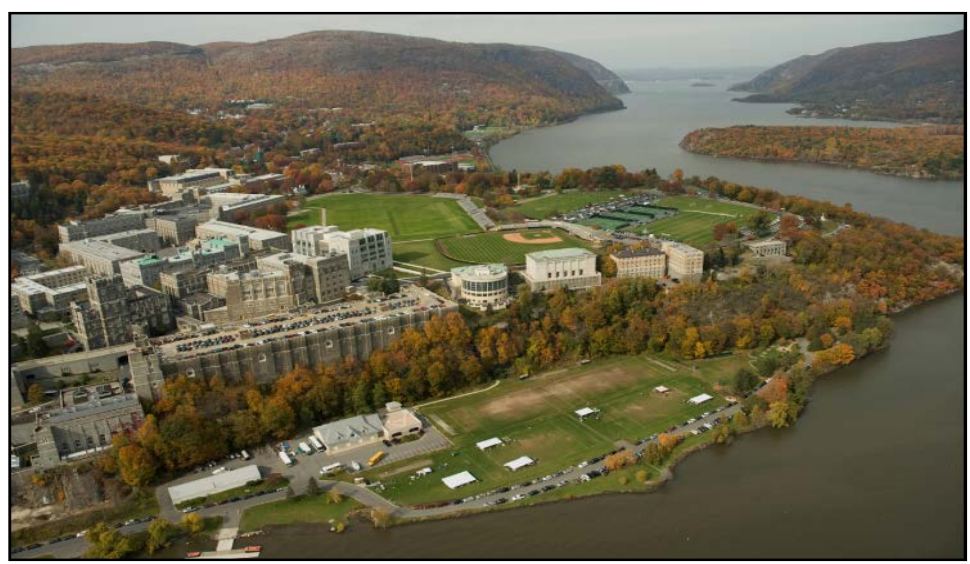


The high density of buildings within the central cluster results in high heating and cooling demands, especially considering new requirements for air-conditioning in barracks. Also, a heating grid on the scale of the central area can become beneficial for a scenario that includes cogeneration of heat and electricity. Use of a combined heat and power strategy may be critical in achieving NZE within a cluster of this size. Due to the privatization of a number of buildings located on the "south loop," which are currently connected to the central heating grid, but which are located at a significant distance from the current CEP, it was decided that these buildings will be disconnected from the central grid and that they would not be included in the NZE Area. In the future, the south cluster of buildings can be provided with its own source of heat and could be added to the NZE Area.

The 44 buildings included in the central area have a gross floor area of about $50 \%$ of the total gross floor area of the entire USMA. The USMA SRM budget is limited. According to information provided by the Directorate of Public Works (DPW), only a few buildings have a potential to be funded for major renovation. Also, a number of buildings that have steam heating systems will be converted to hot water heating system. These two categories of buildings were analyzed for cost efficient energy saving potential.

\subsection{Portsmouth Naval Shipyard (PNSY)}

\subsubsection{Site location and operations}

PNSY, which was established in 1800 , is located close to Kittery, ME, on Seavey's Island in the Piscataqua River, close to its outlet to the Atlantic Ocean (Figure 4-3). The shipyard has buildings and workshops, many of which are listed historical structures. It has three dry docks (DDs) and additional maintenance berths. Figure 4-4 shows the functional layout of the installation.

\subsubsection{Site conditions}

The site has an existing CEP that supplies steam to most of the site and generates the bulk of the installation's electricity requirements. There is a single connection to the grid near the access bridge to the installation. The installation's current role is primarily the repair and refit of submarines. The study included 127 industrial and nonindustrial shipyard buildings. 
Figure 4-3. Aerial view of PNSY.

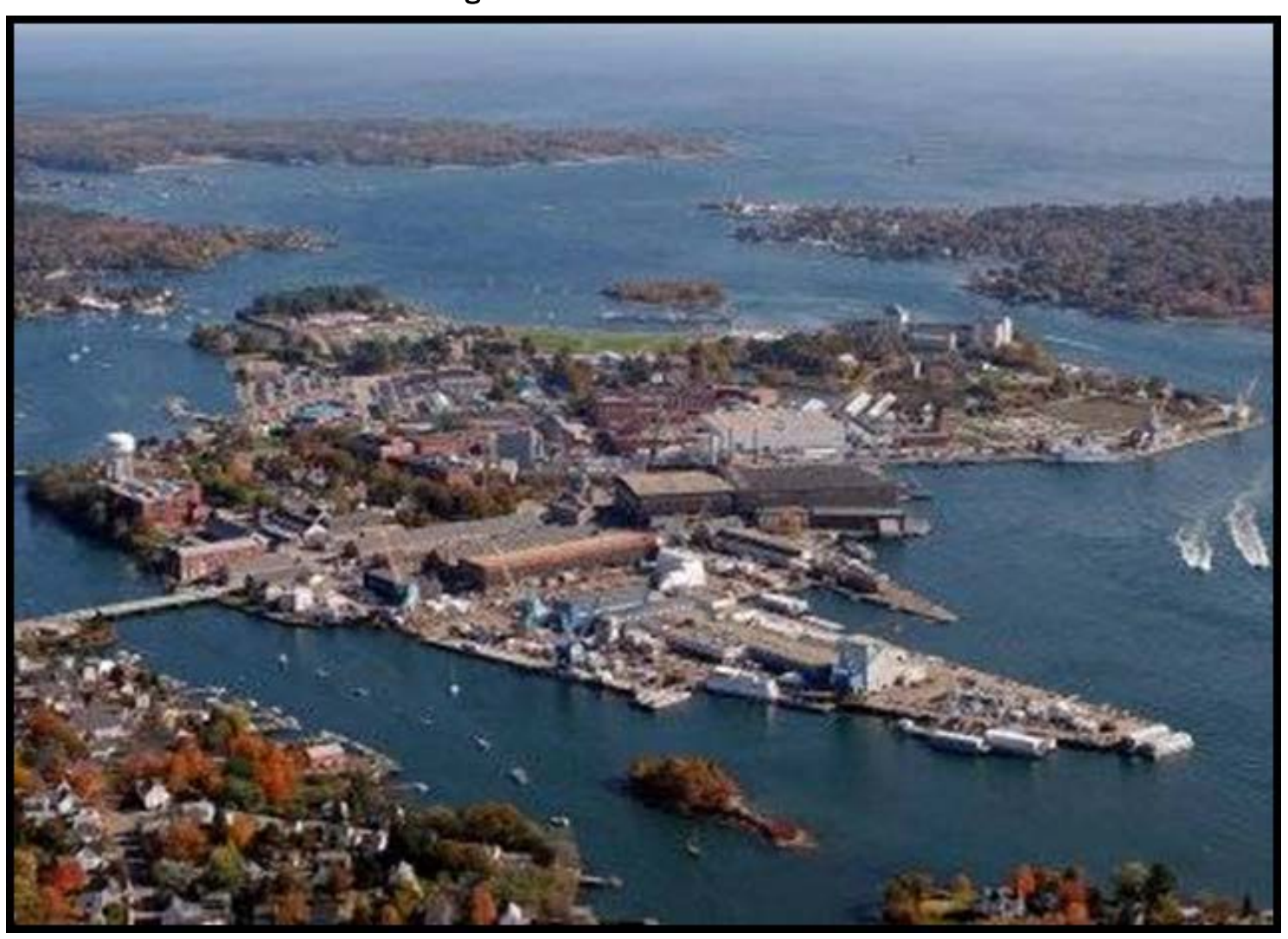

Figure 4-4. Layout of PNSY in the NZP Tool.

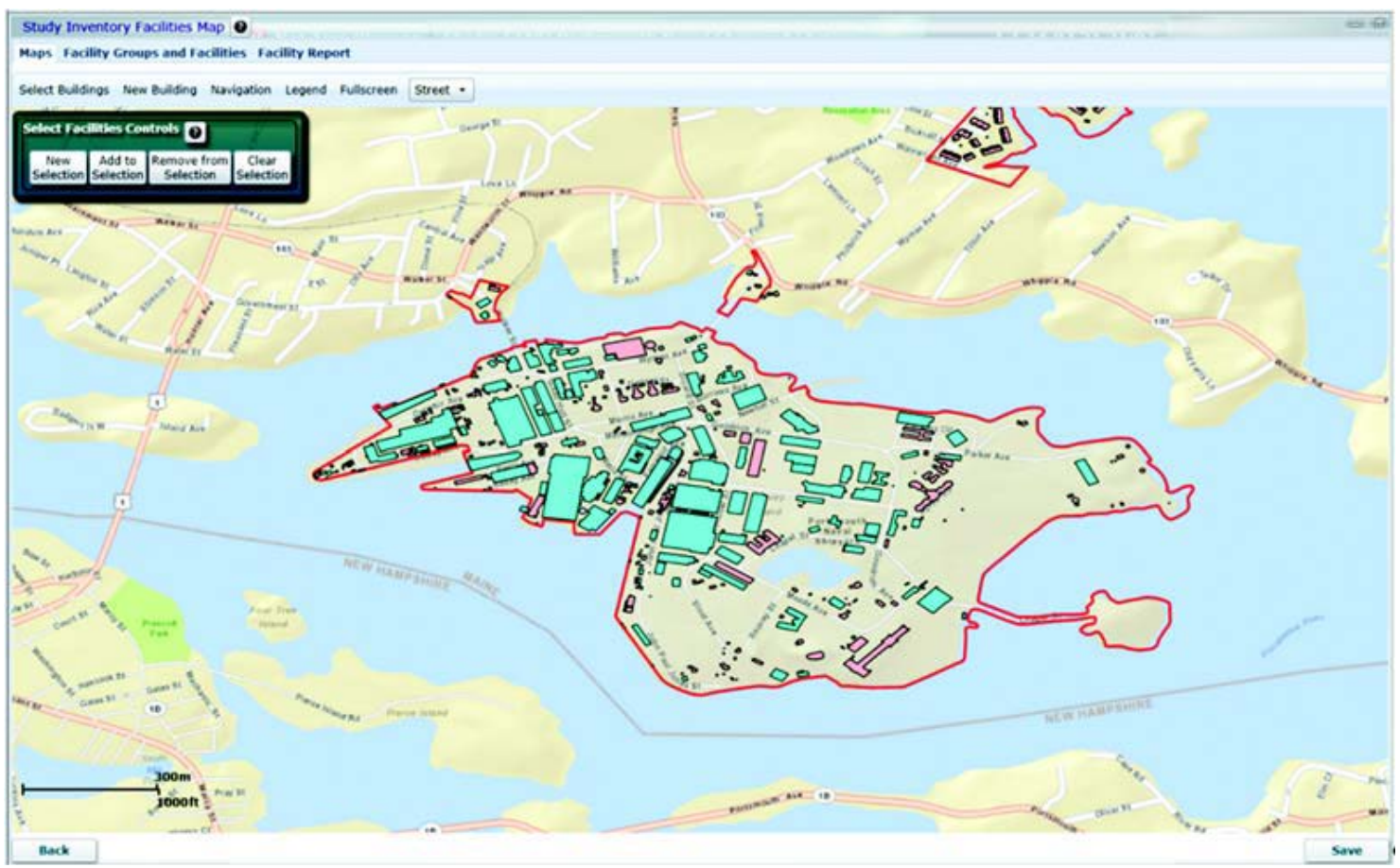




\section{Test Design}

\subsection{Fundamental problem}

Until very recently, energy projects for new and renovated buildings have been planned and executed on an individual facility basis. Utility modernization projects and energy system architecture rarely accounted for potential increases or decreases in energy needs due to perspective changes in installation's real estate (number of buildings and their energy use). A more cost effective overall solution will result in the synergetic effect of energy use reduction in buildings, utilization of waste streams, consistency in baseload, as well as modular and flexible architecture of energy generation systems.

\subsection{Demonstration question}

Can the use of the EMP concept and NZP result in a roadmap to a cost effective implementable scenario for achieving installation energy goals (i.e., NZE community, onsite uninterruptable energy generation to meet or exceed mission critical electrical and thermal needs, etc.)?

\subsection{Conceptual test design}

\subsubsection{Independent variable}

Net Zero Energy communities are achievable. A few examples of such communities are available from around the world. Planning of these projects, which were subsidized by government programs, required significant expertise and time of participating researchers and practitioners (Case et al. 2014; Deru et al. 2009; Zhivov, Herron, and Deru 2009; Liesen et al. 2012; Deru et al. 2012; Langner et al. 2012; HQUSACE 2011; CONCERTO 2006). Good planning can significantly affect the quality of the outcome (i.e., how close you can get to achieving energy goals), and the cost of implementation, operation and maintenance (O\&M). Therefore, the planning cost, including the cost of data collection and application of NZP, is considered to be an independent variable.

Energy use by the building stock can be significantly reduced up to the limit based on mission critical energy users (e.g., power supply to processes and 
plug loads, DHW use, electric lighting). Within these limitations, the minimal possible energy use by the building significantly depends on the investment in the building envelope and energy systems in new construction and renovation projects, and in energy-consuming processes. Energy generation/ conversion efficiency depends on the type and quality of generation and storage systems used and their cost. Achieving an NZE installation requires renewable energy generation, conversion, and storage equipment; as such, it has its own cost. However, the outcome of achieving a NZE installation is that buildings require less energy, energy generation, and conversion; distribution systems experience fewer (and lesser) energy losses; and the overall system requires less energy from renewable sources, which reduces the amount to be invested in these systems. The bottom line: Net Zero Energy or low energy community is achievable and different scenarios to achieve such goals have different investment and O\&M costs. Good planning can significantly affect the quality and the cost of scenarios and the cost of such planning should also be included into the overall cost. Therefore, a cost (annualized or life cycle cost) can be selected as an independent variable. NZP allows for a streamlining of the energy master planning process and for the development of optimized scenarios to meet energy goals.

\subsubsection{Dependent variable(s)}

NZP generates a number of different scenarios to meet an installation's energy goals. These scenarios have different first, replacement, O\&M, and energy costs. These costs can be summarized as an annualized cost, which can be used as a dependent variable.

\subsubsection{Controlled variable(s)}

The analysis was conducted within selected NZE Area boundaries. Energy goals (e.g., source energy use reduction, energy cost reduction, onsite generation capacity [energy security] and peak load limitations) were determined in consultation with each pilot installation and are fixed for the purpose of this demonstration project.

\subsubsection{Hypothesis}

The use of NZP can enable military installation master planners to achieve their energy goals in a cost effective way (SPB for implementation below 15 
years and SPB of planning investment below 1 year), compared to a current base case scenario developed using the standard master planning process.

\subsubsection{Test design}

The NZP test was designed following the EMP process scheme shown in Figure 2-3. The test was performed by two teams comprised of ERDCCERL researchers and PERTAN Company SME working in close collaboration with military installation personnel. Appendix A lists the team members.

The NZP test was designed following the EMP process scheme shown in Figure 2-3. The test was performed by two teams comprised of ERDCCERL researchers and PERTAN Company SME working in close collaboration with military installations personnel. Appendix A lists the team members.

The NZP Tool was tested first at USMA, West Point, and finally at PNSY. To learn the most from this project, the test designs at USMA and PNSY were slightly different.

At the USMA, data for the Baseline and the Base Case were collected and analyzed by a joint team. Different scenarios for building renovation were discussed and developed. Appendix B lists information required from the installation for the analysis. Appendix C includes the level of technical details used for development of EMP at USMA. The Net Zero Energy analysis was conducted independently by SMEs. The data collected by the SMEs was then entered into NZP and the analysis results compared against the SME results. Additionally, condition of the steam distribution system and tunnels was assessed to generate information on the scope and costs of their renovation and/ or conversion. Funding for additional engineering efforts related to development of energy concepts and specifications for new barracks building and renovation of the existing (Scott) barracks, development of building envelope renovation concepts for different building types at USMA steam distribution systems and tunnels analysis was provided by USMA, DASA, and USACE, New York District. These complementary activities provided a more robust technical and economic base for the Master Planning effort and supported critical projects conducted during the study 
at USMA. The collected data were used as an input into the NZP Tool to develop the Baseline, Base Case, and Alternative Scenarios.

A slightly different approach was used at PNSY. Data were collected by the joint ERDC-SME team. After data were collected, ERDC-CERL researchers used the NZP Tool to analyze the Base Case and Alternative Scenarios. Subsequently, PERTAN SMEs conducted an independent analysis. The separate results were compared.

This report presents both results. Sections 5.4 and 5.5 present the differences between the two approaches. The USMA section of the report includes more technical data related to different scenarios while the PNSY section has more details related to comparison of energy master planning using NZP with the SME calculation approach.

\subsection{USMA}

\subsubsection{Energy objectives}

USMA Energy Master Planning was based on the need to meet a combination of the following energy objectives in a cost effective, balanced waywhich comprised a research and analysis challenge.

\subsubsection{Energy efficiency goals}

By 2020, the site energy use on the installation will be $40 \%$ less than 2011 baseline. This includes thermal energy (gas, oil, etc.) supplied to the installation, in addition to the electrical energy purchased from the grid.

\subsubsection{Supply security goals}

The current level of energy reliability will be improved and onsite power generation will be at least $40.9 \mathrm{MBtu} / \mathrm{hr}$ (12 MW) (considering that some cooling load will be provided by absorption chillers). The installation currently has only $8.9 \mathrm{MBtu} / \mathrm{hr}$ (2.6 MW) of onsite power generation capability.

\subsubsection{Fossil fuel reduction goals}

By 2020, the installation should strive for "zero fossil fuel based" energy use and a reduction in greenhouse gas (GHG) emissions from both onsite 
stationary sources (Scope 1) and purchased electricity (Scope 2). Based on an analysis conducted at ERDC-CERL, a definition of a "net zero energy installation" was proposed based on current realities at Army installations:

The amount of fossil fuel based energy used over the course of a year is equal to the amount of energy from renewable energy sources that are exported from the installation to a power or thermal grid for external users' consumption (Zhivov et al. 2014b).

Under this definition, a net zero balance includes a combination of thermal and electrical energies presented in terms of primary (source) energy used (Figure 5-1). This shall not be confused with the installation site energy, which is a combination of thermal energy (gas, oil, biomass, solar, etc.) and electricity produced on site from renewable sources and purchased from the grid. The total site energy is comprised of energy used by end users (e.g., by buildings, external lighting systems, etc.), losses in distribution systems, and conversion losses in energy equipment (boilers, chillers, engines, etc.). In addition, NZE balance does not include renewable energy credits purchased by installation or installation investment into renewable energy technologies installed outside the boundaries of the installation and connected to the grid.

\subsubsection{USMA energy economics goals}

The net investments aimed at achieving energy goals will achieve an Internal Rate of Return (IRR) of at least 5\%, which approaches twice the current return on 30-year U.S. Treasury Bonds. Note that the IRR calculation in the EMP Integration uses the standard MS Excel ${ }^{\circledR}$ IRR function (Microsoft 2013).

Figure 5-1. Schematic of NZE installation concept.

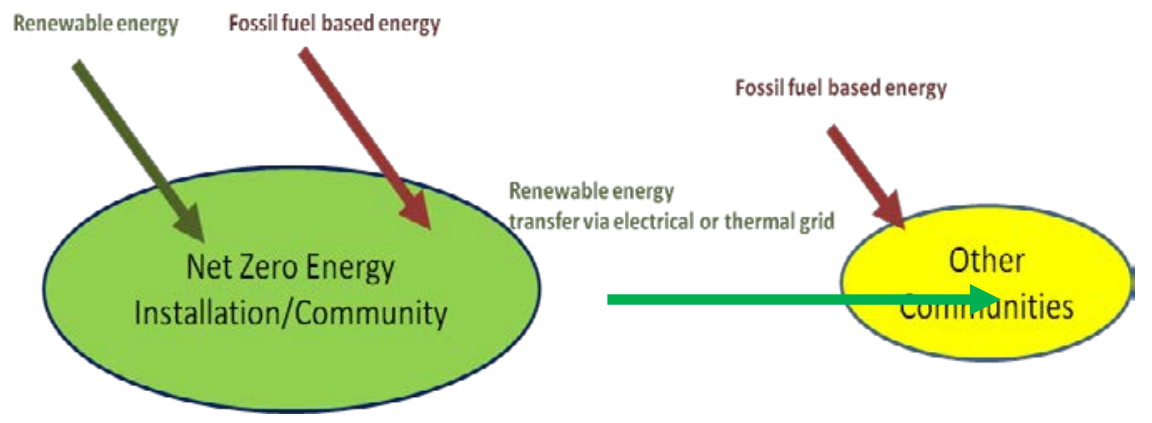




\subsubsection{USMA baseline}

The baseline is a snapshot of USMA's NZE Area energy profile (site and source energy) for the NZE boundary discussed earlier as an average of 2010 and 2011 in the following categories: (1) end uses, (2) building functions, (3) distribution losses on site, (4) steam network losses, (5) onsite electrical use, (6) conversion losses on site (gas turbines, boilers, and steam turbines), (7) off-site conversion and distribution losses, (8) purchased natural gas, and (9) purchased electricity.

The total energy consumed by Categories 1-6 is the site energy use. The total of Categories 7 through 9 contribute to the source energy use. Data sources and estimation approaches are compared to available metering and monitoring data. Table 5-1 lists the baseline energy use for NZE Area buildings connected to CEP. Table 5-2 lists the baseline distribution of energy within the NZE Area. Figure 5-2 shows a schematic of baseline energy uses and wastes at NZE Area. Figure 5-3 shows energy uses and losses in the NZE Area baseline. These values were calculated considering known pipe insulation and estimated amount of missing insulation, and actual summer nighttime steam consumption with no building steam usage. Condensate and steam losses were based on known measured makeup water quantities.

Table 5-1. Baseline energy use for NZE Area buildings connected to CEP.

\begin{tabular}{|c|c|c|c|c|c|c|}
\hline \multirow[b]{2}{*}{ Utility } & \multirow[b]{2}{*}{ Cost } & \multirow[b]{2}{*}{ Usage } & Site Energy & $\begin{array}{l}\text { Source } \\
\text { Energy }\end{array}$ & $\begin{array}{c}\text { Site } \\
\text { Energy }\end{array}$ & $\begin{array}{l}\text { Source } \\
\text { Energy }\end{array}$ \\
\hline & & & \multicolumn{2}{|c|}{ MMBtu/yr } & \multicolumn{2}{|c|}{$\mathrm{MWh} / \mathrm{yr}$} \\
\hline Gas & $\$ 3,673,631$ & $4,770,949 \mathrm{ccf}$ & 487,591 & 510,508 & 142,863 & 149,578 \\
\hline Electricity & $\$ 3,477,866$ & $\begin{array}{l}\text { 143,011 MMBtu } \\
\text { (41,902,000 kWh) }\end{array}$ & 143,011 & 477,657 & 41,902 & 139,953 \\
\hline Total & $\$ 7,151,497$ & & 630,602 & 988,165 & 184,765 & 289,531 \\
\hline \multicolumn{7}{|c|}{ Calculation Notes: } \\
\hline \multicolumn{7}{|c|}{ Site-to-Source $(E \mid A)$ : natural gas $=1.047$; electricity $=3.34$} \\
\hline \multicolumn{7}{|c|}{$\operatorname{CCF}$ to $\mathrm{Btu}=\operatorname{ccf}(100 \mathrm{cf})(1,022 \mathrm{Btu}) / 1,000,000 \mathrm{MMBtu})=\mathrm{MMBtu}$} \\
\hline \multicolumn{7}{|c|}{ Energy Price per year: } \\
\hline \multicolumn{7}{|c|}{ Natural Gas $=\$ / \mathrm{ccf}=(4,770,949 \mathrm{cc}) \times(\$ 0.77 / \mathrm{ccf})=\$ 3,673,631$ per year } \\
\hline \multicolumn{7}{|c|}{ Electricity $=\$ / \mathrm{kWh}=(41,902,000 \mathrm{kWh}) \times(\$ 0.083 / \mathrm{kWh})=\$ 3,477,866$ per year } \\
\hline
\end{tabular}


Table 5-2. Baseline distribution of energy within the NZE Area.

\begin{tabular}{|l|r|r|r|}
\hline Energy Use & \multicolumn{1}{|c|}{ Cost (\$) } & \multicolumn{1}{c|}{ MMBtu/yr } & \multicolumn{1}{c|}{ MWh/yr } \\
\hline A. Thermal energy use by building & $2,267,740$ & 300,991 & 88,190 \\
\hline B. Thermal Energy Distribution Losses On site & 610,274 & 81,000 & 23,733 \\
\hline $\begin{array}{l}\text { C. Thermal Energy Conversion Losses at CEP } \\
\text { (boiler efficiency @ 81.1\%) }\end{array}$ & 729,707 & 96,852 & 28,377 \\
\hline D. Electricity from onsite generation & 65,910 & 8,748 & 2,563 \\
\hline E. Electricity from grid & $3,477,866$ & 143,011 & 41,902 \\
\hline Total purchased energy: & $7,151,497$ & 630,602 & 184,765 \\
\hline
\end{tabular}

Figure 5-2. Schematic of baseline energy uses and wastes at NZE Area.

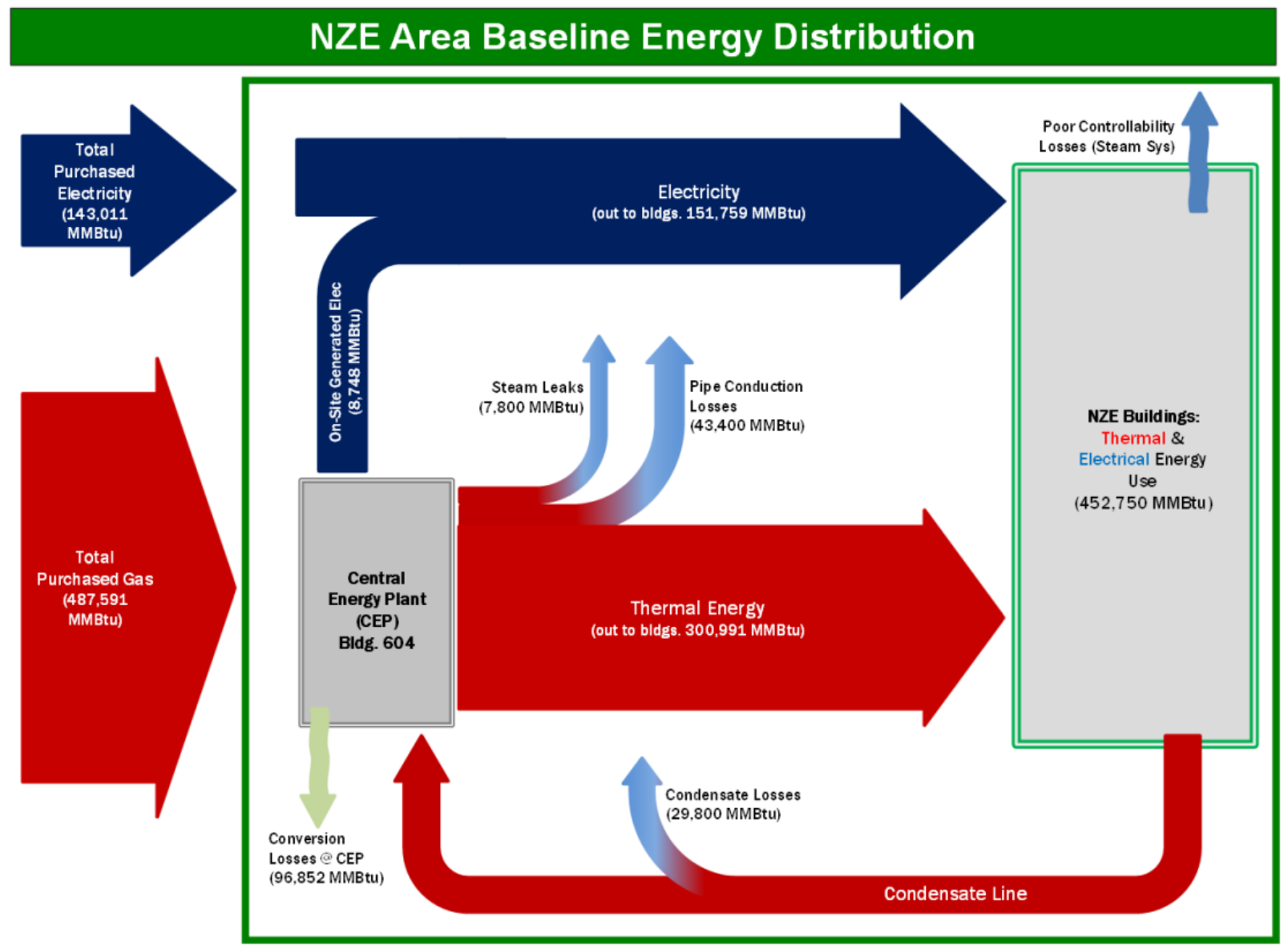


Figure 5-3. NZE Area baseline energy uses and losses.

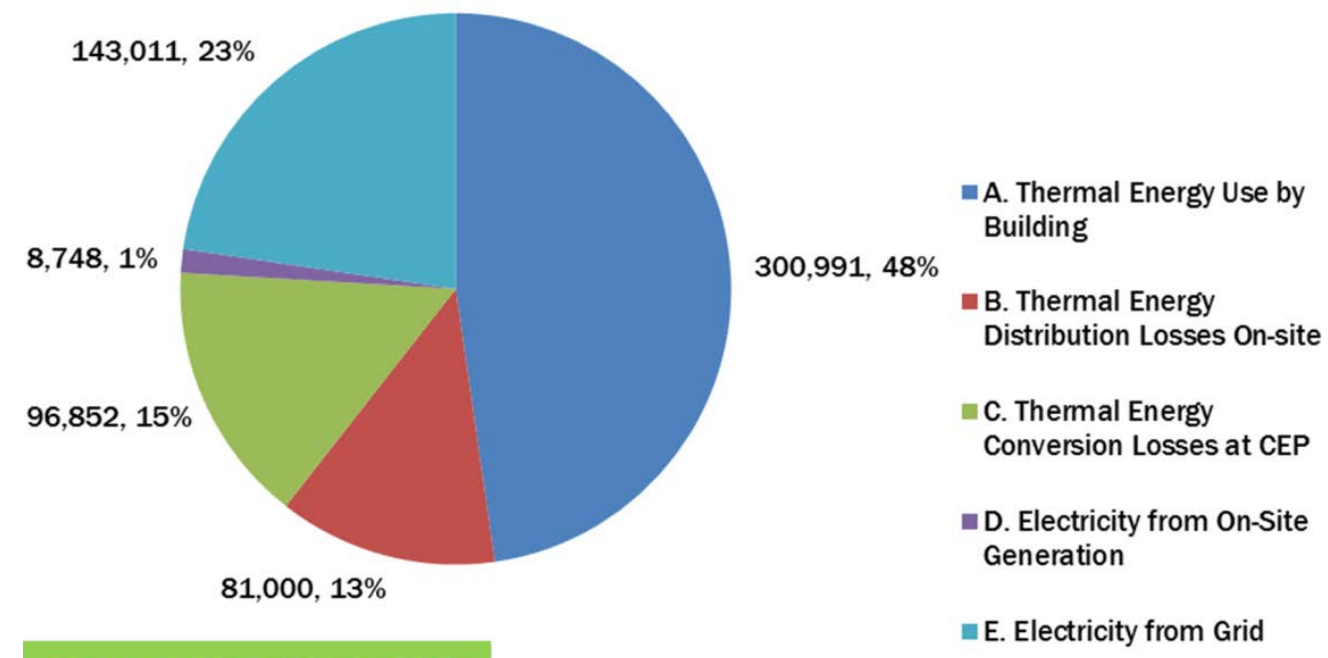

630,602 MMBtu $(184,765 \mathrm{MWh})$

\subsubsection{USMA energy end use - Buildings function}

Forty-four buildings that currently exist in the NZE Area can be divided into 18 building types (not including the CEP Building, which was excluded because it requires very little heating and no cooling throughout the year). Each of the 18 typical building types was modeled for energy use. Based on field survey information and design drawings, the models prescribed the buildings as:

- massive masonry walls with little insulation

- reasonable insulation in the roof

- relatively high air infiltration

- normal lighting levels

- normal use of DHW

- normal occupancy schedule for the building function

- HVAC system selected with normal sizes for equipment.

The results of the model runs provided annual and peak energy use for the HVAC, lighting, DHW, and miscellaneous electrical systems for these buildings. Once the annual energy use and peak energy demand of the typical buildings were estimated in values per square foot of building area, the energy use of the 44 buildings in the NZE Group could be determined. The annual energy use values for each building were estimated by multiplying the energy use per unit of building area for each system by the specific building area. These total values were then compared and adjusted to the 
annual fuel use by the CEP and the peak heating demands on that plant. Tables 5-3 and 5-4 list the adjusted baseline total and peak energy use by the buildings.

Table 5-3. Baseline total energy use by buildings.

\begin{tabular}{|l|l|l|l|l|l|l|l|l|l|}
\hline \multirow{5}{*}{$\begin{array}{l}\text { Gross } \\
\text { Area }\end{array}$} & Cooling & $\begin{array}{l}\text { Other } \\
\text { Electrical } \\
\text { use }\end{array}$ & Total & Space Heat & DHW & $\begin{array}{l}\text { Absorption } \\
\text { Chiller } \\
\text { Heating }\end{array}$ & $\begin{array}{l}\text { Cooking } \\
\text { Heating }\end{array}$ & Total Heating \\
\hline \multirow{5}{*}{ Totals } & sq ft & MMBtu & MMBtu & MMBtu & MMBtu/yr & MMBtu/yr & MMBtu/yr & MMBtu/yr & MMBtu/yr \\
\cline { 2 - 10 }$y$ & $4,447,824$ & 13,873 & 137,885 & 151,759 & 247545 & 23463 & 29810 & 173 & 300991 \\
\cline { 2 - 12 } & $\mathrm{m}^{2}$ & $\mathrm{kWh} / \mathrm{yr}$ & $\mathrm{kWh} / \mathrm{yr}$ & $\mathrm{kWh} / \mathrm{yr}$ & $\mathrm{kWh} / \mathrm{yr}$ & $\mathrm{kWh} / \mathrm{yr}$ & $\mathrm{kWh} / \mathrm{yr}$ & $\mathrm{kWh} / \mathrm{yr}$ & $\mathrm{kWh}$ \\
\cline { 2 - 11 } & 413,648 & 4064889 & $40,400,054$ & $44,464,944$ & $724,811,760$ & $68,699,664$ & $87,283,680$ & 506,544 & $881,301,648$ \\
\hline
\end{tabular}

Table 5-4. Baseline peak energy use by buildings.

\begin{tabular}{|c|c|c|c|c|c|c|c|c|c|c|}
\hline & Gross Area & $\begin{array}{l}\text { Peak } \\
\text { Cooling Load }\end{array}$ & $\begin{array}{l}\text { Peak } \\
\text { Cooling }\end{array}$ & $\begin{array}{l}\text { Peak Other } \\
\text { Electrical }\end{array}$ & $\begin{array}{l}\text { Bldg Peak } \\
\text { Electrical }\end{array}$ & $\begin{array}{l}\text { Peak } \\
\text { Space Heat }\end{array}$ & Peak DHW & $\begin{array}{l}\text { Peak Absorb } \\
\text { Chiller } \\
\text { Heating }\end{array}$ & $\begin{array}{l}\text { Peak } \\
\text { Cooking } \\
\text { Heating }\end{array}$ & $\begin{array}{l}\text { Total Peak } \\
\text { Heating }\end{array}$ \\
\hline \multirow{4}{*}{ Totals } & sq ft & MBtu/hr & Btu/min & Btu/min & Btu/min & MBtu/hr & MBtu/hr & MBtu/hr & MBtu/hr & MBtu/hr \\
\hline & $4,447,824$ & 80213 & 38,990 & 216,979 & 786,179 & 119320 & 5927 & 33020 & 105 & 125247 \\
\hline & $\mathrm{m}^{2}$ & $\mathrm{kWh} / \mathrm{min}$ & $\mathrm{kW} / \mathrm{min}$ & $\mathrm{kW} / \mathrm{min}$ & $\mathrm{kW} / \mathrm{min}$ & $k W h$ & $k W h$ & kWh & $k W h$ & $k W h$ \\
\hline & 413,648 & $234,863,664$ & 4127 & 9685 & 13,812 & $349,368,960$ & $17,354,256$ & $96,682,560$ & 307,440 & $366,723,216$ \\
\hline
\end{tabular}

\subsubsection{USMA conversion and distribution losses}

The gas utility purchase records provided by USMA-DPW for the CEP for 2010 and 2011 state that the CEP consumed an average 5,005,500 ccf of natural gas, or 511,600 MMBtu (149,935 MWh) per year. The results of distribution loss analysis listed in Table 5-5 and shown in Figure 5-4 indicate that the 81,000 MMBtu per year in losses are due to pipe conduction losses, and condensate, steam, and other leaks in the current steam distribution system. Thermal energy is measured via fuel and steam metering. Makeup water is measured directly. Only a small fraction of the makeup water is attributable to boiler blow down.

Table 5-5. Distribution losses from CEP out to buildings.

\begin{tabular}{|l|r|r|}
\hline Distribution Losses & MMBtu/yr & MWh/yr \\
\hline Steam leaks & 7,800 & 2,286 \\
\hline Condensate leakage, condensate pipe conduction losses, and all other losses & 29,800 & 8,734 \\
\hline Pipe conduction losses & 43,400 & 12,719 \\
\hline Total distribution losses: & 81,000 & 23,739 \\
\hline
\end{tabular}


Figure 5-4. Breakdown of distribution losses (MMBtu/yr).

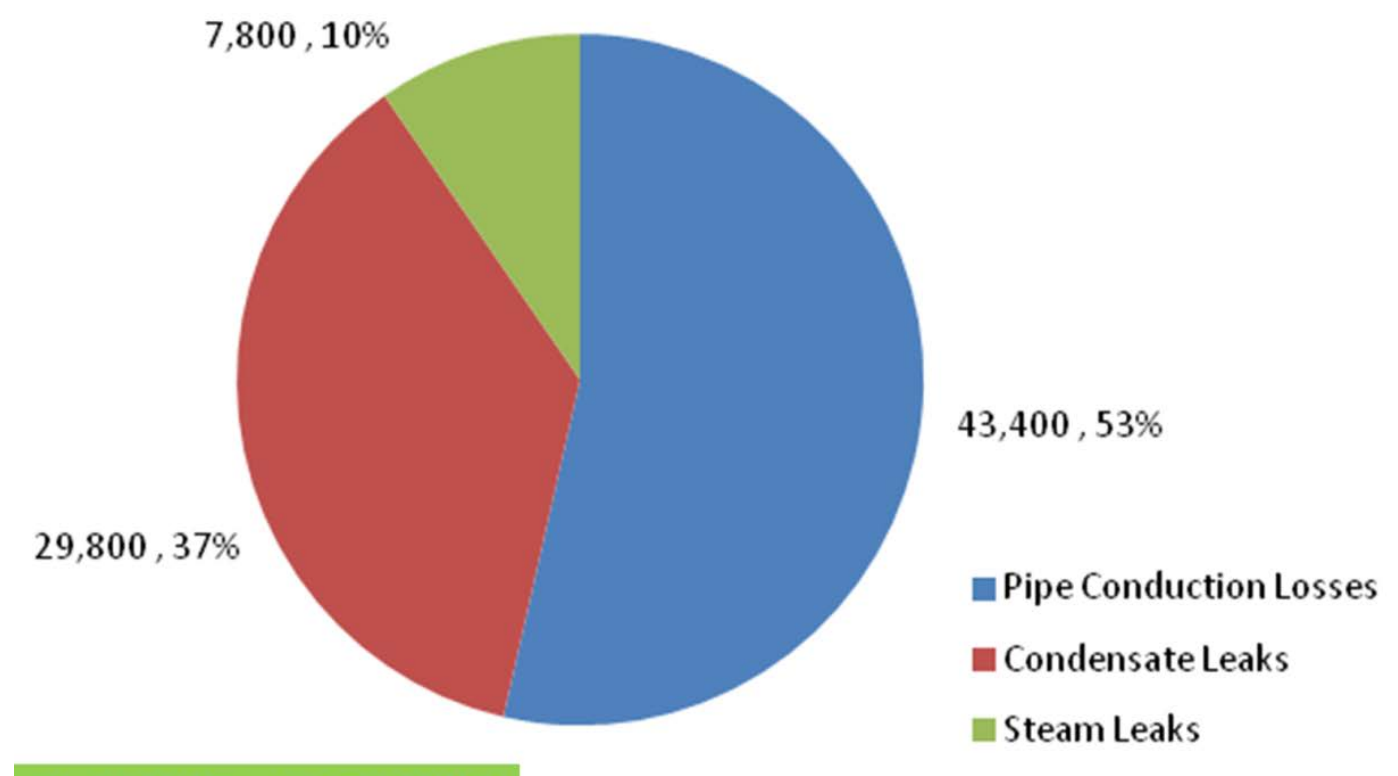

81,000 MMBtu (23,732 MWh)

\subsubsection{Base case and alternatives}

After establishing the baseline, the Base Case and four potential Scenarios were developed for USMA as the long-term energy use reduction solutions for the campus to meet energy goals. Alternatives were selected starting with a historic type of system used at the installation and its modification (district hot and chilled water system) using guidance set forth in a recent Army memorandum (EISA 2007), a decentralized solution, and a variety of options available from the NZP database. Other alternatives were discussed, but not evaluated. Heat pumps, for example, were not feasible at this site because the site is on bedrock, which makes the use of ground source heat pumps cost prohibitive. The criteria used to select these alternatives were total operating costs, LCCs, and sustainability:

- Base Case. The Base Case assumes that the existing situation described in the baseline will be changed only due to already planned projects.

- Alternative 1. Convert steam systems to hot water heating in buildings and decentralize the central boiler system.

- Alternative 2. Convert buildings to hot water heating and reuse existing central boilers to convert steam to hot water.

- Alternative 3. Convert buildings to hot water heating and provide a TriGen System using reciprocal engines to generate electricity and use 
waste heat to provide domestic water heating, winter heating, and summer cooling.

- Alternative 4. Convert buildings to hot water heating and provide a TriGen System using gas and steam turbines to generate electricity and use waste heat to provide domestic water heating, winter heating, and summer cooling.

\subsubsection{Base case}

Compared to the baseline, the Base Case includes the energy impact of the building renovations recently completed or under construction, the planned new barracks building, the energy conservation projects being implemented by an ESPC Contractor, and the planned renovations of the existing nine barracks buildings. The Base Case includes the impact of measures that will be implemented to meet new requirement for summer cooling in all new and renovated barracks. The Base Case scenario can be summarized by the following list of measures:

- CEP will continue to operate with steam distribution.

- Four existing buildings will be renovated over the 2013-2020 period.

- Archive Library, Bartlett Hall, and Arvin Annex will have been renovated.

- ESPC Task Order 1 and Task Order 2 will be implemented.

- Under ESPC contract, Tasks 1 and 2:

- HVAC control systems will be improved and expanded.

- Lighting systems will be upgraded.

- HVAC systems will be upgraded.

- Nine existing barracks will be renovated following the example of Scott Barracks by incorporating:

- High performance building envelope

- A cooling requirement

- Chilled beam and heat recovery dedicated outdoor air supply (DOAS) unit air-conditioning

- Electrical-powered water-cooled chillers

- Energy efficient lighting

- Demand ventilation

- Pool covers and pump controls

- High performance electric motors.

- New cadet barracks will be constructed, including:

- Electrical-powered water-cooled chillers will be incorporated. 
- Heating will be sourced from a central power plant.

- Energy efficient lighting will be incorporated.

- A hot water solar collector system will be incorporated for domestic water heating.

- Emergency natural gas engines will be installed to cover critical electric loads of $61 \mathrm{MMBtu} / \mathrm{hr}(18 \mathrm{MW})$.

Absorption chillers meet the large cooling load of about 9000 tons (316 MWh). The remaining load is met with high efficiency chillers supported with chilled water storage. The absorption chillers cut the peak electrical demand by about $3 \mathrm{MW}$ and the combination of electric chillers and chilled water storage reduce it about another 3 MW. The data in Table 5-6 summarize the Base Case thermal energy use by buildings connected to CEP and electrical energy use in NZE Area. The data in

Table 5-7 and Figure 5-5 denote how the Base Case energy is used in NZE Area.

Table 5-6. Base Case energy cost and usage.

\begin{tabular}{|l|c|c|c|c|c|c|}
\hline \multirow{2}{*}{ Utility } & & & \multicolumn{2}{|c|}{$\begin{array}{c}\text { Source } \\
\text { Energy }\end{array}$} & Site Energy & $\begin{array}{c}\text { Source } \\
\text { Energy }\end{array}$ \\
\cline { 4 - 7 } & Cost & Usage & \multicolumn{2}{|c|}{ MMBtu/yr } & \multicolumn{2}{|c|}{ MWh/yr } \\
\hline Gas & $\$ 2,103,321$ & $2,731,585 \mathrm{ccf}$ & 279,168 & 292,289 & 81,798 & 85,643 \\
\hline Electricity & $\$ 3,087,517$ & $\begin{array}{r}126,960 \mathrm{MMBtu} \\
(37,199,000 \mathrm{kWh})\end{array}$ & 126,961 & 424,050 & 37,199 & 124,245 \\
\hline Totals & $\$ 5,190,838$ & & 406,129 & 716,339 & 118,997 & 209,887 \\
\hline
\end{tabular}

Table 5-7. Base Case energy purchases by distribution within the NZE Area.

\begin{tabular}{|l|r|r|r|}
\hline \multicolumn{1}{|c|}{ Energy Use } & Cost (\$) & MMBtu & MWh/yr \\
\hline A. Thermal energy use by building & $1,266,062$ & 168,041 & 49,237 \\
\hline B. Thermal Energy Distribution Losses On site & 366,164 & 48,600 & 14,240 \\
\hline C. Thermal Energy Conversion Losses at CEP (boiler efficiency @ 80\%) & 426,642 & 56,627 & 16,592 \\
\hline D. Electricity from onsite generation & 44,452 & 5,900 & 1,729 \\
\hline E. Electricity from grid & $3,087,517$ & 126,961 & 37,199 \\
\hline Total purchased energy & $5,190,838$ & 406,129 & 118,997 \\
\hline
\end{tabular}


Figure 5-5. Base Case site energy use.

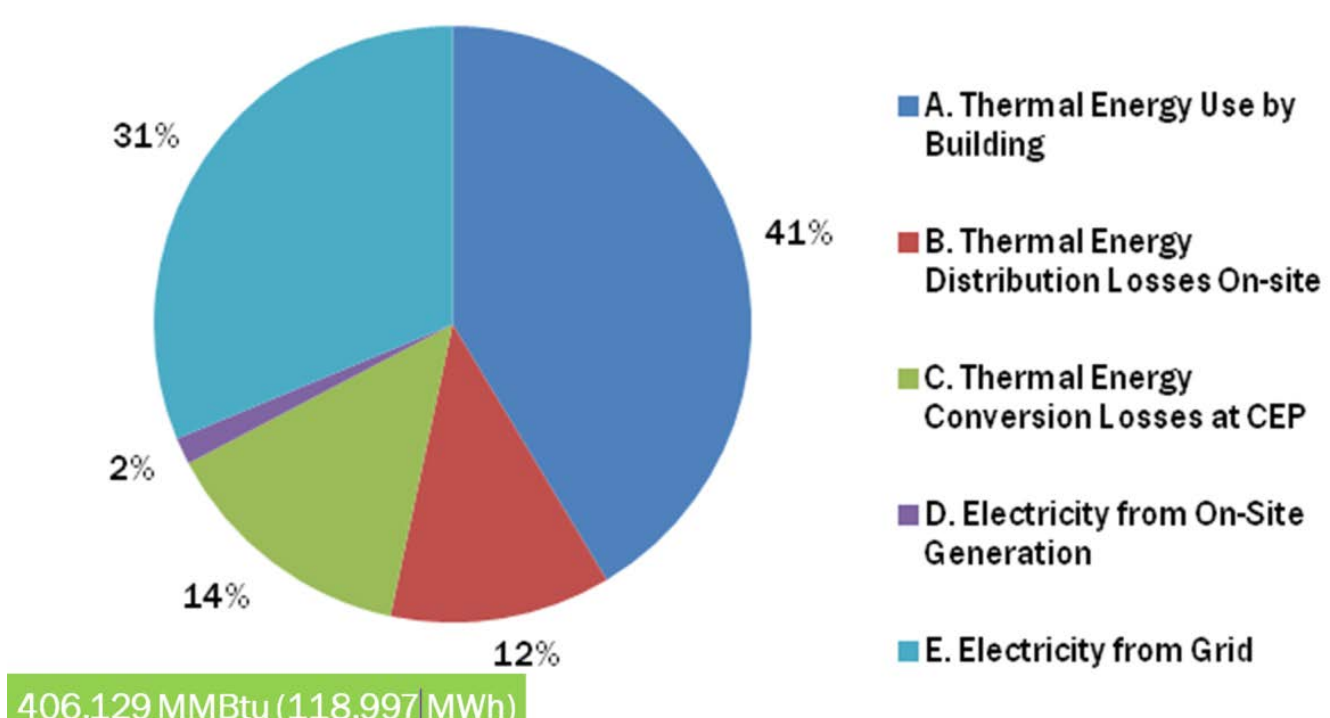

In spite of additional loads due to new construction and new cooling requirements in barracks, energy conservation measures applied to new construction and renovation projects allowed for energy use reduction of both site (34.4\%) and source (26.7\%). Energy cost with the Base Case scenario will be reduced by $26.6 \%$. Energy security issues have not been resolved. Peak load remains close to the grid capacity. To meet the NZE requirement for this area, 724,179 MMBtu (212,236 MWh) must be produced using renewable energy sources.

\subsubsection{Decentralized systems (Alternative 1)}

The Decentralized Systems Alternative was developed to analyze the decommissioning and decentralization of the central energy distribution network in favor of installing individual building systems across the NZE Area. Some spaces may be usable, but flue access would be an issue for the boilers and domestic water heaters. This scenario assumes that a mechani$\mathrm{cal} /$ boiler room/ building will be attached to each building. The cost of each boiler building includes matching the architecture of the adjacent building, and installing two boilers, a domestic water heater, and pumps. The boilers and the water heater will be natural gas fired. To support the new individual systems, a new natural gas (buried) piping distribution system will be required to distribute the gas in sufficient quantity to the buildings. 
The buildings that currently use steam absorption chillers will remain on steam heat. They will not be converted to hot water. Decentralized steam boilers will be installed to serve these buildings. Air-cooled chillers will be provided for all buildings that do not currently have cooling, and they will be added as part of future building upgrades to meet the new cooling requirement.

Eighteen MW of natural gas-fired electrical emergency generation will be provided under this option to serve as emergency backup for the entire USMA, West Point campus. This backup capacity will be generated from three new $20 \mathrm{MMBtu} / \mathrm{hr}$ (6 MW) natural gas-fired engine generators that will be installed near the laundry/ hospital area.

O\&M activities for the decentralized equipment will be much higher than with the CEP options as there will be many more pieces of equipment (boilers) overall in the campus to maintain. Additional maintenance and operational costs will occur for the added chillers and for the emergency generation equipment.

The Decentralized Systems scenario can be summarized by the following list of measures:

- Base Case renovation and new construction projects will be completed.

- Central power plant steam distribution will be shut down.

- Building heat will be provided by individual building natural gas-fired boilers, including:

- New or expanded mechanical/boiler rooms at each building for new boilers

- Some buildings remain on steam to reduce first cost and to be able to use steam for absorption chillers

- Building HVAC and DHW systems that used steam are converted to hot water.

- Buildings requiring new hot water radiators and/ or unit heaters will also receive improved building envelope, including:

- Increased wall and roof insulation

- New or added high efficiency windows.

- Emergency natural gas engines will cover critical electric loads of 61 $\mathrm{MMBtu} / \mathrm{hr}$ (18 MW) installed. 
The breakdown of the total 325,995 MMBtu (95,540 MWh) of energy to be purchased by USMA for the NZE Area within the Decentralized Systems Alternative is:

- Thermal energy used by buildings (154,542 MMBtu [45,292 MWh]: 47.41\%):

- 104,972 MMBtu (30,764 MWh): 32.20\% are heat losses in buildings

- 26,760 MMBtu (7,843 MWh): 8.21\% are used for heat to the absorption chillers for building cooling

- 22,637 MMBtu (6,634 MWh): 6.94\% is used for DHW within buildings

- $173 \mathrm{MMBtu}$ (51 MWh): 0.05\% is used for cooking heat.

- Thermal energy conversion losses in boilers (38,592 MMBtu [11,310 MWh]: 11.84\%).

- Electricity purchased from the grid (132,861 MMBtu (or 38,928 MWh): 40.76\%).

The Decentralized Electrical Annual Consumption for NZE buildings totals $132,828 \mathrm{MMBtu} / \mathrm{hr}$ (38,928 MWh), which is the general demand by buildings and electrical chillers for the NZE Area. The energy associated with emergency electrical generation (natural gas consumption and electricity produced) were not incorporated within the calculated energy use for the Decentralized Systems Alternative. The data in Table 5-8 summarize the Decentralized Heating and Cooling alternative for the NZE Area.

Table 5-8. Summary of the Decentralized Systems conversion alternative.

\begin{tabular}{|c|c|c|c|c|c|c|c|}
\hline \multirow[b]{2}{*}{ Alternative } & \multicolumn{2}{|c|}{ Site Energy } & \multicolumn{2}{|c|}{ Source Energy } & \multirow{2}{*}{$\begin{array}{l}\text { Energy Cost } \\
\text { (\$) }\end{array}$} & \multicolumn{2}{|c|}{ Onsite Power Generation } \\
\hline & MMBtu & MWh & MMBtu & MWh & & Btu & MWh \\
\hline $\begin{array}{l}\text { Decentralized Heating and } \\
\text { Cooling }\end{array}$ & 325,995 & 95,540 & 645,967 & 189,314 & $4,686,143$ & 0 & 0 \\
\hline Baseline & 630,602 & 184,811 & 988,165 & 289,603 & $7,151,497$ & 750,446 & 2,563 \\
\hline \multirow[t]{2}{*}{ Base Case } & 406,129 & 119,025 & 716,339 & 209,938 & $5,190,838$ & 506,251 & 1,729 \\
\hline & & & & \multicolumn{2}{|c|}{ Peak Power } & & \\
\hline Alternative & $\begin{array}{c}\text { Maintenance } \\
\text { Costs }(\$ / y r)\end{array}$ & $\begin{array}{l}\text { Capital Costs } \\
\text { (\$) }\end{array}$ & $\begin{array}{c}\% \text { of Mission } \\
\text { Critical Power } \\
\text { Generated } \\
\text { onsite }\end{array}$ & MMBtu/hr & MW & $\begin{array}{c}\text { Grid } \\
\text { Capability } \\
\text { to meet } \\
\text { Peak Power }\end{array}$ & $\begin{array}{l}\text { LCC } \\
(\$)\end{array}$ \\
\hline $\begin{array}{l}\text { Decentralized Heating and } \\
\text { Cooling }\end{array}$ & $2,344,200$ & $\begin{array}{l}130,788,60 \\
4\end{array}$ & 100 & 57 & 16.8 & 18 & $\begin{array}{l}358,866,11 \\
5\end{array}$ \\
\hline Baseline & $2,455,446$ & - & 0 & 47 & 13.8 & 18 & N/A \\
\hline Base Case & $1,872,823$ & $86,350,800$ & 100 & 57 & 16.8 & 18 & $\begin{array}{l}306,942,54 \\
7\end{array}$ \\
\hline
\end{tabular}


In spite of additional loads due to new construction and new requirement for cooling in barracks, EEMs applied to new construction and renovation projects allowed for energy use reduction both by site (48\%) and by source (35\%) compared to the baseline and energy cost with the Decentralized Heating and Cooling scenario will be reduced by 35\%. Energy security issues will be resolved by installing emergency generator providing 61 MMBtu/hr (18 MW) power capacity. Peak load remains close to the grid capacity.

Compared to the Base Case, additional improvements in buildings related to conversion from steam to hot water heating in buildings will improve efficiency of temperature control in these buildings and thus reduce the heating load. In addition, decentralization will eliminate distribution losses, which will result in a significant reduction in site and source energy and therefore overall energy cost by $\$ 2.5 \mathrm{M}$ or $34 \%$ as compared to the baseline. However, this scenario will require significant additional investments compared to the Base Case, will have a high LCC with a payback exceeding 40 years. To meet the NZE requirement for this area, 645,967 MMBtu (189,314 MWh) must be produced using renewable energy sources.

\subsubsection{Central steam-to-hot water system conversion (Alternative 2)}

According to this scenario, building heating systems and the campus steam piping distribution system will all be converted to a hot water system. The steam piping in the tunnels will be replaced with a pre-insulated steel hot water piping system, which will greatly reduce the piping heat losses and essentially eliminate water makeup as compared to the steam distribution system.

The existing boilers will be used to provide hot water for the system by converting steam to hot water via heat exchangers. The hot water will then be pumped through the central hot water (HW) distribution piping system by circulation pumps to be located within the existing CEP Building.

Air-cooled chillers will be provided for all buildings that do not currently have cooling, and they will be added as part of future building upgrades. 
This option will provide $61 \mathrm{MMBtu} / \mathrm{hr}$ ( $18 \mathrm{MW}$ ) of natural gas-fired emergency electrical generation to serve as emergency backup for the entire USMA, West Point campus. Electrical energy will be generated from three new $20 \mathrm{MMBtu} / \mathrm{hr}$ (6 MW) natural gas-fired engine generators, which will be installed near the laundry/ hospital area.

O\&M activities at the CEP will be slightly more than the existing steam system due to the added heat exchanger and pumps. Maintenance for the HW piping system will be considerably less than the steam piping, primarily due to elimination of the steam traps and to reduction in corrosion and expansion/ contraction within the piping system. (The steam system is down once per year for maintenance.) Operational and maintenance activities of the HW systems at each building will be less than the current steam system. Additional maintenance and operational costs will occur for the added chillers and for the emergency generation equipment. The Central Steam-to-HW System conversion alternative can be summarized by the following list of measures:

- Base Case renovation and new construction projects will be completed.

- Buildings will be converted from steam-to-HW systems.

- Buildings requiring new HW radiators and/ or unit heaters will also receive improved building envelope, including:

- Increased wall and roof insulation

- New or added high efficiency windows.

- Emergency natural gas engines will cover critical electric loads of 61 $\mathrm{MMBtu} / \mathrm{hr}$ (18 MW) installed.

- Steam piping distribution system will be replaced with $\left(200-160{ }^{\circ} \mathrm{F}\right.$, depending on season) HW piping system.

- New electrical chillers will be installed.

The breakdown of the total 310,344 MMBtu (90,953 MWh) of energy to be purchased by USMA for the NZE Area within the Conversion to HW alternative is:

- Thermal energy used by buildings (127,782 MMBtu [37,449 MWh]: 41.17\%):

- 104,972 MMBtu (30,764 MWh): 33.82\% are losses in buildings.

- 22,637 MMBtu (6,634 MWh): 7.29\% is used for DHW within buildings.

- $173 \mathrm{MMBtu}$ (51 MWh): 0.06\% is used for cooking heat. 
- Thermal energy distribution losses onsite (8,565 MMBtu [2,510 MWh]: $2.76 \%)$ :

- 6,710 MMBtu (1,967 MWh): 2.16\% are pipe conduction losses in the distributions lines.

- 1,240 MMBtu (363 MWh): 0.4\% are energy losses with condensate in condensate lines.

- 615 MMBtu (180 MWh): 0.2\% are steam losses in distribution piping.

- Thermal energy conversion losses in boilers and turbines at CEP (36,163 MMBtu [10,598 MWh]: 11.65\%).

- Thermal energy for onsite electricity generation (8,479 MMBtu [2,485 MWh]: 2.73\%).

- Electricity purchased from the grid (129,355 MMBtu [37,910 MWh]: $41.68 \%)$.

The Conversion to HW scenario electrical consumption for NZE buildings totals 11,097,412 Btu/yr (37,901 MWh/yr), which is the general demand by buildings and electrical chillers at the NZE Area. The electrical utility purchase from the grid is reduced by $8,476 \mathrm{MMBtu} / \mathrm{hr}(2,484 \mathrm{MW})$ of electricity that is produced by cogeneration. The natural gas used to cogenerate this electricity totals 8,479 MMBtu (2,485 MWh), which already includes conversion losses that were calculated within the inefficiencies at the CEP. The existing system has a steam turbine that steps the pressure down from 160 psig to 15 psig. Less steam demand from the energy improvements results in less electricity being generated. Since it is not known how much the emergency generation will have to run, no fuel was included in any option for the emergency electrical generation. The 18MW is emergency backup only. The energy associated with emergency electrical generation (natural gas consumption and electricity produced) were not incorporated within the calculated energy use for this alternative.

Table 5-9 summarizes the Central Steam-to-HW System conversion alternative for the NZE Area. 
Table 5-9. Summary of the Central Steam-to-HW System conversion alternative.

\begin{tabular}{|c|c|c|c|c|c|c|c|c|c|c|c|}
\hline & Site Energy & $\begin{array}{l}\text { Source } \\
\text { Energy } \\
\text { (MMBtu) }\end{array}$ & $\begin{array}{c}\text { Energy } \\
\text { Cost }\end{array}$ & $\begin{array}{c}\text { Onsite } \\
\text { Power } \\
\text { Generation }\end{array}$ & $\begin{array}{c}\text { Maintenance } \\
\text { Costs }\end{array}$ & $\begin{array}{l}\text { Capital } \\
\text { Costs }\end{array}$ & $\begin{array}{c}\% \text { of } \\
\text { Mission } \\
\text { Critical } \\
\text { Power } \\
\text { Generated } \\
\text { Onsite }\end{array}$ & $\begin{array}{l}\text { Peak } \\
\text { Power }\end{array}$ & $\begin{array}{c}\text { Grid } \\
\text { Capability } \\
\text { to Meet } \\
\text { Peak } \\
\text { Power }\end{array}$ & LCC & $\begin{array}{l}\text { SPB/ } \\
\text { DPV }^{*}\end{array}$ \\
\hline Alternative IP & MMBtu & MMBtu & (\$) & (Btu) & $(\$ / y r)$ & (\$) & & MMBtu/hr & & (\$) & \\
\hline $\begin{array}{l}\text { Central Steam- } \\
\text { to-HW } \\
\text { Conversion }\end{array}$ & 310,344 & 621,541 & $4,509,399$ & 727,315 & $1,466,000$ & $\begin{array}{l}104,772,60 \\
4\end{array}$ & 100 & 61 & 18 & $299,154,506$ & $\begin{array}{l}17 / 2 \\
4\end{array}$ \\
\hline Baseline & 630,602 & 988,165 & $7,151,497$ & 750,446 & $2,455,446$ & N/A & 0 & 47 & 18 & N/A & N/A \\
\hline Base Case & 406,129 & 716,339 & $5,190,838$ & 506,251 & $1,872,823$ & $86,350,800$ & 100 & 57 & 18 & $306,942,547$ & N/A \\
\hline
\end{tabular}

In spite of additional loads due to new construction and to the new requirement for barracks cooling, EEMs applied to new construction and renovation projects will reduce site energy by $50.8 \%$ and source energy by $37 \%$, compared to the baseline. The conversion from steam to hot-water system will reduce energy costs by $37 \%$. Energy security issues will be resolved by installing emergency generator providing $61 \mathrm{MMBtu} / \mathrm{hr}$ (18 MW) power capacity. Peak load remains close to the grid capacity.

Compared to the Base Case, this scenario will have the following benefits:

- lower installed cost, no steam traps to maintain, lower cost pipe, and less expansion

- reduced heat loss because $200{ }^{\circ} \mathrm{F} \mathrm{HW}$ has a lower temperature than 160 psig steam*

- reduced heat loss because lower supply temperature allows more efficient insulation to be used

- lower maintenance costs for HW because steam traps are not used and there will be less corrosion due to closed piping system

- closed HW system with a longer life than a steam system

- improved efficiency of temperature control in buildings and thus reduced heating load.

This scenario will require additional investments compared to the Base Case, but will have lower LCC with a simple payback of 17 years. To meet

\footnotetext{
* The hot water distribution system will operate in the 160 to $230{ }^{\circ} \mathrm{F}$ temperature range depending on the season. There are two system pressures. Low pressure is distributed at $12 \mathrm{psig}\left(\sim 240^{\circ} \mathrm{F}\right)$ and serves buildings near the CEP. High pressure, which serves the entire NZE, is at $160 \mathrm{psig}\left(\sim 370^{\circ} \mathrm{F}\right)$.
} 
the NZE requirement for this area, 621,541 MMBtu (182,156 MWh) must be produced using renewable energy sources.

\subsubsection{Central steam-to-trigeneration system conversion Scenario} (Alternatives 3 and 4)

The Trigeneration Scenario includes Alternative 3 (with reciprocal engines) and Alternative 4 (with gas turbine).

Similar to Conversion to HW alternative in Alternatives 3 and 4, the following measures will be implemented:

- Base Case renovation and new construction projects will be completed.

- Buildings will be converted from steam-to-HW heating systems.

- Buildings requiring new HW radiators and/ or unit heaters will also receive improved building envelope.

- Wall and roof insulation will be increased.

- New high efficiency windows will be installed.

- Steam piping distribution system will be replaced with HW piping system.

In this scenario, thermal piping losses are significantly reduced compared to the Base Case. The steam piping in the tunnels would be replaced with a pre-insulated steel HW piping system that would greatly reduce the piping heat losses and essentially eliminate heating medium losses.

Alternatives 3 and 4 differ from Alternative 2 in that both TriGen scenarios generate heat and electricity at the CEP location and all cooling needs are provided from one of three central chilled water plants. The TriGen options require central chiller plants to take advantage of the HW for generating chilled water with absorption chillers. It was decided that it was more economical to provide three plants to minimize the piping distribution costs.

The campus space and DHW demand for space and DHW heating is the controlling factor for operation of the TriGen system. The HW requirements during summer and winter push the TriGen electrical generation past what is required for the NZE campus. During these times, excess electricity can be sold back to the grid. During peak heating periods, which can occur during the months of December, J anuary, and February, the heating 
load is beyond what CHP generation equipment can provide. During these periods, the existing boilers are used to supplement the HW load to the campus. In the spring and fall, the heating and cooling loads and the corresponding electrical generation decrease. During these times, additional electricity from the grid will be required to meet the campus needs. The waste heat available from CHP generation provides considerably more cooling with absorption chilling in these options than in the Base Case or the decentralized option.

\subsubsection{Alternative 3}

Conversion of the CEP to the TriGen Engine system will require considerable modification of the CEP to accommodate the needed space and structural improvements for the new equipment (Figure 5-6). The CEP (Building 604) will undergo demolition and complete refurbishment at an estimated cost of $\$ 4,500,000$. The existing steam turbine generators will be removed. Leadership in Energy and Environmental Design (LEED) costs were not considered in the cost estimate. Demolition costs considered the recycling value of the steel.

According to manufacturer cost information, development of a cogeneration plant within the CEP has a total cost of $\$ 29,000,000$. This includes three $14 \mathrm{MMBtu} / \mathrm{hr}$ (4 MW) generators with corresponding HW heat exchangers, which have the capacity to meet the mission critical 41 MMBtu/hr (12 MW) demand. An area north of the existing steam boilers will be cleared and prepared for locating the steam-to-HW heat exchangers. Conversion of the CEP heat exchangers and pumps will cost a total of $\$ 2,000,000$. The low-pressure steam from the steam turbine generators in the CEP will be converted to HW to be distributed to the campus. The redundant pumps and heat exchangers will be located in the CEP on the north side of the existing steam boilers. One less heat exchanger will be required as compared to the HW conversion option because the heat exchangers with the generator will provide redundancy.

New centrifugal electric chillers at the New Cadet Barracks and CEP are to replace existing electric chillers with increased capacity at a cost of $\$ 8,450,000$. The existing electric and absorption chillers would be removed and replaced with larger capacity absorption chillers and electric chillers. A chilled water storage tank is provided to allow for generation of 
chilled water at night for use during the day. This reduces the chiller plant capacity requirements, matches the heating load with the cooling load, and reduces the electrical demand of the NZE campus. The absorption chillers will be sized to take full advantage of the generator waste heat. The electric chillers with chilled water storage tanks will be sized to pick up the remaining chilled water capacity requirement. (Capacity is increased because the study assumes that the dorm air-conditioning is on during the day.) This cost is based on listed manufacturer costs, budget costs, and TKDA (a PERTAN subcontractor) experience associated with replacement of these systems. A centrifugal electric chilled water plant with cooling tower will be provided on the north campus to reduce the required district energy chilled water piping cost and located at Bldg 655, Eisenhower Hall, for a cost of $\$ 3,549,000$.

New absorption chillers with increased capacity will replace existing absorption chillers at a cost of $\$ 11,830,000$. The absorption chillers are sized to use the full amount of waste heat from the generators in the summer and take advantage of the chilled water storage tank, which will double the chiller cooling capacity by storing chilled water at night. The electric chillers are sized to fill the gap between the absorbers and the total cooling load. This cost is based on manufacturer budget costs and architect-engineer firm experience associated with replacement of these systems.

In addition to the improvements at the CEP and Conversion to $\mathrm{HW}$, both a $\mathrm{HW}$ and chilled water storage tank will be constructed on the campus as well as a chilled water distribution system. A 400,000-gal (1,514,000 L) HW storage tank is to be constructed to match the heating load with the electrical load. With the added electrical generation capacity of the CHP system, the CEP will require an electrical upgrade to improve service and capacity. The TriGen system generation efficiency in Alternative 3 is approximately $80 \%, 43 \%$ for electrical generation and $37 \%$ for heat recovery. Thermal losses are lower compared to the Base Case in the HW loop due to its lower operating temperature and the use of more efficient thermal insulation. Waste heat from the reciprocating gas engines is used primarily for domestic water heating, building heating in the winter, and absorption chiller cooling in the summer. 


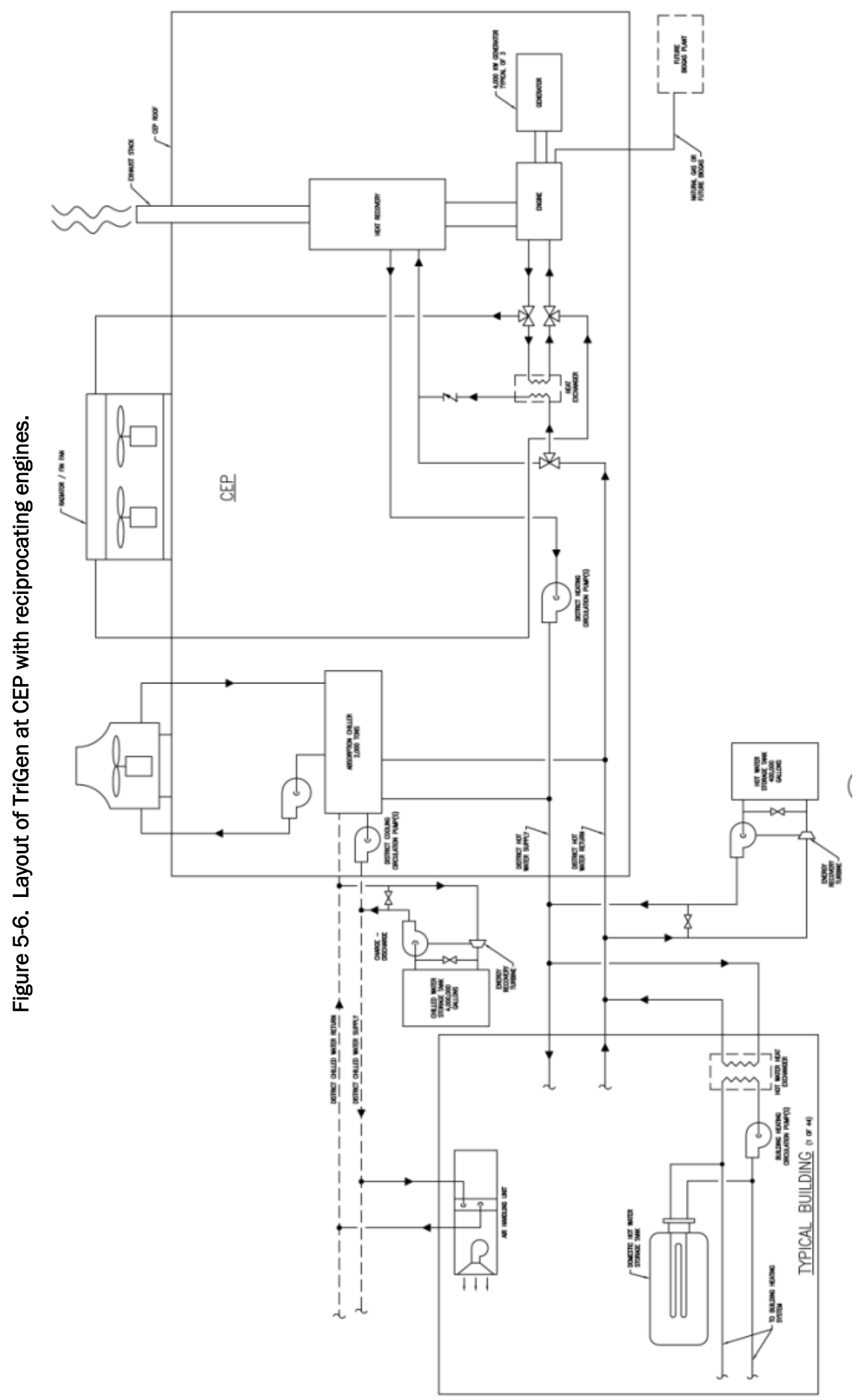




\subsubsection{Alternative 4}

The Combined Cycle Gas Turbine Generator alternative uses two 15 $\mathrm{MMBtu} / \mathrm{hr}$ (4.5 MW) natural gas turbine engine generators to provide the bulk of the electrical generation requirement. The natural gas turbine generator will generate electricity at an efficiency of 30 to $35 \%$. The hot combustion exhaust gases from the turbine are sent to a heat recovery steam generator to generate about $1200 \mathrm{psig}(8,273 \mathrm{kPa})$ steam. Duct burners can be included in the heat recovery steam generator to increase the steam output to meet peak heating demands, to increase the steam turbine output, or with the inclusion of a fresh air fan to create steam without the combustion turbine in operation. The steam from the generator is then used in a steam turbine generator to create up to an additional 10 $\mathrm{MMBtu} / \mathrm{hr}$ (3 MW) of electrical power.

The steam generator will boost the overall system electrical efficiency to about $45 \%$. The steam exits the steam turbine at about $10 \mathrm{psig}(69 \mathrm{kPa})$ and is converted to HW. The heat from the HW is then used throughout the campus for building heat, domestic water heating, and absorption cooling.

A combined cycle electrical generation system could be fit into the existing CEP by installing two $15 \mathrm{MMBtu} / \mathrm{hr}$ (4.5 MW) gas turbine generators with associated heat recovery steam generation (HRSG) in the existing turbine generator room. However, there would not be room available for supplementary burners in this arrangement, so it will be necessary to maintain two of the existing boilers for peak heating and backup. Boiler \#3 would need to be removed to provide space for the steam turbine generator. The steam-to-hot-water heat exchangers and corresponding pumps will be located in the northeast corner of the boiler plant as is proposed for the engine generator option.

The main benefit of a natural gas turbine combined cycle electrical generation system is the lower maintenance requirement as compared to a reciprocating engine generator. A turbine generator needs regular inspection of the turbine blades, but only replacement when worn (which can exceed 100,000 operating hours). This directly explains why the maintenance costs of a turbine generator are so much less than a reciprocating engine generator. 
This system requires more space than the engine generators as the combustion turbine and heat recovery generator layouts are longer and for the inclusion of the steam turbine generator. The additional stage along with the extra sophistication of the equipment results in the combined cycle system being more expensive then the natural gas engine generators. The other important limitation of the natural gas turbine is that it cannot use syngas (as the alternative renewable fuel) without considerable cleaning of the gas. A high speed turbine wheel will simply not tolerate impurities in the supply gas, which will either cause wear on the turbine blades leave or deposits on the blades. Syngas scrubbing equipment is expensive and requires substantial space (and open space is scarce at CEP).

Conversion of the CEP to the TriGen Gas Turbine system will require considerable modification of the CEP to accommodate the needed space and structural improvements for the new equipment (Figure 5-7). The CEP will undergo demolition and complete refurbishment at a cost of $\$ 5,500,000$. The existing steam turbine generators will be removed.

According to manufacturer cost information, the development of the cogeneration plant within the CEP has a total cost of $\$ 56,000,000$. This includes two natural gas turbine generators at $15 \mathrm{MMBtu} / \mathrm{hr}$ (4.5 MW) each with corresponding high-pressure steam boilers, and one steam turbine generator at $10 \mathrm{MMBtu} / \mathrm{hr}$ (3 MW), pollution controls, steam-to-hot-water heat exchanger, pumps, and other auxiliary equipment. These turbines produce $41 \mathrm{MMBtu} / \mathrm{hr}(12 \mathrm{MW}$ ) to meet the mission critical $41 \mathrm{MMBtu} / \mathrm{hr}$ (12 MW) demand. An area north of the existing steam boilers will be cleared and prepared for locating the steam-to-HW heat exchangers. The conversion of the CEP heat exchangers and pumps will cost a total of $\$ 2,000,000$. The low-pressure steam from the steam turbine generators in the CEP will be converted to HW to be distributed to the campus. The redundant pumps and heat exchangers will be located in the CEP near the existing steam boilers. One less heat exchanger will be required as compared to the HW conversion option because the heat exchangers with the generator will provide redundancy.

In spite of additional loads due to new construction and to the new requirement for barracks cooling, EEMs applied to new construction and renovation projects will reduce energy by site (31.1\%) and by source (81.6\%), compared to the baseline. Alternative 3 will reduce energy costs 
by $82.2 \%(\$ 5,879,607)$. Alternative 4 will reduce energy costs by $84 \%$ $(\$ 6,008,850)$. Onsite electricity generation will resolve energy security issues in the amount required for mission critical facilities (12MW). Peak load remains close to the grid capacity. Compared to the Base Case, both TriGen alternatives of this scenario will have the following benefits:

- reduced heat losses because HW has a lower temperature than steam

- reduced heat loss because lower supply temperature allows more efficient insulation to be used

- lower maintenance costs for HW because steam traps are not used

- an HW system that has a longer life than a steam system because it is a closed system

- improved efficiency of temperature control in buildings and thus reduced heating load (due to a $10 \%$ savings resulting from the use of improved controls).

Alternatives 3 and 4 will both require additional investments compared to the Base Case, but will have lower LCC (simple payback of 10 years with Alternative 3, and 16 years with Alternative 4). To meet the NZE requirement for this area, 181,457 MMBtu/yr (53,180 MWh/yr) must be produced using renewable energy sources with Alternative 3 and 162,624 MMBtu/yr (47,660 MWh/yr) with Alternative 4.

As a substitute for some portion of natural gas in Alternative 3, syngas could bring USMA's Central area to source NZE when it becomes economically feasible. If used, syngas would be produced from woodchips onsite at USMA in the area available close to the CEP. Alternative 3 will sometimes generate surplus electrical power, which can be shared with the rest of the USMA cantonment area or sold to the grid. 


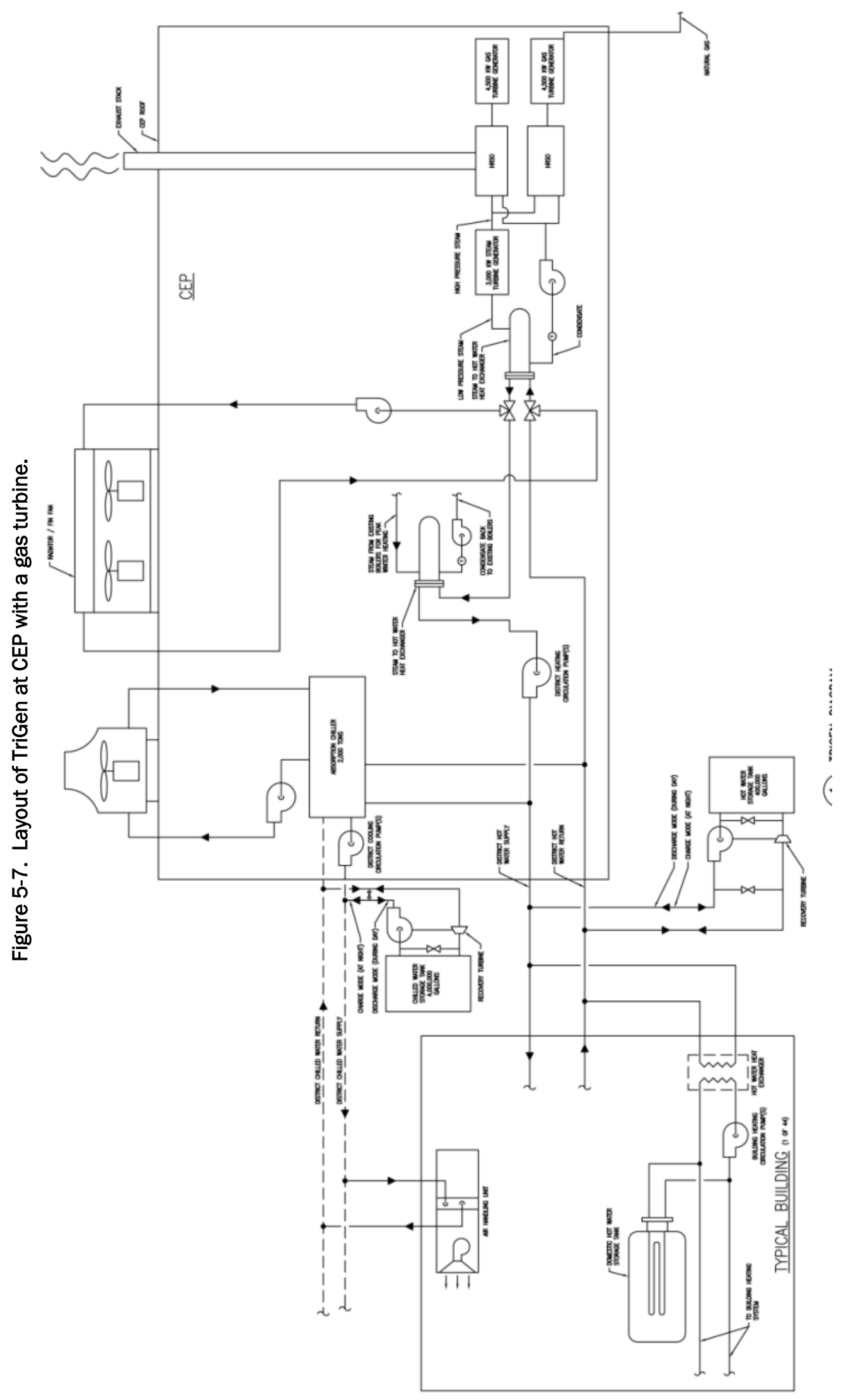




\begin{tabular}{|c|c|c|c|c|c|c|}
\hline $\begin{array}{l}\text { à } \\
\stackrel{0}{0} \\
\text { o. } \\
\text { क }\end{array}$ & $\stackrel{0}{\overbrace{}^{+}}$ & \begin{tabular}{l}
\multirow{N}{N}{} \\
\multirow{-}{*}{}
\end{tabular} & 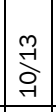 & 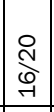 & $\frac{\pi}{z}$ & $\frac{\pi}{z}$ \\
\hline 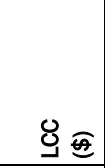 & $\begin{array}{l}\text { ln } \\
7 \\
0 \\
0 \\
\infty \\
\infty \\
\infty \\
0 \\
0\end{array}$ & 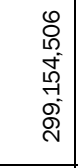 & 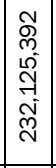 & 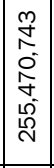 & $\frac{\pi}{z}$ & 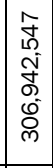 \\
\hline 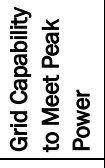 & $\stackrel{\infty}{\sim}$ & $\stackrel{\infty}{\sim}$ & $\stackrel{\infty}{\sim}$ & $\stackrel{\infty}{\sim}$ & $\stackrel{\infty}{\sim}$ & $\stackrel{\infty}{\stackrel{\infty}{*}}$ \\
\hline 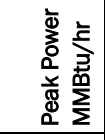 & in & $\overrightarrow{0}$ & $\vec{\gamma}$ & $\vec{\forall}$ & $\stackrel{\vec{H}}{\dot{\sigma}}$ & $\stackrel{m}{\stackrel{m}{i n}}$ \\
\hline 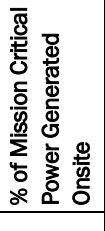 & 엄 & $\underset{ন}{\stackrel{8}{1}}$ & 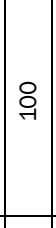 & $\underset{\sim}{\stackrel{-}{2}}$ & 0 & $\underset{-1}{8}$ \\
\hline 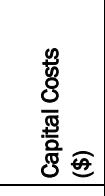 & $\begin{array}{l}1 \\
0 \\
0 \\
\infty \\
\infty \\
2 \\
0 \\
-9\end{array}$ & $\begin{array}{l}0 \\
0 \\
0 \\
N \\
N \\
0 \\
0 \\
0\end{array}$ & 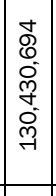 & 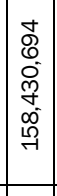 & & $\begin{array}{l}0 \\
\infty \\
\infty \\
0 \\
0 \\
0 \\
0 \\
\infty \\
\infty\end{array}$ \\
\hline 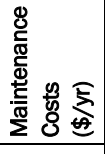 & 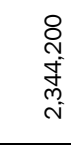 & $\begin{array}{l}8 \\
8 \\
i \\
0 \\
i \\
i\end{array}$ & 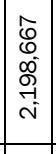 & $\begin{array}{l}\infty \\
\infty \\
0 \\
\infty \\
o \\
o \\
\rightarrow \\
-\end{array}$ & 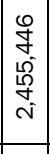 & $\begin{array}{l}0 \\
\infty \\
\infty \\
\mathbb{N} \\
\infty \\
-1 \\
-1\end{array}$ \\
\hline 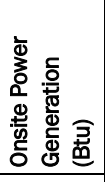 & 0 & $\begin{array}{l}\stackrel{n}{0} \\
\stackrel{N}{N} \\
\stackrel{N}{N}\end{array}$ & 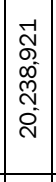 & 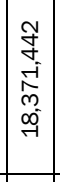 & 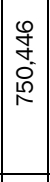 & 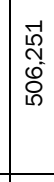 \\
\hline 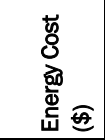 & 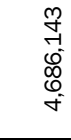 & $\begin{array}{l}\stackrel{8}{0} \\
0 \\
8 \\
8 \\
\circ \\
\dot{+}\end{array}$ & 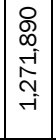 & 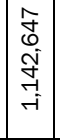 & 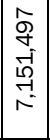 & $\begin{array}{l}\infty \\
0 \\
0 \\
0 \\
0 \\
0 \\
-1 \\
i 5\end{array}$ \\
\hline 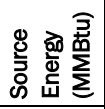 & 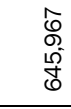 & 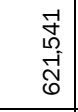 & 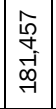 & 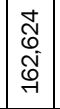 & \begin{tabular}{|l|}
$\qquad$ \\
0 \\
$o$ \\
$\infty$ \\
$\infty$ \\
$\sigma$ \\
\end{tabular} & $\begin{array}{l}\text { O } \\
0 \\
0 \\
0 \\
i \\
i\end{array}$ \\
\hline 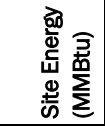 & 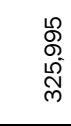 & 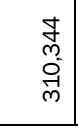 & \begin{tabular}{|c|}
$\infty$ \\
0 \\
0 \\
$\tilde{p}$ \\
$\tilde{y}$ \\
\end{tabular} & 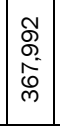 & $\begin{array}{l}0 \\
0 \\
0 \\
0 \\
0 \\
0\end{array}$ & 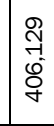 \\
\hline 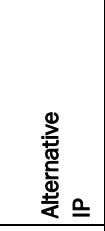 & 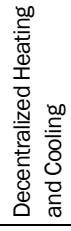 & 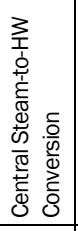 & 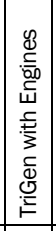 & 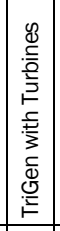 & 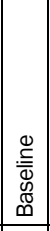 & $\begin{array}{l}\mathscr{8} \\
\mathbb{0} \\
0 \\
0 \\
0 \\
0 \\
\infty \\
\infty\end{array}$ \\
\hline 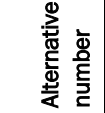 & $-\gamma$ & N & m & $\sigma$ & & \\
\hline
\end{tabular}




\subsubsection{Analysis of results}

In spite of additional loads due to new construction and new requirement for cooling in barracks, all scenarios, the Base Case, and four alternatives significantly reduce energy use. Compared to the baseline, the alternatives reduce energy use from 31 to $51 \%$ for site energy, and from 27 to $84 \%$ for source energy. They reduce energy costs from 27 to $84 \%$ (Figure 5-8a,b).

The greatest site energy reduction ( $\sim 50 \%$ ) can be achieved with conversion to a HW System and Decentralized Systems, followed by the TriGeneration Using Turbines scenario ( $42 \%$ site energy reduction). However, only the TriGeneration alternatives allow for a significant source energy reduction (82 to $84 \%$ ) with a significant (> 80\%) energy cost reduction

All scenarios (excluding the Base Case) will resolve energy security issues. However, Decentralized and Conversion to HW alternatives will require purchase of additional generators, while both TriGen alternatives will reduce the total power demand for mission critical facilities from 61 to 41 MMBtu/hr (18 to $12 \mathrm{MW}$ ) (due to use of higher efficiency central chillers and chilled water storage) and will provide $100 \%$ of electrical demand with onsite power generation.

The TriGeneration options using a combination of gas and steam turbines have the highest investment costs. The Decentralized and TriGeneration Using Reciprocal Engines alternatives have the second highest investment costs. TriGen Engine Alternative 3 has the lowest LCC with the simple payback of 10 years and a discounted payback of 13 years, followed by Alternative 4 (TriGen with gas and steam turbines). To meet the NZE requirement, the Base Case, Decentralized, and HW System alternatives will require onsite power generation using photovoltaic (PV) energy generation in an amount that will vary between 621,541 and 716,339 MMBtu/yr (182,156 and 209,938 MWh/yr).

Both TriGeneration alternatives will provide onsite power generation for mission critical facilities. They will result in a significant site energy reduction (31\% with Alternative 3 and $42 \%$ with Alternative 4 ) and an outstanding fossil fuel based energy use reduction ( $82 \%$ and $84 \%$ respectfully).

Among TriGeneration scenarios, an important benefit of Alternative 4, which combines a natural gas turbine with a cycle electrical generation 
system, is its lower maintenance requirement as compared to a reciprocating engine generator. However, Alternative 4 has a significantly higher investment cost and requires more area than the engine generators.

Figure 5-8. Comparison of all alternatives to the baseline: (a) site, source, and costs as a percentage, (b) types of energy used.

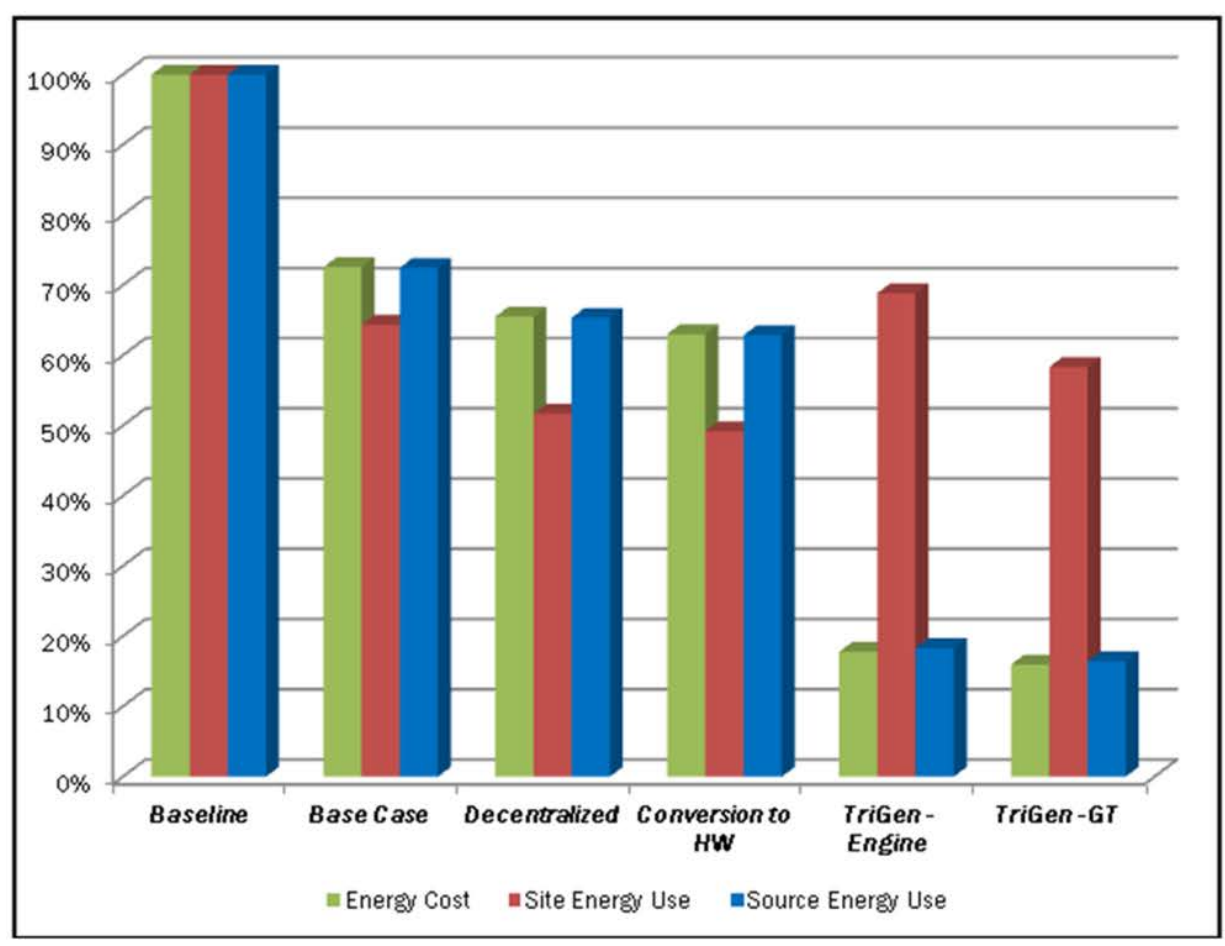

(a)

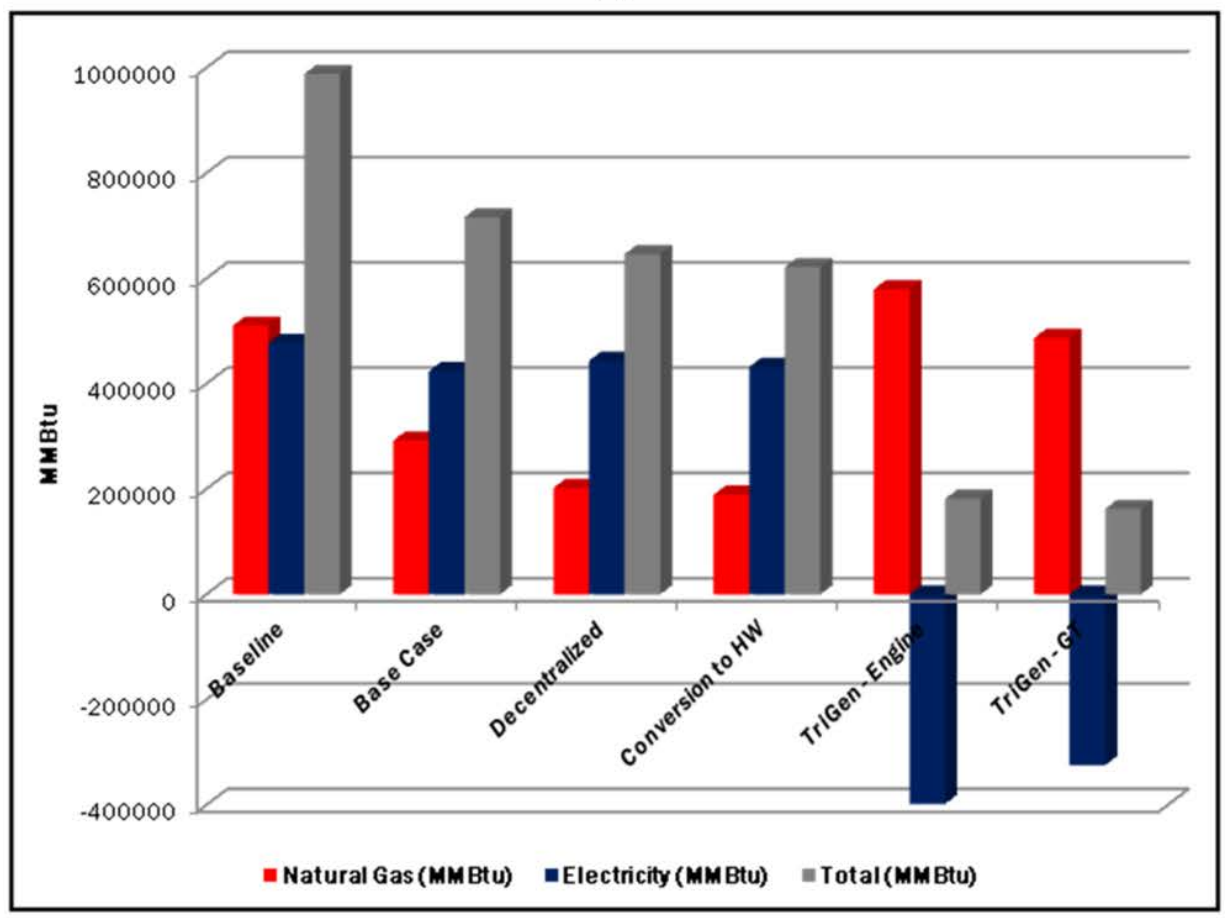

(b) 
The substitution of syngas for natural gas (produced locally from imported biomass) as a fuel in Alternative 3 makes the selected area an NZE Area, and also a net positive energy area. Alternative 3 will sometimes generate surplus electrical power, which can be shared with the rest of the USMA cantonment area or sold to the grid.

Based on technical and economical merits, Alternative 3 is the most fitting selection, as it meets all energy goals (including the potential for NZE) and has the lowest LCC and an attractive return on investment with a simple payback of 10 years.

\subsubsection{Implementation strategy}

The complexity of the project with a significant construction budget of $\$ 130,430,694$ requires its phased implementation. Based on discussions with DPW with, the proposed Trigeneration Scenario (Alternative 3) is recommended to be implemented in the following order:

- Install one 4 MW CHP engine to meet infrastructure limitations.

- Install absorption chillers in CEP.

- Convert existing steam distribution system to HW and add chiller distribution piping.

- Convert remaining buildings from steam-based to HW-based heating systems.

- Install additional two 4 MW CHP engine in CEP and upgrade CEP existing infrastructure to connect with main substation.

- Install additional HW absorption chillers at two other locations.

- Install additional emergency generators (if needed) to fill-in the capacity gap.

- Construct liquefied natural gas (LNG) station as an emergency backup for energy security as an option.

- Construct syngas plant to replace natural gas (when the syngas price becomes cost competitive).

Figures 5-9 and 5-10 show the implementation schedule for the Trigeneration Scenario. 
Figure 5-9. Implementation schedule for Trigeneration Scenario (Alternative 3).

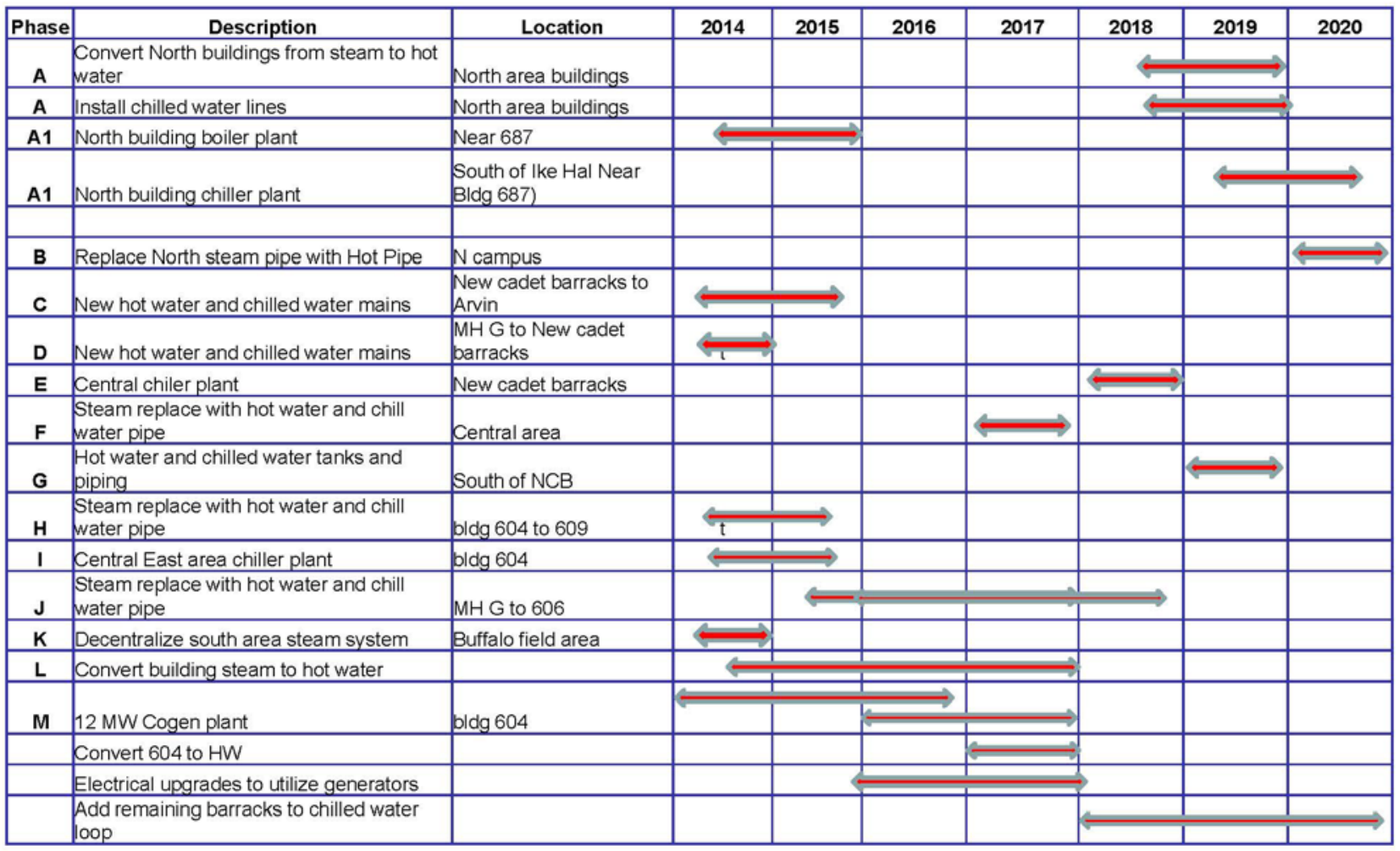

Figure 5-10. Implementation phases for Trigeneration Scenario (Alternative 3).

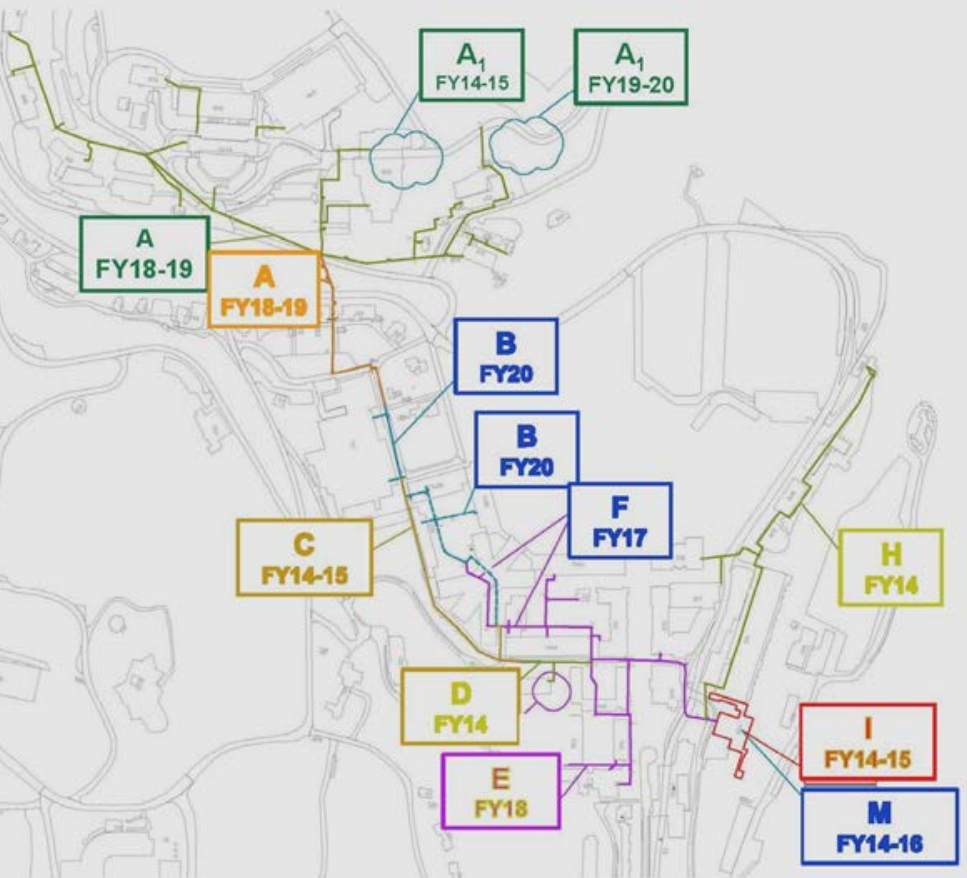




\subsubsection{Modeling of USMA in Net Zero Planner}

As described Chapter 4, for the test at USMA, the SMEs did their analysis first, then the analysis was done using the NZP Tool so that the NZP team could test to see if similar results could be obtained. Both the SME team and the NZP team used an overlapping set of data, with the NZP team also requiring GIS data. Chapter 2 described the process in some detail, so this section will focus on key segments of the process.

\subsubsection{Importing facilities}

Facility data were imported from a Spatial Data Standards for Facilities, Infrastructure, and Environment (SDS/ FIE) compliant GIS database [SDSFIE 2015], augmented by Real Property Inventory data from General Fund Enterprise Business System (GFEBS) (Figure 5-11). The baseline central area was modeled as 45 buildings in 11 groups (Figure 5-12), while the Base Case included 46 buildings in 11 groups (Figure 5-13). One building was split into two for modeling purposes, so the NZP run has one more building than the SME run, but the same area. During modeling, a technique was developed to represent a deep energy retrofit (DER) of existing buildings. The EEM packages used by NZP represent existing buildings and new buildings differently. Existing buildings are generally limited in the extent to which EEM packages can be applied. New buildings represent a clean slate from a design point of view, with a larger number of EEM package options available. When a building goes through a DER, however, much more extensive EEM packages can be applied than with an existing building, especially with respect to the building's envelope. The NZP team developed a technique to address DER by marking existing buildings as "Demolish" and substituting a "Planned" building of the same type, but built to a modern standard in its place. In this way, a larger variety of EEMs are available and the NZP SME can assess the depth of the expected DER and choose appropriate EEMs. 
Figure 5-11. USMA facilities brought into NZP from GIS.

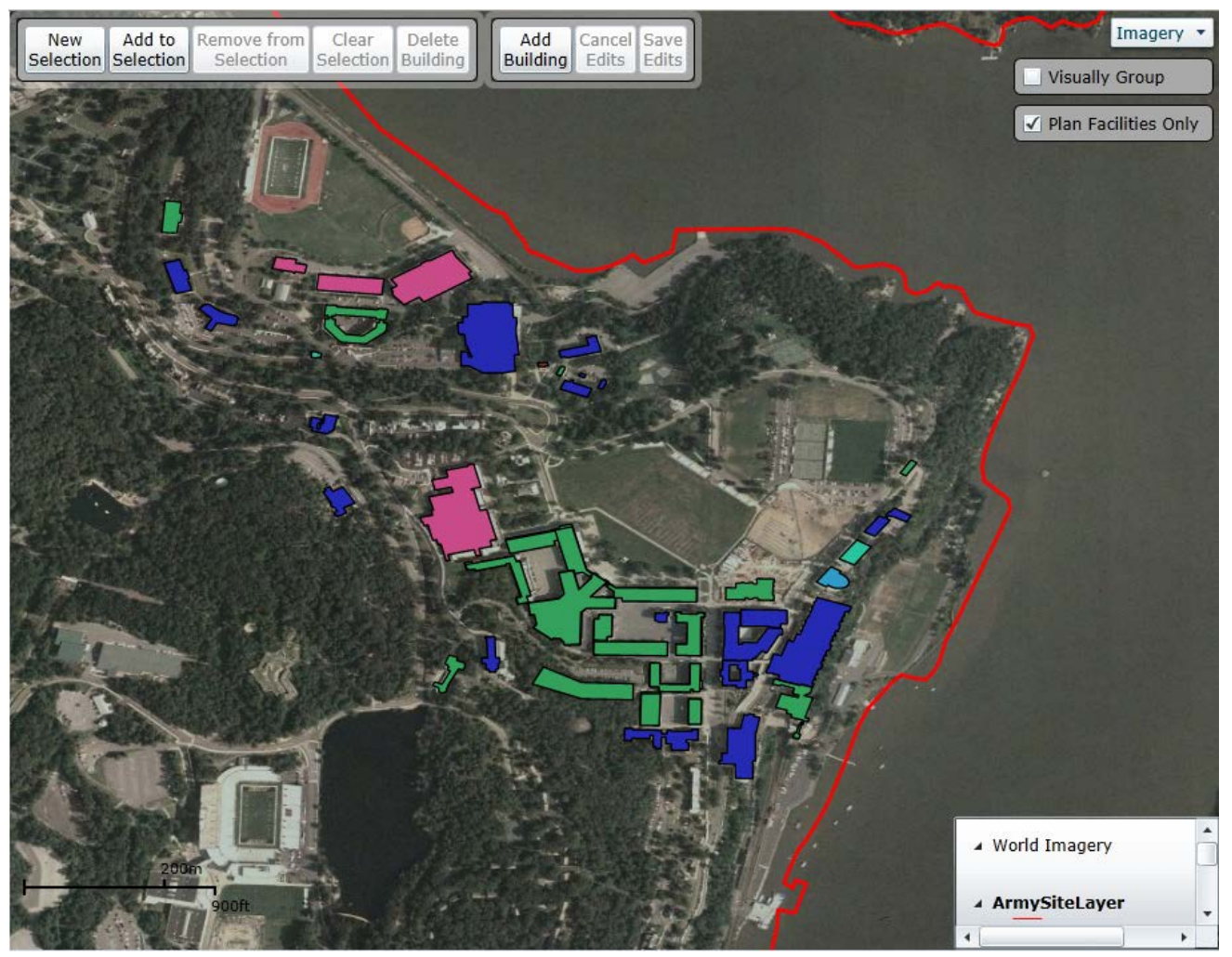

Figure 5-12. The baseline includes 45 facilities in nine groups. See text for explanation of the use of the status column (Existing, Demolished, and Planned) to represent planned DERs.

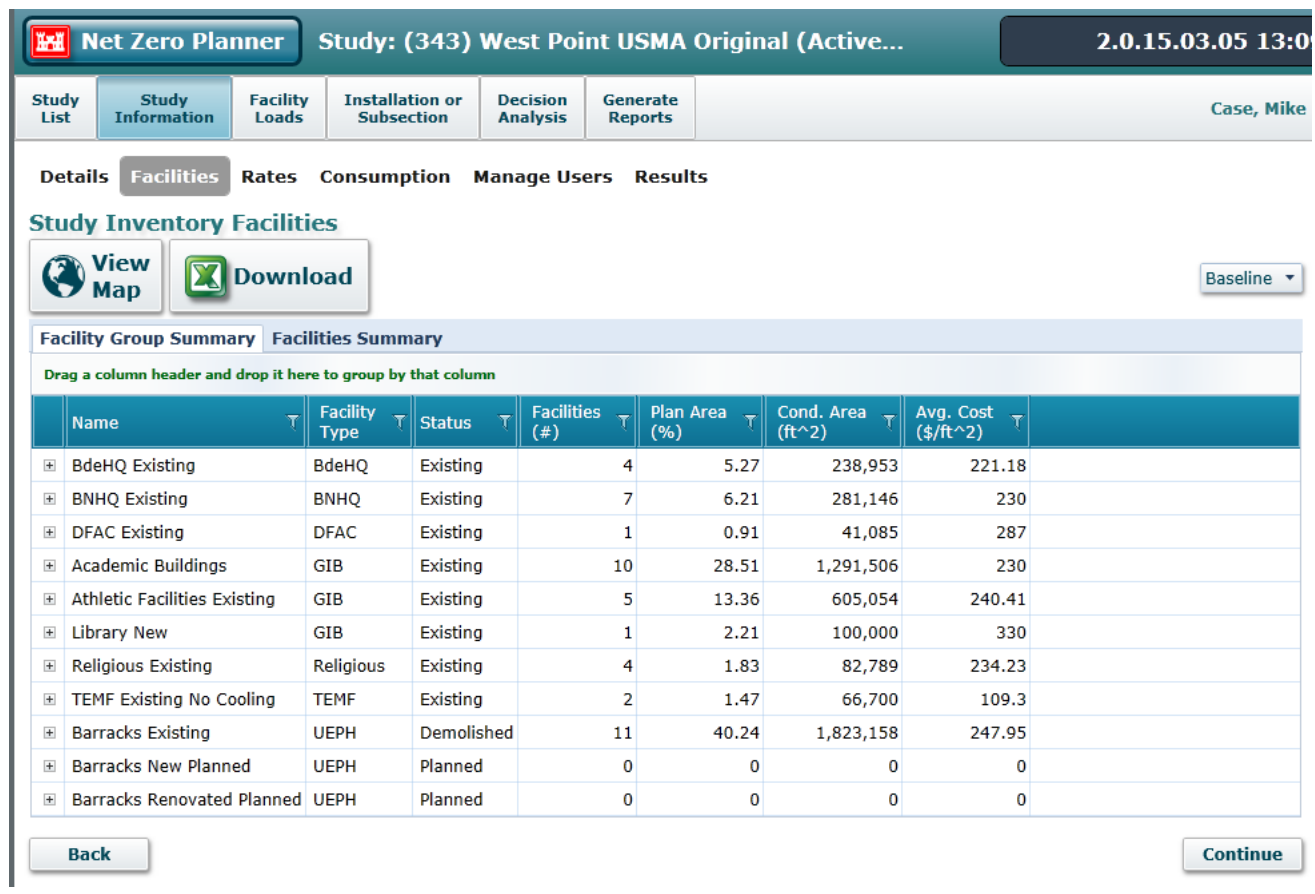


Figure 5-13. The Base Case includes 46 buildings in 10 groups.

\begin{tabular}{|c|c|c|c|c|c|c|c|c|c|c|}
\hline \multicolumn{3}{|c|}{ Fin Net Zero Planner } & \multicolumn{7}{|c|}{ Study: (343) West Point USMA Original (Active... } & \multirow{2}{*}{$\begin{array}{r}\text { 2.0.15.03.05 13:09 } \\
\text { Case, Mike }\end{array}$} \\
\hline $\begin{array}{l}\text { Study } \\
\text { Lust }\end{array}$ & \multicolumn{2}{|c|}{\begin{tabular}{c|c}
$\begin{array}{c}\text { Study } \\
\text { Information }\end{array}$ & $\begin{array}{c}\text { Faculuty } \\
\text { Loads }\end{array}$
\end{tabular}} & \multicolumn{2}{|c|}{$\begin{array}{l}\text { Installation or } \\
\text { Subsection }\end{array}$} & $\begin{array}{l}\text { Decision } \\
\text { Analysis }\end{array}$ & \multicolumn{2}{|c|}{$\begin{array}{l}\text { Generate } \\
\text { Reports }\end{array}$} & & & \\
\hline \multicolumn{3}{|c|}{ Details Facilities Rates } & $\begin{array}{l}\text { Consump } \\
\text { ies }\end{array}$ & ption Mana & Manage Users & \multicolumn{2}{|c|}{ rs Results } & & & \\
\hline \multicolumn{2}{|c|}{ (8) View } & (4.) Downlc & load & & & & & & & Basecase - \\
\hline \multicolumn{11}{|c|}{ Facility Group Summary Facilities Summary } \\
\hline \multicolumn{11}{|c|}{ 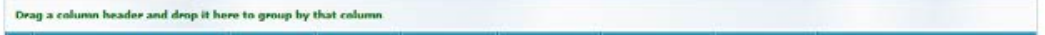 } \\
\hline \multicolumn{3}{|c|}{ Name } & $\begin{array}{l}\text { Facility } \\
\text { Trpe }\end{array}$ & Status T & $\begin{array}{l}\text { Facilitivs } \\
\text { (t) }\end{array}$ & T $T$ & $\begin{array}{l}\text { Pain Arsa } T \text { T } \\
(\%)\end{array}$ & 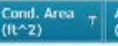 & $\begin{array}{l}\text { Avg. } \operatorname{Cost} \\
\left(\sin ^{-1}-2\right)\end{array}$ & \\
\hline \multicolumn{3}{|c|}{ क. BdeHQ Existing } & BdeHQ & Existing & & 4 & 4.96 & 238,953 & 221.18 & \\
\hline \multicolumn{3}{|c|}{ *. BNHQ Existing } & ENHQ & Existing & & 7 & 5.84 & 281,146 & 230 & \\
\hline \multicolumn{3}{|c|}{ - DFAC Existing } & DFAC & Existing & & 1 & 0.85 & 41,005 & 207 & \\
\hline * & \multicolumn{2}{|c|}{ Academic Bulldings } & GIB & Existing & & 10 & 26.81 & $1.291,506$ & 230 & \\
\hline \multicolumn{3}{|c|}{ * Athletic Facilities Existing } & GIB & Existing & & 5 & 12.56 & 605,054 & 240.41 & \\
\hline - & \multicolumn{2}{|c|}{ Library New } & GIB & Existing & & 1 & 2.08 & 100,000 & 330 & \\
\hline 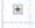 & \multicolumn{2}{|c|}{ - Rellglous Existing } & Rellglous & Existing & & 4 & 1.72 & 82,789 & 234.23 & \\
\hline * & \multicolumn{2}{|c|}{ TEMF Existing No Coolling } & TEMF & Existing & & 2 & 1.38 & 66.700 & 109.3 & \\
\hline \% & \multicolumn{2}{|c|}{ Barracks Existing } & UEPH & Demolished & & 0 & 0 & 0 & 0 & \\
\hline * & \multicolumn{2}{|c|}{ Barracks New Planned } & UEPH & Planned & & 1 & 5.96 & 287,000 & 260 & \\
\hline 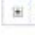 & \multicolumn{2}{|c|}{ * Barracks Renovated Planned } & UEPH & Planned & & 11 & 37.85 & $1,823,158$ & 265.3 & \\
\hline \multicolumn{3}{|c|}{ Back } & & & & & & & & Continue \\
\hline
\end{tabular}

5.4.12.2 Modeling and optimizing the baseline, base case, and alternatives

The baseline was calibrated against the same energy data as the SMEs used, considering total installation bills, conversion efficiencies, and steam system losses. Once calibrated, a Base Case was created by running the standard sets for EEM packages against all of the facility types as per the process described in Chapter 2 and selecting reasonable sets of EEMS for each type. These selected EEMS were used in all of the alternatives considered. To put it another way, the Base Case was used to arrive at a potential decrease in facility loads due to applying packages of EEMs and the same facilities loads were used in all other alternatives. Table 5-11 compares the Baseline and Base Case alternatives. Notice that the site gas energy decreases by about $29 \%$, while the electrical energy actually increases. This can be attributed to the addition of cooling to previously uncooled cadet barracks. NZP also automatically produced load duration curves for Baseline heating (Figure 5-14), Baseline electrical (Figure 5-15), Base Case heating (Figure 5-16), and Base Case electrical (Figure 5-17). Load duration curves show how many hours each year there is a demand for heating and electrical energy and are used to assist in sizing equipment. Although the electrical load is relatively unchanged, the heating load decreases markedly for the Base Case, opening up the possibility of savings resulting from use of smaller equipment. 
Table 5-11. For USMA, the baseline was modeled and calibrated. Next, the Base Case was modeled to include what was considered a realistic set of EEMs.

\begin{tabular}{|c|c|c|c|c|c|c|c|c|c|c|c|c|}
\hline Alternative & Facilities & $\mid \begin{array}{l}\text { Total Area } \\
\left(\mathrm{ft}^{\wedge} \mathbf{2}\right)\end{array}$ & \begin{tabular}{|l} 
Site Electricity \\
(kBtu)
\end{tabular} & \begin{tabular}{|l|} 
Site \\
Electricity \\
Reduction \\
(\%)
\end{tabular} & $\begin{array}{l}\text { Source } \\
\text { Electricity } \\
\text { (kBtu) }\end{array}$ & \begin{tabular}{|l} 
Site Gas \\
(kBtu)
\end{tabular} & \begin{tabular}{|l|} 
Site Gas \\
Reduction \\
$(\%)$
\end{tabular} & $\begin{array}{l}\text { Source Gas } \\
\text { (kBtu) }\end{array}$ & $\begin{array}{l}\text { Site Energy } \\
\text { Cost }(\$ / y r)\end{array}$ & \begin{tabular}{|l|} 
Site Total \\
Energy \\
Intensity \\
$($ kBtu/ft^2) \\
\end{tabular} & $\begin{array}{l}\text { Site Total Energy } \\
\text { (kBtu) }\end{array}$ & \begin{tabular}{|l} 
Source Total \\
Energy (kBtu)
\end{tabular} \\
\hline Baseline & 45 & $4,530,391$ & $147,858,048$ & 0 & $493,845,888$ & $430,718,464$ & 0 & $450,962,272$ & $6,718,413$ & 127.71 & $578,576,512$ & $944,808,192$ \\
\hline BaseCase & 46 & $4,817,391$ & $150,425,760$ & -1.74 & $502,421,984$ & $304,440,736$ & 29.32 & $318,749,280$ & $5,825,346$ & 94.43 & $454,866,496$ & $821,171,264$ \\
\hline
\end{tabular}

Figure 5-14. Baseline load duration curve (heating).

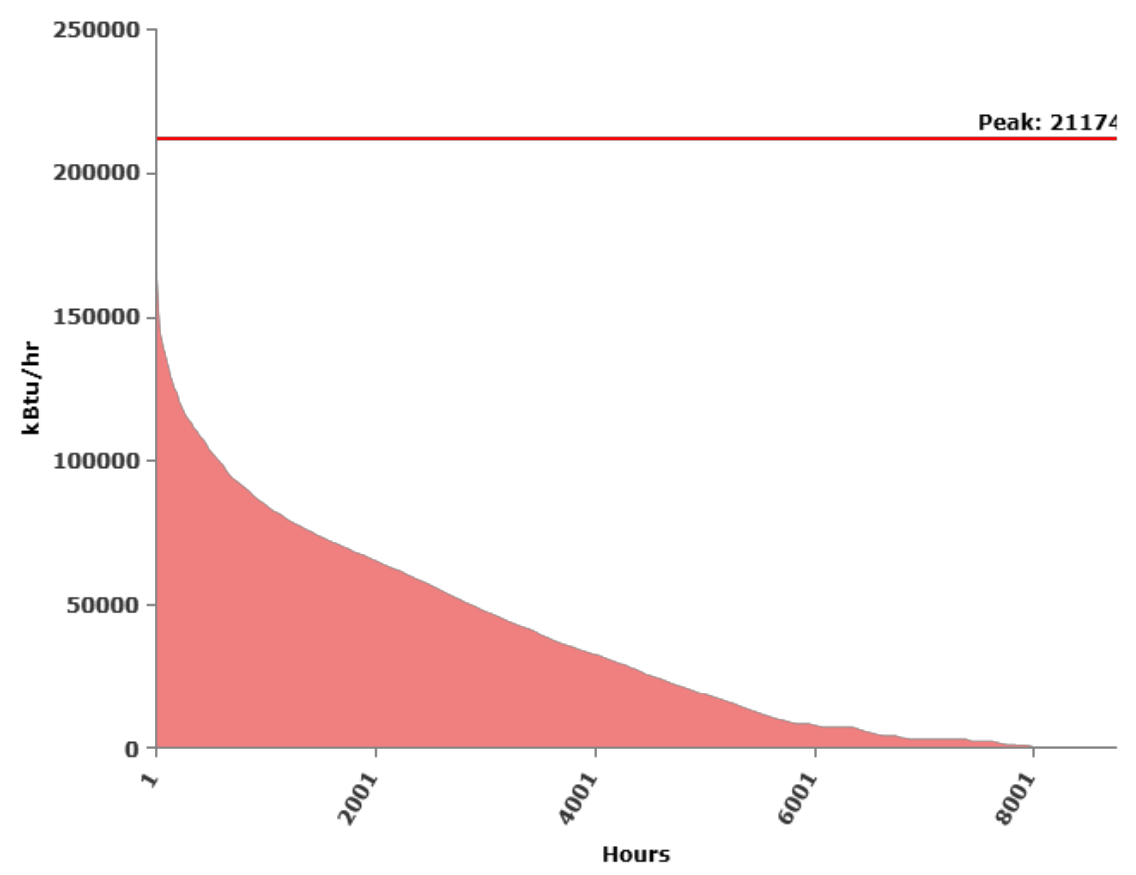

Figure 5-15. Baseline load duration curve (electrical).

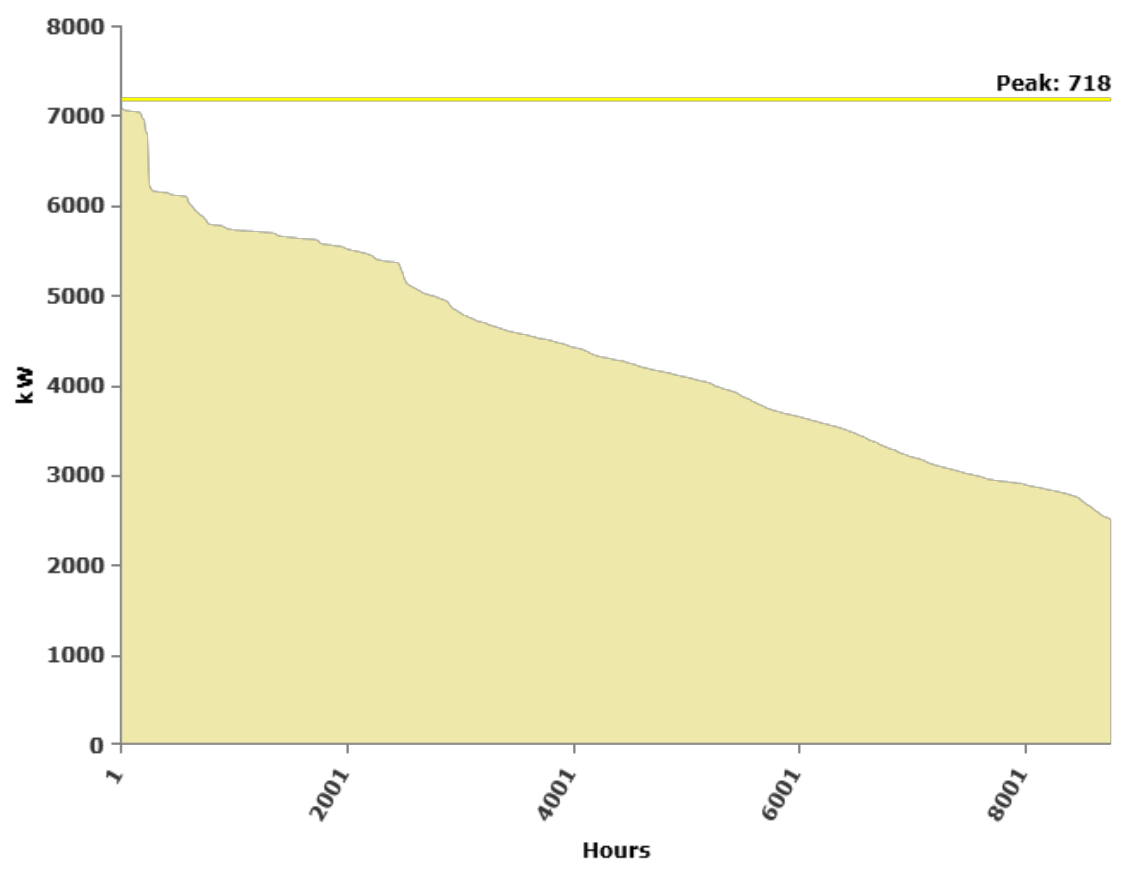


Figure 5-16. Base Case load duration curve (heating).

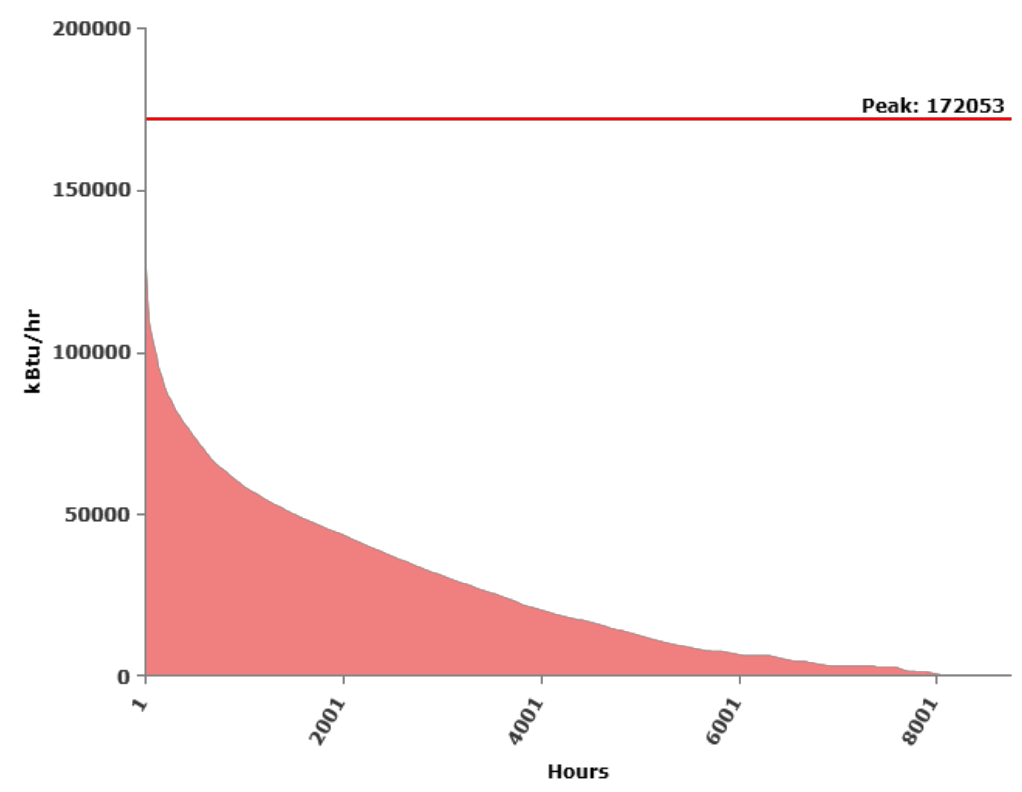

Figure 5-17. Base Case load duration curve (electrical)

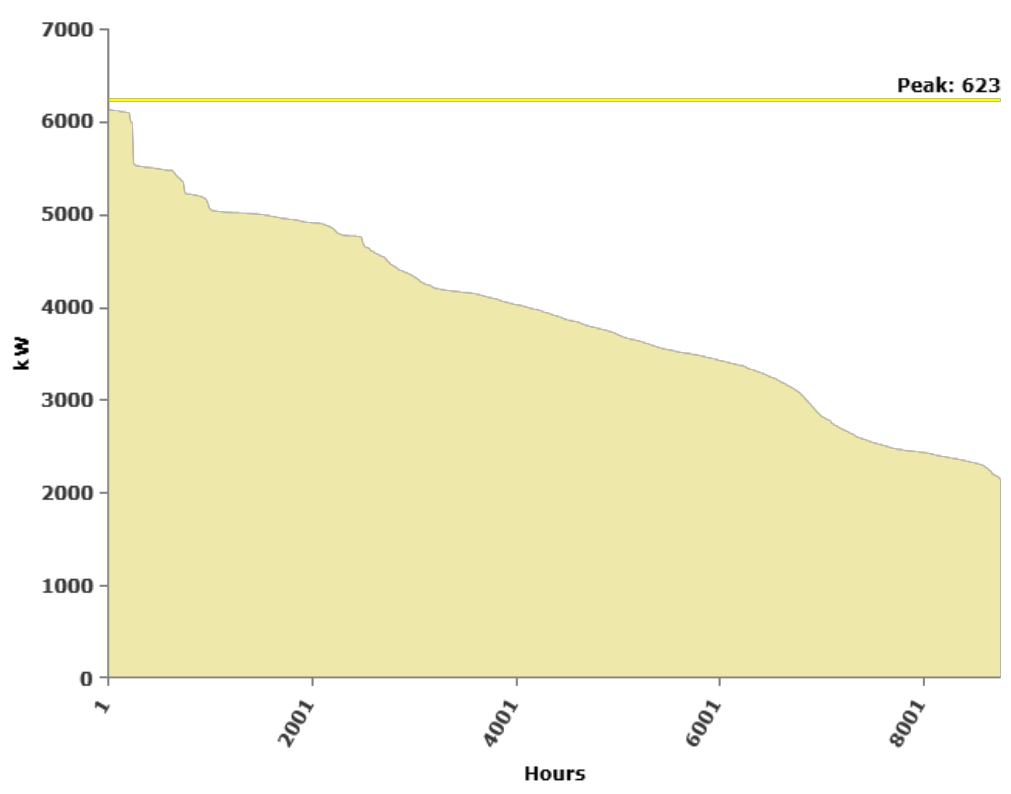

\subsubsection{Modeling and optimizing across the installation}

The facilities modeled within the Facility Loads section of NZP were incorporated into a single cluster (Figure 5-18). The 8,760 hours of simulation data for each facility group are scaled by conditioned area of each group and aggregated to create an 8,760 hour aggregate load that takes into account coincident loads. In other words, instead of adding up the non-coincident peak of each facility that may occur at different times, it calculates 
the coincident demand of the entire system. For example barracks and office buildings have peak electrical loads at different times, so a system designed to meet the sum of the non-coincident loads would be oversized.

Figure 5-18. The USMA central area was modeled as a single cluster. NZP automatically aggregates the building loads and calculates the energy Density.

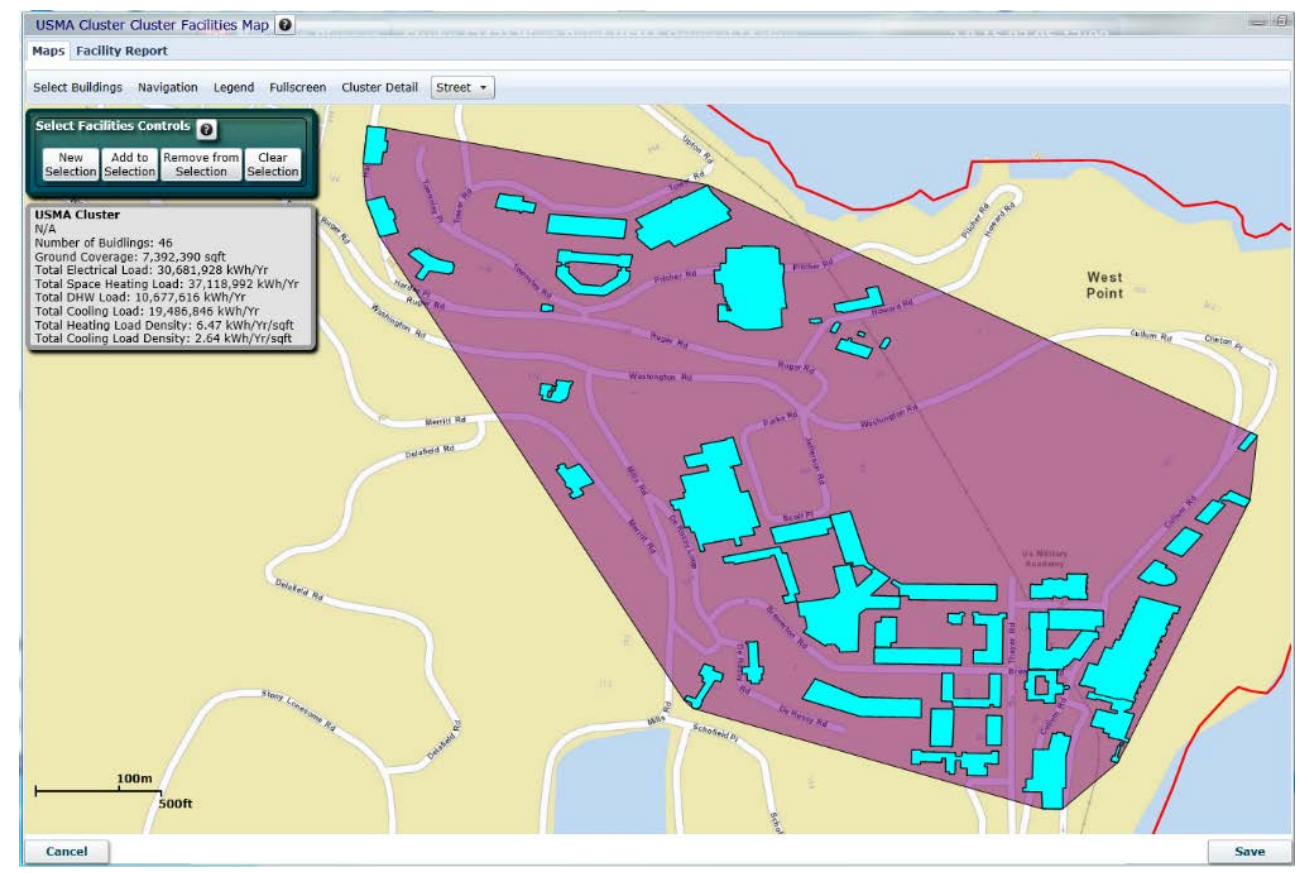

The same alternatives were used in NZP as the SMEs generated, with the additional of an "open optimization" alternative. Whereas the SME alternatives were all configured using SME expert judgment, the open optimization works from a large list of possible equipment to meet the demand and distribute energy. The open optimization ended up with the lowest annualized cost of any of the alternatives. The optimization ended up using significantly more HW storage as well as magnetic levitation electric chillers and was able to make better use of cogeneration. Note also that decentralization of heating, while using the lowest site energy and lower source energy than the Base Case, ends up using much more source energy than the rest of the alternatives at a higher initial cost and annualized cost. 
Table 5-12. Analysis of alternatives as calculated by NZP.

\begin{tabular}{|c|c|c|c|c|c|c|c|c|c|c|c|}
\hline Alternative & Investment & $\begin{array}{c}\text { Total Equivalent } \\
\text { Annual Cost }\end{array}$ & $\begin{array}{c}\text { Total Source } \\
\text { Energy }\end{array}$ & $\begin{array}{c}\text { Total Site } \\
\text { Energy } \\
\end{array}$ & \begin{tabular}{|c|} 
Site \\
Electric
\end{tabular} & $\begin{array}{c}\text { Site } \\
\text { Fossil } \\
\text { Fuel } \\
\end{array}$ & $\begin{array}{c}\text { Electric } \\
\text { Purchase }\end{array}$ & Energy S & Savings & $\mathrm{CO} 2$ & \\
\hline & (\$) & $(\$ / Y r)$ & MWhs/Yr & \begin{tabular}{|c|}
$\begin{array}{c}\text { MWhs/ } \\
\text { Yr }\end{array}$ \\
\end{tabular} & $\begin{array}{c}\text { MWhs/ } \\
Y r\end{array}$ & \begin{tabular}{|c|} 
MWhs/ \\
Yr
\end{tabular} & $\begin{array}{c}\text { MWhs/ } \\
\text { Yr }\end{array}$ & $\begin{array}{c}\begin{array}{c}\text { Source } \\
(\%)\end{array} \\
\end{array}$ & Site (\%) & \begin{tabular}{|c|}
$\%$ \\
reduction
\end{tabular} & MTCe \\
\hline Baselin & 0 & $9,347,780$ & 297,672 & 190,854 & 42,672 & 148,182 & 42,672 & 0 & 0 & 0 & 54,740 \\
\hline BaseCase & $63,070,800$ & 304,697 & 9,421 & 139,551 & 40,694 & 98,857 & 40,694 & 9.57 & 33.29 & 17.9 & \begin{tabular}{|l|l|}
44,943 \\
\end{tabular} \\
\hline Alt 1 - Decen & $230,420,000$ & $25,058,064$ & 226,243 & 120,504 & 43,644 & 76,860 & 43,644 & 24 & 48.13 & 21.06 & 43,214 \\
\hline Alt 2-HW & \begin{tabular}{|l}
$101,772,608$ \\
\end{tabular} & 12,203 & ,902 & 1,521 & 43,644 & 89,132 & 42,390 & 21.09 & 39.85 & 18.8 & \begin{tabular}{|l|l|}
44,448 \\
\end{tabular} \\
\hline \begin{tabular}{|l} 
Alt 3 - Recip \\
TriGen \\
\end{tabular} & $114,100,696$ & $13,400,418$ & 149,198 & 142,501 & 41,039 & 142,501 & 0 & 49.88 & 3.83 & 55.49 & \begin{tabular}{|l|}
24,368 \\
\end{tabular} \\
\hline \begin{tabular}{|l} 
Alt 4 - Turbine \\
Trigen \\
\end{tabular} & $134,100,696$ & 4,452 & 160,248 & 153,055 & 41,068 & 153,055 & 0 & 46.17 & -3.29 & 52.19 & 26,172 \\
\hline \begin{tabular}{|l|} 
Alt 5- Open \\
Optimization
\end{tabular} & $93,598,192$ & $12,074,586$ & 149,084 & 142,392 & 39,675 & $\mid 142,392$ & 0 & 49.92 & 3.91 & 55.52 & 24,349 \\
\hline
\end{tabular}

With quantitative results in hand, it is now possible to construct a decision model in NZP. Figure 5-19 shows a simple MCDA model that considers energy (site and $\mathrm{CO}_{2}$ emissions) and cost (first investment cost and total equivalent annual cost). $\mathrm{CO}_{2}$ emissions correlate roughly with source energy. A relatively higher weight is assigned to cost than to energy, reflecting the requirement that energy projects be life cycle cost effective. NZP shows the available quantitative metrics to the user while they are constructing the model. The MCDA module was not available in NZP at the time of the USMA test, so the below MCDA example was created after the test using data from the test. Thus, the weights do not reflect values assigned by USMA leadership.

Figure 5-20 shows the rankings of the alternatives using the MCDA model. In the tradeoff between energy, greenhouse gases, and cost, it is illustrative that the Baseline and Base Case appear in the "middle of the pack." Open optimization is the clear winner, with decentralized heating the most expensive and largest user of source energy. If the model had been based on site energy alone without consideration of cost, the decentralized alternative would have taken preference. 
Figure 5-19. The MCDA Decision Model is constructed from the NZP model output data. The user has access to all metrics in the final report and uses them to construct a weighted model in the tool. Weights are set in consultation with installation decision makers (note: these weights are for demonstration purposes only and do not reflect policy decisions by USMA leadership).

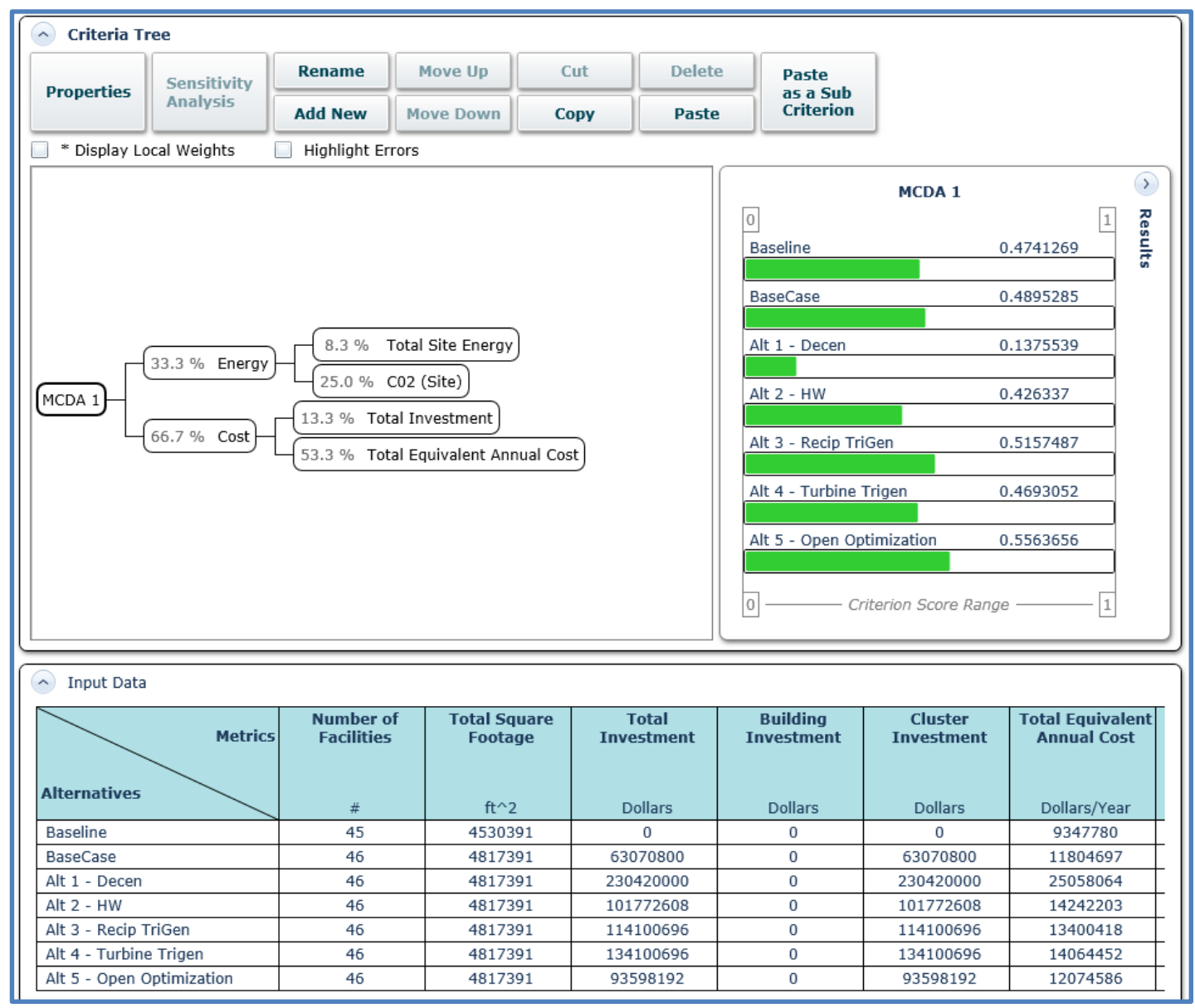


Figure 5-20. The MCDA decision model results in a ranked ordering of alternatives. An interesting result of the weights used for demonstration purpose is that some of the options turn out to score much lower than the status quo.

\begin{tabular}{|c|c|c|}
\hline Name & MCDA 1 & \\
\hline Description & Emphasis on source energy and life cycle cost. & \\
\hline Created & Case, Mike (3/20/2015 4:58 PM) & \\
\hline Modified & Case, Mike (3/20/2015 5:13 PM) & \\
\hline Access Level & Edit Model Structure, Value Functions and Weights & \\
\hline Rank & Alternative Name & MCDA Score \\
\hline 1 & Alt 5 - Open Optimization & 0.5563656 \\
\hline 2 & Alt 3 - Recip TriGen & 0.5157487 \\
\hline 3 & BaseCase & 0.4895285 \\
\hline 4 & Baseline & 0.4741269 \\
\hline 5 & Alt 4 - Turbine Trigen & 0.4693052 \\
\hline 6 & Alt $2-\mathrm{HW}$ & 0.426337 \\
\hline 7 & Alt 1 - Decen & 0.1375539 \\
\hline
\end{tabular}

\subsubsection{Discussion}

USMA was the first installation test of NZP. To summarize, SMEs did the study first and then the NZP team attempted to follow a similar process using the same data. NZP used the same alternatives as the SMEs, with the addition of an open optimization alternative that ended up identifying a new combination of equipment that was better than those considered by the SMEs. There were several additional benefits observed by the NZP team in using the tool. First, the speed of calculations and rollup was much better in the tool than in the process employed by the SMEs. Chapter 7 discusses the relative labor costs of the SME approach versus the NZP approach in detail. It is worth noting here that the NZP Tool took $\sim 3$ weeks to set up and run the models while the SMEs took about 3 months. Second, once the models were created, it was considerably easier and less costly to make changes to the model, and then examine the results. The SME team required a good deal of time to coordinate results by passing spreadsheets back and forth. By contrast, NZP's ability to maintain, organize, and roll up the data made a change in the model relatively painless. The assembly of the SME report for USMA was highly time consuming and expensive, taking 2 months. This experience led the NZP team to create a module that will automatically generate reports from Microsoft Word templates, funded out of the NZP research program. This capability is expected to be available by the end of FY15 and will save 1 to 2 months of manually generating assessment documents. 


\subsection{Portsmouth Naval Shipyard (PNSY)}

\subsubsection{Energy objectives}

The PNSY kickoff meeting identified strategic areas for energy objectives. Specific energy objectives were defined for each area and confirmed by the shipyard leadership. The challenges for the PWT are to develop recommendations that meet all of the following goals as closely as possible in a balanced and integrated way:

- Energy Efficiency. By 2040, the source energy use of the installation will be $40 \%$ less than the 2010/2011 baseline. This was stated as "Forty by Forty." Source energy includes all energy used on the installation plus the energy used to generate and distribute electricity purchased from the grid. The 2040 source energy goal is $221,120 \mathrm{MWh}(754,493$ MMBtu) from the baseline of 368,530 MWh (1,257,477 MMBtu).

- Supply Security. There will be no degradation of the current levels of energy reliability and supply security as a result of the EMP recommendations. The installation currently meets all necessary reliability and security levels. Energy security cannot be put in jeopardy by energy savings.

- Carbon Footprint. By 2040, the installation should strive to reduce GHG emissions from 65,210 metric ton (mt) to zero from both onsite stationary sources (Scope 1) and purchased electricity (Scope 2).

- Energy Economics. The net investments aimed at achieving the goals will be cost effective by using standard government LCC analysis.

The team and the facilities leadership at the shipyard agreed to these energy goals. The 2040 efficiency target is relative to the source energy and encompasses efficiencies in fuel conversion, energy distribution, and end use.

\subsubsection{Baseline}

PNSY provided detailed usage and rate breakdowns for fiscal year 2010 (FY10) and FY11.

- Table 5-13 lists both the energy consumed on the installation itself (site energy) along with the total energy used to generate and transport electricity and gas to the site (source energy). The site-to-source factors are U.S. averages of 3.34 for electricity, 1.047 for natural gas, and 1.01 for heating oil/propane. 
Table 5-13 also provides a complete energy use picture that includes the cost and energy consumed on the installation itself (site energy), along with the total energy used to generate and transport electricity and gas to the site (source energy).

Two-thirds of all energy purchases are ultimately used for heating in buildings, industrial processes, and berths and DDs; by far the largest part of that portion is used for the heating of buildings. Over three-quarters of the installation's energy costs are for natural gas, primarily to run the gas turbines (GT). Notice that the purchased electricity is $\sim 9 \%$ of total energy purchases, but $\sim 22 \%$ of the energy costs.

\subsubsection{Baseline site energy uses}

Of the total 1,010,140 MMBtu (296,043 MWh) purchased by PNSY, $113,450 \mathrm{MMBtu}(33,249 \mathrm{MWh})$, or 11\%, is lost in boiler and turbine inefficiencies, leaving the balance of 896,700 MMBtu (262,797 MWh) for distribution around the shipyard. The inefficiencies assumptions are based on the manufacturers' specifications and input from the PNSY operating staff. Of this total onsite energy supply, 896,700 MMBtu (262,797 MWh), 64\% is distributed as steam, $25 \%$ is electricity generated onsite by the two GTs, with the balance, or $10 \%$, being electricity purchased from Central Maine Power. There is also a small amount or $0.4 \%$ propane and $\sim 1 \%$ heating oil of additional fuels.

After determining the onsite distribution losses and the off-site conversion and distribution losses, the next task was to estimate how this energy was broken down by all end uses in the shipyard. The detailed distribution of site energy is:

- steam losses: $29 \%$

- deaerator: $9 \%$

- building and industrial energy: $6 \%$

- building and industrial heating: $27 \%$

- electricity for compressed air, water, sewer, others: $3 \%$

- berth and DD electricity: $12 \%$

- berth and DD steam: 3\%

- electrical losses: $1 \%$. 
Table 5-13. Baseline: Total energy footprint for 2010/2011 and energy purchases.

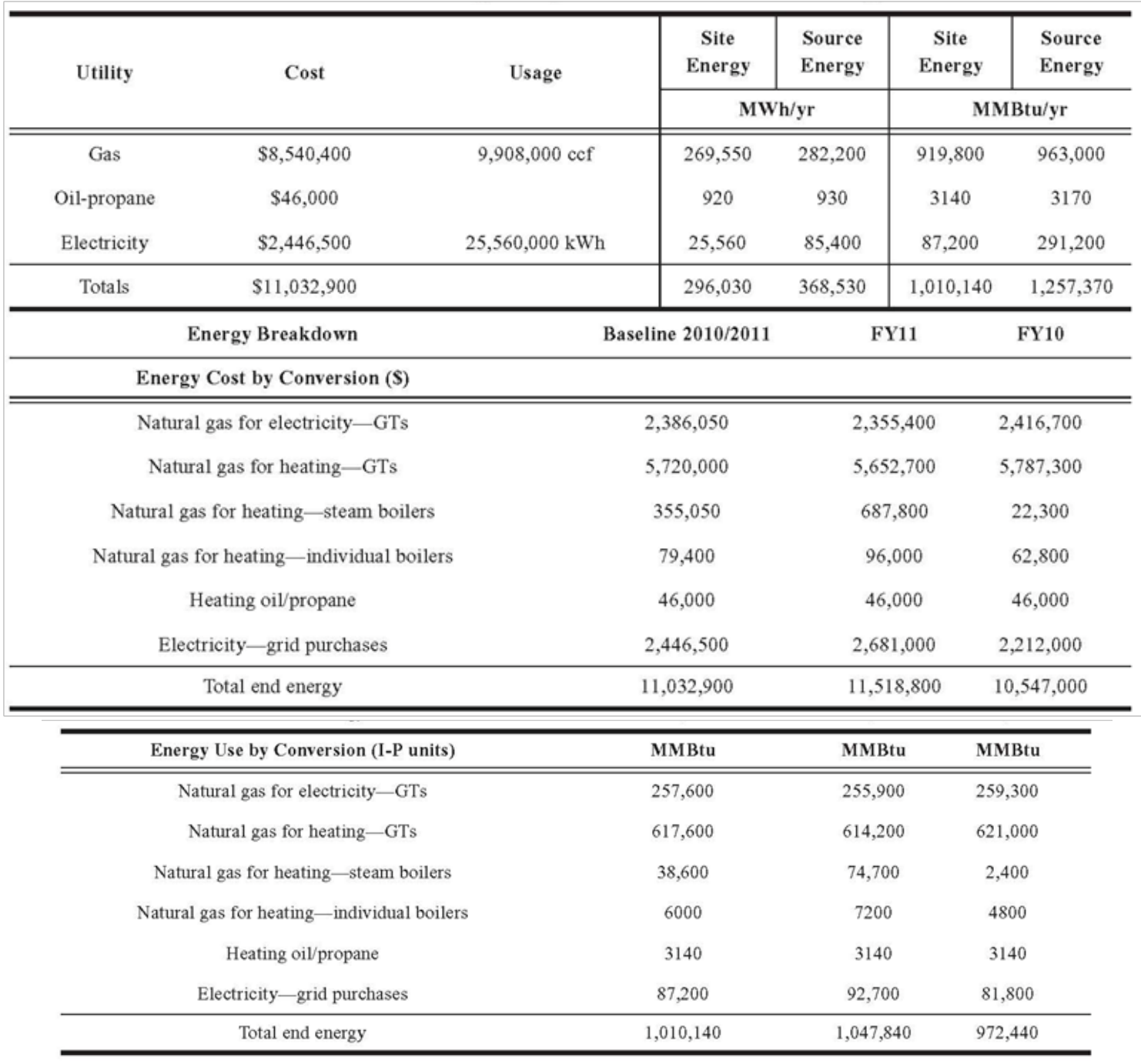

From the detailed energy breakdown, the high level of steam losses, $-38 \%$ (29\% steam and 9\% deaerator losses) - is very significant. The PNSY staff was aware that the steam system had high losses. To confirm the level of these losses, a "no-load" or "dark factory" test of the steam network was carried out in September 2012. ("Dark factory test" is a phrase attributed to Toyota as an element of their systematic energy efficiency "treasure hunts.") These include at least 1 day where no production is running to assess how well the site manages nonproductive energy use. This entailed systematically removing all steam use from the system to get data on the network losses. Steam generated at this no-load moment is an accurate estimate of the losses in the steam distribution network. In the no-load condition, the dark factory steam test confirmed very high network losses of 
about $40 \%$. This was underlined by the high level of steam maintenance costs of nearly \$2 million in 2012.

\subsubsection{Baseline source energy uses}

The total source energy consumed by the shipyard is 1,257,000 MMBtu (368,500 MWh) per year. The estimated breakdown of the total source energy is summarized as follows: building and industrial processes at $29 \%$, berths and DDs at $12 \%$, onsite distribution at $21 \%$, onsite conversion at $18 \%$, and off-site conversion and distribution at $20 \%$.

Source energy is roughly equivalent to the total fuel needed to supply the shipyard, including that used by electricity generation and transmission supplied by the external grid. An estimated 59\% of all this fuel used by PNSY is attributable to the generation and distribution of heat and electricity, both on and off the shipyard, of which $20 \%$ is grid-purchased electricity.

\subsubsection{Baseline energy use - Buildings}

The shipyard has 127 industrial and nonindustrial buildings, many of which, with minor exceptions, do not have metering. To estimate their energy needs, a modeling approach was used to estimate both the magnitude and type of energy use. The first step of the building modeling process is to select all buildings to be considered as a part of the installation's EMP and distribute them among different building types/ categories. Buildings were constructed at the PNSY range from the early 1800s up to the present.

From a review of the site plans and site visit, there were four main usage types on site: office, residential, warehouse, and industrial. To further refine the categories, a walkthrough of all major buildings was carried out to assess age, construction, and systems. At the same time, any anomalies that did not fit comfortably into the broad categories were noted. Construction on the site had clearly happened in waves, allowing the initial categorization of the nonindustrial buildings. Industrial buildings on the site were categorized in a slightly different way. First, they were grouped by age, after which generalized models for warehouse and offices of an appropriate age were assigned to each industrial building.

In addition to the energy end use from the normal building functions, the industrial buildings had an industrial process load added to them by the SME team. The black box buildings that the shipyard had no control over 
were included in the installation total energy use based on their total metered or allocated utility data. While there are a large number of buildings, relatively few account for the bulk of the energy use. The data in Table 5-14 summarize the detailed categorization of each building by building function and age within the shipyard. This categorization of the buildings was used by the SME team and the NZP Tool for building energy use estimation.

All energy use estimates used the weather profile for Pease Air Force Base, Portsmouth, NH (ASHRAE Station Code: 726055_TMY3) from the 2005 ASHRAE Handbook-Fundamentals. The modeling approach derives the energy use and annual total by major building function for each building and then totaled for the site estimates.

Of the total 1,010,140 MMBtu (296,043 MWh) purchased by PNSY, only about 368,000 MMBtu (108,000 MWh), or 37\%, is used for buildings and industrial process. Of that, more than half, $53 \%$, is for space heating.

Industrial processes are $8 \%$ of end use, about 3\% of purchased energy, and were much less than expected by the intended function of this installation. The building and process energy end use estimates were:

- process electric load: $3 \%$

- process ventilation heating: $5 \%$.

PNSY repairs and modernizes nuclear submarines. The basic industrial processes carried out in the industrial buildings surrounding the DDs are typical for any naval repair and refit facility.

In addition, there are industrial processes specific to the nuclear plant and systems on the submarines. For security reasons, these were beyond the scope of this work. The 35 buildings categorized as industrial support the shipboard activities by providing places for repairing, staging, modifying, manufacturing, and finishing components and assemblies for the specific tasks. By the nature of these tasks, the use of the various machines is intermittent with varying work intensity. Most of the equipment appeared to be at a modern level of industrial practice, flexibly organized to accommodate sporadic workloads. The site nominally works three shifts with by far the greatest concentration during the day and afternoon shifts. 
Table 5-14. Baseline: Summary of categorization of shipyard buildings by age and function.

\begin{tabular}{|c|c|c|c|}
\hline Building Category & Area, $\mathrm{ft}^{2}$ & Area, $\mathrm{m}^{2}$ & $\%$ Total \\
\hline $\begin{array}{c}\text { Barracks/residential- } \\
\text { modem }\end{array}$ & 76,336 & 7092 & $2 \%$ \\
\hline $\begin{array}{l}\text { Barracks/residential- } \\
\text { post-1980s }\end{array}$ & 28,909 & 2686 & $1 \%$ \\
\hline $\begin{array}{c}\text { Barracks/residential- } \\
\text { pre-1900 }\end{array}$ & 30,340 & 2819 & $1 \%$ \\
\hline $\begin{array}{l}\text { Black box-assigned } \\
\text { energy intensity }\end{array}$ & 81,593 & 7580 & $3 \%$ \\
\hline Individual buildings & 118,698 & 11,027 & $4 \%$ \\
\hline Industrial-mid-century & 127,104 & 11,808 & $4 \%$ \\
\hline Industrial-post-1980s & 22,862 & 2124 & $1 \%$ \\
\hline Industrial-pre-1900 & 94,955 & 8822 & $3 \%$ \\
\hline $\begin{array}{l}\text { Industrial—with a heavy } \\
\text { process load }\end{array}$ & 15,743 & 1463 & $0.5 \%$ \\
\hline $\begin{array}{l}\text { Industrial—with little or no } \\
\text { process load }\end{array}$ & 310,644 & 28,860 & $10 \%$ \\
\hline $\begin{array}{l}\text { Industrial — with medium } \\
\text { process load }\end{array}$ & 398,213 & 36,995 & $12 \%$ \\
\hline $\begin{array}{l}\text { Industrial—with some } \\
\text { local process load }\end{array}$ & 418,592 & 38,888 & $13 \%$ \\
\hline Office-mid-century & 37,921 & 3523 & $1 \%$ \\
\hline Office-modem & 29,807 & 2769 & $1 \%$ \\
\hline Office-post-1980s & 182,749 & 16,978 & $6 \%$ \\
\hline Office-pre-1980s & 129,023 & 11,987 & $4 \%$ \\
\hline Recreation & 32,261 & 2997 & $1 \%$ \\
\hline To be demolished & 53,653 & 4984 & $2 \%$ \\
\hline Warehouse-mid-century & 112,982 & 10,796 & $4 \%$ \\
\hline Warehouse-post-1980s & 124,793 & 11,594 & $4 \%$ \\
\hline Warehouse - pre-1900 & 770,830 & 71,612 & $24 \%$ \\
\hline $\begin{array}{l}\text { Unconditioned-excluded } \\
\text { from modeling }\end{array}$ & 7033 & 653 & $0.2 \%$ \\
\hline Total floor area & $3,205,052$ & 297,757 & $100 \%$ \\
\hline
\end{tabular}

\subsubsection{Baseline energy Use - Berths and DDs}

The steam and electricity system of the shipyard supplies the three DDs along with their associated berths. As with all other major end uses on the shipyard, there is no metering or similar monitoring data available. The following estimating approaches were used:

- Steam. The total delivery of steam to the DDs and berths was assumed to be the balance remaining after the network losses and the modeled requirements for heating buildings and industrial processes. This amounted to 36,400 MMBtu (10,668 MWh) annually. This was then 
broken down into estimates of the main applications for the steam: Dehumidifying one DD is 14,420 MMBtu (4226 MWh); heating two DDs-9800 MMBtu (2872 MWh); barge heating systems and usage$2530 \mathrm{MMBtu}$ ( $741 \mathrm{MWh}$ ); temporary structures, portable heaters, freeze protection, etc. -9650 MMBtu (2828 MWh) for a total of 36,400 MMBtu (10,668 MWh).

- Electricity. A similar approach was adopted to estimate the total electricity use in the absence of any metered data. The total electricity use was derived from the balance of the remaining demand after subtracting distribution losses, building usage, and industrial process usage from the total purchases and onsite generation. Based on this approach, the baseline electricity usage is 115,100 MMBtu/yr (33,720 $\mathrm{MWh} / \mathrm{yr})$. The applications contributing to this are:

- air handlers for dehumidifying one DD

- cooling and air handling for conditioning DDs

- electricity needs of barges, including some heating services

- miscellaneous electrical loads including tools and lighting.

In summary, the berths and DDs consume about $17 \%$ of all the energy distributed on the installation.

\subsubsection{Simulating baseline energy use}

The above assumptions for buildings, utilities, and process load calculations were the starting point for the SME approach and NZP Tool. Table 5-15 lists the analysis results for the two procedures for comparison. There is the job server in the NZP Tool that runs a program called "PARAMS," a parametric software tool that overlays the EnergyPlus building energy simulation software. The same energy simulation program was ultimately used for both methods, but the process to specify each of the models is quite different. The results listed in Table 5-15 indicate that the total energy answers are different, but relatively close between methods. For the larger building groups, industrial, warehouse, and office, the differences between the methods are small. Some of the smaller groups have more variance, but balance out in the total energy.

Even with the simplified parametric program input in the NZP Tool with different persons entering the installation data, the output data for each of the building categories show good overall comparison. 


\subsubsection{Base case}

The Base Case covers the energy used on the installation from present to the end of the study period in 2040 and assumes that the buildings and site would undergo business as usual. This generally assumes that the activity level would be unchanged and function of existing buildings would not change. The major changes from the Baseline to the Base Case for buildings are those involved in the consolidation of the structural shops, consisting of demolition of Bldgs. 155 and 46 and integration into Bldg. 76. An additional impact is from the consolidation of demolished Bldg. 176 into Bldg. 45. An additional DD will be dehumidified and climate controlled from 2013, increasing both steam and electricity needs. As a result, annual DD steam use will increase by 14,420 MMBtu (4226 MWh) and electricity by $6031 \mathrm{MMBtu}$ ( $1830 \mathrm{MWh}$ ), extrapolated from existing DD usage. The result is that steam use increases annually to 59,490 MMBtu (17,435 MWh) from 36,400 MMBtu (10,668 MWh) and electricity to 121,131 MMBtu (35,550 MWh) from 115, 100 MMBtu (33,720 MWh). Both then remain constant through 2040.

Table 5-15. Baseline: Comparison of SME calculations to NZP Tool calculations.

\begin{tabular}{|c|c|c|c|c|c|c|c|c|c|c|c|c|}
\hline \multirow[b]{2}{*}{$\begin{array}{l}\text { Building } \\
\text { Category }\end{array}$} & \multicolumn{6}{|c|}{ SME Calculation Baseline } & \multicolumn{6}{|c|}{ NZP Tool Calculation Baseline } \\
\hline & $\begin{array}{l}\text { Electric } \\
\text { MWh/y }\end{array}$ & $\begin{array}{c}\text { Steam } \\
\text { MWh/y }\end{array}$ & $\begin{array}{c}\text { Total } \\
\text { MWh/y }\end{array}$ & $\begin{array}{c}\text { Electric } \\
\text { MMBtu/y }\end{array}$ & $\begin{array}{c}\text { Steam } \\
\text { MMBtu/y }\end{array}$ & $\begin{array}{c}\text { Total } \\
\text { MMBtu/y } \\
\end{array}$ & $\begin{array}{l}\text { Electric } \\
\mathbf{M W h} / \mathbf{y}\end{array}$ & $\begin{array}{c}\text { Steam } \\
\text { MWh/y }\end{array}$ & $\begin{array}{c}\text { Total } \\
\mathbf{M W h} / \mathbf{y} \\
\end{array}$ & $\begin{array}{c}\text { Electric } \\
\text { MMBtu/y }\end{array}$ & $\begin{array}{c}\text { Steam } \\
\text { MMBtu/y }\end{array}$ & $\begin{array}{c}\text { Total } \\
\text { MMBtu/y } \\
\end{array}$ \\
\hline Indu & 22,739 & 29,285 & 52,024 & 77,585 & 99,920 & 177,505 & 24,333 & 28,384 & 52,717 & 83,027 & 96,850 & 179,877 \\
\hline Warehouse & 10,970 & 20,103 & 31,072 & 37,428 & 68,590 & 106,018 & 10,996 & 17,885 & 28,881 & 37,519 & 61,027 & 98,547 \\
\hline Office & 6844 & 4330 & 11,174 & 23,352 & 14,773 & 38,125 & 5813 & 3555 & 9368 & 19,834 & 12,132 & 31,966 \\
\hline $\begin{array}{c}\text { Barracks/ } \\
\text { Residential }\end{array}$ & 2234 & 2043 & 4277 & 7623 & 6970 & 14,593 & 1785 & 3122 & 4907 & 6089 & 10,654 & 16,743 \\
\hline Recreation & 555 & 2050 & 2605 & 1893 & 6994 & 8887 & 2075 & 5147 & 7222 & 7081 & 17,562 & 24,643 \\
\hline Other & 3488 & 3319 & 6807 & 12,449 & 14,461 & 23,602 & 1389 & 3139 & 4527 & 4739 & 10,709 & 15,448 \\
\hline $\begin{array}{l}\text { Berths and } \\
\text { Dry Docks }\end{array}$ & 33,732 & 10,668 & 44,400 & 115,100 & 36,400 & 151,500 & 33,819 & 10,656 & 44,475 & 115,395 & 36,359 & 151,754 \\
\hline Total & 80,562 & 71,798 & 152,359 & 275,430 & 248,108 & 520,230 & 80,209 & 71,888 & 152,097 & 273,685 & 245,292 & 518,977 \\
\hline
\end{tabular}

\subsubsection{Facility level optimization}

The facility level optimization is the next step in the process after determining the Baseline and the Base Case to compare against. At the facility level, all of the building EEM options are applied to each facility group. The NZP Tool saves substantial time when conducting studies through its ability to automatically apply packages of EEMs to facility types. Packages 
are put together by SMEs with experience in facility optimization and are organized by facility type and era of construction (e.g., built to ASHRAE 90.1-2007). The NZP Tool obtains the EEM package from the "PARAMS" server in an extensible markup language (XML) format and dynamically modifies the user interface to display them to the user. The NZP Tool displays packages of EEMs, such as lighting, high efficiency equipment, and airtightness (infiltration). Up to 12 different sets of packages might be applied, although there is no limit, and packages can depend on each other. The user can review the EEM parameters or accept the defaults for a first pass, coming back later to refine the EEMs and possibly select newer technology. At the end of the facility optimization step, the NZP Tool contains a dataset for each alternative with a full set of building load profiles. The user selects the EEM package based on the cost effectiveness, site criteria, DoD policy, and meeting the stated energy goals.

The electric and heating results from the facility optimization (Table 5-16) show significant reductions in energy consumption, especially in heating energy. If decentralized options are being investigated, the EEM case would have a significant impact on the sizing of HVAC equipment and ultimately, the cost. Table 5-16 lists both the building and DDs and berth energy together for comparison. The NZP Tool calculated building energy savings from baseline as 42\% (baseline 367,252 MMBtu [107,631 MWh] to EEM's 213,453 MMBtu [62,557 MWh] and the SME energy savings as 45\% (baseline 368,375 MMBtu [107,960 MWh] to EEM's 203,739 MMBtu [59.710 $\mathrm{MWh}$ ]. The process on how EEMs are applied differs in that it applies standard packages, but the overall results are still similar. The efficient buildings are then analyzed with the supply and distribution alternatives.

The assumptions for the EEMs are that the easier and less costly improvements may be done earlier on their own energy savings merit. The more extensive EEMs retrofits will be accomplished during a DER. DERs are done on the building for reasons other than for energy efficiency and then the incremental cost for energy improvements are only considered as justification for the building EEM. For PNSY, most of the buildings are old, and many are designated as historical and will be in need of a deep retrofit in the near future. Since the building savings are not enough to meet the energy goals, additional optimization of the supply and distribution infrastructure was performed. 
Table 5-16. Building Results: EEMs calculated from the SME method and the NZP Tool.

\begin{tabular}{|c|c|c|c|c|c|c|c|c|}
\hline & \multirow[b]{2}{*}{$\begin{array}{l}\text { Building } \\
\text { Facilities }\end{array}$} & \multirow[b]{2}{*}{$\begin{array}{c}\text { Building } \\
\text { Area, } \\
\mathrm{ft}^{2}\end{array}$} & \multicolumn{3}{|c|}{ SME Calculations } & \multicolumn{3}{|c|}{ NZP Tool Calculations } \\
\hline & & & $\begin{array}{l}\text { Building } \\
\text { and DD } \\
\text { Electricity, } \\
\text { MMBtu }\end{array}$ & $\begin{array}{c}\text { Building } \\
\text { and DD } \\
\text { Gas, } \\
\text { MMBtu }\end{array}$ & $\begin{array}{c}\text { Building and } \\
\text { DD Total } \\
\text { Energy, } \\
\text { MMBtu }\end{array}$ & $\begin{array}{l}\text { Building } \\
\text { and DD } \\
\text { Electricity, } \\
\text { MMBtu }\end{array}$ & $\begin{array}{l}\text { Building } \\
\text { and DD } \\
\text { Gas, } \\
\text { MMBtu }\end{array}$ & $\begin{array}{c}\text { Building and } \\
\text { DD Total } \\
\text { Energy, } \\
\text { MMBtu }\end{array}$ \\
\hline Baseline & 122 & $3,203,449$ & 274,889 & 244,985 & 519,874 & 273,684 & 245,292 & 518,977 \\
\hline Base case & 118 & $3,032,196$ & 268,467 & 240,044 & 508,512 & 301,787 & 244,975 & 546,762 \\
\hline $\begin{array}{l}\text { EEM case for } \\
\text { buildings }\end{array}$ & 118 & $3,032,196$ & 240,351 & 144,163 & 384,514 & 257,013 & 154,765 & 411,777 \\
\hline District steam & 118 & $3,032,196$ & 240,351 & 144,163 & 384,514 & 257,013 & 154,765 & 411,777 \\
\hline $\begin{array}{c}\text { District hot } \\
\text { water }\end{array}$ & 118 & $3,032,196$ & 240,351 & 144,163 & 384,514 & 257,013 & 154,765 & 411,777 \\
\hline Decentralized & 118 & $3,032,196$ & 240,351 & 144,163 & 384,514 & 257,013 & 154,765 & 411,777 \\
\hline $\begin{array}{l}\text { Net zero } \\
\text { fossil fuel }\end{array}$ & 118 & $3,032,196$ & 240,351 & 144,163 & 384,514 & 257,013 & 154,765 & 411,777 \\
\hline
\end{tabular}

\subsubsection{Energy supply and distribution analysis optimization}

The next major step in the process is to define the appropriate supply and distribution alternatives for this installation, determined by SME experience, site visits, and discussions with site energy personnel. The supply and distribution analysis of PNSY was broken down into four different groups of buildings based on their current heating sources. The heating load for these groups are met by steam from the central plant, natural gas from a distributed network, propane with building-specific storage tanks, and fuel oil with building-specific storage tanks. This breakdown was chosen to best account for the existing network infrastructure, which transports the majority of the energy used on PNSY. This study will focus on the energy sources for the first cluster, as these buildings use approximately 93\% of PNSY's total energy demand.

The buildings in this cluster use steam to meet their space heating, DHW, and industrial process loads. The cooling loads are primarily met with distributed air-cooled chillers and the electricity loads are met using a combination of generation at the central plant and power from the electrical grid. This study focuses on the heating and electricity loads, since the cooling loads for this installation are very small in comparison. Hourly heating, cooling, and electric loads for these buildings were provided using methods described in the previous section. Figure 5-21 shows the resulting load data for the combined $\sim 3,205,000$ sq $\mathrm{ft}$ of buildings in the baseline as load duration curves. 
Figure 5-21. Heating, cooling, and electric load duration curves for the baseline.

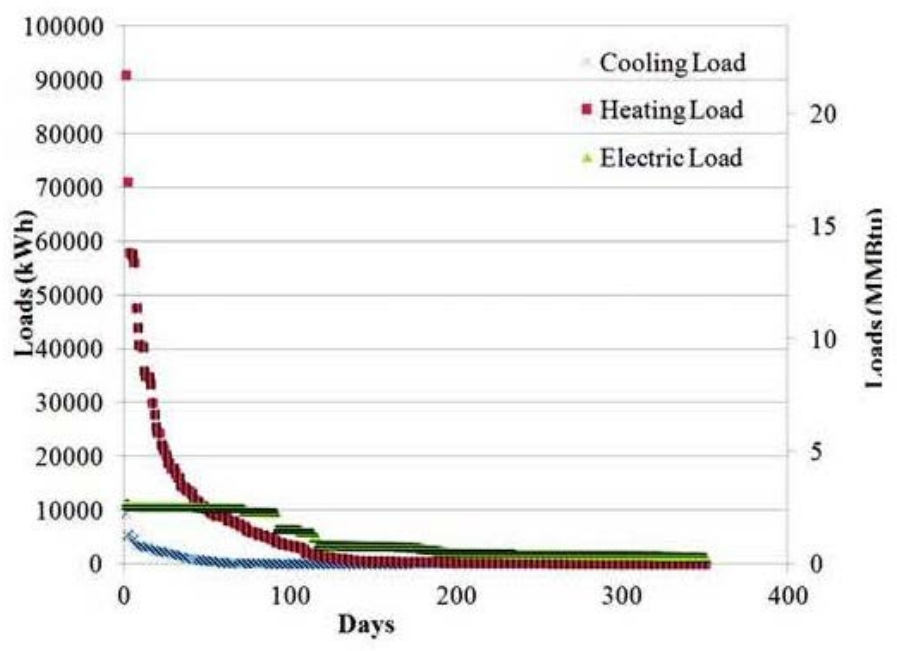

With the integrated building demand, supply and distribution scenarios were considered for the buildings connected to the existing steam network for comparative analysis and comparison to Baseline and Base Case. These scenarios are:

1. Baseline. This scenario models the building cluster as it exists today. All of the existing central plant equipment (Table 5-17) is included in this study and its operation is simulated. The energy and cost values from this scenario should match closely with PNSY's current situation.

2. Base Case. This scenario models the building cluster as it would be with all planned building construction, renovation, and demolition. It includes the existing central plant equipment and provides a status quo scenario that can be used as a comparison for the remaining scenarios.

3. District Steam. This scenario models the building cluster with a modern steam system. One of the existing natural GT is replaced with two natural gas reciprocating engines with approximately half the electrical output capacity each. These were added to increase the electricity to heat ratio of the generation equipment and better match PNSY's needs.

4. District HW and Spot Steam (District HW). The scenario models the building cluster with a modern HW system and spot steam generation to meet process load requirements. As with the district steam scenario, one of the existing natural GT is replaced with two natural gas reciprocating engines with approximately half the electrical output capacity each.

5. Decentralized. This sœenario models the building cluster with decentralized boilers/ furnaces and spot steam generation to meet process load requirements. The central plant equipment is not maintained in the scenario, but the samelevel of electrical backup is still required (15.4 MW 
[52.5 MMBtu/ hr] for the installation, as is present in the existing central plant).

6. Net Zero Fossil Fuel. This scenario models the building cluster with a modern HW system and finds the lowest equivalent annual cost equipment suite to meet net zero fossil fuel goals. This scenario allows many different energy conversion technologies to be evaluated to find the lowest cost solution. This scenario was only analyzed using the NZP Tool.

This study economic analysis was performed with an interest rate of 5\% and the following energy rates:

- electricity: \$0.095/kWh (\$27.84/ MMBtu)

- natural gas (at the central plant): $\$ 0.032 / \mathrm{kWh}(\$ 9.38 / \mathrm{MMBtu})$

- retail natural gas (distributed to individual buildings): $\$ 0.05 / \mathrm{kWh}$ (\$14.65/MMBtu)

- diesel: $\$ 0.10 / \mathrm{kWh}(\$ 29.30 / \mathrm{MMBtu})$

- propane: $\$ 0.06 / \mathrm{kWh}(\$ 17.58 / \mathrm{MMBtu})$

- biomass: $\$ 0.036 / \mathrm{kWh}(\$ 10.55 / \mathrm{MMBtu})$.

\subsubsection{Supply and distribution analysis results}

Tables 5-17 and 5-18 summarize the results of the alternatives with the Base Case. The analysis shows the potential for long-term cost savings by investing in the infrastructure now. Results from the Baseline and Base Case scenarios show the cost and usage that would be expected when the existing equipment is used with an optimal dispatch schedule. Though no investment costs are associated with these scenarios, they are among the most costly solutions on an annualized basis. These high annual costs are primarily the result of an aging and very inefficient steam network. The dark factory test determined the standby energy loss to be $\sim 29,000 \mathrm{lb} / \mathrm{h}(\sim 10,000$ $\mathrm{kW})$. This is about $25 \%$ more heat than is produced by full load operation of one of the natural GT. 
Table 5-17. Summary of the energy supply equipment used for each alternative.

\begin{tabular}{|c|c|c|c|c|c|c|}
\hline NZP Results & Baseline & Base Case & District Steam & $\begin{array}{l}\text { District } \\
\text { Hot Water }\end{array}$ & Decentralized & $\begin{array}{l}\text { Net Zero } \\
\text { Fossil Fuel }\end{array}$ \\
\hline $\begin{array}{l}\text { Supply and distribution } \\
\text { investment cost (\$) }\end{array}$ & 0 & 0 & 54.6 million & 43.9 million & 40.6 million & 153.3 million \\
\hline \multicolumn{7}{|l|}{ On-demand capacity: } \\
\hline Heating, kW (MMBtu/h) & $129,000(440)$ & $129,000(440)$ & $107,000(364)$ & $109,000(371)$ & NA & $\begin{array}{c}118,000 \\
(402)\end{array}$ \\
\hline Electricity (kW) & 15,400 & 15,400 & 15,700 & 15,700 & 16,000 & 15,400 \\
\hline Net electricity purchase (kWh) & 23.2 million & 31.0 million & 14.5 million & 16.2 million & 78.2 million & 0 \\
\hline Electricity generation (kWh) & 59.2 million & 59.8 million & 63.9 million & 62.3 million & 0 & 61 million \\
\hline $\begin{array}{l}\text { Natural gas use, } \mathrm{kWh} \\
\text { (MMBtu) }\end{array}$ & $\begin{array}{l}259 \text { million } \\
(885,000)\end{array}$ & $\begin{array}{l}259 \text { million } \\
(887,000)\end{array}$ & $\begin{array}{l}196 \text { million } \\
(670,000)\end{array}$ & $\begin{array}{l}188 \text { million } \\
(643,000)\end{array}$ & $\begin{array}{l}46 \text { million } \\
(157,000)\end{array}$ & 0 \\
\hline Biomass use, kWh (MMBtu) & 0 & 0 & 0 & 0 & 0 & $\begin{array}{c}245 \text { million } \\
(838,000)\end{array}$ \\
\hline Green house gas, mt (t) & $60,300(66,470)$ & $65,000(71,650)$ & $43,500(47,950)$ & $43,300(47,730)$ & $61,700(68,010)$ & 0 \\
\hline $\begin{array}{l}\text { Source fossil-fuel-based } \\
\text { energy use, } \mathrm{kWh} \text { (MMBtu) }\end{array}$ & $\begin{array}{l}348 \text { million/ } \\
1,190,000\end{array}$ & $\begin{array}{l}375 \text { million/ } \\
1,283,000\end{array}$ & $\begin{array}{l}254 \text { million/ } \\
868,000\end{array}$ & $\begin{array}{l}251 \text { million/ } \\
858,000\end{array}$ & $\begin{array}{l}308 \text { million/ } \\
1,057,000\end{array}$ & 0 \\
\hline Renewable percentage & 0 & 0 & 0 & 0 & 0 & 100 \\
\hline Equivalent annual cost (\$) & 21.2 million & 22 million & 16.4 million & 15.7 million & 17.0 million & 29.30 million \\
\hline
\end{tabular}

Table 5-18. Summary of the energy supply equipment used for each alternative.

\begin{tabular}{|c|c|c|c|c|c|c|}
\hline & Baseline & $\begin{array}{l}\text { Base } \\
\text { Case }\end{array}$ & $\begin{array}{l}\text { District } \\
\text { Steam }\end{array}$ & $\begin{array}{l}\text { District } \\
\text { Hot Water }\end{array}$ & Decentralized & $\begin{array}{l}\text { Net Zero } \\
\text { Fossil Fuel }\end{array}$ \\
\hline $\begin{array}{c}\text { Existing Nebraska boilers, } \\
25500 \mathrm{~kW}(87 \mathrm{MMBtu} / \mathrm{h}) \text { thermal }\end{array}$ & 3 & 3 & 3 & 3 & & 2 \\
\hline $\begin{array}{l}\text { Existing natural gas turbines, } \\
5700 \mathrm{~kW}(19.4 \mathrm{MMBtu} / \mathrm{h}) \text { electric } \\
8040 \mathrm{~kW}(27.4 \mathrm{MMBtu} / \mathrm{h}) \text { thermal }\end{array}$ & 2 & 2 & 1 & 1 & & 1 \\
\hline $\begin{array}{l}\text { Existing duct boilers, } \\
18,200 \mathrm{~kW}(62.1 \mathrm{MMBtu} / \mathrm{h}) \text { thermal }\end{array}$ & 2 & 2 & 1 & 1 & & 1 \\
\hline $\begin{array}{c}\text { Existing diesel generators, } \\
2000 \mathrm{~kW}(6.7 \mathrm{MMBtu} / \mathrm{h}) \text { electric }\end{array}$ & 2 & 2 & 2 & 2 & 2 & 2 \\
\hline $\begin{array}{l}\text { Natural gas reciprocating engine with steam generation, } \\
\begin{array}{l}3000 \mathrm{~kW}(10.2 \mathrm{MMBtu} / \mathrm{h}) \text { electric } \\
2000 \mathrm{~kW}(6.7 \mathrm{MMBtu} / \mathrm{h}) \text { thermal })\end{array}\end{array}$ & & & 2 & & & \\
\hline $\begin{array}{l}\text { Natural gas reciprocating engine with hot-water generation, } \\
3000 \mathrm{~kW}(10.2 \mathrm{MMBtu} / \mathrm{h}) \text { electric } \\
3100 \mathrm{~kW}(10.55 \mathrm{MMBtu} / \mathrm{h}) \text { thermal }\end{array}$ & & & & 2 & & \\
\hline $\begin{array}{c}\text { Diesel generators, } \\
2000 \mathrm{~kW}(6.7 \mathrm{MMBtu} / \mathrm{h}) \text { electric }\end{array}$ & & & & & 4 & \\
\hline $\begin{array}{l}\text { Biomass with hot-water generation, } \\
5100 \mathrm{~kW}(17.3 \mathrm{MMBtu} / \mathrm{h}) \text { electric } \\
7650 \mathrm{~kW}(26 \mathrm{MMBtu} / \mathrm{h}) \text { thermal }\end{array}$ & & & & & & 1 \\
\hline $\begin{array}{c}\text { Biomass boiler, } \\
16,000 \mathrm{~kW}(54.6 \mathrm{MMBtu} / \mathrm{h}) \text { thermal }\end{array}$ & & & & & & 1 \\
\hline $\begin{array}{c}\text { Decentralized boilers, } \\
\text { (sized for building loads in base case) }\end{array}$ & & & & & 1 & \\
\hline
\end{tabular}


Additionally, maintenance and operations costs for the network topped $\$ 4.5$ million for FY 2012. This has resulted in a very expensive and energyintensive supply and distribution system. However, the electricity produced by the natural GT at the central plant has helped to significantly reduce PNSY's source energy usage, when compared to using grid electricity and provided a secondary source of electricity for the installation.

The district steam scenario would require an approximately $\$ 54.6$ million investment (NZP Tool estimate) in a modern steam system and two reciprocating engines, but would be significantly less expensive than the Base Case on an annual basis. The heat from the exhaust of the two engines would be used to produce steam for the network, but the heat that could be recovered from the engine itself will be at too low a temperature to be useful for providing heat to the network. This means that some of the heat is wasted from the reciprocating engines. However, there are two advantages to maintaining steam distribution. First, steam is still used for a few of the process loads throughout the installation, and alternative steam sources will be needed if the steam network is replaced with HW. Second, many of the buildings have low-pressure steam distribution, which would need to be largely replaced if the building is to be heated with HW. The source energy and annual equivalent cost for this scenario drops approximately onethird when compared to the Base Case.

The district HW scenario is very similar to the district steam scenario, but with a few key differences. This scenario would require an approximately \$44 million investment (NZP Tool estimate) for a modern HW distribution network and the same two reciprocating engines used in the modern steam alternative. Switching to a HW network will require changing out some of the heat exchangers for buildings that currently distribute lowpressure steam. Spot steam generation will be required for the few remaining process-related loads. Both of these changes increase the investment cost of the scenario, but it still remains significantly less costly than the modern district steam scenario. The lower operating temperatures of the system lead to lower conduction losses in the network and ultimately, lower costs of operation. Furthermore, this HW system can take advantage of all of the waste heat generated by the natural gas reciprocating engines. This fact leads to the district HW scenario having lower source energy consumption and operating costs than the district steam scenario. 
The decentralized scenario would meet the building heating loads for the buildings connected to the current steam system using individualized building boilers and would require an investment of approximately $\$ 41$ million (NZP Tool estimate). The costing for this scenario was done using RS Means per square foot costing estimates and the total was multiplied by the PNSY markup rate. Additionally, four new diesel generators were included to meet the $15.4 \mathrm{MW}$ (52.5 MMBtu/hr) critical electricity requirements (same as the other scenarios). This scenario assumes that the extension of the natural gas lines to the remaining buildings (either by PNSY or a third party) would result in a natural gas rate that is the same as what is currently paid for the existing decentralized buildings. This "retail" natural gas rate is about $50 \%$ higher than the rate paid for natural gas at the central plant. The additional cost reflects the increased cost of distributing natural gas to many buildings with lower usage. This brings up an interesting point: a pipeline network of some sort (whether a fuel or thermal fluid) is currently required for buildings in a climate that requires significant heating. Some have argued against centralized heating systems due to the costs related to thermal distribution networks; however, pipeline network costs are present even in decentralized solutions. These costs are often masked, as they are rolled into the energy price of the natural gas. The modeling results show that the decentralized scenario uses less source energy than the Base Case and costs significantly less on an annual basis, but uses more source energy and costs more on an annual basis than the two modern thermal distribution systems. This scenario has the additional benefit of being relatively simple and modular to implement. However, this scenario does not provide the same site energy security as the central systems.

The Net Zero Fossil Fuel scenario finds the lowest equivalent annual cost solution to providing the heating, cooling, and electrical needs of the building cluster without netting any fossil fuel over the course of the year. In theory, this means that the installation can use fossil fuel, but must export power (generally renewably generated) off the installation to offset someone else's fossil fuel consumption. Table 5-17 lists the energy supply equipment used in this scenario, including the addition of biomass cogeneration and biomass boilers. A few points stand out from the results. First, most of the existing equipment was maintained in this solution. This equipment was maintained to fulfill the thermal and electrical capacity/redundancy requirement. Essentially, this fossil fuel based equipment would be used for peaking (using biogas) and to meet loads during emergencies. 
The majority of the time, the loads would be met using heat and electricity derived from biomass. Second, this scenario is about twice as expensive on an annual basis as the modernized HW system alone and almost 50\% more expensive annually than the Base Case, although it does achieve the net zero fossil fuel energy goal. This analysis provides a rough estimate of the cost of attaining the net zero goals for PNSY. Finally, the solution lends itself well to having a resilient and highly redundant installation. The installation would be able to provide electricity from four different sources (grid, natural GT, diesel generators, and biomass-based steam turbines) and heating from four sources (natural gas, biogas, diesel/fuel oil, and biomass). This should allow the installation to maintain critical functions even under severe fuel supply restrictions.

\subsubsection{Comparison of SME and NZP tool results}

The SME group analyzed the same set of alternatives as for the NZP Tool, except the Net Zero Fossil Fuel scenario. Table 5-19 lists a comparison of the SME and NZP Tool results. The table shows that the energy and investment costs results of the two groups have some differences, but the cost and energy ranking of the scenarios by both groups are nearly the same. The major differences in the life cycle costs (LCC) between the SME group and the NZP Tool are determined by what is included in the Base Case finances.

The building loads and fuel usage for the scenarios (Table 5-16) are different and discussed in the facility level optimization section with all the energy results compared in more detail. The baselines are close, but the SME process for applying EEMs is customized, while the NZP Tool applies standardized packages by facility group with customization of the input parameters for the installation. This leads to different and more conservative results than the SME process. The data in Table 5- 19 show that the deviation between fuel usages starts to vary more after the building EEMs are applied beyond the Base Case scenario. However, most important is that the strategic decisions and rankings are maintained between the two processes. 
Table 5-19. Energy comparison between SME analysis and the NZP Tool results by scenario.

\begin{tabular}{|c|c|c|c|c|c|c|c|}
\hline \multirow[b]{2}{*}{ Scenarios } & \multicolumn{7}{|c|}{ I-P Units SME Energy, MMBtu/yr } \\
\hline & $\begin{array}{l}\text { Total Fossil Fuel } \\
\text { and Biomass Fuel }\end{array}$ & $\begin{array}{c}\text { Total } \\
\text { Electricity }\end{array}$ & $\begin{array}{l}\text { Total Site } \\
\text { Energy }\end{array}$ & $\begin{array}{l}\text { Total } \\
\text { Source } \\
\text { Energy }\end{array}$ & $\begin{array}{c}\text { \% Source } \\
\text { Energy } \\
\text { Reduction } \\
\text { from Baseline }\end{array}$ & $\begin{array}{c}\text { Investment } \\
\$\end{array}$ & $\begin{array}{c}\text { Life Cycle Cost } \\
\text { (Discount Rate } \\
\quad=3 \% \text { ) }\end{array}$ \\
\hline Baseline & 919,743 & 87,214 & $1,006,957$ & $1,257,443$ & $0 \%$ & & \\
\hline Base case & 956,185 & 68,823 & $1,025,007$ & $1,230,896$ & $2 \%$ & & $\$ 262,290,000$ \\
\hline District steam & 411,504 & 82,949 & 494,453 & 707,849 & $44 \%$ & $\$ 119,160,000$ & $\$ 267,020,000$ \\
\hline District hot water & 232,469 & 158,050 & 390,520 & 771,246 & $39 \%$ & $\$ 106,940,000$ & $\$ 250,070,000$ \\
\hline \multirow[t]{2}{*}{ Decentralized } & 118,538 & 231,582 & 350,120 & 897,564 & $29 \%$ & $\$ 116,690,000$ & $\$ 268,930,000$ \\
\hline & \multicolumn{7}{|c|}{ I-P Units NZP Energy, MMBtu/yr } \\
\hline Scenarios & $\begin{array}{c}\text { Total } \\
\text { Fossil Fuel }\end{array}$ & $\begin{array}{c}\text { Total } \\
\text { Electricity }\end{array}$ & $\begin{array}{c}\text { Total } \\
\text { Site } \\
\text { Energy }\end{array}$ & $\begin{array}{l}\text { Total } \\
\text { Source } \\
\text { Energy }\end{array}$ & $\begin{array}{c}\text { \% Source } \\
\text { Energy } \\
\text { Reduction } \\
\text { from Baseline }\end{array}$ & $\begin{array}{c}\text { Investment } \\
\$\end{array}$ & $\begin{array}{c}\text { Life Cycle Cost } \\
\text { (Discount Rate } \\
\quad=3 \% \text { ) }\end{array}$ \\
\hline Baseline & 883,096 & 79,257 & 962,354 & $1,189,302$ & $0 \%$ & & \\
\hline Base case & 885,192 & 105,845 & 991,036 & $1,280,301$ & $-8 \%$ & & $\$ 477,361,000$ \\
\hline District steam & 669,647 & 49,435 & 719,082 & 866,227 & $27 \%$ & $\$ 155,220,000$ & $\$ 460,051,000$ \\
\hline District hot water & 641,520 & 55,239 & 696,759 & 856,161 & $28 \%$ & $\$ 144,570,000$ & $\$ 435,313,000$ \\
\hline Decentralized & 155,471 & 266,939 & 422,410 & $1,054,345$ & $11 \%$ & $\$ 141,240,000$ & $\$ 467,827,000$ \\
\hline
\end{tabular}

The assumptions for the building EEM investments are made using a generalized investment strategy, much like the generalized energy modeling. The SMEs used on average overall $\sim \$ 10 / \mathrm{sq} \mathrm{ft}\left(\$ 107.64 / \mathrm{m}^{2}\right)$ for the $3,205,000$ sq $\mathrm{ft}\left(297,754 \mathrm{~m}^{2}\right)$ of buildings at PNSY for a cost of $\$ 32,000,000$. With the PNSY DoD markup, the investment becomes $\$ 59,200,000$. The NZP analysis used an approximate investment cost of $\$ 17 / \mathrm{sq} \mathrm{ft}\left(182.99 / \mathrm{m}^{2}\right)$ or $\$ 54,000,000$, and with the PNSY DoD markup, the EEM incremental investment is $\$ 100,640,000$. This incremental EEM investment is the additional cost to upgrade the energy efficiency of the buildings added on to the base cost when the buildings are retrofitted or repaired. This investment is assumed to take place over the first 10 years in the NZP analysis.

The supply and distribution investment costs determined by the SME group for the three scenarios agreed with the NZP estimates to within $\pm 17 \%$ for all components except the thermal distribution networks. The NZP estimates for the thermal network costs were significantly higher than those of the SME group ( $\sim 40 \%$ larger). This difference underscores the difficulty in costing large networks in built-up urban areas. However, the investment cost ranking was still consistent between the two groups (decentralized has the lowest first cost and district steam has the highest). 
Some of the differences may also be a result of the different costing data sources. NZP cost estimate data for the networks and central plant equipment were determined from recent work with other military installations, discussions with a company that does costing work for the Army Corps of Engineers, and National Renewable Energy Laboratory publications (NREL) on current price ranges for renewable energy technologies. The SME team cost estimates were determined from European and Canadian costing guides and sources.

The same trend in LCC appears in both methods, where maintaining the status quo (i.e., "doing nothing") is costly and investing in a district heating system is cost effective. In both sets of results, decentralization is not as cost effective as the district heating system and district steam system. In the SME results, decentralization is not shown to be as cost effective as business as usual or the Base Case, but these results are very close and may be within error bars for assumptions used. Remember that the modern steam system is not the old steam systems typically seen in legacy systems. These modern systems are direct buried with very few steam traps and no rigid supports.

Since the approaches by the SME group and NZP Tool are different in the way that building EEMs are applied and that observation and measurements are determined, the Base Case LCC numbers obtained by SME and from NZP Tool cannot be directly compared. Comparison of LCC numbers is invalid and should not be done because each individual analysis includes different Base Case values. The important aspect is that, with similar investments, both methodologies recommend the same strategic direction. The economic analysis by the SMEs was done by a proprietary spreadsheet method, while the NZP results were input into Building Life Cycle Cost (BLCC-NIST 2013) 5.3 software program from National Institute of Standards and Technology.

Note that currently the LCC analysis for the Net Zero Fossil Fuel case is not cost effective. Either the price of fuel will escalate faster than the NIST predictions, or there will be a valuation of GHG or carbon tax to make these types of scenarios cost effective using government LCC procedures. 


\subsection{Discussion}

Modeling results at the building loads step in the process using the NZP tool were very close to those obtained using the SME approach, but required much less effort (in time and labor, and resulting labor costs). The reduction of the loads with the EEMs was not enough to meet the energy goals for the installation, which include energy security and carbon footprint reduction with source energy and GHG. Navy installations can purchase renewable energy credits (RECs), but PNSY leadership has expressed a desire to not exercise that option to attain the targets.

The baseline analysis of the installation is always very insightful and allowed the analysis teams to quantify the magnitude of the steam distribution losses. It was fortunate that PNSY took this seriously and performed the dark factory test, and provided the data from the procedure.

The investment cost and energy usage results for both groups agreed within 10 to $20 \%$ for all of the scenarios, despite the differences in the process used by each group. Furthermore, the energy usage and investment cost rankings were the same for both groups and ultimately resulted in the same recommendations to the installation.

The Energy Master Plan developed for PNSY through ESTCP project using NZE Planner was demonstrated in December 2014 to the PNSY PWT team. During the 2 days of training conducted at the installation site (Figures 5-22 and 5-23), master planners and energy engineers learned how to modify scenarios already included into the PNSY specific model, how to modify Baseline and Base Case inputs, and how to develop other alternatives using different energy prices, energy supply strategies, and different levels of buildings' energy improvement.

Also, in J uly 2014, ERDC researchers participated in Sustainability Component development of Energy Master Plan at Fort Hunter Liggett. During the week long training of installation's master planners and energy engineers, they demonstrated use of the NZE Planner Tool for modeling of alternative of sustainable strategies and comparing modeling results to determine which strategies would be best to implement at Fort Hunter Liggett. 
Figure 5-22. Technology transfer - Net Zero Planner user training.
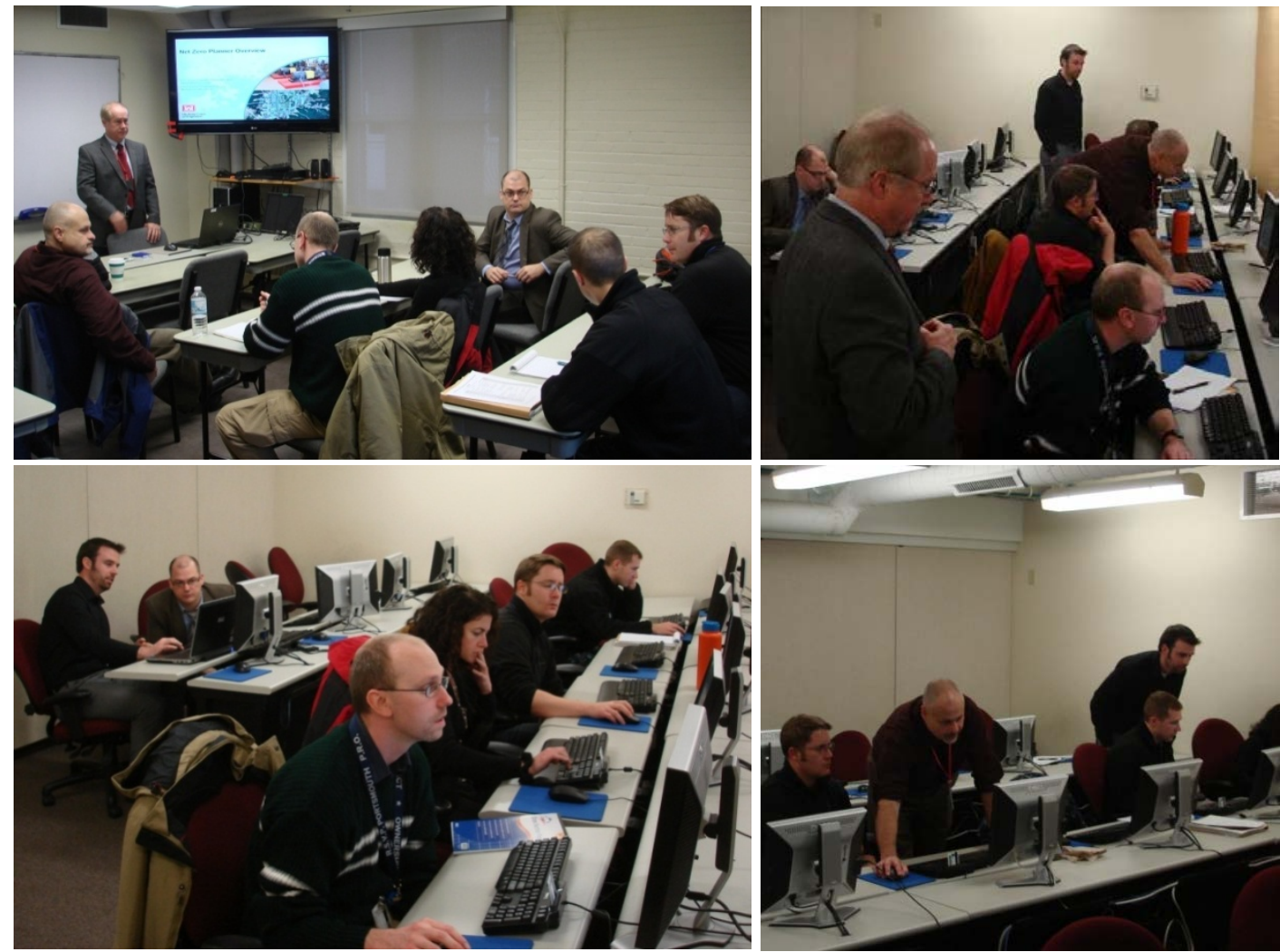

Figure 5-23. Net Zero Planner installation onsite training.

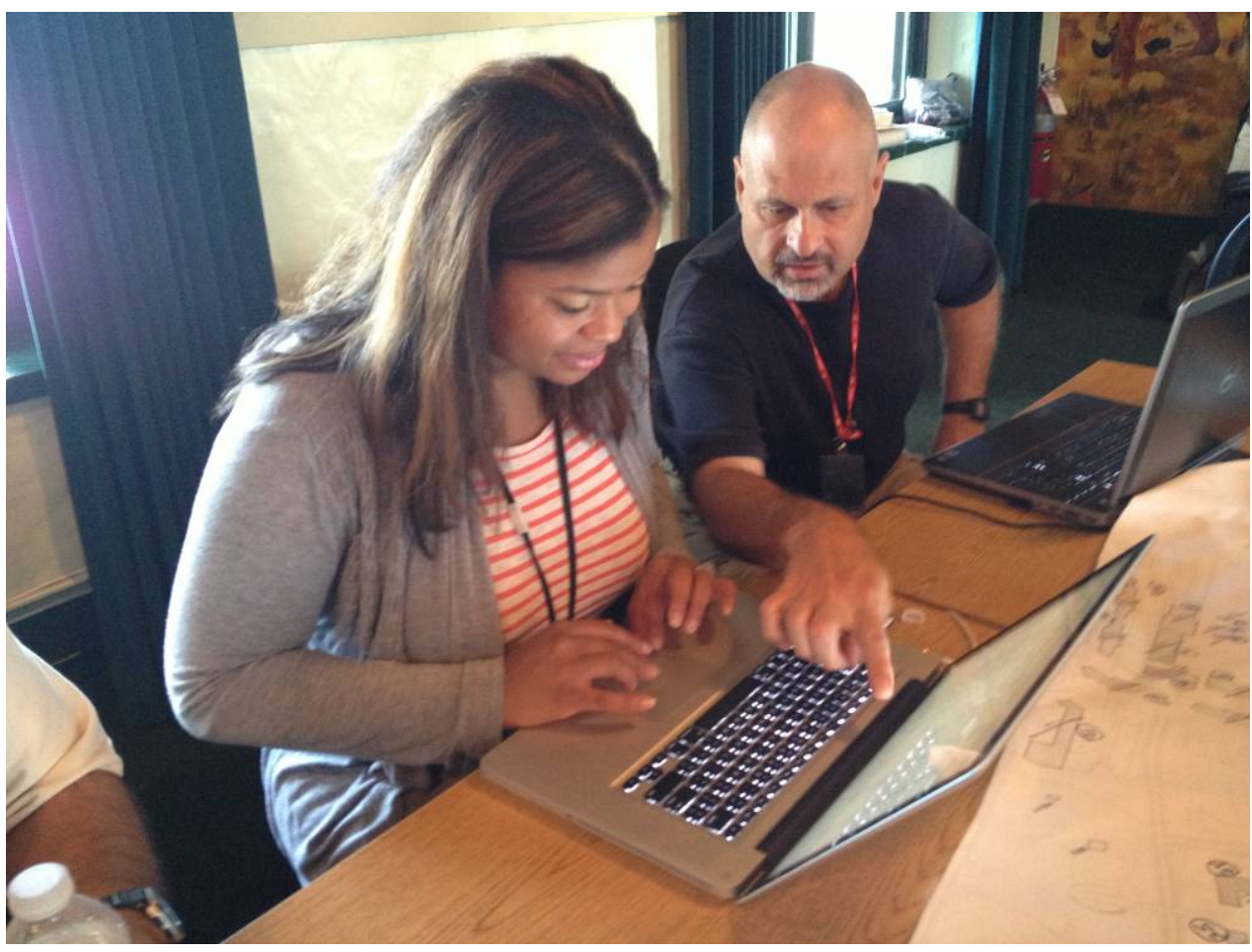




\section{Performance Assessment}

The six performance objectives listed in Table 3-1 (p 50) include:

- Installation/ campus-wide 55\% source energy use

- Energy cost reduction of $60 \%$ compared to Base Case

- Projected electricity peak load below capacity limitation

- Achieved energy security to satisfy $100 \%$ critical facilities power needs by onsite uninterruptable power generation

- Not more than 15 years simple payback of proposed best scenario compared to Base Case

- Less than 1 year planning costs recovery.

Table 6-1 lists the results of an analysis of the demonstration projects alongside the first five performance objectives, for comparison. These data show that performance parameters at the USMA NZE Area exceed the stated goals while source energy and energy cost reduction and SPB goals at PNSY have not been met. The main reason for not meeting these goals is that PNSY is the Navy industrial site and most of energy use is based on missionrelated processes. Though process-related energy consumption can be reduced (e.g., by installation of energy efficient scaffolding and other processrelated measures), the level of energy use reduction is limited.

For the project demonstration, "Objective 6 - Planning Cost Recovery," is the most critical. The success criterion for this objective was that the roadmap planning costs could be recovered from 1 year's energy savings.

Table 6-1. Cost summary for analysis using the SME and NZP.

\begin{tabular}{|c|c|c|c|c|c|c|}
\hline \multirow[b]{2}{*}{ Installation } & \multirow{2}{*}{$\begin{array}{l}\text { Number of } \\
\text { Buildings }\end{array}$} & \multirow{2}{*}{$\begin{array}{l}\text { Number of } \\
\text { Building } \\
\text { Categories }\end{array}$} & \multicolumn{2}{|c|}{ Time Required } & \multicolumn{2}{|c|}{$\begin{array}{l}\text { Cost of Data Analysis Using, } \\
\qquad \$ 1000\end{array}$} \\
\hline & & & SME & NZP & SME & NZP \\
\hline USMA, West Point & 45 & 11 & 5 months & 5 wks & 167 & 50 \\
\hline PNSY & 127 & 22 & 4 months & $5 \mathrm{wks}$ & 130 & 50 \\
\hline
\end{tabular}


This project has tested the cost effectiveness of using NZP Planner Tool compared to current best practices. The NZE Area selected for analysis at USMA, West Point included 45 buildings in 18 building categories (separated by building type and age). The PNSY NZE Area included 127 buildings in 22 building categories. The demonstration at both sites was conducted using two separate teams of experts with relevant experiences from the United States and around the world. This cost analysis assumed that data collection to develop a baseline would follow a similar process with and without use of the NZP Planner Tool, and would thus require the same effort and the same level of funding.

Tasks 2, 3, 5, and 7 of the ERDC contract with the PERTAN Company provided SME support for USMA and PNSY projects in development of building analysis and district/ cluster analysis. The part of the budget dedicated to energy analysis of different scenarios at the USMA NZE Area was about $\$ 130 \mathrm{~K}$, and at PNSY was about $\$ 100 \mathrm{~K}$. Both projects involved unique, historic buildings, which required more effort in their analysis.

Based on the data collected by the ERDC researchers and SMEs before energy analysis and used in both approaches (with and without NZE Planner Tool), the second approach required data setup, building level modeling, calibration, and the modeling and iteration of generation and distribution scenarios. This work, which was performed by the ERDC team, took about 3 weeks and cost about $\$ 50 \mathrm{k}$, when using the NZP Tool (this cost is further discussed in the next section).

Thus, the use of NZP Tool reduces the time required for the analysis and the analysis cost to only a fraction ( $\sim 33 \%)$ of that of the alternative current best practice (Table 6-1). Chapter 8, "Cost Assessment" includes more detailed information on the costs associated with performing an Energy Master Plan, including the reductions due to the streamlining work developed through this project

Besides its use on pilot projects funded by ESTCP program, NZP is currently being used at Fort Leonard Wood, MO and several other installations. After the ESTCP project is finalized, ERDC is planning to conduct technology transfer to Federal and private sector teams that provide support to DoD installations. All DoD installations can therefore benefit from adaptation of the demonstrated concept and the software package. In ad- 
dition a pilot program is being developed at the USACE Fort Worth District to provide usage of the NZP Tool to provide the SCP overlay for the required ADPs at installations. In 2015, 23 SCPs are being developed using the NZP Tool with teams provided by the district office. If this pilot program is successful, and a Standard Procedure is developed to implement the NZP Tool in the ADP/ SCP process, then this can be scaled up to other districts across the Army. 


\section{Cost Assessment}

This chapter discusses the costs associated with performing an Energy Master Plan (EMP) and compares those costs with and without the use of the Net Zero Planner (NZP) Tool.

\subsection{Cost model}

Table 7-1 briefly summarizes the cost elements involved in developing an Energy Master Plan using the NZP Tool (the cost of performing an EMP without the tool will be taken as the contractor costs for the work performed on PNSY and WPMA). The cost estimates provided apply to studies with 100-200 buildings. The total cost will increase or decrease with the total number of buildings for communities that are much larger or smaller than the range provided. Many of the cost elements (related to the NZP Tool) were not charged to the ESTCP project (such as server costs and training costs) because a separate research project was paying for these costs. However, the labor costs were significantly higher as the overall process was being studied and performed by contractors and the NZP Tool team in parallel. The elements needed to perform an Energy Master Plan using the NZP Tool are:

1. Labor: This cost element is for the team that performs the Energy Master Plan for the installation. This team can be composed of as little as two people (depending on the size of the installation or area). The work takes an average of five full time equivalent weeks for both members, but could be spread over a longer period of time. The work includes:

2. Discussion of the goals for the study with installation personnel

3. Gathering general site data (GIS, metering data, real property data, utility rate schedules, etc.) and preparing the study

4. Traveling to the site to confirm the electronic data and perform building and central plant walkthroughs

5. Correcting and supplementing the study information based on the site visit

6. Follow-up with the installation personnel and further corrections

7. Generation of potential energy alternatives for the installation

8. Traveling to the second site visit to communicate the results

9. Follow-up with installation personnel and final report. The costs associated with this element scale with the size and complexity of the installation or area.

10. Travel: This cost element is straightforward and scales with the locality costs and travel distance/ complexity. 
11. Server Costs: This cost element is related to the cost of hosting the NZP Tool siteand providing computational power (servers) to perform theanalysis. This is a set cost for each installation or area.

12. Training: This cost element is associated with training new NZP Tool users and should be thought of as an average training cost per project. To date, training has been performed in a classroom setting for groups of 1525 people and during site visits for 1-2 users as a final preparation for independent use of the tool. The training shows users how to perform all of the analysis tasks in the tool, provides a basic understanding of the energy master planning process, and gives the user some rule of thumb type knowledge to help guide them in the field. About five of the classroom-type training events have been held to date, but this will become standard as the tool continues to see increased use. This element is a fixed cost for each installation or area.

13. Maintenance and Feature Development: This cost element is associated with the computer scientists and research engineers that continue to develop and improve the NZP Tool. They play a critical support role and can continue to reduce the amount of manual work that must be done to complete the Energy Master Plan. This cost element is fixed for each installation or area.

14. Organizational Overhead: This cost element is associated with the organization that supports the workers that perform the Energy Master Plan and the maintenance and development personnel. This cost element is fixed for each installation or area.

Table 7-1. Cost Model for use of the NZP Tool on an Installation.

\begin{tabular}{|c|c|c|}
\hline Cost Element ${ }^{*}$ & Description & Estimated Costs \\
\hline Labor & $\begin{array}{l}\text { Labor for SMEs that perform the study on the } \\
\text { installation or an ADP within the installation. }\end{array}$ & $\begin{array}{l}\$ 130 / \mathrm{hr} \text { for } 5 \text { weeks } \\
(40 \mathrm{hrs} * 5) \times 2 \\
\text { People }=\$ 52,000\end{array}$ \\
\hline Travel & Travel costs to installation ( 2 trips for the team). & $\begin{array}{l}\$ 2,000 / \text { trip } * 2 \\
\text { people } \times 2 \text { trips }= \\
\$ 8,000\end{array}$ \\
\hline Server Costs & $\begin{array}{l}\text { Costs associated with owning and operating (or } \\
\text { renting) the servers that run the NZP Tool. }\end{array}$ & $\$ 7,000$ \\
\hline Training & $\begin{array}{l}\text { Costs associated with training additional } \\
\text { engineers to use the tool. This training may } \\
\text { involve travel to a site to learn from an } \\
\text { experienced group. }\end{array}$ & $\$ 5,000$ \\
\hline $\begin{array}{l}\text { Maintenance and } \\
\text { Feature } \\
\text { Development }\end{array}$ & $\begin{array}{l}\text { Additional labor for research team that continues } \\
\text { development and fixes bugs with the NZP Tool. } \\
\text { This also covers importing and adjusting the } \\
\text { installation's geospatial data. }\end{array}$ & $\$ 16,000$ \\
\hline
\end{tabular}




\begin{tabular}{|l|l|l|}
\hline Cost Element ${ }^{*}$ & Description & Estimated Costs \\
\hline Subtotal & & $\$ 88,000$ \\
\hline $\begin{array}{l}\text { Organizational } \\
\text { Overhead }\end{array}$ & Overhead costs for support personnel, building, & $\sim 40 \%$ add-on $=$ \\
& etc. & $\$ 35,200$ \\
\hline Grand total & & $\$ 123,200$ \\
\hline
\end{tabular}

\subsection{Cost drivers}

The main cost drivers associated with the Energy Master Plan are the size and complexity of the installation or area.

The size (in terms of area and buildings considered) adds to the labor involved in performing a site walkthrough and confirming data for the existing building stock. This factor generally increases the cost of study linearly as the size increases. The costs listed in Table 7-1 are average values for an installation or area with $\sim 100-200$ buildings.

The complexity of a site can add additional cost and time to a study as well. The complexity of the site generally refers to energy usages that are unknown (things like the large steam process loads for manufacturing or repair found at Portsmouth) or issues that have not been handled before in the process. These complexities require a break from the established data collection and verification process and sometime require additional work to the NZP Tool. However, now that many studies have been performed in the tool (there will be greater than 30 studies completed in the tool by the end of 2015), most of the issues and complexities that arise in studies have been studied and solved.

\subsection{Cost analysis and comparison}

This section compares the cost of completing an EMP using the Net Zero Planner (NZP) Tool to the cost of completing the same plan without the tool. The initial work that led to installation Baseline and Base Case cost approximately $\$ 150 \mathrm{k}$ for each contractor group/installation. This cost covered all the initial data collection (including utility bills, utility rate schedules, building data collected through walkthroughs, central plant and distribution network data, etc.), customer interactions (to determine energy goals, installation priorities and preferences, etc.), and the analysis required to develop models of the current status of the installation (baseline) and the business as usual situation (Base Case). Most of these steps require roughly the same amount of time and work when performed by a 
contractor group or by using the NZP Tool, but the workload of the analysis step is significantly reduced when using the NZP Tool. This workload reduction drops the cost of developing the Baseline and Base Case when using the NZP Tool to $\sim \$ 75 \mathrm{k}$. The benefits of using the NZP Tool are even greater when developing energy alternatives for the installation.

The cost of adding contractor-developed energy alternatives to the Baseline and Base Case analysis was $\sim \$ 130 \mathrm{k}$ for the USMA, West Point study. This cost was based on the size ( 44 buildings and $\sim 4.4$ million sq $\mathrm{ft}$ of conditioned area) and complexity of the installation. The complexity in the USMA, West Point study was primarily due to the historic nature of the buildings (limiting the potential for exterior renovations), the existing steam system (with vastly different pressure/ temperatures being delivered to different buildings and seasonal shutoffs), and the seasonal nature of the energy usage for some of the buildings (due to the university type of usage).

The cost of adding contractor-developed energy alternatives to the Baseline and Base Case analysis was $\sim \$ 167 \mathrm{k}$ for the Portsmouth Naval Shipyard study. Again, the cost was based size (127 buildings and 3.2 million sq $\mathrm{ft}$ of conditioned area) and complexity of the installation. The complexity in the Portsmouth Naval Shipyard study was primarily due to the unknown size of the steam and electrical process loads related to the repair of naval equipment, the poor condition of the steam distribution lines (sections of these lines become completely submerged in the salt water at various times of the year), the security division of the installation (restricting certain changes within this region), and the number and variety of buildings in the installation.

The cost of adding energy alternatives to the Baseline and Base Case analysis using the NZP Tool is about $\$ 50 \mathrm{k}$ (resulting in the total cost of $\sim \$ 125 \mathrm{k})$. This dramatic reduction in the cost is due to the automation of the data handling associated with producing these alternatives. For example, changes to the building models and applying EEMs can be made with just a few mouse clicks and quickly applied to entire groups of similar builds. These changes are then automatically recalculated so the results are available to the user within minutes. The contractor group would need to go into each building model to make specific changes to multiple parameters, then rerun all the building models, and finally sum up all the re- 
sults for all the building types. This is a significant effort when done manually for any large number of buildings and the sheer volume of manual data handling increases the chance for errors.

Additionally, new alternatives can be built off of existing alternatives using a single copy button. This functionally allows the transfer of all study information (weather, climate, utility rate structures, etc.), building data, and central plant infrastructure data to be copied over for the next alternative. The user can then make small changes (for example, adding the potential to use cogeneration equipment at the central plant) to the alternative, and have updated results for the new scenario within 15-30 minutes. This is a vast reduction in the amount of time that is needed to develop additional alternatives.

In the end the approximate cost of the contractor-led Energy Master Plans was $\sim 300 \mathrm{k}$ for each installation. Compared with the $\sim 125 \mathrm{k}$ listed in Table 7-1, this amounts to a savings of over half.

A fee of $\sim \$ 100 \mathrm{k}$ was charged to installations for 23 Energy Master Plans that are being performed during the FY15 (about halfway done at the writing of this report). The cost is slightly lower than the cost of the work done for USMA, West Point and Portsmouth Naval Shipyard due to the reduced size and complexity of these studies and the increased efficiency of the process, as a result of the work done here. The energy master planning process was further developed since it was used for USMA, West Point and Portsmouth. It is now called a Sustainability Component Plan (SCP) and is performed after the completion of an $\mathrm{ADP}$ to add energy guidance to the planning process. The Sustainability Component Plan currently provides energy usage data for the Baseline, Basecase, Better Case, and Best Case alternatives. The Better case provides energy usage data for each building (and the cumulative area) if it was renovated to the current ASHRAE standard. The Best case provides energy usage data for each building (and the cumulative area) with additional EEMs applied (to the greatest extent possible). The SCP report provides a list of the measures applied to each building, the changes in building parameters for each (changes in infiltration, lighting density, etc), a planning level cost for the improvements (assuming they are performed during a major renovation). Further, the report captures the buildings slated for demolition and planned buildings into the analysis and provides short-term, long-term, and potential capacity phases for the construction and energy usage (a summary that shows 
the current status of all buildings at each of the three phases). Finally, the report provides a scoping study on potential "installation scale" energy technologies that have significant energy and/ or cost saving potential for the area. These technologies include district energy systems and renewable energy systems. 


\section{Net Zero Planner (NZP) Tool Enhancement}

Throughout this project at both installations, SMEs used the results of this work to refine both the process and the NZP Tool. The energy planning process was refined and several steps were added, e.g., the introduction of the Baseline and the Base Case, which are now clearly defined and integrated into the process and the Tool. During the projects, it became apparent that there was a need to determine how to calibrate the Baseline; thus, inputting data from energy meters became an important step in the beginning of the study. During the projects, (especially while executing USMA and PNSY projects, and reviewing the different approaches taken by each SME group that did the comparative validating analysis), it became clear that there was a need to frame goals that establish the type of study that needs to be done, i.e., a planning or pre-engineering analysis.

The process alignment also helped define the customer for the NZP Tool, and who at the installation would be the user of the program. Two groups of users were determined each with different output requirements. The Installation Master Planner's is a group that has a need to use the NZP Tool to quantify and provide a Sustainability Component Plan to overlay their building Energy Master Plans. The other identified user is the installation energy manager, who has a need for help in identifying and coordinating the sequence of energy projects, which requires a pre-engineering assessment.

Many user interface changes were made throughout the program to facilitate the process, to make it easier for the user to enter data, and to help determine what information needed to be provided for output reports. Directly impacted sections were:

- Process Improvements. The process was refined and areas that were addressed from the USMA and PNSY project were:

o Added energy goals and then tied them to the decision model to clarify and focus on customer program intents.

o Added Demolished, Existing, and Planned building status to accommodate different buildings status. Added the ability to draw in buildings to customize and add buildings for either existing or planned.

- Added login and installation security as the installation analysis was added. 
o Many speed and performance upgrades were added after using the NZP Tool for realistic projects instead of much less complex and smaller test projects.

o Added the capability to modify schedules to allow for changes in seasonal academic scheduling like in USMA for standard Army building types.

- Reporting. There were many data additions during the projects to address questions that were asked by the installations. Besides many small changes, some larger questions were addressed:

o Peak demands were added to determine if the buildings could help alleviate peak electrical load for electrical distribution and capacity limitations.

o Source energy was added to reports to address the need for PNSY to meet their stated source fuel energy goals.

o Site source conversions were added to fuel rates.

o Added Excel spreadsheets for populating reports.

o Overall, the Output reports for facilities and installation were modified to produce results and downloads that meet the data requirements for real projects.

- Costing.

o In doing these projects the NZP team re-evaluated detailed costing for the building and installation, and implemented a more tractable scheme using typical or planning level costing. It was determined that rolled up or complex detailed implementations of costing and utility network infrastructure were too difficult for planning type analysis. The rollup method utilizing more detailed information was overwhelming, unwieldy, and was already causing development and maintenance issues.

o In addition a methodology was implemented to only use the delta cost to buy the additional energy/ water/ waste efficiency measure above the Base Case cost. So a costing scheme that replaced the detailed rollup technique using an average $\$$ / sq ft for the added efficiency measure was added so that the total integrated cost of all measures fit the \% increase typically seen in building and retrofit projects.

- NZI-OPT. Installation and plant device data were expanded to account for equipment at legacy steam systems and how to determine solution relevance at both locations. Sensitivity analyses were conducted using the alternatives and risk factors such as price volatility, availability, and 
maintenance costs. The integrated plan contains a phased implementation strategy over the study period, showing investment costs, predicted energy, water, and waste reductions, and return on investment. These alternatives addressing existing conditions and a limit analysis on alternatives, such as all decentralized or net fossil fuel zero, are evaluated. Much of this process was directly determined from the ESTCP projects.

- Thermal Network Analysis and PV Solar Data. The steam or HW systems needed to have data to determine the modeled performance for an integrated solution. The initial models tried to implement a quasidetailed thermal network analysis built into the tool. This approach ended up with the same issues as the costing; it was becoming unwieldy and more difficult to do this installation network analysis in the tool. Standalone installation network tools were researched and then the output from these tools was used as the input data that were entered and stored in the tool. This approach was more tractable and allowed for multiple tools to provide the input data for the networks and the analysis from reputable sources to do the analysis. This approach is also being applied for the PV performance data as well.

- MCDA Report. During the tool development process, it was determined that one of the primary outcomes for the NZP Tool was providing the data to make long-term planning decisions. With the help of ERDC decision group, a MCDA tool was integrated. The custom designed interface for decision display and analysis was added to help quantify data and perform a qualitative analysis in a quantitative decision tool. It was very apparent in the PNSY study that this feature would be very beneficial. The alternatives analyzed illustrated that some of the short-term projects were leading to possible long-term implications that could ultimately have a much higher life cycle cost. When the limits of totally decentralized, fossil fuel net zero configurations within a district system were analyzed as alternatives, these data provided the necessary quantified analysis to make an educated scenario decision. Once the long-term decision was determined, then all short-term decisions can be made to follow this plan and to meet the long-term goals. This was added to help with the visualization of the analysis and to tie the decision model to the energy goals input for that project. It also was the basis for the project philosophy that short-term project decisions should not be made without a long-term plan. 
The current version of the NZP Tool increases the speed and efficiency of the EMP process significantly by providing repeatability and reduction of human error in the tedious tasks required in the process. In addition, this eases the burden of doing repeated tasks for both the experienced and less skilled users, and allows access to many additional users typically under the guidance of SMEs. The NZP Tool still allows the creative user to customize the tool as needed to meet the specific needs of an individual installation. The process provides the accessibility to the analysis by less skilled people. All users benefit from the simplification of repeated tasks, which "lowers the bar" for making changes and redoing analyses dynamically. 


\section{Acronyms and Abbreviations}

\begin{tabular}{|c|c|}
\hline Term & Definition \\
\hline ADP & Area Development Plan \\
\hline AMPL & A Mathematical Programming Language \\
\hline ANSI & American National Standards Institute \\
\hline ARRA & American Recovery and Reinvestment Act \\
\hline ASHRAE & American Society of Heating, Refrigerating, and Air-Conditioning Engineers \\
\hline BLCC & Building Life Cycle Cost \\
\hline BSC & Building Science Corporation \\
\hline CAC & Common Access Card \\
\hline CBECS & Commercial Buildings Energy Consumption Survey \\
\hline $\mathrm{CCF}$ & Centum Cubic Feet (100 cubic feet) \\
\hline CEP & Central Energy Plant \\
\hline CERL & Construction Engineering Research Laboratory \\
\hline $\mathrm{CHP}$ & Combined Heat and Power \\
\hline $\mathrm{COF}$ & Company Operations Facility \\
\hline $\mathrm{CMU}$ & Concrete Masonry Unit \\
\hline $\cos$ & Centers of Standardization \\
\hline DD & Dry Dock \\
\hline DDC & Direct Digital Control \\
\hline DHW & Domestic Hot Water \\
\hline DOAS & Dedicated Outdoor Air Supply \\
\hline DoD & U.S. Department of Defense \\
\hline DPV & Discounted Present Value \\
\hline DPW & Directorate of Public Works \\
\hline ECB & Engineering and Construction Bulletin \\
\hline ECBCS & Energy Conservation in Buildings and Community Systems \\
\hline ECM & Energy Conservation Measure \\
\hline EEE & European Centre for Renewable Energy \\
\hline EEM & Energy Efficiency Measure \\
\hline EIA & Energy Information Administration \\
\hline EISA & U.S. Energy Independence and Security Act of 2007 \\
\hline EMCS & Energy Management Control System \\
\hline EMP & Energy Master Planning \\
\hline ERDC & Engineer Research and Development Center \\
\hline ERV & Energy Recovery Ventilator \\
\hline ESMAP & Energy Sector Management Assistance Program \\
\hline ESPC & Energy Savings Performance Contract \\
\hline ESTCP & Environmental Security Technology Certification Program \\
\hline EUI & Energy Use Intensity \\
\hline
\end{tabular}




\begin{tabular}{|c|c|}
\hline Term & Definition \\
\hline EW & Energy and Water \\
\hline FY & Fiscal Year \\
\hline GFEBS & General Fund Enterprise Business Systems \\
\hline GHG & Greenhouse Gas \\
\hline GIS & Geographic Information System \\
\hline GT & Gas Turbines \\
\hline HEDS & High Efficiency Dehumidification System \\
\hline HEPA & High Efficiency Particulate Air (filter) \\
\hline HP & Horsepower \\
\hline $\mathrm{HQ}$ & Headquarters \\
\hline HQUSACE & Headquarters, U.S. Army Corps of Engineers \\
\hline HRSG & Heat Recovery Steam Generation \\
\hline HVAC & Heating, Ventilating, and Air-Conditioning \\
\hline HW & Hot Water \\
\hline IAQ & Indoor Air Quality \\
\hline IEA & International Energy Agency \\
\hline IP & Intellectual Property \\
\hline IRR & Internal Rate of Return \\
\hline JPAS & Joint Personnel Adjudication System \\
\hline LCC & Life Cycle Cost \\
\hline LEED & Leadership in Energy and Environmental Design \\
\hline LNG & Liquefied Natural Gas \\
\hline MCDA & Multi-Criteria Decision Analysis \\
\hline MILCON & Military Construction \\
\hline MILP & Mixed-Integer Linear Programming \\
\hline MS & Microsoft \\
\hline MW & Megawatt \\
\hline N/A & Not Applicable \\
\hline NAVFAC & Naval Facilities Engineering Command \\
\hline NATO & North Atlantic Treaty Organization \\
\hline NEPA & National Environmental Policy Act \\
\hline NIST & National Institute of Standards and Technology \\
\hline NREL & National Renewable Energy Laboratory \\
\hline NSN & National Supply Number \\
\hline NZ & Net Zero \\
\hline NZE & Net Zero Energy \\
\hline NZEI & Net Zero Energy Installation \\
\hline NZP & Net Zero Planner Tool \\
\hline OASA & Office of the Assistant Secretary of the Army \\
\hline OMB & Office of Management and Budget \\
\hline$P \& D$ & Planning and Design \\
\hline
\end{tabular}




\begin{tabular}{ll} 
Term & Definition \\
POC & Point of Contact \\
PNSY & Portsmouth Naval Shipyard \\
PV & Photovoltaic \\
PWD & Public Works Department \\
PWT & Project Working Team \\
RECS & Residential Energy Consumption Survey \\
RFP & Request for Proposal \\
RH & Relative Humidity \\
RPMP & Real Property Master Plan \\
SAR & Same As Report \\
SCP & Sustainability Component Plans \\
SDSFIE & Spatial Data Standards for Facilities, Infrastructure, and Environment \\
SERDP & Strategic Environmental Research and Development Program \\
SME & Subject Matter Expert \\
SPB & Simple Payback \\
SRM & Sustainment, Restoration, and Modernization \\
TKDA & Toltz, King \& Day (architectural and engineering firm in Minnesota, MN) \\
TR & Technical Report \\
UEPH & Unaccompanied Enlisted Personnel Housing \\
UFC & Unified Facilities Criteria \\
USACE & U.S. Army Corps of Engineers \\
USCC & USMA Cadet Club \\
USMA & U.S. Military Academy \\
VAV & Variable Air Volume \\
VFD & Variable Frequency Drive \\
XML & Extensible Markup Language \\
XPS & Extruded Polystyrene \\
& \\
\hline &
\end{tabular}




\section{Conclusions and Lessons Learned}

\subsection{Conclusions}

This work concludes that the use of the NZP Tool dramatically reduces the cost of developing an Energy Master Plan for an installation. The tool itself helps guide the energy master planning process and leads to a more repeatable and controlled development of the plan. This process helps to reduce or eliminate some of the common biases of engineers and planners who develop the Energy Master Plan (especially biases toward or against certain technologies). Finally, the NZP provides an energy model of the installation that is accessible by the installation staff for further updating and use in identifying, developing, and reporting on current and future energy projects.

\subsection{Lessons learned}

Detailed reports describing the Energy Master Planning process, documenting information used for the Baseline, Base Case, alternatives, and proposed scenarios and their implementation strategies have been provided to installations and presented to installations' leadership. On the PNSY request, ERDC team has provided training to Public Works Department (PWD) personnel to ensure they are capable of using NZE Planner Tool and modify the installation's model as needed based on future developments. USMA has implemented energy concepts and criteria during the new barracks design process and considered provided renovation concept during the Scott Barracks renovation. Both USMA designs account for current buildings connection's to district steam systems and future connection to district hot water systems.

On the request from USACE HQ master planners, ERDC researchers provided support to USACE Fort Worth District master planners and energy engineers working on development of Installation Sustainability Plans for selected Army installations (e.g., Schofield Barracks, Fort Campbell, Fort Leonard Wood, Fort Hunter Liggett, Fort Hood, and NASA J ohnson Space Center). In these projects A critical aspect in developing the energy modeling for these projects was that ERDC researchers worked closely with USACE contractors from the Urban Collaborative, LLC using the Net Zero Planner. 
ERDC is currently working with HQUSACE on incorporating the energy master planning concept into UFC 2-100-01, Installation Master Planning and using the NZP Tool for Sustainability and Energy Component Plan development for a number of installations.

Among major end users concerns are:

1. Installation-wide energy master planning requires setting numerous energy goals (site and source energy efficiency, energy security, limitations of power and natural gas utilities, etc.) upfront. Setting realistic and quantifiable goals presents a challenge to most of installations.

2. Complexity of NZE solutions and the need to follow them through.

3. Significant first costs of their implementation.

4. Significant effort required to manage the transition process.

USACE or DPW develop installations Master Plans either in-house, or by subcontracting to private sector companies. The NZP Tool can be used either by in-house personnel or by contractors. While the limited number of USACE energy master planners can be trained to apply energy master planning concepts and to use the tool, use of NZP Tool by contractors will require a broader program to train all potential contractors involved in energy master planning. Trainees will need to have “*.mil” Internet access and Common Access Cards (CACs). 


\section{Project-Based Publications}

Case, M., R. Liesen, A. Zhivov, M. Swanson, B. Barnes, and J . Stinson. 2014. A computational framework for low-energy community analysis and optimization. ASHRAE Transactions 120(1).

Case, M.P., R. Liesen, M. Swanson, J . Yu, and A. Zhivov. 2015. Integration of Master Planning and Energy Planning: From Detailed to Conceptual Analysis. ASHRAE Transactions 121(1).

Liesen, R., M. Swanson, M. Case, A. Zhivov, A. Latino, D. Dreyer. 2015. Energy master planning toward net zero energy installation - Portsmouth Naval Shipyard. ASHRAE Transactions 121(1).

Proceedings of the NATO Advanced Research Workshop - 984778. Triple Net Zero Energy, Water and Waste Models Applications. Energy Chapter. In preparation for publication in 2015.

Swanson, M., R. Liesen, M. Case, A. Zhivov, and B. Barnes. 2014. Community-scale energy supply and distribution optimization using mixed integer linear programming. ASHRAE Transactions 120(1).

Zhivov, A., M. Case, R. Liesen, J . Kimman, and W. Broers. 2014. Energy master planning toward net zero energy communities/ campuses ASHRAE Transactions. NY-14010. 120(1).

Zhivov, A., M. P. Case, R. L. Liesen, M. Swanson, B. Barnes, A. Woody, A. Latino, C. Björk, and L. Fiedler. 2015. Energy master planning toward net zero energy installation - United States Military Academy, West Point. ASHRAE Transactions 121(1).

Zhivov, Herron, D., Liesen, R., Budde, K., Richter, S., Ochse, S., Fiedler, L., Steitz, P., Guthrie, V.,Alguire, H., Turner, S., Shepard, N., Energy Optimization for Fort Carson Combat Aviation Brigade Complex, ASHRAE Transactions 120(1). 


\section{References}

Annex 46. 2009. Energy and Process Assessment Protocol. International Energy Agency (IEA), Energy Conservation in Buildings and Community Systems (ECBCS). Atlanta, GA: American Society of Heating, Refrigerating, and Air-Conditioning Engineers (ASHRAE).

Annex 51. 2013. Case Studies and Guidelines for Energy Efficient Communities. A Guidebook on Successful Urban Energy Planning. Fraunhopher IRB Verlag. ISBN 978-3-8167-9122-5.

ASA(IE\&E). 2010. Army Vision for Net Zero. Net Zero is a force multiplier. 15 Washington, DC: Assistant Secretary of the Army for Installations, Energy and Environment (ASA(IE\&E), www.asaie.army.mil

—. Net Zero Installations Policy. 28 J anuary 2014. Army Directive 2014-02. Washington, DC: ASA(IE\&E).

American Society of Heating, Refrigerating, and Air-Conditioning Engineers (ASHRAE). 2004. ASHRAE Standard 90.1 - 2004. Energy Standard for Buildings Except Low-Rise Residential Buildings. Atlanta, GA: ASHRAE.

— 2007. ASHRAE Standard 90.1 - 2007. Energy Standard for Buildings Except Low-Rise Residential Buildings. Atlanta, GA: ASHRAE.

—. 2010. ASHRAE Standard 90.1 - 2010. Energy Standard for Buildings Except Low-Rise Residential Buildings. Atlanta, GA: ASHRAE.

Bose, R. K. 2010. Energy Efficient Cities. Assessment Tolls and Benchmarking Practices. ESTMAP. Washington, DC: The International Bank for Reconstruction and Development and The World Bank.

C40CITIES Climate Leadership Group. 2011. Global Leadership on Climate Change. Clinton Initiative Web page. Accessed 17 December 2012, www.c40cities.org/

Case, M., R. Liesen, A. Zhivov, M. Swanson, B. Barnes, and J . Stinson. 2014. A computational framework for low-energy community analysis and optimization. ASHRAE Transactions 120(1).

Case, M.P., R. Liesen, M. Swanson, J . Yu, and A. Zhivov. 2015. Integration of Master Planning and Energy Planning: From Detailed to Conceptual Analysis. ASHRAE Transactions 121(1)

CBECS. 2003. The Commercial Buildings Energy Consumption Survey, http://www.eia.gov/consumption/commercial/

CONCERTO : http://www.concerto-act2.eu.

Headquarters, Department of the Army (HQDA). 2009. Army Energy Security Implementation Strategy, http://www.asaie.army.mil/./AESIS_13JAN09 Approved\%20403-09.pdf: 
Deru, M., D. Herron, A. Zhivov, D. Fisher, and V, Smith. 2009. Energy design guidelines for Army dining facilities. ASHRAE Transactions. LO-09-095 115(2).

Deru, M., R. Langner, A. Zhivov. R. Liesen, D. Herron and V. Smith. 2012. Extremely lowenergy design for Army buildings: Dining facility. ASHRAE Transactions. CH-12009 115(2).

EnEff: Stadt. Energieeffiziente Stadt. Research Initiative funded by German Federal Ministry of Economics and Energy. https://www.ptj.de/energieeffiziente-stadt

Energy Independence and Security Act of 2007, The (EISA2007). Public Law 110-140-Dec.19, 2007, http://www.gpo.gov/fdsys/pkg/PLAW-110publ140/pdf/PLAW-110publ140.pdf

Energy Policy Act of 2005 (EPAct). 2005. http://thomas.loc.gov/cgibin/bdquery/z?d109:h.r.00006

Güssing, Borough of. 2011. Case study: The European Centre for Renewable Energy EEE in Güssing as an example of how synergies can be realized. Web page. Accessed 17 December 2012, http://www.guessing.co.at/

Headquarters, U.S. Army Corps of Engineers (HQUSACE). 2011. MILCON Energy Efficiency and Sustainability Study of Five Types of Army Buildings. Washington, DC: HQUSACE.

HQUSACE, Naval Facilities Engineering Command (NAVFAC), and the Air Force Civil Engineer Support Agency (AFCESA). 2012. Installation Master Planning. Unified Facilities Criteria (UFC) 2-100-01. Washington, DC: HQUSACE, NAVFAC, and AFCESA.

Kerschberger, A., and E. Boehm. 2014. From U.S. Army installation to zero energy community: The B\&O Bad Aibling Park looks to the future. ASHRAE Transactions. NY-14-016 120(1).

Kimman, J ., R. Rovers, and R. Ravesloot. 2010. Toward 0-impact Buildings and Built Environments. Amsterdam, The Netherlands: Techne Press. ISBN:978-90-8594028-9.

Langner, R. M. Deru, A. Zhivov, R. Liesen, and D. Herron. 2012. Extremely low-energy design for Army buildings: Tactical equipment maintenance facility. ASHRAE Transactions. CH-12-010 115(2).

Liesen, R., P. Ellis, A. Zhivov, and D. Herron. 2012. Extremely Low Energy Design for Army Buildings: Barracks. ASHRAE Transactions. CH-12-008 115(2).

Loorbach, D. 2007. Transition Management. Utrecht: International books.

RECS. 2003. Residential Energy Consumption Survey. http://www.eia.gov/consumption/residential/

Strasser, H. 2015. Implementation of energy strategies in communities - From pilot project in Saltzburg, Austria to urban strategy. ASHRAE Transactions. CH-15-016. 121(1). 
Swanson, M., R. Liesen, M. Case, A. Zhivov, and B. Barnes. 2014. Community-scale energy supply and distribution optimization using mixed integer linear programming. ASHRAE Transactions 120(1).

Stockholm, City of. 2010. Vision2030 - A Guide to the Future. Stockholm, Sweden: City Hall, SE 105 35, www.stockholm.se

Zhivov, A, R. Liesen, S. Richter, R. J ank, and F. Holcomb. 2010. Toward a net zero building cluster energy systems analysis for a brigade combat team complex. Proceedings of ASME 2010 4th International Conference on Energy Sustainability. ES2010. May 17-22, 2010 Phoenix, Arizona. Paper Number: ES2010-90487.

Zhivov, A., Herron, D. and M. Deru 2009. Achieving energy efficiency and improving indoor air quality in Army maintenance facilities. ASHRAE Transactions. LO-09094 115(2).

Zhivov, A., M. Case, R. Liesen, J . Kimman, and W. Broers. 2014. Energy master planning toward net zero energy communities/ campuses. ASHRAE Transactions. NY-14010. 119(1).

Zhivov, A., R. Liesen, S. Richter, R. J ank, D. Underwood, D. Neth, A. Woody, C. Björk and S. Duncan. Net zero building cluster energy systems analysis for U.S. Army installations. 2012. ASHRAE Transactions. CH-12-007 115(2).

Zhivov, A., R. Lohse, J . Shonder, C. Nasseri, H. Staller, O. Moerck, and M. Nokkala. 2015. Business and technical concepts for deep energy retrofit of public buildings. ASHRAE Transactions 121(2).

Zhivov, Alexander M., Mike C.J. Lin, Alfred Woody, William M. Worek, Michael J. Chimack, and Robert A. Miller. 2006. Energy and Process Optimization and Benchmarking of Army Industrial Processes. ERDC/CERL TR-06-25. Champaign, IL: ERDC-CERL, http://www.cecer.army.mil/techreports/erdc-cerl_tr-06-25/erdc-cerl_tr-06-25.pdf

Zhivov, A., D. Herron, R. Liesen, K. Budde, S. Richter, S. Ochse, L. Fiedler, O. Steitz, V. Guthrie, H. Alguire, S. Turner, and N. Shepard. 2014. Energy optimization for Fort Carson Combat Aviation Brigade Complex, ASHRAE Transactions. NY-14-017. 120(1). 


\section{Bibliography}

Aycok, Allison, MG. 2013. Memorandum, Subject: District and Islanded/ Decentralized Heating Systems Selection Evaluation with Life Cycle Cost analysis Guidance. Washington, DC: Assistant Chief of Staff for Installation Management (ACSIM).

Briggs, R. S., R. G. Lucas, and T. Taylor. 2003. Climate classification for building energy codes and standards: part 2 - zone definitions, maps and comparisons. Technical and Symposium Papers, ASHRAE Winter Meeting, Chicago, IL, J anuary, 2003. Atlanta, GA: ASHRAE.

Building Life Cycle Cost-National Institute of Standards and Technology (BLCC-NIST). 2013. The National Institute of Standards and Technology Building Life Cycle Cost Program, www1.eere.energy.gov/femp/information/download_blcc.html

Council on Environmental Quality. 2012. Guidance for Federal Greenhouse Gas Accounting and Inventories. www.whitehouse.gov/administration/eop/ceq/sustainability/fed-ghg

Modeling Net Zero Energy (NZE) Installations. 6.2. Basic Research Projects. United States Army Corps of Engineers Engineer Research and Development Center. http://www.cecer.army.mil/td/tips/product/details.cfm?ID=1004

National Renewable Energy Laboratory (NREL). Energy Technology Cost and Performance Data for Distributed Generation, www.nrel.gov/analysis/tech_cost_data.html

Richter, S., and T. Hamacher. 2003. URBS, A model for investigations on future urban energy systems. PowerGen Europe. Conference Proceedings, International Conference and Fair, CCD Düsseldorf (Germany), May 2003.

Swanson, M., R. Liesen, M. Case, A. Zhivov, and B. Barnes. 2014. Community-scale energy supply and distribution optimization using mixed integer linear programming. ASHRAE Transactions 120(1).

U.S. Army Corps of Engineers (USACE), ERDC-CERL, National Renewable Energy Laboratory (NREL), and Pacific Northwest National Laboratory (PNNL). Undated. Army MILCON Energy Enhancement and Sustainability Study of Five Buildings. A collaboration by USACE, ERDC-CERL, NREL, PNNL.

Underwood, David M., Alexander Zhivov, J ames P. Miller, J ohn Vavrin, Alfred Woody, Curt Bjork, Erja Reinkinen, Roland Ziegler, William D. Chvala, and Emily M. Rauch. 2008. Energy Optimization Assessment at U.S. Army Installations: West Point Military Academy, NY. ERDC/ CERL TR-08-14. Champaign, IL: ERDCCERL.

Underwood, David M., Alexander Zhivov, Scot Duncan, Alfred Woody, Curt Björk, Stephan Richter, Dieter Neth, Dan Pinault, and Reinhard J ank. Working Towards Net Zero Energy at Fort Irwin, CA. ERDC/ CERL TR-10-24. Champaign, IL: Engineer Research and Development Center, Construction Engineering Research Laboratory (ERDC-CERL). 
U.S. Energy Independence and Security Act of 2007 (EISA2007). 2007, http://thomas.loc.gov/cgi-bin/bdquery/z?d110:h.r.00006

White House, The. 2014. GHG Emissions Calculations by White House Council on Environmental Quality Guidance for Federal Greenhouse Gas Accounting and Inventories. Washington, DC: Council on Environmental Quality, www.whitehouse.gov/administration/eop/ceq/sustainability/fed-ghg

Whole Building Design Guide. Energy and Water Conservation Design Guide (for Sustainment, Restoration and Modernization (SRM) and MILCON Projects), http://www.wbdg.org/references/pa_dod_energy.phpMILCON Projects 


\section{Appendix A: Points of Contact}

\begin{tabular}{|c|c|c|c|}
\hline Point of Contact & Organization & Phone \& E-mail & Role in Project \\
\hline Alexander Zhivov & ERDC-CERL ${ }^{(1)}$ & $\begin{array}{l}\text { (217) 373-4519 } \\
\text { Alexander.M.Zhivov@usace.army.mil }\end{array}$ & Project Manager \\
\hline Michael Case & ERDC-CERL & $\begin{array}{l}\text { (217) 373-7259 } \\
\text { Michael.P.Case@usace.army.mil }\end{array}$ & ERDC NZ Planner Tool project manager \\
\hline Richard Liesen & ERDC-CERL & $\begin{array}{l}(740) 3660165 \\
\text { Richard.J.Liesen@usace.army.mil }\end{array}$ & Master Planning and Modeling \\
\hline David Underwood & ERDC-CERL & $\begin{array}{l}\text { (217) } 3736780 \\
\text { David.M.Underwood@usace.army.mil }\end{array}$ & Energy Assessment \\
\hline Laura Curvey & ERDC-CERL & $\begin{array}{l}\text { (217)373- } 7338 \\
\text { Laura.Curvey@usace.army.mil }\end{array}$ & Master Planning \\
\hline Matthew Swanson & ERDC-CERL & $\begin{array}{l}\text { (217) } 3736788 \\
\text { Matthew.M.Swanson@usace.army.mi } \\
\text { ! }\end{array}$ & Modeling \\
\hline Benjamin Barnes & ERDC-CERL & $\begin{array}{l}(217) 3737584 \\
\text { Benjamin.P.Barnes@usace.army.mil }\end{array}$ & Modeling \\
\hline William Brown & ERDC-CERL & $\begin{array}{l}\text { (217) } 3737292 \\
\text { William.T.Brown@usace.army.mil }\end{array}$ & Project Administrator \\
\hline James Stinson & ERDC-ITL (2) & $\begin{array}{l}\text { (601) 634-3404 } \\
\text { stinsoj@wes.army.mil }\end{array}$ & Modeling \\
\hline Gonzalo Perez & PERTAN (3) & $\begin{array}{l}\text { (217) } 356 \text { 1348, Ext. } 202 \\
\text { gonza.perez@pertan.com }\end{array}$ & Contractor, Manager \\
\hline Anthony Latino & PERTAN & $\begin{array}{l}\text { (217) } 3561348 \text { Ext. } 206 \\
\text { anthony.latino@pertan.com }\end{array}$ & Contractor, Representative \\
\hline Alfred Woody & PERTAN & $\begin{array}{l}\text { (248) } 8915519 \\
\text { awoody@comcast.net }\end{array}$ & Contractor, Mechanical \\
\hline Alfred Kershenberger & PERTAN & $\begin{array}{l}+49(711) 2851613 \\
\text { RK-Stuttgart@t-online.de }\end{array}$ & Contractor, Master Planner \\
\hline Stephan Richter & PERTAN & $\begin{array}{l}\text { +496224 } 971389 \\
\text { stephan.richter@GEF.DE }\end{array}$ & Contractor, CEP \\
\hline Lon Fiedler & PERTAN & (651) 292-4525, lon.fiedler@tkda.com & Contractor, CEP \\
\hline Peter Steitz & PERTAN & $\begin{array}{l}\text { (651) 292-4413, } \\
\text { rusty.steitz@tkda.com }\end{array}$ & Contractor, CEP \\
\hline Curt Björk & PERTAN & +30 (228) 5075429 curtb@otenet.gr & Contractor, Mechanical \\
\hline $\begin{array}{l}\text { Christopher } \\
\text { Schumacher }\end{array}$ & PERTAN & $\begin{array}{l}\text { (519).504.4257 } \\
\text { CHRIS@BUILDINGSCIENCE.COM }\end{array}$ & Contractor, Building Science \\
\hline Peter Garforth & PERTAN & $\begin{array}{l}\text { (419) } 5789613, \\
\text { peter@garforthint.com }\end{array}$ & Contractor, Master Planning \\
\hline Annie Marston & PERTAN & $\begin{array}{l}\text { (202) } 2439959, \\
\text { a.marston@eb-engineers.com }\end{array}$ & Contractor Modeling \\
\hline
\end{tabular}

* Project management and coordination with PERTAN Company and Installations is described in Appendix D.9. 


\begin{tabular}{|c|c|c|c|}
\hline Point of Contact & Organization & Phone \& E-mail & Role in Project \\
\hline Gerd Fleischhammer & PERTAN & $\begin{array}{l}\text { +49 (174) } 2176782 \\
\text { fleischhammer@email.de }\end{array}$ & Contractor, Modeling and CEP \\
\hline Paul Volkman & DASA (IE\&E)(4) & $\begin{array}{l}\text { (703) 697-3765 } \\
\text { paul.m.volkman.civ@mail.mil }\end{array}$ & Army Sponsor \\
\hline Glenn Hubbard & NAVFAC,HQ(5) & $\begin{array}{l}\text { (202) } 4332705 \\
\text { Glenn.hubbard@navy.mil }\end{array}$ & CDR, Navy Sponsor \\
\hline Matthew Talaber & USMA ${ }^{(6)}$ & $\begin{array}{l}(845) 9383415 \\
\text { matthew.talaber@usma.edu }\end{array}$ & USMA-DPW, Director \\
\hline Frank Bloomer & USMA & $\begin{array}{l}(845) 9383415 \\
\text { frank.bloomer@usma.edu }\end{array}$ & DPW, Deputy Director \\
\hline Paul Simintis & USMA & $\begin{array}{l}\text { (845)-938-2224 } \\
\text { Paul.Simihtis@usma.edu }\end{array}$ & Energy Manager \\
\hline Husain Shehreyar & USMA, & $\begin{array}{l}(845) \text { 938-2832 } \\
\text { Shehreyar.Husain@usma.edu }\end{array}$ & Energy Engineer \\
\hline Peter Mcgaughran & USMA, O\&M & $\begin{array}{l}\text { (845) } 9382818 \\
\text { Peter.Mcgaughran@usma.edu }\end{array}$ & Chief O\&M \\
\hline Carl Meyer & USMA & $\begin{array}{l}\text { (845) } 938 \text { 4856, } \\
\text { carl.meyer@usma.edu }\end{array}$ & Master Planner \\
\hline Russell.Lachance & USMA & $\begin{array}{l}\text { (845) } 9383582 \\
\text { Russell.Lachance@usma.edu }\end{array}$ & COL, Acting Deputy Head Dean \\
\hline Jeffrey Friese & $\begin{array}{l}\text { USACE, NY District } \\
\text { (7) }\end{array}$ & $\begin{array}{l}(845) 9382116 \\
\text { Jeffery.Friese@usma.edu }\end{array}$ & Project Manager, NY District \\
\hline Andrew Zuzulock & USACE, NY District & $\begin{array}{l}\text { (917) 790-8241 } \\
\text { Andrew.J.Zuzulock@usace.army.mil }\end{array}$ & Project manager, NY District \\
\hline Brian Weinstein & PNSY (8) & $\begin{array}{l}(207) \text { 438-5534 } \\
\text { brian.weinstein@navy.mil }\end{array}$ & PWD, Commander \\
\hline John Wyeth & PNSY & (207) 438-5094, john.wyeth@navy.mil & Deputy Public Works Officer \\
\hline Melissa Kalicin & PNSY & $\begin{array}{l}\text { (207) 438-1049 } \\
\text { melissa.kalicin@navy.mil }\end{array}$ & Project Manager \\
\hline Melanie Spreen & PNSY & $\begin{array}{l}(207) \text { 438-1017 } \\
\text { melanie.spreen@navy.mil }\end{array}$ & Master Planning \\
\hline David Dreyer & PNSY & $\begin{array}{l}(207) \text { 438-4638 } \\
\text { david.m.dreyer@navy.mil }\end{array}$ & LT., Energy Manager \\
\hline Lance Mahar & PNSY & (207) 438-5980 & Energy Engineer \\
\hline Steve Dakin & PNSY & $\begin{array}{l}(207) \text { 438-6625 } \\
\text { stephen.dakin@navy.mil }\end{array}$ & Utilities Energy Manager \\
\hline Adam Gray & PNSY & $\begin{array}{l}(207) \text { 438-4363 } \\
\text { adam.I.gray@navy.mil }\end{array}$ & $\begin{array}{l}\text { Industrial Engineer, continuous } \\
\text { improvement/Lean manufacturing }\end{array}$ \\
\hline
\end{tabular}




\begin{tabular}{|c|c|}
\hline 1 & $\begin{array}{l}\text { U.S. Army Corps of Engineers } \\
\text { Engineer Research and Development Center } \\
\text { Construction Engineering Research Laboratory (ERDC-CERL) } \\
2902 \text { Newmark Drive } \\
\text { Champaign, Illinois } \\
61826-9005 \text {, USA. }\end{array}$ \\
\hline 2 & $\begin{array}{l}\text { U.S. Army Corps of Engineers } \\
\text { Engineer Research and Development Center } \\
\text { Information Technology Laboratory (ERDC ITL) } \\
\text { Engineer Research and Development Center } \\
3909 \text { Halls Ferry Road } \\
\text { Vicksburg, MS 39180-6199 }\end{array}$ \\
\hline 3 & $\begin{array}{l}\text { The PERTAN Group } \\
44 \text { Main Street, Suite } 403 \\
\text { Champaign, IL } 61820\end{array}$ \\
\hline 4 & $\begin{array}{l}\text { OASA (IE\&E), ODASA (Energy and Sustainability) } \\
\text { Department of Defense } \\
\text { Pentagon, Room 3D453 } \\
\text { Washington, DC } 22202\end{array}$ \\
\hline 5 & $\begin{array}{l}\text { NAVFAC HQ } \\
\text { Energy Branch Head, N441 } \\
\text { CNIC, B } 33 \\
716 \text { Sicard Street, SE, Suite } 1000 \\
\text { Washington Navy Yard, DC } 20374\end{array}$ \\
\hline 6 & $\begin{array}{l}\text { USMA West Point } \\
\text { IMNE-MIL-Bldg 667-A } \\
\text { West Point, Highlands, NY } 10996\end{array}$ \\
\hline 7 & $\begin{array}{l}\text { U.S. Army Corps of Engineers } \\
\text { New York District } \\
26 \text { Federal Plaza, Rm } 2113 \\
\text { New York, NY } 10278\end{array}$ \\
\hline 8 & $\begin{array}{l}\text { Public Works Department - Maine } \\
\text { Portsmouth Naval Shipyard } \\
\text { Kittery, ME } 03804\end{array}$ \\
\hline
\end{tabular}




\section{Appendix B: Energy Efficiency Measures for Building Renovations and New Cadet Bar- racks}

\section{B.1 Introduction}

This appendix discusses the development and upgrades of USMA's Campus building inventory that are relevant to the NZE project through the implementation of EEMs as they relate to the building envelope and mechanical systems. These EEMs include measures that will be implemented along with optional improvements.

\section{B.2 Overview of future projects: New cadet barracks building and major renovations}

With the construction and completion of new buildings, there is normally a good opportunity to implement higher and improved energy standards to reduce the heating, cooling, and electrical demand. However, there is currently only one new building project at USMA scheduled for development over the next few years, i.e., the new cadet barracks. This project is planned to increase the available housing space for cadets with an additional 288,000 sq ft of gross floor area, but will not replace an older barracks. Also, there are currently no planned demolition of any larger campus buildings in the next fewyears. The current building stock will remain more or less as it is today, including the one new additional large barracks planned to be built in the foreseeable future.

Although no large building programs are planned, several refurbishments and upgrades to campus buildings are in progress. According to USMADPW schedules, larger refurbishment measures are ongoing or planned at a number building complexes.

Current and ongoing projects include:

- Bartlett Hall (Bldg. 753) and the Archive Library (Bldg. 757). These buildings are both undergoing rehabilitation and modernization to form the future science center. The first phase of the refurbishment of Bartlett Hall is complete; Phase II is currently underway.

- Arvin Annex (Bldg. 673). Bldg. 673 has undergone a rehabilitation and upgrade program that will be completed in the near future. 
Planned refurbishment projects in the NZE Area include:

- Grant Barracks (Bldg. 602), complete rehabilitation and HVAC retrofit

- Scott Barracks (Bldg. 735), under concept design stage for complete renovation

- McArthur Barracks (Bldg. 745 D, 745 E), HVAC retrofit

- Pershing Barracks (Bldg. 751), HVAC retrofit

- Thayer Hall (Bldg. 600), HVAC retrofit

- Cullum Hall (Bldg. 605), historical restoration and HVAC retrofit

- Eisenhower Hall (Bldg. 655), HVAC retrofit

- Cadet Chapel (Bldg. 722), masonry repair

- An overview of modernization and retrofit efforts includes:

- Gross floor area will slightly increase with the completion of the new barracks.

- The number of planned retrofit projects will remain relatively low.

- The planned retrofit projects will not dramatically decrease energy consumption, due to the fact that most retrofits are limited to HVAC modernizations, which translate to a minimum reduction of demand, but more of an optimization of supply.

- There will be a significant increase in energy consumption with the addition of cooling to each of the Cadet Barracks in the future.

The following sections discuss in detail significant projects currently in progress and incorporated into this analysis as discussed in the Base Case.

\section{B.2.1 Building renovations}

During the demonstration project (2011-2012), several major building construction projects were underway. The 2011 building energy use discussed in Chapter 7 did not reflect the change in building energy use that would result after these renovations are completed. For example, Arvin Annex was vacant during 2011 while work was being conducted; therefore the energy use in this building was minimal in 2011. The renovations of Arvin Annex will be completed in the near future. Two large academic buildings, Bartlett Hall and the Archive Library, were also undergoing renovations to improve their building envelopes. The building renovations included increased insulation of the exterior walls and roofs, improved windows, and more efficient HVAC systems. The Archive Library building project was completed in 2012 and the Bartlett Hall project is nearing completion. The resulting energy use of these renovated buildings will be 
reflected in the Baseline and Base Case building energy use, which is to be discussed in the following corresponding sections.

\section{B.2.2 New cadet barracks}

Currently, the only planned new construction at USMA is a new cadet barracks. The new barracks design calls for a six story, 287,600 sq ft structure composed of 325 cadet rooms capable of housing 650 cadets. The new barracks are designed to be built with several improvements as compared to the existing cadet barracks on campus. The new design includes an improved building envelope, HVAC systems to provide space cooling in addition to heating and ventilation air to all cadet rooms, and improved indoor air quality. Planned enhancements include:

- wall insulation with an $\mathrm{R}$-value $=13$

- roof insulation with an $\mathrm{R}$-value $=20$

- window with a $U$-value $=0.2$

- DOAS Units with heat recovery systems

- radiant heating and cooling in each cadet room

- high efficient lighting systems

- roof top solar HW collector system.

This Appendix provides an analysis of this building's energy use improvements resulting from the application of the NZE Planner Tool.

\section{B.2.3 Cadet barracks modernization}

Among the most important planned building renovation projects at USMA are modernization of the existing nine barracks buildings, which will affect the energy use of the buildings in the NZE Group. This program will begin with modernization of Scott Barracks and then progress to the remaining buildings over a 4- to 5-year period. This program will mirror efforts and EEMs outlined above in the new cadet barracks, which are to include improved building envelope, provide an enhanced HVAC system to deliver cooling in the summer, and provide high efficiency lighting.

The estimated energy use of the renovated barracks, after implementation of the above EEMs, was estimated using EnergyPlus computer modeling. Table B-1 lists the annual energy use estimates on a square foot basis that are applied to all barracks being renovated. The predicted annual energy savings of these improvements, using Scott Barracks as an example, are 7,494 MMBtu/yr of heat and 431,500 kWh/yr electrical use. The data in 
Table B-2 show an increase in DHW use, which is the result of the inclusion of laundry facilities within each barracks. Note that, even with the additional electrical use for space cooling, there is a reduced annual electrical use caused mostly by the more efficient lighting system. The impact of these building renovations on the NZE Group's energy use is discussed in Chapter 1.

Table B-1. EnergyPlus model results for energy use in renovated barracks.

\begin{tabular}{|l|c|c|c|c|c|c|}
\hline $\begin{array}{l}\text { Energy Plus } \\
\text { Model Run }\end{array}$ & $\begin{array}{c}\text { Annual Space } \\
\text { Heat } \\
\text { (MBtu/sq ft) }\end{array}$ & $\begin{array}{c}\text { Annual DHW } \\
\text { (MBtu/sq ft) }\end{array}$ & $\begin{array}{c}\text { Annual Cool } \\
(\mathrm{kWh} / \mathrm{sq} \mathrm{ft})\end{array}$ & $\begin{array}{c}\text { Annual } \\
\text { Cooling Load } \\
\text { (MBtu/sq ft) }\end{array}$ & $\begin{array}{c}\text { Annual Other } \\
\text { Elect. } \\
(\mathrm{kWh} / \mathrm{sq} \mathrm{ft})\end{array}$ & $\begin{array}{c}\text { Annual Total } \\
\text { Elect/sq ft } \\
(\mathrm{kWh})\end{array}$ \\
\hline HVAC & 12.70 & - & 2.70 & 41.1 & 8.0 & 10.7 \\
\hline DHW & - & 8.7 & - & - & - & - \\
\hline
\end{tabular}

Table B-2. Barracks renovation energy use saving estimate.

\begin{tabular}{|l|c|c|c|c|c|c|c|c|}
\hline & $\begin{array}{c}\text { Space } \\
\text { Heating } \\
\text { after } \\
\text { Renovation } \\
\text { (MMBtu/yr) }\end{array}$ & $\begin{array}{c}\text { DHW after } \\
\text { Renovation } \\
(\text { MMBtu/yr) }\end{array}$ & $\begin{array}{c}\text { Absorp } \\
\text { Chiller } \\
\text { Heating } \\
\text { (MMBtu/yr } \\
\text { ) }\end{array}$ & $\begin{array}{c}\text { Cooking } \\
\text { Heating } \\
(\text { MMBtu/yr })\end{array}$ & $\begin{array}{c}\text { Cooling } \\
\text { Total } \\
\text { Heating } \\
\text { (MMBtu/yr) }\end{array}$ & $\begin{array}{c}\text { Electrical } \\
\text { After } \\
\text { Renovation } \\
\text { (kWh/yr) }\end{array}$ & $\begin{array}{c}\text { Other } \\
\text { Electrical } \\
\text { (kWh/yr) })\end{array}$ & $\begin{array}{c}\text { Electrical } \\
\text { Total after } \\
\text { Renovation } \\
\text { (kWh/yr) }\end{array}$ \\
\hline $\begin{array}{l}\text { Before } \\
\text { Renovation }\end{array}$ & 9935 & 721 & 0 & 0 & 10656 & 0 & 1968034 & 1968034 \\
\hline $\begin{array}{l}\text { After } \\
\text { Renovation }\end{array}$ & 1877 & 1285 & 0 & 0 & 3162.4 & 347319 & 1189216 & 1536534 \\
\hline $\begin{array}{l}\text { Energy } \\
\text { Savings }\end{array}$ & 8058 & -564 & 0 & 0 & 7494 & -347319 & 778819 & 431500 \\
\hline
\end{tabular}

\section{B.2.4 Architectural energy conservation measures}

This section provides an overview of the energy conservation measure (ECM) packages for the building envelope, including information on unit costs and other discussions.

A number of buildings have less-than-desirable building envelopes that compromise efficient energy use. All of these building have a historical significance and thus their aesthetic integrity must be protected. As the result, normal energy conservation approaches to the building envelope are not typically available. For example, the window's visual appearance needs to be duplicated when replacing single pane glazing with double or triple pane low-E glazing. These historic window retrofits become quite expensive as this measure may require custom fabrication and the replacement often is not cost effective based on energy savings. A simple alternative is to place another window, or storm pane, on the exterior side of the original 
window to achieve a more cost effective R-value. The same reasoning applies to insulating walls, which must be accomplished from within the interior of these buildings.

Due to the high cost of building envelope improvements, these measures are best accomplished when a major building renovation or rehabilitation is taking place or when some other significant change is occurring to the building. This allows the cost of the major renovation to offset or supplement the high envelope improvement costs. The envelope improvements in the barracks renovation projects are an example. Another major change that is related to this program is the switching of a group of buildings from steam-distributed heating to the use of local heating equipment or distributed hot water. In either case, for some of the USMA buildings, the buildings' heating systems will need to be changed. Steam radiators or unit heaters cannot function without steam; this equipment will need to be replaced with a hot water (or some other type of) system. This change will require new piping to be run and along with other new system components. The installation of this equipment will cause significant removal of building interior dry wall and possibly some flooring. As such, the timing would be appropriate to upgrade the energy efficiency of the building envelope.

The cost for these building improvements is estimated to be approximately $\$ 8,787,000$; the estimated energy savings impact on these buildings' energy use is 4,612 MMBtu per year. The cooling energy savings would be insignificant. The following sections describe ECMs that address this opportunity.

Table B-3. Cost for building improvements (architectural ECMs).

\begin{tabular}{|c|r|}
\hline Bldg. \# & First Costs(\$) \\
\hline 609 & 185,400 \\
\hline 635 & 175,370 \\
\hline 639 & 923,540 \\
\hline 663 & $2,479,680$ \\
\hline 667 & $3,059,350$ \\
\hline 685 & $1,675,430$ \\
\hline 726 & 287,410 \\
\hline Total & $8,787,000$ \\
\hline
\end{tabular}




\section{B.2.5 Material costs}

\section{B.2.5.1 Exterior perimeter walls}

Exterior perimeter walls will require:

- Additional inner dry wall with 4 in. of 2.0 pcf ccSPF insulation, steel studs, and inner gypsum board as finish (as described in BSC report page 61, Number 4a): \$19.79/ sq ft

- Additional inner EPS-gypsum-sandwich board with 4 in. of EPS-rigid foam insulation glued to the inside surface of outer wall, including inner finish: $\$ 8.60 / \mathrm{sq} \mathrm{ft}$

- Exterior insulation composite system with 5 in. of mineral wool insulation and outer plaster: $\$ 18.38 / \mathrm{sq} \mathrm{ft}$

\section{B.2.5.2 Windows}

Replace existing windows with aluminum casement windows (blast resistant) with Rwindow $=4 \mathrm{sq} \mathrm{ft}{ }^{\circ} \mathrm{F} / \mathrm{Btu}$ (double glazing with one low-e coating and argon filling) glazing quality (similar to windows used for retrofit of the Arvin Annex. Table B-4 summarizes window replacement costs.

Table B-4. Costs to replace existing windows with blast resistant aluminum casement windows.

\begin{tabular}{|c|c|}
\hline Window size & Windows $\mathrm{R}=\mathbf{4}$ \\
\hline$<10 \mathrm{sq} \mathrm{ft}$ & $\$ 93.55 / \mathrm{sq} \mathrm{ft}$ \\
\hline $10-20 \mathrm{sq} \mathrm{ft}$ & $\$ 71.03 / \mathrm{sq} \mathrm{ft}$ \\
\hline $20-30 \mathrm{sq} f t$ & $\$ 65.11 / \mathrm{sq} \mathrm{ft}$ \\
\hline$>30 \mathrm{sq} \mathrm{ft}$ & $\$ 65.11 / \mathrm{sq} \mathrm{ft}$ \\
\hline
\end{tabular}

For Gillis field house (Bldg. 663) gable facades (only), replace steel tilt windows with insulated ventilation flap construction: $\$ 95.05 / \mathrm{sq} \mathrm{ft}$

\section{B.2.5.3 Shading}

Install new inner roller blinds with high quality, reflective surface sc $<=$ 0.31: \$11.19/ sq ft.

\section{B.2.5.4 Roofs}

To improve roofs:

- Flat Roofs. Comprehensive reroofing with additional insulation 6 in. Extruded Polystyrene (XPS) or Polyurethane rigid foam boards, new 
roof membrane, adjustment of roof drainage. Reduced by sunk costs for repair water pocket, remake caulking, flashing in better quality: $\$ 11.94 /$ sq ft.

- Gable Roof Gillis Field House. Add an additional 6 in. of mineral wool board insulation to the exterior; new roof membrane; adjust of roof elements (drainage, connection details, gable details and gutter details): $\$ 16.27 /$ sq ft.

- Attic Insulation Bldg. 635. Roll out 6 in. of mineral wool mats on top of the ceiling: $\$ 5.26 / \mathrm{sq} \mathrm{ft}$.

\section{B.3 Envelope improvements}

\section{B.3.1 Envelope improvements, Bldgs. 639, 667, and 685 (5IDW).}

\section{B.3.1.1 Existing conditions}

This building group consists of administration buildings with brick face (partly granite face) walls with limestone trim and a massive core of brick or concrete masonry unit (CMU) infill in the load-bearing concrete frame. The majority of the office rooms have an interior drywall layer. The buildings have an insulated built-up roof on a concrete slab. The insulation thickness is estimated to be 3 in. The windows are mostly a double hung aluminum type, but there are also some aluminum casement windows in use. All windows have double glazing. The current status of the building is:

- Roof. An acceptable roof should consist of about 6 in. of insulation, which can be accomplished using either closed cell spray foam or rigid insulation panels during the next reroofing process.

- Outer Walls. It is unknown if there is insulation behind the dry wall on perimeter walls. The exterior walls should have at least $4 \mathrm{in}$. of insulation. It is recommended that a continuous vapor barrier be installed on the warm side of this insulation.

- Windows. The windows appear to have reached the end of their useful life and require replacement. The windows should be replaced with thermally broken, aluminum-framed low-e, argon filled, double-glazed windows of a similar sash and operational arrangement. Interior shading with roller blinds should also be implemented to reduce interior solar gain.

- Doors. The current doors are in acceptable condition, but the edges and connection areas around the doors have fallen into disrepair. There are gaps around the door and the frames allow unconditioned 
outdoor air to enter the building. It is recommended that all of the door weather-stripping be replaced and maintained to obtain a sufficient seal. This will reduce infiltration of outdoor air.

\section{B.3.1.2 Solution}

This building's envelope needs to be upgraded to achieve a more efficient energy use. These buildings have significant steam-using heating equipment and, with the conversion off steam major portions, will need to be replaced with equipment compatible with the new heating energy source. With such a major building upgrade, the building envelope should also be upgraded. Table B-5 lists recommended upgrades.

Table B-5. Recommended upgrades for Bldgs. 639, 667, and 685.

\begin{tabular}{|c|c|c|c|}
\hline $\begin{array}{l}\text { Building } \\
\text { Component }\end{array}$ & R-value Before & Measure & Resulting R-value \\
\hline Outer wall & $\mathrm{R}=5.6 \mathrm{~h} \mathrm{sq} \mathrm{ft}^{\circ} \mathrm{F} / \mathrm{Btu}$ & Spray foam on $85 \%$ of walls & $\mathrm{R}=14.2 \mathrm{~h} \mathrm{sq} \mathrm{ft}{ }^{\circ} \mathrm{F} / \mathrm{Btu}$ \\
\hline \multirow[t]{2}{*}{ Windows } & Rglass $=2.0 \mathrm{~h} \mathrm{sq} f{ }^{\circ} \mathrm{F} / \mathrm{Btu}$ & \multirow{2}{*}{$\begin{array}{l}\text { Replace windows with double low-e } \\
\text { argon filled glazing and PVC frames }\end{array}$} & Rglass $=4.1 \mathrm{~h} \mathrm{sq} \mathrm{ft}{ }^{\circ} \mathrm{F} / \mathrm{Btu}$ \\
\hline & Rframe $=1.6 \mathrm{~h} \mathrm{sq} \mathrm{ft}{ }^{\circ} \mathrm{F} / \mathrm{Btu}$ & & Rframe $=3.8 \mathrm{~h} \mathrm{sq} f{ }^{\circ} \mathrm{F} / \mathrm{Btu}$ \\
\hline Roof & $\mathrm{R}=5.0 \mathrm{~h} \mathrm{sq} \mathrm{ft}^{\circ} \mathrm{F} / \mathrm{Btu}$ & $\begin{array}{l}\text { Add } 6 \text { in. XPS-insulation during next } \\
\text { reroofing }\end{array}$ & $\mathrm{R}=31.6 \mathrm{~h} \mathrm{sq} \mathrm{ft}{ }^{\circ} \mathrm{F} / \mathrm{Btu}$ \\
\hline Floor & $\mathrm{R}=4.4 \mathrm{~h} \mathrm{sq} \mathrm{ft}^{\circ} \mathrm{F} / \mathrm{Btu}$ & No measures intended & $\mathrm{R}=4.4 \mathrm{~h} \mathrm{sq} \mathrm{ft}^{\circ} \mathrm{F} / \mathrm{Btu}$ \\
\hline Shading & $\mathrm{sc}=0.67$ & Roller blinds & $s c=0.31$ \\
\hline Airtightness $\eta 50$ & $4.01 / \mathrm{h}$ & $\begin{array}{l}\text { Tighter windows, doors, and } \\
\text { construction connections }\end{array}$ & $2.01 / \mathrm{h}$ \\
\hline Thermal Bridge & $\mathrm{R}=56.8 \mathrm{~h} \mathrm{sq} \mathrm{ft}{ }^{\circ} \mathrm{F} / \mathrm{Btu}$ & Inner insulation & $\mathrm{R}=37.9 \mathrm{~h} \mathrm{sq} \mathrm{ft}{ }^{\circ} \mathrm{F} / \mathrm{Btu}$ \\
\hline
\end{tabular}

\section{B.3.1.3 Savings}

The energy savings were determined by computer model runs presenting "before and after" energy use. The heating energy savings were determined to be $41.7 \%$ of the annual use. The analysis also showed an annual cooling energy increase of $5.2 \%$, which is caused by an increased need for cooling during the spring and fall to remove internally generated heat. (Before the building envelope improvements this heat was simply removed by the cool outdoor weather.) Since this space cooling can be accomplished via natural ventilation (opening windows) and the cooling equipment may be not operating during these months, this cooling energy increase will be ignored.

The resulting energy savings for these buildings are: 
Bldg. 639:

Energy Savings $=922 \mathrm{MMBtu} / \mathrm{yr} \times(.417)=385 \mathrm{MMBtu} / \mathrm{yr}$ Cost Savings $=385 \mathrm{MMBtu} / \mathrm{yr} \times \$ 7.70 / \mathrm{MMBtu}=\$ 2,960 / \mathrm{yr}$

Bldg. 667:

Energy Savings $=6,176 \mathrm{MMBtu} / \mathrm{yr} \times(.417)=2,575 \mathrm{MMBtu} / \mathrm{yr}$

Cost Savings $=2,575 \mathrm{MMBtu} / \mathrm{yr} \times \$ 7.70 / \mathrm{MMBtu}=\$ 19,830 / \mathrm{yr}$

Bldg. 685:

Energy Savings $=3,305 \mathrm{MMBtu} / \mathrm{yr} \times(.417)=1,378 \mathrm{MMBtu} / \mathrm{yr}$

Cost Savings $=1,378 \mathrm{MMBtu} / \mathrm{yr} \times \$ 7.70 / \mathrm{MMBtu}=\$ 10,610 / \mathrm{yr}$

Total Savings for Bldgs. 639, 667, and 685:

4,338 MMBtu/yr

$\$ 33,400 / \mathrm{yr}$.

\section{B.3.1.4 Investment}

The costs to upgrade the building envelope are based on unit cost values shown in the following calculations. For Bldg. 639, the total implementation cost is $\$ 923,500$, or $\$ 26.51 /$ sq ft. Since Bldg. 685 is similar in shape to Bldg. 639, this average cost will be used to estimate a new envelope cost of $\$ 1,675,000$ for Bldg. 685. The new building envelope cost for Bldg. 667 is estimated to be $\$ 3,059,000$ : 
Bldg. 639:

Insulate Wall Cost $=25,143$ SF X 0.85 X $\$ 19.79=\$ 422,950$

Insulate Roof Cost $=12,633 \mathrm{SF} X \$ 11.94 / \mathrm{SF}=\$ 150,840$

Window and Door Cost:

less than 10 SF: 46.5 SF $X \$ 93.55 / S F=\$ 4,350$

10 SF - 20 SF: 208.2 SF X $\$ 71.03 / \mathrm{SF}=\$ 14,790$

20 SF - 30 SF: 1,320 SF X $\$ 65.11 / S F=\$ 85,940$

Over 30 SF: 3,336 SF X $\$ 65.11 /$ SF $=\$ 217,200$

Window Subtotal Cost $=\$ 322,280$

Roller Blind Cost $=2,455$ SF X $\$ 11.19 / \mathrm{SF}=\$ 27,470$

Total cost for Bldg. $639=\$ 923,540$

Bldg. 667:

Insulate Wall Cost $=88,415$ SF X $\$ 19.79=\$ 1,749,730$

Insulate Roof Cost $=37,527 \mathrm{SF} X \$ 11.94 / \mathrm{SF}=\$ 448,070$

Window and Door Cost:

less than 10 SF: 439 SF $X \$ 93.55 / S F=\$ 41,070$

10 SF - 20 SF: 1,843 SF X $\$ 71.03 / \mathrm{SF}=\$ 130,910$

20 SF - 30 SF: 3,691 SF X $\$ 65.11 / S F=\$ 240,320$

Over 30 SF: 5,012 SF X $\$ 65.11 /$ SF $=\$ 326,330$

Subtotal Cost $=\$ 738,630$

Roller Blind Cost $=10,985$ SF X $\$ 11 \cdot 19 / \mathrm{SF}=\$ 122,920$

Total cost for Bldg. $667=\$ 3,059,350$

Bldg. 685:

63,200 sq ft. for Bldg. $685 \times \$ 26.51 /$ sq ft. $=\$ 1,675,430$

Total cost for Bldg. $685=\$ 1,675,430$.

Total ECM Investment for Bldgs. 639, 667, and 685: $\$ 5,658,320$.

\section{B.3.1.5 Payback}

For Bldgs. 639, 667, and 685, the simple payback periods are 312, 154 and 158 years respectively. The cost savings of a smaller heating system due to a building lower heating demand is not included in these calculations. Since the building upgrades would be done as part of a normal major building renovation, they need not be justified solely on their energy cost savings.

\section{B.3.2 Envelope improvements, Bldg. 663 (7MW)}

\section{B.3.2.1 Existing conditions}

This building is large physical training building (Gillis field house) with brick face and massive outer walls. A massive core of brick in front of the 
load-bearing steel frame, together with outer limestone trim, forms the outer wall. The building has a large gable roof with a bituminous waterproof skin. Roof insulation is $1.5 \mathrm{in}$. thick. The window area is small compared to the wall area and most windows are single-glazed tilt windows. The building is located on a slope so the main entrance on the south side is one story above the first floor on the river side. The winter space temperature in the building is maintained at a relatively cool temperature to accommodate the athletic events occurring inside.

The current status and general recommendations for the building are:

- Roof. The roof insulation should be increased by an additional 6 in. if the load-bearing capabilities of the roof structure can handle the additional weight. It is recommended this be done during the next reroofing of the building. Insulation material should be selected dependent on fire protection regulations, weight, and insulation quality of the material.

- Outer Walls. Mount 4-in. EPS-gypsum-sandwich boards to the interior walls.

- Windows. Replace the single-glazed windows with thermally broken, aluminum-framed, low-e, argon filled double-glazed windows. Interior shading with roller blinds should also be implemented to reduce interior solar gain.

- Doors. The current doors are in acceptable condition, but the edges and connection areas around the doors have fallen into disrepair. There are gaps around the door and the frames allow unconditioned outdoor air to enter the building. It is recommended that all of the door weather-stripping be replaced and maintained to obtain a sufficient seal. This will reduce infiltration of outdoor air.

\section{B.3.2.2 Solution}

This building's envelope needs to be upgraded to achieve a more efficient energy use. Bldg. 663 has significant steam-using heating equipment and, with the conversion off steam major portions, will need to be replaced with equipment compatible with the new heating energy source. With such a major building upgrade, the building envelope should also be upgraded. Table B-6 lists recommended upgrades. 
Table B-6. Recommended upgrades for Bldg. 663.

\begin{tabular}{|c|c|c|c|}
\hline $\begin{array}{l}\text { Building } \\
\text { Component }\end{array}$ & R-value Before & Measure & Resulting R-value \\
\hline Outer wall & $\begin{array}{l}\mathrm{R}=3.9 \mathrm{~h} \mathrm{sq} \mathrm{ft} \\
{ }^{\circ} \mathrm{F} / \mathrm{Btu}\end{array}$ & $\begin{array}{l}\text { 4-in. Knauf InTherm EPS- } \\
\text { Gypsum-Sandwichboard }\end{array}$ & $\begin{array}{l}\mathrm{R}=21.0 \mathrm{~h} \mathrm{sq} \mathrm{ft} \\
{ }^{\circ} \mathrm{F} / \mathrm{Btu}\end{array}$ \\
\hline \multirow{2}{*}{ Window 1} & $\begin{array}{l}\text { Rglass }=2.0 \mathrm{~h} \mathrm{sq} \mathrm{ft} \\
{ }^{\circ} \mathrm{F} / \mathrm{Btu}\end{array}$ & \multirow{2}{*}{$\begin{array}{l}\text { Replace with thermally } \\
\text { broken, aluminum-framed } \\
\text { low-e, argon filled double- } \\
\text { glazed windows }\end{array}$} & $\begin{array}{l}\text { Rglass }=4.1 \mathrm{~h} \mathrm{sq} \mathrm{ft} \\
{ }^{\circ} \mathrm{F} / \mathrm{Btu}\end{array}$ \\
\hline & $\begin{array}{l}\text { Rframe }=1.6 \mathrm{~h} \mathrm{sq} \mathrm{ft} \\
{ }^{\circ} \mathrm{F} / \mathrm{Btu}\end{array}$ & & $\begin{array}{l}\text { Rframe }=3.8 \mathrm{~h} \mathrm{sq} \mathrm{ft} \\
{ }^{\circ} \mathrm{F} / \mathrm{Btu}\end{array}$ \\
\hline \multirow{2}{*}{ Window 2} & $\begin{array}{l}\text { Rglass }=1.0 \mathrm{~h} \mathrm{sq} \mathrm{ft} \\
{ }^{\circ} \mathrm{F} / \mathrm{Btu}\end{array}$ & \multirow{2}{*}{$\begin{array}{l}\text { Replace steel tilt windows } \\
\text { with } \\
\text { Insulated ventilation flap } \\
\text { construction }\end{array}$} & \multirow{2}{*}{$\begin{array}{l}\text { Rvent }=11.4 \mathrm{~h} \mathrm{sq} \mathrm{ft} \\
{ }^{\circ} \mathrm{F} / \mathrm{Btu}\end{array}$} \\
\hline & $\begin{array}{l}\text { Rframe }=1.1 \mathrm{~h} \mathrm{sq} \mathrm{ft} \\
{ }^{\circ} \mathrm{F} / \mathrm{Btu}\end{array}$ & & \\
\hline Roof & $\begin{array}{l}\mathrm{R}=6.4 \mathrm{~h} \mathrm{sq} \mathrm{ft} \\
{ }^{\circ} \mathrm{F} / \mathrm{Btu}\end{array}$ & 6-in. Mineral fiber insulation & $\begin{array}{l}\mathrm{R}=28.4 \mathrm{~h} \mathrm{sq} \mathrm{ft} \\
{ }^{\circ} \mathrm{F} / \mathrm{Btu}\end{array}$ \\
\hline Floor & $\begin{array}{l}\mathrm{R}=4.4 \mathrm{~h} \mathrm{sq} \mathrm{ft} \\
{ }^{\circ} \mathrm{F} / \mathrm{Btu}\end{array}$ & No measures intended & $\begin{array}{l}\mathrm{R}=4.4 \mathrm{~h} \mathrm{sq} \mathrm{ft} \\
{ }^{\circ} \mathrm{F} / \mathrm{Btu}\end{array}$ \\
\hline Shading & $s c=0.78$ & $\begin{array}{l}\text { Roller blinds on half the } \\
\text { windows }\end{array}$ & $s c=0.67$ \\
\hline Airtightness $\eta 50$ & $4.01 / \mathrm{h}$ & $\begin{array}{l}\text { Tighter windows, doors, and } \\
\text { construction connections }\end{array}$ & $2.01 / \mathrm{h}$ \\
\hline Thermal Bridge & $\begin{array}{l}\mathrm{R}=56.8 \mathrm{~h} \mathrm{sq} \mathrm{ft} \\
{ }^{\circ} \mathrm{F} / \mathrm{Btu}\end{array}$ & Inner insulation & $\begin{array}{l}\mathrm{R}=56.8 \mathrm{~h} \mathrm{sq} \mathrm{ft} \\
{ }^{\circ} \mathrm{F} / \mathrm{Btu}\end{array}$ \\
\hline
\end{tabular}

\section{B.3.2.3 Savings}

The heating energy use (determined by computer modeling) totals 4,477 $\mathrm{MMBtu} / \mathrm{yr}$, or $49 \mathrm{Btu} / \mathrm{yr}$ per building sq $\mathrm{ft}$. This value was calculated to include the NORESCO improvements, which brings the buildings energy use into an acceptable range. Therefore no energy savings were calculated.

Since this is fairly representative for this type and function of building, any further heating energy savings done to improve the building envelope were thought to be insignificant. Almost all the building area is used for athletic activities where a cooler space temperature than those in other buildings is maintained.

\section{B.3.2.4 Investment}

The following calculations determine the costs to upgrade the building envelope based on unit cost values. For Bldg. 663, the total implementation cost is $\$ 2,480,000$, or $\$ 26.97 /$ sq ft: 
Insulation Cost:

Insulate Wall Cost $=73,418$ SF $X \$ 8.60=\$ 631,400$

Insulate Roof Cost $=94,521$ SF X $\$ 16.27 / \mathrm{SF}=\$ 1,537,860$

Window and Door Cost:

less than $10 \mathrm{SF}$ : $0 \mathrm{SF} X \$ 93.55 / \mathrm{SF}=\$ 0$

$10 \mathrm{SF}-20 \mathrm{SF}: 0 \mathrm{SF} X \$ 71.03 / \mathrm{SF}=\$ 0$

20 SF - 30 SF: 592 SF X $\$ 65.11 / \mathrm{SF}=\$ 38,570$

Insulated Louvers $=2,825 \mathrm{SF} X \$ 95.05 / \mathrm{SF}=\$ 268,540$

Roller Blind Cost $=296$ SF X $\$ 11 \cdot 19 / \mathrm{SF}=\$ 3,310$

Total ECM Investment for Bldg. $663=\$ 2,479,680$.

\section{B.3.2.5 Payback}

Since the building energy savings are considered insignificant, no payback period was calculated. Since the building upgrades would be done as part of a normal major building renovation, they need not be justified solely on their energy cost savings.

\section{B.3.3 Envelope Improvements BIdg. 609 (8IDW)}

\section{B.3.3.1 Existing conditions}

This recreation type building has granite-faced walls and a limestone trim on a massive core of brick or CMU infill in the load-bearing concrete frame. The majority of the rooms are fitted with inner dry walls. The building has a heavy load-bearing roof, similar to Bldg. 601, Thayer Hall. The roof construction and flashing shows a lot of cracks and other damages. The drawings do not indicate insulation in the roof construction. The outer walls are similar to the older administration buildings built in the 1930s: granite cladding, massive CMU or brick walls and an inner dry wall in the majority of the rooms. The building is fitted with aluminum tilt windows with special brown colored sun protection double glazing.

The current status and general recommendations for the building are:

- Roof. It was not possible to determine whether insulation currently exists underneath the exposed concrete roof. At minimum, 4 in. of insulation should be installed.

- Outer Walls. It is unknown if there is insulation behind the dry wall on perimeter walls. Insulation should be at least 4 in. thick. There should also be a continuous vapor barrier on the warm side of this insulation.

- Windows. The windows appear to have reached the end of their useful life and require replacement. The windows should be replaced with 
thermally broken, aluminum-framed, low-e, argon filled, double-glazed windows of a similar sash and operational arrangement. Interior shading with roller blinds should also be installed to reduce interior solar gain.

- Doors. The current doors are in acceptable condition, but the edges and connection areas around the doors have fallen into disrepair. There are gaps around the door and the frames allow unconditioned outdoor air to enter the building. It is recommended that all of the door weather-stripping be replaced and maintained to obtain a sufficient seal. This will reduce infiltration of outdoor air.

\section{B.3.3.2 Solution}

In 2003, Bldg. 609 was completely renovated, including installation of new windows. Because of the building was used only temporarily, the windows and the existing inner dry wall are in good condition. Implementation of new ECMs should not be a high priority for Bldg. 609. However, Table B-7 lists building envelope modifications that should be considered for Bldg. 609 with the change from a steam central distribution system.

Table B-7. Recommended upgrades for Bldg. 609.

\begin{tabular}{|c|c|c|c|}
\hline $\begin{array}{l}\text { Building } \\
\text { Component }\end{array}$ & R-value Before & Measure & Resulting R-value \\
\hline Outer wall & $\begin{array}{l}\mathrm{R}=5.6 \mathrm{~h} \mathrm{sq} \mathrm{ft} \\
{ }^{\circ} \mathrm{F} / \mathrm{Btu}\end{array}$ & $\begin{array}{l}\text { Spray } 4 \text { in. foam on } \\
\text { estimated } 85 \% \text { of interior } \\
\text { walls }\end{array}$ & $\begin{array}{l}\mathrm{R}=14.2 \mathrm{~h} \mathrm{sq} \mathrm{ft} \\
{ }^{\circ} \mathrm{F} / \mathrm{Btu}\end{array}$ \\
\hline \multirow{2}{*}{ Windows } & $\begin{array}{l}\text { Rglass }=2.0 \mathrm{~h} \mathrm{sq} \mathrm{ft} \\
{ }^{\circ} \mathrm{F} / \mathrm{Btu}\end{array}$ & \multirow{2}{*}{$\begin{array}{l}\text { Replace windows with } \\
\text { double low-e argon filled } \\
\text { glazing and aluminum } \\
\text { frames }\end{array}$} & $\begin{array}{l}\text { Rglass }=4.1 \mathrm{~h} \mathrm{sq} \mathrm{ft} \\
{ }^{\circ} \mathrm{F} / \mathrm{Btu}\end{array}$ \\
\hline & $\begin{array}{l}\text { Rframe }=1.6 \mathrm{~h} \mathrm{sq} \mathrm{ft} \\
{ }^{\circ} \mathrm{F} / \mathrm{Btu}\end{array}$ & & $\begin{array}{l}\text { Rframe }=3.8 \mathrm{~h} \mathrm{sq} \mathrm{ft} \\
{ }^{\circ} \mathrm{F} / \mathrm{Btu}\end{array}$ \\
\hline Roof & $\begin{array}{l}\mathrm{R}=3.8 \mathrm{~h} \mathrm{sq} \mathrm{ft} \\
{ }^{\circ} \mathrm{F} / \mathrm{Btu}\end{array}$ & $\begin{array}{l}\text { Knauf InTherm EPS- } \\
\text { Gypsum-Sandwichboard }\end{array}$ & $\begin{array}{l}\mathrm{R}=20.3 \mathrm{~h} \mathrm{sq} \mathrm{ft} \\
{ }^{\circ} \mathrm{F} / \mathrm{Btu}\end{array}$ \\
\hline Floor & $\begin{array}{l}\mathrm{R}=4.4 \mathrm{~h} \mathrm{sq} \mathrm{ft} \\
{ }^{\circ} \mathrm{F} / \mathrm{Btu}\end{array}$ & No measures intended & $\begin{array}{l}\mathrm{R}=4.4 \mathrm{~h} \mathrm{sq} \mathrm{ft} \\
{ }^{\circ} \mathrm{F} / \mathrm{Btu}\end{array}$ \\
\hline Shading & $\mathrm{sc}=0.67$ & $\begin{array}{l}\text { Roller blinds on } 85 \% \text { of the } \\
\text { windows }\end{array}$ & $s c=0.31$ \\
\hline Airtightness $\eta 50$ & $4.01 / \mathrm{h}$ & $\begin{array}{l}\text { Tighter windows, doors, and } \\
\text { construction connections }\end{array}$ & $2.01 / \mathrm{h}$ \\
\hline Thermal Bridge & $\begin{array}{l}\mathrm{R}=56.8 \mathrm{~h} \mathrm{sq} \mathrm{ft} \\
{ }^{\circ} \mathrm{F} / \mathrm{Btu}\end{array}$ & Inner insulation & $\begin{array}{l}\mathrm{R}=37.9 \mathrm{~h} \text { sq ft } \\
{ }^{\circ} \mathrm{F} / \mathrm{Btu}\end{array}$ \\
\hline
\end{tabular}




\section{B.3.3.3 Savings}

The energy savings were determined by computer modeling to show "before and after" energy use. The heating energy savings were determined to be $39.8 \%$ of the annual use. The analysis also showed an annual cooling energy increase of $4.1 \%$, which is caused by an increased need for cooling during the spring and fall to remove internally generated heat. Before the building envelope improvements, this heat was simply removed by the cool outdoor weather. Since this space cooling can be accomplished via natural ventilation (opening windows) and the cooling equipment may be not operating during these months, this cooling energy increase will be ignored.

The resulting energy savings are:

Energy Savings $=157 \mathrm{MMBtu} / \mathrm{yr} \times(.398)=63 \mathrm{MMBtu} / \mathrm{yr}$ Cost Savings $=63 \mathrm{MMBtu} / \mathrm{yr} \times \$ 7.70 / \mathrm{MMBtu}=\$ 490 / \mathrm{yr}$.

\section{B.3.3.4 Investment}

The costs to upgrade the building envelope are based on unit cost values, as the following calculations show. For Bldg. 609, the total implementation cost is $\$ 186,000$, or $\$ 26.91 /$ sq $\mathrm{ft}$ :

\section{Insulation Cost:}

Insulate Wall Cost $=5,319$ SF $\times 0.85 \times \$ 19.79=\$ 89,470$

Insulate Roof Cost $=3,283 \mathrm{SF} X \$ 8.60 / \mathrm{SF}=\$ 28,230$

Window and Door Cost:

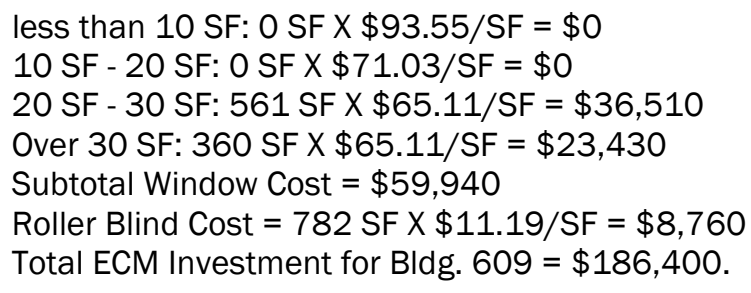

\section{B.3.3.5 Payback}

For Bldg. 609, the simple payback period is 384 years. The cost savings of a smaller heating system due to a building lower heating demand is not included in these calculations. Since the building upgrades would be done as part of a normal major building renovation, they need not be justified solely on their energy cost savings. 


\section{B.3.4 Envelope improvements: Bldg. 635 (8MW)}

\section{B.3.4.1 Existing conditions}

Bldg. 635 serves as the USMA Cadet Club (USCC). Its construction consists of a built-up brick-faced wall with limestone trim with a thick structural core of bricks. Several interior walls are finished brick and do not possess sufficient cavity space for insulation, whereas other walls that are finished with differing materials may have cavity space behind the interior layer. It was surmised that, if any insulation exist within the assembly, it is most likely insufficient. The building is capped by a gabled metal standing seam roof with standard wood frame construction. The existing windows are replacements to the original, and are wooden-framed, double hung, and double-glazed. These are rather deteriorated and should be replaced. The building sits on a concrete slab with thick granite exterior facing at the foundation.

The current status and general recommendations for the building are:

- Roof. It was not possible to determine whether insulation currently exists within the attic space above the ceiling. At minimum, an additional 6 in. of insulation should be installed. If possible, more than 6 in. should be installed.

- Outer Walls. There is currently no insulation within the walls. The interior of the walls should be furred out to accommodate additional insulation, an air barrier, and a new finish material.

- Windows. The windows appear to have reached the end of their useful life and require replacement. The windows should be replaced with thermally broken, aluminum-framed, low-e, argon filled, double-glazed windows of a similar sash and operational arrangement. Interior shading with roller blinds should also be implemented to reduce interior solar gain.

- Doors. The current doors are in acceptable condition, but the edges and connection areas around the doors have fallen into disrepair. There are gaps around the door and frames that allow unconditioned outdoor air to enter the building. It is recommended that all of the door weather-stripping be replaced and maintained to obtain a sufficient seal. This will reduce infiltration of outdoor air. 


\section{B.3.4.2 Solution}

This building's envelope needs to be upgraded to achieve a more efficient energy use. Bldg. 635 has significant steam-using heating equipment and, with the conversion off steam major portions, will need to be replaced with equipment compatible with the new heating energy source. With such a major building upgrade, the building envelope should also be upgraded. Table B-8 lists recommended upgrades.

Table B-8. Recommended upgrades for Bldg. 635.

\begin{tabular}{|c|c|c|c|}
\hline $\begin{array}{l}\text { Building } \\
\text { Component }\end{array}$ & R-value Before & Measure & Resulting R-value \\
\hline Outer wall & $\begin{array}{l}\mathrm{R}=5.6 \mathrm{~h} \mathrm{sq} \mathrm{ft} \\
{ }^{\circ} \mathrm{F} / \mathrm{Btu}\end{array}$ & $\begin{array}{l}\text { On exterior walls place } 6 \text { in. } \\
\text { mineral wool insulation with } \\
\text { plaster finish }\end{array}$ & $\begin{array}{l}\mathrm{R}=21.8 \mathrm{~h} \mathrm{sq} \mathrm{ft} \\
{ }^{\circ} \mathrm{F} / \mathrm{Btu}\end{array}$ \\
\hline \multirow{2}{*}{ Windows } & $\begin{array}{l}\text { Rglass }=2.0 \mathrm{~h} \mathrm{sq} \mathrm{ft} \\
{ }^{\circ} \mathrm{F} / \mathrm{Btu}\end{array}$ & \multirow{2}{*}{$\begin{array}{l}\text { Replace windows with } \\
\text { double low-e argon filled } \\
\text { glazing and aluminum } \\
\text { frames }\end{array}$} & $\begin{array}{l}\text { Rglass }=4.1 \mathrm{~h} \mathrm{sq} \mathrm{ft} \\
{ }^{\circ} \mathrm{F} / \mathrm{Btu}\end{array}$ \\
\hline & $\begin{array}{l}\text { Rframe }=3.1 \mathrm{~h} \mathrm{sq} \mathrm{ft} \\
{ }^{\circ} \mathrm{F} / \mathrm{Btu}\end{array}$ & & $\begin{array}{l}\text { Rframe }=3.8 \mathrm{~h} \mathrm{sq} \mathrm{ft} \\
{ }^{\circ} \mathrm{F} / \mathrm{Btu}\end{array}$ \\
\hline Roof & $\begin{array}{l}\mathrm{R}=5.7 \mathrm{~h} \mathrm{sq} \mathrm{ft} \\
{ }^{\circ} \mathrm{F} / \mathrm{Btu}\end{array}$ & $\begin{array}{l}\text { Install } 6 \text { in. of mineral wool } \\
\text { insulation with vapor barrier } \\
\text { on top of the ceiling }\end{array}$ & $\begin{array}{l}\mathrm{R}=33.4 \mathrm{~h} \mathrm{sq} \mathrm{ft} \\
{ }^{\circ} \mathrm{F} / \mathrm{Btu}\end{array}$ \\
\hline Floor & $\begin{array}{l}\mathrm{R}=4.4 \mathrm{~h} \mathrm{sq} \mathrm{ft} \\
{ }^{\circ} \mathrm{F} / \mathrm{Btu}\end{array}$ & No measures intended & $\begin{array}{l}\mathrm{R}=4.4 \mathrm{~h} \mathrm{sq} \mathrm{ft} \\
{ }^{\circ} \mathrm{F} / \mathrm{Btu}\end{array}$ \\
\hline Shading & $s c=0.67$ & No measures intended & $S c=0.67$ \\
\hline Airtightness $\eta 50$ & $6.01 / \mathrm{h}$ & $\begin{array}{l}\text { Tighter windows, doors, and } \\
\text { construction connections }\end{array}$ & $2.01 / \mathrm{h}$ \\
\hline Thermal Bridge & $\begin{array}{l}\mathrm{R}=56.8 \mathrm{~h} \mathrm{sq} \mathrm{ft} \\
{ }^{\circ} \mathrm{F} / \mathrm{Btu}\end{array}$ & Inner insulation & $\begin{array}{l}\mathrm{R}=56.8 \mathrm{~h} \mathrm{sq} \mathrm{ft} \\
{ }^{\circ} \mathrm{F} / \mathrm{Btu}\end{array}$ \\
\hline
\end{tabular}

\section{B.3.4.3 Savings}

The energy savings were determined by computer modeling to show "before and after" energy use. The heating energy savings were determined to be $49.5 \%$ of the annual use. The analysis also showed an annual cooling energy increase of $9.2 \%$, which is caused by an increased need for cooling during the spring and fall to remove internally generated heat. Before the building envelope improvements, this heat was simply removed by the cool outdoor weather. Since this space cooling can be accomplished via natural ventilation (opening windows) and the cooling equipment may be not operating during these months, this cooling energy increase will be ignored.

The resulting energy savings are: 
Energy Savings $=426 \mathrm{MMBtu} / \mathrm{yr} \times(.495)=211 \mathrm{MMBtu} / \mathrm{yr}$

Cost Savings $=211 \mathrm{MMBtu} / \mathrm{yr} \times \$ 7.70 / \mathrm{MMBtu}=\$ 1,620 / \mathrm{yr}$

\section{B.3.4.4 Investment}

The costs to upgrade the building envelope are based on unit cost values shown the following calculations. For Bldg. 635, the total implementation cost is $\$ 175,000$, or $\$ 26.80 /$ sq ft.

Insulation Cost:

Insulate Wall Cost $=4,648$ SF $\times 0.85 \times \$ 18.38=\$ 85,440$

Insulate Roof Cost $=6,546 \mathrm{SF} \times \$ 5.26 / \mathrm{SF}=\$ 34,430$

Window and Door Cost:

less than 10 SF: 0 SF $X \$ 93.55 / S F=\$ 0$
10 SF - 20 SF: 89 SF $X \$ 71.03 / S F=\$ 6,330$
20 SF - 30 SF: 578 SF X $\$ 65.11 / S F=\$ 37,670$
Over 30 SF: 177 SF $X \$ 65.11 / S F=\$ 11,500$
Subtotal Window Cost $=\$ 55,500$
Total ECM Investment for Bldg. $635=\$ 175,370$.

\section{B.3.4.5 Payback}

For Bldg. 609, the simple payback period is 108 years. These calculations do not include the cost savings from the use of a smaller heating system due to a building's lower heating demand. Since the building upgrades would be done as part of a normal major building renovation, they need not be justified solely on their energy cost savings.

\section{B.3.5 Envelope improvements, Bldg. 726 (9MW)}

\section{B.3.5.1 Existing conditions}

The Water Treatment Plant building is minimally heated except in office and lab areas. Cooling is provided by window air conditioners. The construction of this building consists of walls with an exterior finish of granite-faced block with a core of CMU infill, together with the usual limestone trim. No inner dry wall was found during the onsite visit except some piping chases. The roof is of an insulated built-up type on a concrete slab with an insulation thickness of about $2 \mathrm{in}$. The aluminum-framed casement windows are double-glazed and have no thermal break or sealant strips. 
The current building status and general recommendations are:

- Roof. Currently, the flat roof has 2 in. of insulation. At a minimum, an additional 4 in. of insulation should be installed during the next reroofing.

- Outer Walls. There is currently no insulation within the walls. The interior of the walls should be furred out to accommodate the addition of $4 \mathrm{in}$. of insulation and a new finish material.

- Windows. The windows should be replaced with thermally broken, aluminum-framed, low-e, argon filled, double-glazed windows of a similar sash and operational arrangement. Interior shading with roller blinds should also be implemented to reduce interior solar gain.

- Doors. The current doors are in acceptable condition, but the edges and connection areas around the doors have fallen into disrepair. There are gaps around the door and frames that allow unconditioned outdoor air to enter the building. It is recommended that all of the door weather-stripping be replaced and maintained to obtain a sufficient seal, which will reduce infiltration of outdoor air.

\section{B.3.5.2 Solution}

This building's envelope needs to be upgraded to achieve a more efficient energy use. Bldg. 726 has significant steam-using heating equipment and, with the conversion off steam major portions, will need to be replaced with equipment compatible with the new heating energy source. With such a major building upgrade, the building envelope should also be upgraded. Table B-9 lists recommended upgrades.

Table B-9. Recommended upgrades for Bldg. 726.

\begin{tabular}{|c|c|c|c|}
\hline $\begin{array}{l}\text { Building } \\
\text { Component }\end{array}$ & R-value Before & Measure & Resulting R-value \\
\hline Outer wall & $\begin{array}{l}\mathrm{R}=4.4 \mathrm{~h} \mathrm{sq} \mathrm{ft} \\
{ }^{\circ} \mathrm{F} / \mathrm{Btu}\end{array}$ & $\begin{array}{l}\text { Spray 4-in. foam on } \\
\text { estimated } 70 \% \text { of interior } \\
\text { walls }\end{array}$ & $\begin{array}{l}\mathrm{R}=10.1 \mathrm{~h} \mathrm{sq} \mathrm{ft} \\
{ }^{\circ} \mathrm{F} / \mathrm{Btu}\end{array}$ \\
\hline \multirow[t]{2}{*}{ Windows } & $\begin{array}{l}\text { Rglass }=2.0 \mathrm{~h} \mathrm{sq} \mathrm{ft} \\
{ }^{\circ} \mathrm{F} / \mathrm{Btu}\end{array}$ & \multirow{2}{*}{$\begin{array}{l}\text { Replace windows with } \\
\text { double low-e argon filled } \\
\text { glazing and aluminum } \\
\text { frames }\end{array}$} & $\begin{array}{l}\text { Rglass }=4.1 \mathrm{~h} \mathrm{sq} \mathrm{ft} \\
{ }^{\circ} \mathrm{F} / \mathrm{Btu}\end{array}$ \\
\hline & $\begin{array}{l}\text { Rframe }=1.6 \mathrm{~h} \mathrm{sq} \mathrm{ft} \\
{ }^{\circ} \mathrm{F} / \mathrm{Btu}\end{array}$ & & $\begin{array}{l}\text { Rframe }=3.8 \mathrm{~h} \mathrm{sq} \mathrm{ft} \\
{ }^{\circ} \mathrm{F} / \mathrm{Btu}\end{array}$ \\
\hline Roof & $\begin{array}{l}\mathrm{R}=4.7 \mathrm{~h} \mathrm{sq} \mathrm{ft} \\
{ }^{\circ} \mathrm{F} / \mathrm{Btu}\end{array}$ & $\begin{array}{l}\text { Add } 6 \text { in. XPS-insulation } \\
\text { during next reroofing }\end{array}$ & $\begin{array}{l}\mathrm{R}=31.5 \mathrm{~h} \mathrm{sq} \mathrm{ft} \\
{ }^{\circ} \mathrm{F} / \mathrm{Btu}\end{array}$ \\
\hline Floor & $\begin{array}{l}\mathrm{R}=2.8 \mathrm{~h} \mathrm{sq} \mathrm{ft} \\
{ }^{\circ} \mathrm{F} / \mathrm{Btu}\end{array}$ & No measures intended & $\begin{array}{l}\mathrm{R}=2.8 \mathrm{~h} \mathrm{sq} \mathrm{ft} \\
{ }^{\circ} \mathrm{F} / \mathrm{Btu}\end{array}$ \\
\hline Shading & $s c=0.67$ & Roller blinds & $s c=0.31$ \\
\hline
\end{tabular}




\begin{tabular}{|l|l|l|l|}
\hline Airtightness $\eta 50$ & $4.01 / \mathrm{h}$ & $\begin{array}{l}\text { Tighter windows, doors, and } \\
\text { construction connections }\end{array}$ & $2.01 / \mathrm{h}$ \\
\hline Thermal Bridge & $\begin{array}{l}\mathrm{R}=56.8 \mathrm{~h} \mathrm{sq} \mathrm{ft} \\
{ }^{\circ} \mathrm{F} / \mathrm{Btu}\end{array}$ & Inner insulation & $\begin{array}{l}\mathrm{R}=37.9 \mathrm{~h} \mathrm{sq} \mathrm{ft} \\
{ }^{\circ} \mathrm{F} / \mathrm{Btu}\end{array}$ \\
\hline
\end{tabular}

\section{B.3.5.3 Savings}

The heating energy use (determined by computer modeling) totals 1,281 $\mathrm{MMBtu} / \mathrm{yr}$, or $49 \mathrm{Btu} / \mathrm{yr}$ per building sq ft. This value, which was calculated to include the NORESCO improvements, brings the buildings energy use into an acceptable range; therefore, no energy savings were calculated. Since this is fairly representative for this type and function of building, any further heating energy savings done to improve the building envelope were thought to be insignificant. The majority of the building is used either for treating the potable water for the site or for storage; thus the space temperature is maintained at cooler temperatures than those in other buildings.

\section{B.3.5.4 Investment}

The costs to upgrade the building envelope are based on unit cost values shown the following calculations. For Bldg. 726, the total implementation cost is $\$ 287,000$ or $\$ 31.07 /$ sq ft:

\section{Insulation Cost:}

Insulate Wall Cost $=5,739$ SF X $0.85 \times \$ 19.79=\$ 96,540$

Insulate Roof Cost $=8,933$ SF X $\$ 11.94 / \mathrm{SF}=\$ 106,670$

Window and Door Cost:

less than $10 \mathrm{SF}: 18 \mathrm{SF} \times \$ 93.55 / \mathrm{SF}=\$ 1,670$
$10 \mathrm{SF}-20 \mathrm{SF}: 846 \mathrm{SF} \times \$ 71.03 / \mathrm{SF}=\$ 60,060$
$20 \mathrm{SF}-30 \mathrm{SF}: 137 \mathrm{SF} \times \$ 65.11 / \mathrm{SF}=\$ 8,940$
Over $30 \mathrm{SF}: 112 \mathrm{SF} \times \$ 65.11 / \mathrm{SF}=\$ 7,300$
Subtotal Window Cost $=\$ 77,970$
Roller blind Cost $=556 \mathrm{SF} X \$ 11.19 / \mathrm{SF}=\$ 6,230$

Total ECM Investment for Bldg. $726=\$ 287,410$.

\section{B.3.5.5 Payback}

Building energy savings are considered insignificant so no payback period was calculated. Since the building upgrades would be done as part of a normal major building renovation, they need not be justified solely on their energy cost savings. 


\section{B.4 Mechanical EEMs}

The Mechanical EEM package, outlined below, includes those measures that are incorporated in the barracks renovation projects, the improvements made when the building heating systems are switched from service by steam distribution to local heating equipment, to a central HW system, and/ or to other systems economically feasible for implementation. The implementation timing of these EEMs may take place when appropriate in terms of costs and schedule. Thus, the barracks-related projects would take place during the specific renovation and the improvements related to the heating systems would occur when the steam system is phased out. The other HVAC EEMs are standalone and can take place at any time. It is therefore recommended these EEMs be accomplished when funding becomes available.

A total of eight EEMs were evaluated, seven HVAC types and one electri$\mathrm{cal}$. The last HVAC EEM has an excessively long payback period and thus is not recommended, but is included to highlight that this measure was studied. The total implementation cost of the recommended Mechanical EEMs totals $\$ 867,000$. The total annual estimated energy savings is $18,725 \mathrm{MMBtu} / \mathrm{yr}$ (5,488 MWh/yr) [15,935 MMBtu/yr of heat energy and $818,000 \mathrm{kWh} / \mathrm{yr}$ of electrical]. The energy saving impact of implementing the recommended EEMs on the (Base Case) building energy use is discussed in Section 2.1.4.

The following sections present the evaluated EEMs.

\section{B.4.1 Mechanical EEM \#1: Implement demand ventilation for various buildings}

\section{B.4.1.1 Existing conditions/problems}

Many of the buildings in the main group of buildings in the central NZE Area at USMA, West Point have Air Handling Units (AHUs) that run many hours per week (some of them continuously), and that have a high percentage of outdoor air $(\mathrm{OA})$ intake. $\mathrm{OA}$ and energy use are directly related: the more OA used, the more energy used to heat or cool this air.

\section{B.4.1.2 Solution}

Install carbon dioxide $\left(\mathrm{CO}_{2}\right)$ sensors and connect them with existing controls with the sensor signal as input, generating an output controlling the 
OA damper position. NORESCO Task Order 1 has done (or is about to do) this for Bldgs. 745A and 745B. This should be done to a large number of buildings and systems within these buildings.

Keeping $\mathrm{CO}_{2}$ levels below $800 \mathrm{ppm}$ is the (adjustable) target. As long as the level is lower, no OA is required to provide a good indoor climate. If the upper level is exceeded, the OA damper is opened, in increments, to reduce the $\mathrm{CO}_{2}$ level.

\section{B.4.1.3 Savings}

It is estimated that this measure can reduce the average OA levels by at least $10 \%$. This reduction is used in the savings calculations below. Some of the units in respective buildings are heating-only units or makeup air units that have no return air. These units can be switched off completely when there is no need to bring in outside air. Some units have both heating and cooling coils. These units accrue savings during both summer and winter by reducing the amount of OA. Table B-10 summarizes the fan motor horsepower (HP) that can be switched off completely and the associated calculated electricity savings (30\%).

Note that some buildings do have more AHUs than listed below, but not all units are suitable for this kind of controls, e.g., AHUs in Bldg. 757 (with heat recovery) that run continuously to match laboratory exhaust fans.

Actual savings will vary depending on actual conditions when the measures are implemented:

Weather data for Newburgh/Stewart International Airport that were used as a base for the calculations are:

- Heating Degree Days $=5964^{\circ} \mathrm{F}$

- Cooling Degree Days $=752^{\circ} \mathrm{F}$

- Estimated COP on average for chillers $=2.5$

- Fan motors are estimated to be loaded $80 \%$.

Minimum outdoor air requirements were found in mechanical schedules. During the assessment of buildings, some AHUs that should have been at minimum OA were not, so actual savings from the proposed measures may actually be higher than the estimated $10 \%$. 
Total value of the savings will be:

Electricity: $(52,456+113,386 \mathrm{kWh}) * \$ 0.083 / \mathrm{kWh}=\$ 13,800$

Heat: 7,600 Million Btu at $\$ 7.70 / \mathrm{MMBtu}=\$ 58,500$

Total savings: $\$ 72,300$ per year.

Table B-10. Fan Motor hp and the Associated Electricity Savings.

\begin{tabular}{|c|r|r|r|r|r|r|r|r|}
\hline Bldg. \# & $\begin{array}{c}\text { \# of } \\
\text { AHUs } \\
\text { or HVUs }\end{array}$ & $\begin{array}{c}\text { Total } \\
\text { min } \\
\text { OA } \\
\text { (CFM) }\end{array}$ & $\begin{array}{c}\text { Total min } \\
\text { OA } \\
\text { cooling } \\
\text { (CFM) }\end{array}$ & $\begin{array}{c}\text { Operating } \\
\text { hours } \\
\text { per week }\end{array}$ & $\begin{array}{c}\text { Total HP } \\
\text { for } \\
\text { units } \\
\text { without } \\
\text { RA }\end{array}$ & $\begin{array}{c}10 \% \\
\text { Savings } \\
\text { cooling } \\
\text { season } \\
\text { (kWh/yr) }\end{array}$ & $\begin{array}{c}10 \% \\
10 \% \\
\text { Savings } \\
\text { heating } \\
\text { season } \\
\text { (MMtu/yr) }\end{array}$ & $\begin{array}{c}\text { Savings } \\
\text { units } \\
\text { without } \\
\text { RA } \\
\text { (kWh/yr) }\end{array}$ \\
\hline 601 & 16 & 10900 & 109000 & 97 & 0 & 14918 & 967 & 0 \\
\hline 602 & 2 & 6000 & 6000 & 168 & 0 & 1422 & 92 & 0 \\
\hline 606 & 5 & 6500 & 6500 & 50 & 0 & 459 & 30 & 0 \\
\hline 607 & 1 & 9000 & 9000 & 55 & 0 & 698 & 45 & 0 \\
\hline 639 & 3 & 4000 & 4000 & 70 & 0 & 395 & 26 & 0 \\
\hline 655 & 11 & 38000 & 38000 & 110 & 0 & 5898 & 382 & 0 \\
\hline 727 & 36 & 108000 & 24000 & 97 & 0 & 3285 & 958 & 0 \\
\hline 735 & 2 & 13800 & 0 & 168 & 10 & 0 & 212 & 5274 \\
\hline 738 & 6 & 35500 & 0 & 168 & 30 & 0 & 545 & 15821 \\
\hline 740 & 7 & 40000 & 0 & 168 & 40 & 0 & 615 & 21095 \\
\hline $745 \mathrm{C}$ & 2 & 57000 & 0 & 168 & 40 & 0 & 876 & 21095 \\
\hline $745 \mathrm{D}$ & 2 & 43000 & 0 & 168 & 30 & 0 & 661 & 15821 \\
\hline $745 \mathrm{E}$ & 1 & 37000 & 0 & 168 & 20 & 0 & 568 & 10547 \\
\hline 750 & 2 & 2200 & 2200 & 50 & 0 & 155 & 10 & 0 \\
\hline 752 & 4 & 16000 & 16000 & 120 & 0 & 2709 & 176 & 0 \\
\hline 756 & 2 & 76000 & 76000 & 168 & 45 & 18015 & 1168 & 23732 \\
\hline 758 & 10 & 29000 & 29000 & 110 & 0 & 4501 & 292 & 0 \\
\hline Totals & 112 & 630000 & 319700 & & & 52456 & 7622 & 113386 \\
\hline & & & & & & & & \\
\hline
\end{tabular}

\section{B.4.1.4 Investment}

The investments are moderate. $\mathrm{A} \mathrm{CO}_{2}$ sensor has a list price of approximately $\$ 600$. The sensor needs to be wired to the Energy Management Control System (EMCS) hardware and the correct sequences programmed into the direct digital control (DDC) controls system. Controls and actuators for the OA dampers already exist. The total cost per AHU or Heating Ventilation Unit (HVU), including one sensor per unit, is estimated to be around $\$ 3,000$. For 112 units, the total cost will be around $\$ 336,000$.

\section{B.4.1.5 Payback}

Payback is calculated to occur within 4.6 years. 


\section{B.4.2 Mechanical EEM \#2: Heat recovery from exhaust air to preheat out- side air}

\section{B.4.2.1 Existing conditions/problems}

At USMA, West Point, there are several systems installed to recover heat by using heat recovery coils with a glycol-water mix, from exhaust air to preheat outside air. Such systems are installed in Bldgs. 757 and 727. The renovation of Bldg. 753 also includes such heat recovery (HR) system. The systems are installed in these buildings because of the existence of laboratory exhausts not suitable to use as return air (Bldgs. 753 and 757). The systems are installed in Bldg. 727 probably due to the design of its one large central exhaust system, coupled with the many AHUs for independent supply of air to various areas.

The HR system in Bldg. 727, Arvin Gym, has never worked properly due to poor design or the lack of commissioning. NORESCO will, in Task Order 2, make alterations to the HR system in Arvin Gym and have it commissioned. The scope of work will include replacement of the glycol system pump motors with variable frequency drive (VFD) controlled motors, installation of numerous temperature sensors, and change the controls for the HR system.

There are some concerns regarding the NORESCO proposed scope of work. The design of the HR coil section of the AHUs and HVUs that supply heated or cooled air to the premises is not correct. The face area of the AHUs and HVUs is reduced before the HR coils and then expanded again after the HR coils. This means that the face velocity across the coil is much higher than it should have been if the face area of the coil would have been equal to the face area of the rest of the HVU. A higher face velocity, in combination with the fact that the HR coil only has two rows (maybe without fins on the tubes), means that the OA temperature will only be increased by a few degrees. To make an HR system work properly and highly efficiently, the face velocity should normally not exceed $500 \mathrm{fpm}$. To remedy the situation, the coil (and the up- and downstream parts of the HVU encasement) should be replaced to enable the accommodation of an HR coil with a larger face area and with at least six rows of finned tubes. Four to eight rows are normal for run-around coils, but in some cases, up to 12 rows may be optimal. 
If coils are being changed, it is also essential to change the pumps and the pump motors to match the new flow and the pressure drop through the new coils.

The team was not able to see the HR coil(s) in the exhaust stream in Arvin Gym during the assessment, but it is equally important that the coil(s) in this part of the system be designed properly for a low face velocity and with at least six rows of finned tubes. A review of mechanical schedules pertaining to some of the above mentioned buildings indicates that a solution with $40 \%$ propylene glycol is being used. Note that a system with 30\% ethylene glycol has a higher efficiency and still provides adequate freeze protection.

A review of the mechanical schedules for the HR system in Bldg. 757, with lab exhausts, revealed that, on the exhaust side of the system, with 105,000 CFM and a $108 \mathrm{sq} \mathrm{ft}$ coil, the face velocity is $972 \mathrm{fpm}$, twice the recommended maximum for a system that works with good efficiency. No information about the number of rows of tubes or whether the tubes are finned or not, could be found in the schedules. It was noted, however, that the HR system in Bldg. 757 has never worked very well even though the system is only a year old.

The mechanical schedules for the new systems in Bldg. 753 were also studied. These schedules do not reveal any information about the HR coils and their sizing (number of rows of tubes or face area), but for the cooling coils, the design is such that the face area of the three units with HR system are 55, 32, and $30 \mathrm{sq} \mathrm{ft}$, respectively, with face velocities of 490, 500, and $497 \mathrm{fpm}$, respectively. These are acceptable numbers and should be used, if there still is time, as guidelines for the HR coils as well. Again, make the coils with at least six rows of finned tubes.

Bldg. 665, the Pistol Range building, has separate systems for air supply and air exhaust. The exhaust air is not suitable for use as return air because it contains lead. The exhaust air units, HFU- 1 to HFU-4, all have high efficiency particulate air (filter) (HEPA) filters. There is space available in the units to install HR coils downstream of the HEPA filters and to pump a mix of water and ethylene glycol to matching coils in HV-1 to HV4 to preheat the outside air entering each of these units and thus to save energy. 
According to the EMCS operating schedule, the HFUs and the HVs all have VFDs and run $12 \mathrm{hrs} /$ day, 7 days per week. During the assessment, it was noted that filters in the HVs were very much clogged.

\section{B.4.2.2 Solutions}

\section{B.4.2.3 Bldg. 727}

It is believed that the HR system in this building, if it is running at all, has a maximum efficiency of 10\%. The NORESCO scope of work for this building should be revised such that new heat recovery coils (with more rows of finned tubes), new partitions of the AHUs and HVs, and new pumps are considered for installation, to increase the efficiency of the HR loops so that at least $50 \%$ of the energy in the exhaust air stream can be recovered and used to preheat the outside air. This should be done for all three HR loops. If such changes are done, it is also of outmost importance for the performance of the HR systems that filter banks be installed upstream of the coils, both on the supply and the exhaust sides of the system, to keep coils clean. There are no filters at all today, meaning that the cleanness of the coils is questionable. Savings for Bldg. 727 are not calculated at this stage. NORESCO's calculated savings will be used in calculations of future building loads.

\section{B.4.2.4 Bldg. 757}

The systems for heat recovery in this building need to be re-designed and renovated/ upgraded. There is no need for an HR system if it does not recover heat to the extent that it is supposed to. The savings calculations below assume that this system has an efficiency of $20 \%$ and show the savings up to an efficiency of $50 \%$.

\section{B.4.2.5 Bldg. 753}

Bldg. 753 is under renovation and new HVAC systems will be installed. Also in this case, apparently, it is a great risk that the efficiency will not be in range of $50 \%$. Calculations below will be based on assumptions of $20 \%$ efficiency and show the gains up to an efficiency of $50 \%$.

\section{B.4.2.6 Bldg. 665}

Install HR coils, pipes, expansion tanks, pumps, sensors, and controls for an HR system for systems HFU- 1 to HFU- 4 and HV- 1 to HV- 4 . 


\section{B.4.2.7 Savings}

\section{B.4.2.8 Bldgs. 753 and 757 :}

Savings were calculated for the cooling and the heating of outside air. In Bldg. 753, there will be a total of 84,000 CFM outside air to heat or cool and laboratory exhausts with $84,000 \mathrm{CFM}$. The calculations assumed a minimum of 34,000 CFM of outside air. For Bldg. 757, supply of outside air was 102,000 CFM; lab exhaust with HR was 133,000 CFM. The calculations use 50,000 CFM.

The data in Table B-11 show annual savings, heating, and cooling of HR efficiencies from 20 to $50 \%$.

Table B-11. Annual savings, heating, and cooling of HR efficiencies from 20 to $50 \%$.

\begin{tabular}{|c|c|c|c|c|}
\hline Bldg. \# & $\begin{array}{c}\text { Total min } \\
\text { OA } \\
\text { (CFM) }\end{array}$ & $\begin{array}{c}\text { Operating hours } \\
\text { per week }\end{array}$ & $\begin{array}{c}\text { Savings cooling } \\
\text { season } \\
(\mathrm{kWh} / \mathrm{yr})\end{array}$ & $\begin{array}{c}\text { Savings Heating } \\
\text { Season } \\
\text { (MMBtu/yr) }\end{array}$ \\
\hline 753 & 34000 & 72 & 10362 & 654 \\
\hline 757 & 50000 & 110 & 23281 & 1470 \\
\hline
\end{tabular}

Weather data were used as a base for the calculations:

Heating Degree Days $=5964^{\circ} \mathrm{F}$

Cooling Degree Days $=752^{\circ} \mathrm{F}$

Estimated COP on average for chillers is 2.5.

\section{B.4.2.9 Bldg. 665}

The savings calculations are done for the heating of outside air. There is no cooling of air in this building. In Bldg. 665, there will be an estimated total of 57,500 CFM of outside air to heat and exhausts with matching flow.

Table B- 12 shows annual savings, heating, and cooling, by installing an HR with an efficiency of $50 \%$.

Table B-12. Annual savings, heating, and cooling by installing an HR with an efficiency of $50 \%$.

\begin{tabular}{|c|c|c|c|}
\hline Bldg. \# & $\begin{array}{c}\text { Total min } \\
\text { OA } \\
\text { (CFM) }\end{array}$ & $\begin{array}{c}\text { Operating hours } \\
\text { per week }\end{array}$ & $\begin{array}{c}\text { Savings heating } \\
\text { season } \\
\text { (MMBtu/yr) }\end{array}$ \\
\hline 665 & 57500 & 72 & 1845 \\
\hline
\end{tabular}


Total savings are calculated as:

Bldg. 753:

Electricity: $(10,300 \mathrm{kWh}) *(\$ 0.083 / \mathrm{kWh})=\$ 850$

Heat: 650 MMBtu at $\$ 7.70$ per MMBtu $=\$ 5,000$

Total savings: $\$ 5,850$ per year

Bldg. 757:

Electricity: $(23,300 \mathrm{kWh}) *(\$ 0.083 / \mathrm{kWh})=\$ 1,900$

Heat: 1,470 MMBtu at $\$ 7.70$ per MMBtu $=\$ 11,300$

Total savings: $\$ 13,200$ per year

Bldg. 665:

Heat: 1,845 MMBtu at $\$ 7.70$ per MMBtu $=\$ 14,200$

Total savings: $\$ 14,200$ per year

Required investments are calculated as:

Upgrading the systems in Bldg. 753 is estimated to cost $\$ 80,000$

Upgrading the systems in Bldg. 757 is estimated to cost $\$ 100,000$

A totally new HR system in Bldg. 665, for $4 \mathrm{HV}$ and $4 \mathrm{HFU}$ units are estimated to cost $\$ 150,000$.

Total Investment for Mechanical ECM \#2: \$330,000

Cost estimates are based on experiences from other projects and include the capital cost of equipment, controls, installation, and design fees.

\section{B.4.2.10 Payback}

Payback is calculated as:

- Bldg 753: Within 13.7 years

- Bldg 757: Within 7.6 years

- Bldg 665: Within 10.6 years.

\section{B.4.3 Mechanical EEM \#3: Install pool covers for all three pools at Arvin Gym, Bldg. 727}

\section{B.4.3.1 Existing conditions/problems}

Arvin Gym has three indoor pools. The pools are heated to somewhere between 80 and $84^{\circ} \mathrm{F}$. Also the space temperature is relatively high, around $80^{\circ} \mathrm{F}$. Heat losses from a pool are mainly by evaporation. NORESCO has proposed, in Task Order 2, to replace some old heating and ventilation 
units with two dehumidification units and to reclaim heat from the exhaust air to the supply air or to heat the pool water. This will be done for the Instructional and Intramural pools. the Crandall Pool is currently undergoing a major renovation that includes replacement of the entire HVAC systems.

NORESCO has decided not to install pool covers although such covers would make it possible to significantly reduce the heat losses from the pools during all hours when those pools are not open to the public.

\section{B.4.3.2 Solution}

Install pool covers for all three pools at Arvin Gym.

Indoor pools are not exposed to the environment, but they still can lose a lot of energy from evaporation. They also require room ventilation to control indoor humidity caused by the large amount of evaporation. The ventilated air must also be conditioned, which adds to the energy costs. The supply and exhaust air systems much also be balanced to avoid infiltration of humid and to some extent, corrosive air to other parts of the building. During the assessment, it was noted that HV-19 exhaust was not functioning, but the supply air fan was still running, creating a large positive pressure that pushed warm and humid air out of the Intramural pool area. From the condition of the internal windows facing this pool, the risk of corrosion is $100 \%$.

Pool covers minimize evaporation from both outdoor and indoor pools. Covering a pool when it is not in use is the single most effective means of reducing pool heating costs. Savings of 50 to $70 \%$ are possible. Pool covers on indoor pools not only can reduce evaporation, but also the need to ventilate indoor air and replace it with unconditioned outdoor air. When an indoor pool is covered, exhaust fans may be shut off, which saves even more energy.

Semi-automatic covers use a motor-driven reel system. They use electrical power to roll and unroll the cover, but usually require someone to pull on the cover when unrolling, or guide the cover onto the reel when rolling up the cover. Semi-automatic covers can be built into the pool deck surrounding the pool, or can use reels on carts. 
Automatic covers have permanently mounted reels that automatically cover and uncover the pool at the push of a button. They are the most expensive, but also the most convenient option.

Some pool covers fit into tracks along the sides of the pool. This prevents anything or anybody from getting into the pool. They even support the weight of several people. If liability is a concern, these are a good option to explore. They can be run manually, semi-automatically, or automatically. Safety covers are recommended for public pools, and may be required by inspectors.

Alternatively, if the air temperature is set back during unoccupied hours or for the heating versus cooling seasons, it is possible to reduce evaporation from a pool surface to a low level or even zero by this strategy. One must be careful, however, not to go out of recommended ranges for temperatures and relative humidity. A compromise must be found between energy efficiency, swimmer comfort, and building maintenance through humidity control

\section{B.4.3.3 Savings}

IndoorPoolCalc, an online spreadsheet from the Washington State University Extension Energy Program, may be used to estimate the savings that accrue from using of several ECMs for pools: www.energyideas.org/documents/spreadsheets/IndoorPoolCalc.xls

Results from using this spreadsheet to evaluate the three pools in Arvin Gym were:

- Input data:

- 13,500 sq ft pool area

- $60 \%$ relative humidity $(\mathrm{RH})$ in space

- $82^{\circ} \mathrm{F}$ water temperature

- $80^{\circ} \mathrm{F}$ space temperature

- Dehumidification of exhaust air

- 50 people in the pool and 50\% occupancy during hours when pool is uncovered

- Change number of uncovered hours from 8760 to 5000 hours (matching all hours of the year that Arvin Gym is open to the public).

- Output: 
- The covering of the pool saves 2,300 MMBtu of heating and 386,000 $\mathrm{kWh}$ of electricity for the dehumidification unit(s). Total savings are at $43 \%$.

- Using $\$ 7.70$ per MMBtu for heat and $\$ 0.083$ cents per $\mathrm{kWh}$, the values of the savings are $\$ 49,700$ per year.

- Actual pool sizes may differ from this example, but the calculations can easily be re-done to match actual pool size whenever this measure is considered to be implemented.

- Investment:

- The investment for an automatic pool cover was estimated to be less than $\$ 6 / \mathrm{sq} \mathrm{ft}$, including all required equipment. For a total pool surface area of 13,500 sq ft this equates to $\$ 81,000$.

\section{B.4.3.4 Payback}

Payback is calculated to occur within 1.6 years.

\section{B.4.4 Mechanical EEM \#4: Duty-cycle pool water pumps at Arvin Gym}

\section{B.4.4.1 Existing conditions/problems}

The Crandall Pool in Arvin Gym has three $10 \mathrm{hp}$ pool pump motors, two of which run continuously. The purpose of these pumps is to circulate water through the heat exchanger to heat the pool water, and through filters to clean the water. During the assessment, the team was not able to examine the pumps for the two other pools located within the gym, the Intramural and Instructional pools. There is no reason to believe that the configuration of these pools is not similar to Crandall Pool. It is believed that it is not necessary to run these pumps continuously.

\section{B.4.4.2 Solution}

Connect the pool pumps for all three pools to the EMCS and duty-cycle the pumps. Run two pumps at the time for 1 or 2 hours (adjustable). Turn off the pumps for 1 or 2 hours. Repeat. The temperature reduction of the pool water during 1 or 2 hours will be very small. This measure will be even less noticeable in combination with the installation of pool covers as stated in Mech ECM-3. 


\section{B.4.4.3 Savings}

Assume that six pool pumps with $10 \mathrm{hp}$ motors run continuously, at $80 \%$ load. Reducing the running hours for these pumps by 12 hours per day will save, in a year:

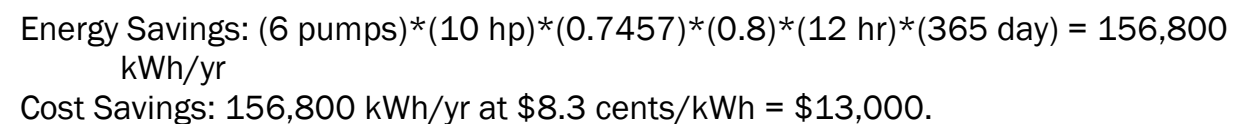

\section{B.4.4.4 Investment}

The investment for this measure are in controls only and are estimated to be below $\$ 10,000$ per pool or a total of $\$ 30,000$ for implementation at the three pools.

\section{B.4.4.5 Payback}

Payback is calculated to occur within 2.3 years

\section{B.4.5 Mechanical EEM \#5: Improve humidity control in BIdgs. 753 and 757}

\section{B.4.5.1 Existing conditions/problems}

According to USMA staff, there is poor control of relative humidity in Bldg. 757. J udging from the available data for the renovation of Bldg. 753, Bartlett Hall, there is a high probability that the same issue will occur in this building. Both buildings have, and will have, large AHUs with runaround heat recovery from laboratory exhausts and steam humidifiers. Bldg. 757 currently uses four humidifiers with the capacity of three units at $771 \mathrm{lbs} / \mathrm{hr}$, and one unit at $100 \mathrm{lbs} / \mathrm{hr}$ of steam. When the renovation is complete, Bldg. 753 will have seven humidifiers with capacities of 55, 130, 160, 180, and $495 \mathrm{lbs} / \mathrm{hr}$, and two units at $340 \mathrm{lbs} / \mathrm{hr}$.

In Bldg. 757, humidity sensors are located in each of the AHUs, but are placed directly downstream of the humidifier, which means that there is no accurate information available concerning the relative humidity within the building itself. Available mechanical schedules for the new systems in Bldg. 753 do not reveal where the $\mathrm{RH}$ sensors are to be located and nothing is written concerning how $\mathrm{RH}$ will be controlled. Therefore, it is assumed that $\mathrm{RH}$ will be addressed much in the same way as in 757 , for which there are better solutions to address this issue. 
Bldg. 758, J efferson Hall, presents a different issue. The air supply for the building is either constant volume or variable air volume (VAV), the former for all atrium spaces, the latter for all non-atrium spaces. However, the VAV-boxes have no re-heat coils. Re-heat is intended to be done by radiators. This configuration is obviously not working as designed. During the onsite assessment, the team measured $\mathrm{RH}$ and space temperature in the atrium spaces between levels 3 and 6 . While the temperature variation was adequate, $2^{\circ} \mathrm{F}$ from lowest to highest, the $\mathrm{RH}$ values varied from 43.4 to $64.8 \%$. Of course, the current wall and roof leakage issues do affect the indoor climate, using radiators for re-heat, which are off during periods of the summer; this is inadequate. The likelihood of serious mold damage to books and other old and valuable paper publications exposed to these current high levels of $\mathrm{RH}$ within the library is high.

Bldg. 758 is a clear candidate for a High Efficiency Dehumidification System (HEDS).

\section{B.4.5.2 Solution}

Install RH sensors, either in the spaces that are served by the AHUs or in the exhaust air stream from those spaces. Control the humidifiers with input from the RH sensors so that the target $\mathrm{RH}$ is achieved in the spaces.

\section{B.4.5.3 Savings}

This measure may save energy or it may lead to increased energy use depending on how much steam is used in the humidifiers today. The important thing is to ensure that the humidifiers are serving their purpose, to provide the necessary $\mathrm{RH}$ within the building during the winter heating season.

To evaluate if there are savings available, it is necessary to put loggers in the spaces and collect data on how the relative humidity varies under the current (and in the case of 753, future) operation. The data will show how well the $\mathrm{RH}$ set point is met.

One could assume that the humidifiers deliver too much steam into the AHUs. If they deliver $10 \%$ of their respective capacity on average, more than is necessary to meet the set points, it would result in a total over-humidification of $400 \mathrm{lbs}$ of steam per hour. During 22 weeks of winter (Nov - March) with average weekly hours of operation at 90 hours, this will 
waste $(400 \mathrm{lbs} / \mathrm{hr} * 22$ wks $* 90 \mathrm{hrs})=790,000 \mathrm{lbs}$ of steam. The energy contents of $10 \mathrm{psi}$ steam is $1,160 \mathrm{Btu} / \mathrm{lb}$ if one considers that there is no condensate return so that all the steam generated in the central plant is from makeup water. This makes the total energy use approximately $900 \mathrm{MMBtu}$ (530 MMBtu for Bldg 757 and 370 MMBtu for Bldg 753), at a value of $\$ 6,900$ per year.

\section{B.4.5.4 Investment}

The investments are moderate to very low: The controls currently exist, but new sensors and wiring to those sensors may be necessary, and a total of 11 sensors are required. With a maximum total cost of $\$ 1,000$ per sensor, the total investment will be $\$ 11,000$.

\section{B.4.5.5 Payback}

Payback is calculated to occur within 1.6 years for the assumed case above.

\section{B.4.6 Mechanical EEM \#6: Install Thermostatic valves for HW radiators}

\section{B.4.6.1 Existing conditions/problems}

Some buildings at USMA use perimeter radiators for space heating, most of which are steam radiators. NORESCO, Task Order 1, ECM-09, includes the installation of new thermostatic radiator valves on approximately 205 steam radiators in Bldg. 667, the DPW Building.

During the assessment of Bldg. 752, Mahan Hall, it was discovered that the radiator heating system within this building lacks user controls. The HW radiators (Figure B-1) are covered and have no access or control valves for the occupants. Also fan coil units (FCU) are installed within the building to provide heating and possibly cooling of the spaces, with most likely the same lack of controls. Occupants of the building commented on the lack of control, the over-heating of the rooms, and their need to open windows in the winter to make the space bearable. On the other hand researchers also saw electric heaters below desks in some spaces, indicating that there may be periods when the heat is insufficient. 
Figure B-1. HW radiator within office of Mahan Hall.

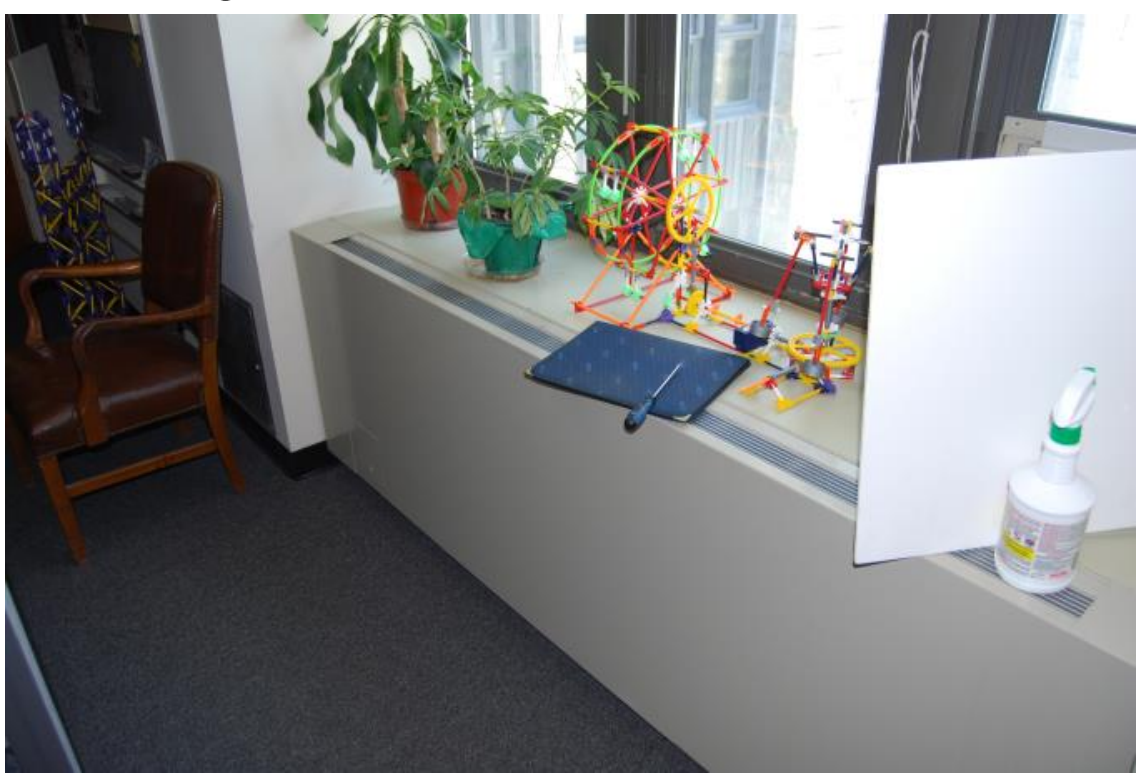

The steam-to-HW converter for the HW radiation system has a capacity of 7,750 MBh and is designed for $200^{\circ} \mathrm{F} / 180^{\circ} \mathrm{F}$ supply and return temperatures respectively. Some new finned-tube radiators were installed in 1997, designed for $150^{\circ} \mathrm{F}$ supply water temperature

\section{B.4.6.2 Solution}

Install thermostatic valves for all the HW radiators in Bldg. 752.

\section{B.4.6.3 Savings}

Installing thermostatic radiator valves for all the radiators throughout the building can save up to $20 \%$ of the total energy used for heating. Using the current building load for Mahan Hall, equal to 11,700 MMBtu per year for heating (based on the building modeling), and assuming that $50 \%$ of this heat is provided by radiators and FCUs, savings may be estimated as:

$$
(11,700 \mathrm{MMBtu} *(0.5) *(0.2)=1,170 \mathrm{MMBtu} \text { per year }
$$

This measure will also eliminate the need for electric heaters in spaces where they are found today.

The total annual cost savings, with $\$ 7.70 / \mathrm{MMBtu}=\$ 9,000$ per year 


\section{B.4.6.4 Investment}

The investments are moderate to very low. The cost of a thermostatic Radiator Valve, e.g., Danfoss RAS-C2, is $\$ 20$. The cost of installing the valve will be higher, making the total investment $\sim \$ 120$ per radiator. The total number of radiators and/ or FCUs (where this measure is applicable) is unknown, but the total number is estimated to be around 350, using 550 sq $\mathrm{ft}$ of building space per radiator/ FCU. The total investment is then $(350) *(\$ 120)=\$ 42,000$.

\section{B.4.6.5 Payback}

Payback is calculated to occur within 4.7 years.

\section{B.4.7 Mechanical EEM \# 7: Control kitchen hood air flow in dining facili- ties - Bldgs 602 and 603}

\section{B.4.7.1 Existing conditions}

Kitchen hoods located in the identified dining facilities (Bldgs. 602 and 603) typically operate during the working hours of the kitchen (Figure $\mathrm{B}-2)$. Thus, these hoods continue to exhaust air even though there is no cooking occurring under them. The dining facility located in Bldg. 602, Grant Hall, is open from 7am to 1:15 or 44 hours per week. It is estimated that there is a 2-hour time period with little or no cooking under the kitchen hood. In the USMA, West Point Club, Bldg. 603, the dining facility is open from $7 \mathrm{am}$ to $4 \mathrm{pm}$, except Thursday and Friday when it is open until $11 \mathrm{pm}$. It is closed on Saturdays. The resulting is 68 operating hours per week with an estimated 28 hours of non-cooking time for the main kitchen and 40 hours per week for the second floor serving center. When cooking is not occurring, the hoods do not need to operate at full flow, otherwise energy is wasted. Energy can be saved by reducing hood air flow when there are no cooking operations. 
Figure B-2. Kitchen hood that is good candidate for variable air flow.

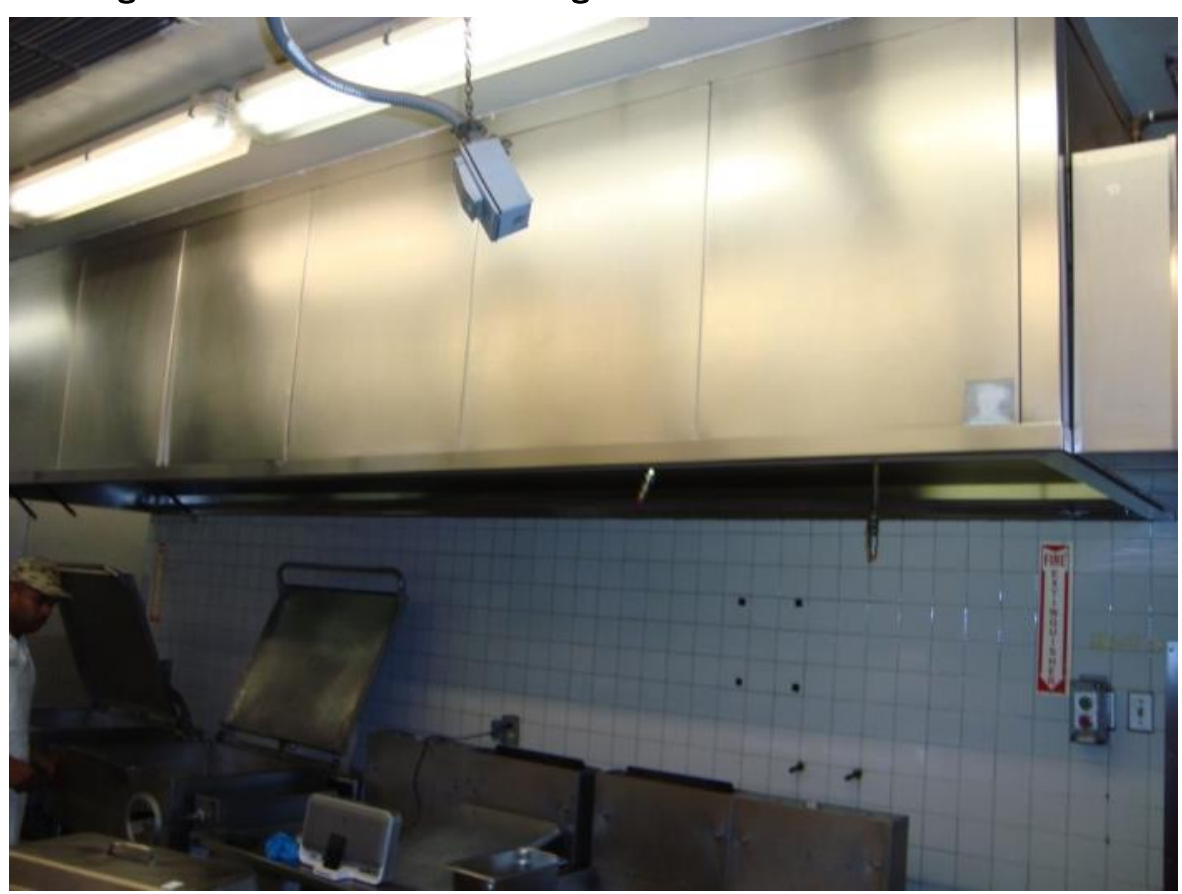

\section{B.4.7.2 Solution}

Controls can be placed on the exhaust system that will monitor cooking operations and vary the air flow as appropriate, from full flow when cooking, down to half-flow for no cooking. An optic sensor in the hood monitors the presence of smoke and cooking vapors. A temperature sensor placed in the duct attached to the hood will note an increase in temperature. The start of cooking activities under the hood will provide a positive indication by either of these sensors and will increase the exhaust air flow to full flow.

\section{B.4.7.3 Savings}

The following analysis will use the first hood to exhibit the savings calculations. This kitchen hood is proposed to have end skirts so the lower air flow takes that change into account. Also, the projected fan motor energy savings of $53 \%$ has already removed $27 \%$ of the motor energy use due to the use of the skirts. In this dining facility, the hoods are operating for an estimated 24 hours per day. Cooking operations occur only 8 hours per day; thus for 16 hours per day its air flow could be reduced from 5,400 $\mathrm{CFM}$ to a flow of approximately 2,700 CFM. This would provide a reduced horse power use equal to the cube of 2,700/5,400 or approximately $20 \%$ of the $7.5 \mathrm{HP}$ when motor losses are included. The savings difference is 
$80 \%$ of the motor electrical use for 16 hours per day, or $67 \%$ of the time (Tables B-13 and B-14).

Table B-13. Savings associated with reduced exhaust hood operation in Bldg. 602.

\begin{tabular}{|c|c|c|c|c|c|c|c|}
\hline $\begin{array}{c}\text { Hood } \\
\text { Size }\end{array}$ & $\begin{array}{c}\text { Exhaust } \\
\text { Air } \\
\text { (CFM) }\end{array}$ & $\begin{array}{c}\text { Estimated } \\
\text { Motor hp }\end{array}$ & $\begin{array}{c}\text { Operating } \\
\text { hrs./wk }\end{array}$ & $\begin{array}{c}\text { Reduced } \\
\text { Air Flow } \\
\text { (CFM) }\end{array}$ & $\begin{array}{c}\text { Motor hp } \\
\text { Savings } \\
(\%)\end{array}$ & $\begin{array}{c}\text { Low Flow } \\
\% \text { of } \\
\text { Time }\end{array}$ & $\begin{array}{c}\text { Saving } \\
\text { (kWh/yr) }\end{array}$ \\
\hline $12 \times 4$ & 5250 & 5 & 44 & 2625 & $53 \%$ & $32 \%$ & 4349 \\
\hline
\end{tabular}

Table B-14. Savings associated with reduced exhaust hood operation in Bldg. 603.

\begin{tabular}{|c|c|c|c|c|c|c|l|}
\hline Hood Size & $\begin{array}{c}\text { Exhaust Air } \\
\text { (CFM) }\end{array}$ & $\begin{array}{c}\text { Estimated } \\
\text { Motor hp }\end{array}$ & $\begin{array}{c}\text { Operating } \\
\text { Hrs./wk }\end{array}$ & $\begin{array}{c}\text { Reduced } \\
\text { Air Flow } \\
\text { (CFM) }\end{array}$ & $\begin{array}{c}\text { Motor hp } \\
\text { Savings } \\
\text { (\%) }\end{array}$ & $\begin{array}{c}\text { Low Flow } \\
\% \text { of Time }\end{array}$ & $\begin{array}{c}\text { Saving } \\
\text { (kWh/yr) }\end{array}$ \\
\hline $20 \times 3^{*}$ & 6000 & 5 & 68 & 3000 & $53 \%$ & $59 \%$ & 6721 \\
\hline $20 \times 3^{*}$ & 6000 & 5 & 68 & 3000 & $53 \%$ & $59 \%$ & 6721 \\
\hline $9 \times 4$ & 2250 & 3 & 68 & 1125 & $53 \%$ & $41 \%$ & 4033 \\
\hline $12 \times 4$ & 3550 & 3 & 68 & 1775 & $53 \%$ & $41 \%$ & 4033 \\
\hline
\end{tabular}

Savings are calculated as:

Fan motor power reduction $=(5 \mathrm{hp}) *(53 \%) *(.746 \mathrm{~kW} / \mathrm{hp}) 8(44 \mathrm{hrs} / \mathrm{wk}) *(52$ $\mathrm{wks} / \mathrm{yr}) *(32 \%)=4,349 \mathrm{kWh} / \mathrm{yr}$

Electrical cost savings $=(48,686 \mathrm{kWh} / \mathrm{yr}) *(\$ 0.0831 / \mathrm{kWh})=\$ 361 / \mathrm{yr}$

Heating energy savings $=(1.08) *(5,280 \mathrm{CFM}) *(50 \%) *(5,964$ degree days $) *(24$ $\mathrm{hr} /$ day $) *(2 \mathrm{hrs}) /(24) /(0.75$ heating system efficiency $)=45 \mathrm{MMBtu} / \mathrm{yr}$

Heating energy cost savings $=(45 \mathrm{MMBtu} / \mathrm{yr}) *(\$ 7.70 / \mathrm{MMBtu} / \mathrm{yr})=\$ 346 / \mathrm{yr}$

Total savings for Bldg. 602 are calculated as:

Energy Savings = Elect: 4,349 kWh/yr; Heat: 45 MMBtu/yr

Cost Savings $=\$ 707 / \mathrm{yr}$

Savings are calculated as:

Total fan motor electrical savings for the nine hoods $=21,509 \mathrm{kWh} / \mathrm{yr}$.

Electrical cost savings $=(21,509 \mathrm{kWh} / \mathrm{yr}) *(\$ 0.083 / \mathrm{kWh})=\$ 1,785 / \mathrm{yr}$

Heating energy savings $=(1.08) *[((12,000 \mathrm{CFM}) *(50 \%) *(28 / 168))+((5,800$ CFM $) *(50 \%) *(40 / 168))]^{*}(5,964$ degree days $) *(24 \mathrm{hr} /$ day $) /(0.75$ heating system efficiency) $=191 \mathrm{MMBtu} / \mathrm{yr}$

Heating energy cost savings $=(191 \mathrm{MMBtu} / \mathrm{yr}) *(\$ 7.70 / \mathrm{MMBtu} / \mathrm{yr})=\$ 1,470 / \mathrm{yr}$

Total savings for Bldg. 603 are calculated as:

Energy Savings = Elect: 21,509 kWh/yr; Heat: $191 \mathrm{MMBtu} / \mathrm{yr}$

Cost Savings $=\$ 3,256 / \mathrm{yr}$

Total Mechanical ECM \#7 Savings:

Energy Savings: Elect: 25,858 kWh/yr; Heat: $236 \mathrm{MMBtu} / \mathrm{yr}$

Cost Savings $=\$ 3,963 / \mathrm{yr}$

\section{B.4.7.4 Investment}

For Bldg. 602, the estimated cost to provide temperature and smoke detectors and the controls to adjust fan speed for the exhaust air system is 
approximately $\$ 7,700$. The cost to have variable speed motors for the two $5 \mathrm{hp}$ motors is $\$ 9,600$, for a total cost of $\$ 17,300$.

For Bldg. 603, the estimated cost to provide temperature and smoke detectors and the controls to adjust fan speed for the exhaust air system is approximately $\$ 30,800$. The cost to have variable speed motors for two 3 hp motors and two $5 \mathrm{hp}$ motors is $\$ 18,500$, for a total cost of $\$ 49,300$.

The total cost for all three dining facilities $=\$ 66,600$.

The cost estimates are based on information from RS Means cost estimating guide and past experience.

\section{B.4.7.5 Payback}

The resulting payback period for the dining facilities is shown as 16.8 years and thus the implementation of this ECM is not recommended.

\section{B.5 Energy efficient electric motors}

\section{B.5.1 ELECT EEM \#1: Energy efficient electric motors - Various buildings}

\section{B.5.1.1 Existing conditions}

Electric motors (Figure B-3) are required to power a wide range of equipment and devices. The loads on the motors can vary or be relative constant. When selecting a motor, it is best to match the process load to the proper motor size. A partially loaded motor operates at a lower efficiency than one fully loaded.

Motor efficiency ranges from $75 \%$ for a standard $1 \mathrm{hp}$, three-phase induction motor operating at full load, to $90 \%$ for a standard $50 \mathrm{hp}$ motor. In 1992, the Energy Policy Act was passed that required most motors manufactured after October 1997 to meet higher efficiency standards. The efficiency set for 1 and 50 horsepower motors are $82.5 \%$ and 93\% respectively. Later premium efficient motors became available, at extra cost, the efficiencies of which range from 85.5 to $94.13 \%$ for the same range of motors. Single phase motors are normally 5 to $10 \%$ lower in efficiency. Another benefit of the higher efficient motors is that they run cooler and should provide a longer life of service. 
Electric motors have a limited life. When they become inoperable, they typically can be repaired by rewinding to become functional again. A downside to this repair is a loss in efficiency. It is often more economical to replace a burned out motor with a new premium motor than to rewind it. The cost difference between operating the two motors will easily pay for the extra cost of the new one.

Figure B-3. Typical pump motor.

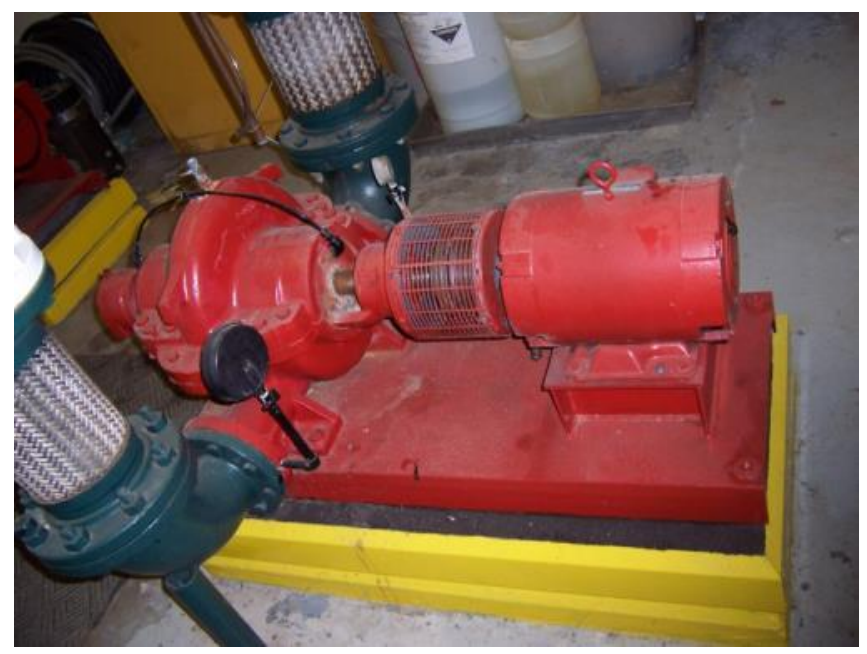

\section{B.5.1.2 Solution}

A number of electric motors were found at USMA that are not of the premium efficiency type. Standard and high efficient horsepower motors were found at the locations shown in the following table, which power pumps and fans. It is recommended to replace these motors with premium efficient motors when they fail and need replacement. Table B-15 lists the annual savings and the cost of the premium motors alongside that associated with the use of standard efficiency motors, for comparison. The analysis shown assumes that the motors operate continuously and are fully loaded. The cost used in the simple payback calculation is half the premium cost, which approximates the cost of a new motor compared to that of rewinding a failed motor.

Table B-15. Savings associated with reduced exhaust hood operation in Bldg. 603.

\begin{tabular}{|c|l|c|c|c|c|c|c|c|c|c|c|}
\hline Bldg. \# & $\begin{array}{c}\text { Motor } \\
\text { Function }\end{array}$ & $\begin{array}{c}\text { Number } \\
\text { of Motors }\end{array}$ & $\begin{array}{c}\text { Motor } \\
\text { Size }\end{array}$ & $\begin{array}{c}\text { Existing } \\
\text { Efficiency } \\
(\%)\end{array}$ & $\begin{array}{c}\text { Proposed } \\
\text { Efficiency } \\
(\%)\end{array}$ & Hrs/yr & $\begin{array}{c}\text { Energy } \\
\text { Saved } \\
(\mathbf{k W h} / \mathbf{y r})\end{array}$ & $\begin{array}{c}\text { Energy } \\
\text { Cost } \\
\text { Savings } \\
(\$ / y r)\end{array}$ & $\begin{array}{c}\text { Total Cost } \\
\text { Premium } \\
(\$)\end{array}$ & $\begin{array}{c}\text { Additional } \\
\text { Cost of New } \\
\text { Motor vs. } \\
\text { Rewinding }\end{array}$ & $\begin{array}{c}\text { Simple } \\
\text { Payback } \\
\text { (yr) }\end{array}$ \\
\hline 655 & Pump & 2 & 5 & $82.50 \%$ & $89.50 \%$ & 4380 & 2287 & $\$ 190$ & $\$ 553$ & $\$ 553$ & 2.9 \\
\hline 726 & pump & 4 & 20 & $90.20 \%$ & $93.60 \%$ & 4380 & 8888 & $\$ 738$ & $\$ 1,505$ & $\$ 3,010$ & 4.1 \\
\hline 727 & Pump & 3 & 20 & $85.50 \%$ & $93.60 \%$ & 4380 & 15880 & $\$ 1,318$ & $\$ 1,505$ & $\$ 2,258$ & 1.7 \\
\hline
\end{tabular}




\begin{tabular}{|c|c|c|c|c|c|c|c|c|c|c|c|}
\hline Bldg. \# & $\begin{array}{l}\text { Motor } \\
\text { Function }\end{array}$ & $\begin{array}{c}\text { Number } \\
\text { of Motors }\end{array}$ & $\begin{array}{c}\text { Motor } \\
\text { Size }\end{array}$ & $\begin{array}{c}\text { Existing } \\
\text { Efficiency } \\
(\%)\end{array}$ & $\begin{array}{c}\text { Proposed } \\
\text { Efficiency } \\
\text { (\%) }\end{array}$ & $\mathrm{Hrs} / \mathrm{yr}$ & $\begin{array}{l}\text { Energy } \\
\text { Saved } \\
(\mathrm{kWh} / \mathrm{yr})\end{array}$ & $\begin{array}{l}\text { Energy } \\
\text { Cost } \\
\text { Savings } \\
(\$ / y r)\end{array}$ & $\begin{array}{c}\text { Total Cost } \\
\text { Premium } \\
\text { (\$) }\end{array}$ & $\begin{array}{l}\text { Additional } \\
\text { Cost of New } \\
\text { Motor vs. } \\
\text { Rewinding }\end{array}$ & $\begin{array}{c}\text { Simple } \\
\text { Payback } \\
\text { (yr) }\end{array}$ \\
\hline & Pump & 3 & 15 & $86.50 \%$ & $93.00 \%$ & 4380 & 9557 & $\$ 793$ & $\$ 1,207$ & $\$ 404$ & 0.5 \\
\hline & Pump & 2 & 10 & $86.50 \%$ & $91.70 \%$ & 4380 & 3398 & $\$ 282$ & $\$ 900$ & $\$ 900$ & 3.2 \\
\hline & Pump & 3 & 5 & $87.50 \%$ & $89.50 \%$ & 4380 & 980 & $\$ 81$ & $\$ 553$ & $\$ 829$ & 10.2 \\
\hline & Subtotal & & & & & & 29816 & $\$ 2,475$ & 4164 & 4390 & 1.8 \\
\hline \multirow[t]{4}{*}{752} & Pump & 3 & 75 & $93.00 \%$ & $95.00 \%$ & 4380 & 14704 & $\$ 1,220$ & $\$ 3,592$ & $\$ 5,388$ & 4.4 \\
\hline & Pump & 2 & 50 & $91.20 \%$ & $95.00 \%$ & 4380 & 12416 & $\$ 1,031$ & $\$ 2,675$ & $\$ 2,675$ & 2.6 \\
\hline & Pump & 1 & 10 & $84.00 \%$ & $92 \%$ & 4380 & 2516 & $\$ 209$ & $\$ 900$ & $\$ 450$ & 2.2 \\
\hline & Subtotal & & & & & & 29636 & $\$ 2,460$ & 7167 & 8513 & 3.5 \\
\hline 753 & Pump & 2 & 20 & $92.40 \%$ & $93.60 \%$ & 4380 & 1568 & $\$ 130$ & $\$ 1,505$ & $\$ 753$ & 5.8 \\
\hline \multirow[t]{4}{*}{756} & Fan & 4 & 15 & $92.40 \%$ & $93 \%$ & 4380 & 1176 & $\$ 98$ & $\$ 1,207$ & $\$ 604$ & 6.2 \\
\hline & & 2 & 15 & $91.00 \%$ & $93.60 \%$ & 4380 & 2549 & $\$ 212$ & $\$ 790$ & $\$ 790$ & 3.7 \\
\hline & Subtotal & & & & & & 3725 & $\$ 309$ & 1997 & 1394 & 4.5 \\
\hline & Total & & & & & & 75920 & 6301 & 16890 & 18611 & 3.0 \\
\hline
\end{tabular}

\section{B.5.1.3 Savings}

Table B-15 lists the estimated savings of operating a premium efficient motor instead a less efficient one. These savings are based on operation for half a year (4380 hours). The estimated savings of the identified pump motors is $76,000 \mathrm{kWh} / \mathrm{yr}$ for a $\$ 6,301$ annual cost savings.

\section{B.5.1.4 Investments}

Table B-15 the cost of a new premium efficient motor. It is assumed in the simple payback calculations that the cost of rewinding the old motor is half the cost of a new premium efficient motor. The estimated cost to replace these motors is $\$ 37,200$. The additional cost when a rewinding is required would be $\$ 18,600$. 


\section{Appendix C: USMA, West Point New Cadet Barracks Energy Analysis}

This appendix includes data derived from an energy analysis of USMA, West Point New Cadet Barracks (Figure C-1). Table C-1 lists the site's energy targets. Table C-2 lists the NZE Packages that have been simulated. Table C-3 lists existing restrictions on site energy use reduction. Table C-4 lists baseline and target building site energy, for comparison. Figure C-2 shows the annual EUI for each EEM package at the site. Table C-5 lists building source energy.

Figure C-1. USMA, West Point New Cadet Barracks.

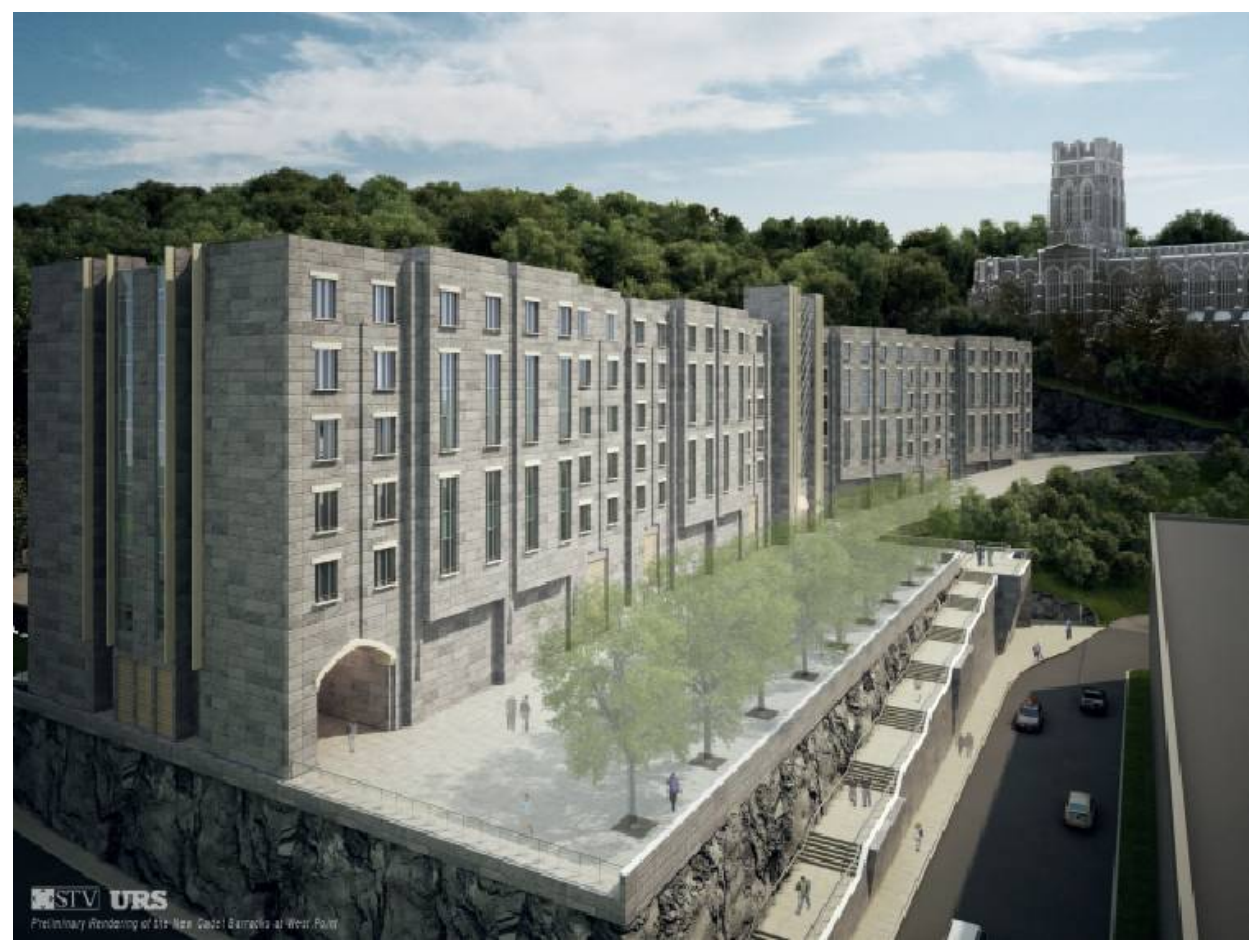


Table C-1. Targets USMA, West Point, NY - Zone 5A.

\begin{tabular}{|l|c|}
\hline Site Energy Targets (kBtu/sq ft - yr) & Measure \\
\hline ASHRAE 90.1-2004 EUI & 97 \\
\hline ASHRAE 90.1-2007 EUI & 94 \\
\hline EPACT 2005 Target EUI + plug loads & 68 \\
\hline ASHRAE 189.1 Target EUI + plug loads & 72 \\
\hline ECB 2011 Target EUI + plug loads & 56 \\
\hline Source Energy Targets (kBtu/sq ft - yr) & \\
\hline 2003 CBECS Dormitory/ fraternity/ sorority total source fuel & 225 \\
\hline EISA 2007-2010 Source Energy Target & 101 \\
\hline EISA 2007-2015 Source Energy Target & 79 \\
\hline EISA 2007 Fossil Fuel Targets (kBtu/sq ft -yr) & \\
\hline EISA 2007 Fossil Fuel Source Energy & 172 \\
\hline EISA 2007-2010 Fossil Fuel Source Energy Target & 77 \\
\hline EISA 2007-2015 Fossil Fuel Source Energy Target & 60 \\
\hline
\end{tabular}

In 2010 and 2015, EISA 2007 mandated that buildings reduce energy consumption by 55\% and 65\% compared to CBECS 2003 baseline standard. EISA 2007 and CBECS both include process loads; EPACT 2005 does not include process loads. ECMs simulated for UEPH 189.1 and ECB specifications include:

- increased insulation levels

- advanced windows

- increased air tightness at $0.25 \mathrm{cfm} / \mathrm{sq} \mathrm{ft}$

- cool roof

- advanced lighting system with occupancy sensors

- advanced HVAC system with dedicated outside air system (for ventilation, pressurization, and makeup air), energy recovery, and ASHRAE 62.1 ventilation requirements

- radiant heating and cooling in cadet rooms

- Energy Star appliances and equipment

- reduced flow fixtures and solar-thermal HW heating

- HVAC Options simulated

- DOAS system and individual room fan coils for soldier comfort

- central exhaust with energy recovery (70\% sensible and latent recovery) to pre-condition ventilation air

- raise supply air temperature from 53 to $55^{\circ} \mathrm{F}$

- high efficiency water-cooled chiller with water-side economizer

- high efficiency fans and pumps

- radiant heating and cooling in cadet rooms (replacing fan coils). 
Table C-2. NZE Packages Simulated.

\begin{tabular}{|c|c|}
\hline Package & Description \\
\hline Baseline & $\begin{array}{l}\text { ASHRAE 90.1-2007 envelope; DOAS with Energy Recovery } \\
\text { Ventilator (ERV); variable speed pumps; district heating; air-cooled } \\
\text { chiller, } 0.4 \mathrm{cfm} / \mathrm{sq} \mathrm{ft}\end{array}$ \\
\hline Baseline $+55^{\circ} \mathrm{F}$ SAT & $55^{\circ} \mathrm{F}$ supply air temperature \\
\hline ASHRAE 189.1 & Envelope improved to ASHRAE 189.1 \\
\hline Army ECB 2011-1 & $\begin{array}{l}\text { ERDC recommendations for high performance envelope (roof }- \\
R=50 c i, \text { Walls }-R=30 c i \text {, floors above unconditioned space }-R=16 \text {, } \\
\text { windows }-R=5 \text { ); reduced infiltration } 0.25 \text { CFM/sq ft; Cool Roof; } \\
\text { reduced thermal bridges }\end{array}$ \\
\hline Lighting & Efficient lighting; occupancy sensors \\
\hline HVAC & $\begin{array}{l}\text { Efficient fans, pumps, chiller; water-cooled chiller with water-side } \\
\text { economizer }\end{array}$ \\
\hline Radiant & Radiant heating and cooling in cadet rooms \\
\hline Radiant + ASHRAE 62.1 & Ventilation reduced to ASHRAE 62.1 \\
\hline DHW & Low-flow showers, approx. 2 GPM reduced to 1.5 GPM \\
\hline $\begin{array}{l}\text { Equipment Centers of } \\
\text { Standardization (COS) }\end{array}$ & Plug loads reduced to COS level (1.67 W/sq ft) \\
\hline Equipment EPA & Plug loads reduced additional $25 \%$ (1.25 W/sq ft) \\
\hline $\begin{array}{l}\text { Equipment } \\
\text { EPA+ASHRAE } 62.1\end{array}$ & Ventilation reduced to ASHRAE 62.1 \\
\hline
\end{tabular}

Table C-3. Restrictions on Site Energy Use Reduction.

\begin{tabular}{|c|c|c|c|c|c|c|c|c|c|}
\hline \multirow[b]{2}{*}{ Package } & \multicolumn{9}{|c|}{ Energy (kbtu/ft2/yr) } \\
\hline & Total & Heating & Cooling & Lights & Equipment & Fans & Pumps & $\begin{array}{c}\text { Heat } \\
\text { Recovery }\end{array}$ & DHW \\
\hline Baseline & 86.67 & 22.08 & 17.49 & 13.74 & 16.07 & 3.18 & 0.52 & 0.02 & 13.58 \\
\hline Baseline + 55 F SAT & 81.72 & 19.03 & 15.66 & 13.74 & 16.07 & 3.18 & 0.44 & 0.02 & 13.58 \\
\hline ASHRAE 189.1 & 80.41 & 17.72 & 15.67 & 13.74 & 16.07 & 3.18 & 0.43 & 0.02 & 13.58 \\
\hline Army ECB 2011-1 & 76.08 & 13.36 & 15.64 & 13.74 & 16.07 & 3.33 & 0.35 & 0.02 & 13.58 \\
\hline Lighting & 73.83 & 18.18 & 15.33 & 7.03 & 16.07 & 3.27 & 0.37 & 0.02 & 13.58 \\
\hline HVAC & 65.43 & 16.69 & 8.83 & 7.03 & 16.07 & 2.83 & 0.40 & 0.02 & 13.58 \\
\hline Radiant & 63.26 & 14.84 & 8.77 & 7.03 & 16.07 & 2.56 & 0.40 & 0.02 & 13.58 \\
\hline Radiant + ASHRAE 62.1 & 53.98 & 7.85 & 7.51 & 7.03 & 16.07 & 1.68 & 0.25 & 0.02 & 13.58 \\
\hline $\mathrm{DHW}$ & 61.03 & 14.99 & 8.77 & 7.03 & 16.07 & 2.56 & 0.40 & 0.02 & 11.20 \\
\hline Equipment $\operatorname{COS}$ & 59.55 & 15.39 & 8.75 & 7.03 & 14.20 & 2.56 & 0.40 & 0.02 & 11.20 \\
\hline Equipment EPA & 57.54 & 15.76 & 8.75 & 7.03 & 11.83 & 2.56 & 0.40 & 0.02 & 11.20 \\
\hline Equipment EPA + ASHRAE 62.1 & 47.75 & 8.41 & 7.36 & 7.03 & 11.83 & 1.68 & 0.23 & 0.02 & 11.20 \\
\hline $30 \%$ Solar Thermal DHW & 44.39 & 8.41 & 7.36 & 7.03 & 11.83 & 1.68 & 0.23 & 0.02 & 7.84 \\
\hline $30 \%$ Solar \& $20 \%$ Grey HRX DHW & 42.15 & 8.41 & 7.36 & 7.03 & 11.83 & 1.68 & 0.23 & 0.02 & 5.60 \\
\hline $100 \%$ Solar Thermal DHW & 36.55 & 8.41 & 7.36 & 7.03 & 11.83 & 1.68 & 0.23 & 0.02 & - \\
\hline
\end{tabular}

Table C-4. Building Site Energy.

\begin{tabular}{|l|c|c|c|}
\hline \multicolumn{1}{|c|}{ Configuration } & $\begin{array}{c}\text { Baseline } \\
(\mathrm{kBtu} / \mathrm{sq} \text { ft/yr) }\end{array}$ & $\begin{array}{c}\text { Army ECB 2011-1 } \\
(\mathrm{kBtu} / \mathrm{sq} \mathrm{ft} / \mathrm{yr})\end{array}$ & $\begin{array}{c}\text { Equipment EPA + ASHRAE 62.1 } \\
\text { (kBtu/sq ft/yr) }\end{array}$ \\
\hline Full Building & 78.13 & 70.75 & 46.64 \\
\hline Barracks Only (Floors 2-6) & 86.67 & 76.08 & 47.75 \\
\hline One Floor Only (Floor 2) & 85.29 & 75.43 & 47.09 \\
\hline Non-Barracks Only (Floors 1-M) & 43.86 & 42.11 & 36.46 \\
\hline
\end{tabular}


Figure C-2. Annual EUI for each EEM Package.

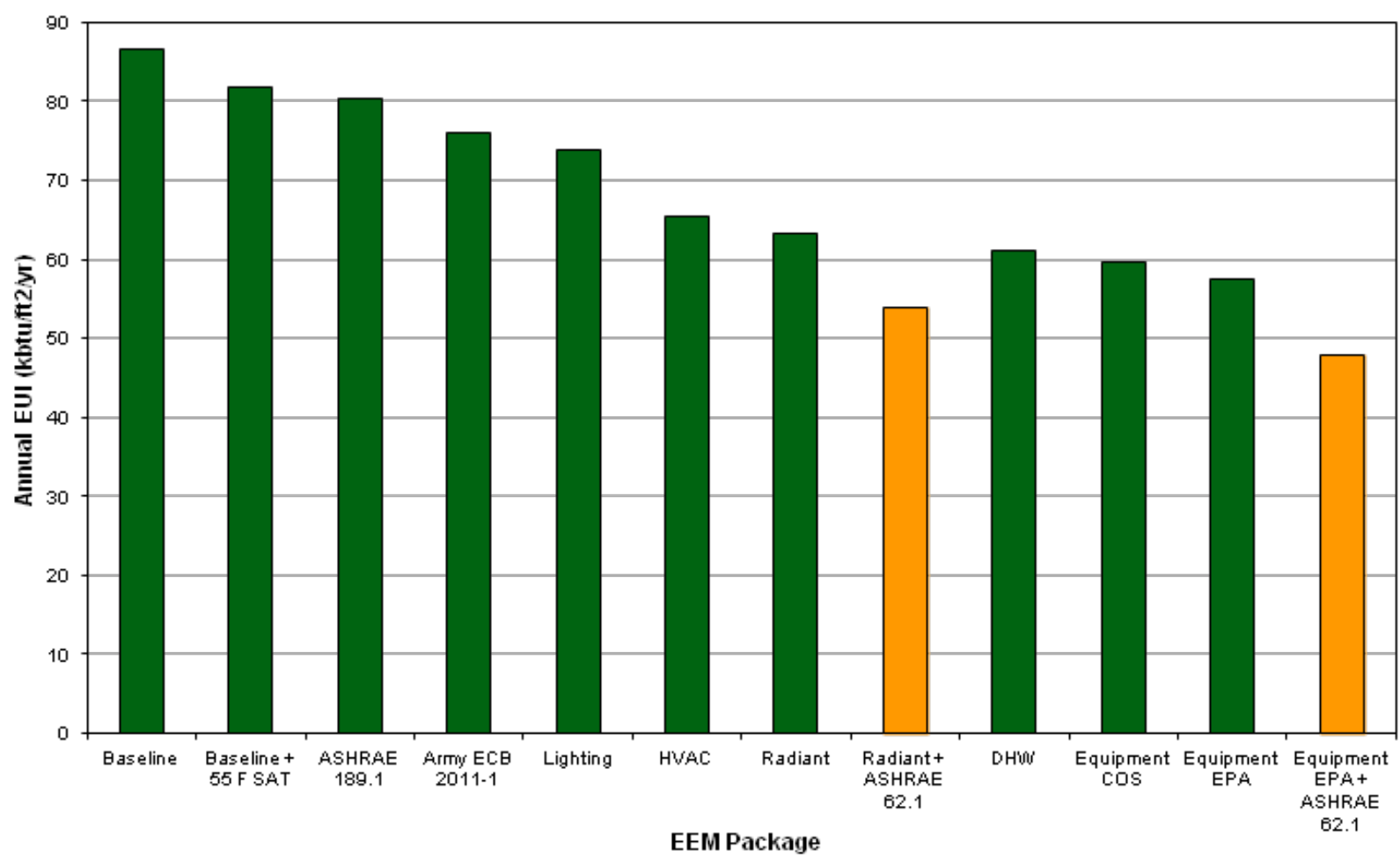

Table C-5. Building Source Energy.

\begin{tabular}{|l|r|r|r|}
\hline Package & $\begin{array}{l}\text { \% Reduction } \\
\text { from Baseline }\end{array}$ & $\begin{array}{l}\text { Source Fuel } \\
\text { (kbtu/ft2/yr) }\end{array}$ & $\begin{array}{l}\text { Fossil Fuel } \\
\text { (kbtu/ft2/yr) }\end{array}$ \\
\hline Baseline & $0 \%$ & 208 & 158 \\
\hline Baseline + 55 F SAT & $-5 \%$ & 198 & 151 \\
\hline ASHRAE 189.1 & $-5 \%$ & 197 & 149 \\
\hline Army ECB 2011-1 & $-7 \%$ & 192 & 145 \\
\hline Lighting & $-16 \%$ & 174 & 133 \\
\hline HVAC & $-28 \%$ & 149 & 115 \\
\hline Radiant & $-30 \%$ & 146 & 112 \\
\hline Radiant + ASHRAE 62.1 & $-37 \%$ & 131 & 100 \\
\hline DHW & $-31 \%$ & 144 & 110 \\
\hline Equipment COS & $-34 \%$ & 138 & 106 \\
\hline Equipment EPA & $-37 \%$ & 130 & 101 \\
\hline Equipment EPA + ASHRAE 62.1 & $-45 \%$ & 115 & 87 \\
\hline $30 \%$ Solar Thermal DHW & $-47 \%$ & 111 & 84 \\
\hline $30 \%$ Solar \& 20\% Grey HRX DHW & $-48 \%$ & 109 & 81 \\
\hline 100\% Solar Thermal DHW & $-51 \%$ & 103 & 76 \\
\hline
\end{tabular}




\section{Appendix D: Preliminary Information Re- quired for Baseline Characterization for NZE Study}

\section{D.1 General}

- Are Camera permits needed?

- Is a J oint Personnel Adjudication System (J PAS) visit request needed? Additional requirements for Foreign National SMEs?

- Facility Map (electronic if possible).

\section{D.1.1 Definition questions/goals for discussion}

- What is your definition of the end state to be achieved (e.g., Net Zero Energy)?

- Does it apply to all facilities on the installation or a part of the campus (if the latter, which part)?

- What is the time frame to for meeting the ultimate goal?

- Is it a phased approach? If yes, what are these phases?

- Is there any preliminary plan developed to achieve the goal?

- What other goals does the installation want to accomplish along with energy use reduction (e.g., repair buildings, repair and upgrade utilities, accommodate mission changes, improvement of the campus, architectural improvement, improve comfort or indoor air quality (IAQ), etc.)?

- Is there any renewable, carbon footprint, or critical infrastructure requirements that they would like to investigate in the study?

- Listing of historical buildings (relevant for mitigation/ remediation).

\section{D.1.2 Economic questions for discussion}

- What are desired economic characteristics (boundaries): e.g., minimum first costs, LCC?

- Need to Agree on the utility and maintenance labor costs to be used in the analysis.

- Is there any budget allocated for this project or parts of this project?

- Current and projected utility rates and bills as detailed as possible. 


\section{D.1.3 Project structure and points of contact (POCs) at installation}

- Project structure project manager, decision makers, stakeholders, project team (national labs, ESCOs, other contractors), external reviewers?

- Need copies of Organization Charts/ Organization phone listing.

- POCs that are SMEs in:

- Utilities (Water, Electricity, Fuel, Natural Gas, HVAC, Steam)

- Operations

- Local utility/ service providers.

- POCs for utility companies (Electric, Water, Natural Gas, POL).

\section{D.2 Campus and building information}

- Map and boundaries of NetZero Energy area.

- Building Inventory, preferable electronic as a Spreadsheet.

- List of all buildings belonging to the NetZero Energy area.

- Building characteristics or function (Barracks, Head Quarters, Dining, etc.).

- Square footage, number of stories, etc.

- Which existing buildings will be demolished and which will be built?

- Which buildings are planned to be retrofitted under SRM program and what are current scopes of these projects?

- List of industrial facilities and processes and the list of their own ideas related to energy, process improvement and productivity improvements.

- GIS Data. (as applicable. Environmental Systems Research Institute, Inc. (ESRI) electronic format if possible. Best is "File Geodatabase" (*.gdb), followed by “Personal Geodatabase" (*.mdb), and then Shape files.)

- Existing facilities.

- Planned facilities.

- Electrical distribution system (GIS and single line drawings).

- Hot water/ steam distribution system.

- Cold water distribution system.

- Potable water distribution system.

- Storm drainage system.

- Wastewater system (sewers).

- Natural gas distribution system.

- Petroleum, Oils, and lubricants (POL - fuel oil tanks, lines, pumps).

- Installation boundary.

- Backup generators. 
- Transportation network (Roads).

- SCADA systems.

\section{D.3 Air handling/ventilation systems}

- List of systems with the basic characteristics (location, power output, max. and average air flow, age, electricity consumption, combination with air condition, air heat recovery).

\section{D.4 Distribution systems}

- Map of the heating grids with piping diameters and connection points.

- Description of the condition of pipes, insulation qualities, utility tunnels, connection points, buildings interfaces etc.

- What maintenance, repair, and improvement measures in distribution systems are planned already anyway?

- Is there any chilled water distribution grid? Need information, similar to one for heating grid.

- Potential sites for hot/ chilled water thermal storage tanks.

- Potential locations for underground hot \& chilled water distribution piping.

\section{D.5 Supply systems (all, big, and small)}

- List of all heating/ cooling/ DHW plants, boilers, and chillers with their basic characteristics (location, power output, covered buildings, fuel, annual consumption, age, condition, estimated efficiency, need for maintenance and repair etc.).

- Information on any current equipment that could be used at a central plant (or as part of a distributed network). This would include equipment efficiency, generation capacity, remaining life, repair costs (possibility), maintenance costs, etc.

- List of all power generating/ converting facilities with their basic characteristics (location, power output, covered buildings, fuel, annual fuel consumption, age, condition, estimated efficiency, need for maintenance and repair etc.).

- Emergency power generation? Please describe as above.

- Price estimates for recent or planned equipment that should be considered in the study. 


\section{D.6 Basic fuel potentials}

- Which fuels are available on site?

- Roof/ground area available for solar power/ hot water generation?

- Ground water characteristics (depth, temperature, flowing speed).

- Is it allowed, to use the water from adjoining sources for heating or cooling purposes, directly or indirectly? (This question aims for compliance with the legal framework).

- Monthly average wind speed and wind direction.

- Is there a significant potential of forest in the region so wood chips for heating/ cogeneration consideration?

\section{D.7 Possible synergies}

- Are there facilities with a demand for heating/ DHW and cooling at the same time located close to each other? If yes, what are they?

- Is there waste heat on site or nearby (e.g., manufacturing process waste heat) that can be considered as a potential heat source?

\section{D.8 Information required for building modeling}

The following information is required for detailed building modeling. The order of priority is based on when buildings are scheduled to be built or retrofitted

- $\mathrm{CAD}$ drawings with plan and elevation views with material sections for walls, roofs, floors, windows, etc. Enough detail to model the buildings. HVAC drawings as well with specifications of as built equipment.

- It is great to have a plan view of the building colored in with the major function of each area indicated, i.e., office space, classrooms, barracks, etc. This can be electronic or paper.

- For the functional areas need schedules and loads for occupants, lights, equipment, etc.

- Current and projected utility rates and bills as detailed as possible, see above items.

- GIS shape files (see item 2 above).

- Print out of the Site Map with road and building names.

\section{D.9 Project management and customer involvement}

The project was executed under the oversight of ESTCP management and its technical committee by the ERDC team in collaboration with PERTAN 
Company (Figure D-1). The project manager developed good communication channels with the management of each installation and their respective commands. The ERDC R\&D team that has developed the energy master planning concept and the NZ Planner Tool worked closely with PERTAN Company, which included SMEs in energy master planning, building science, mechanical, electrical, and energy systems. Installation team members were an important part of the Project Team and contributed to a better quality of the input data. They provide important contributions to the process of developing different scenarios and defining energy goals and boundary conditions. Customers' participation fostered smoother and faster decision making processes, and facilitated customer buy-in. Installation team members became critical factor during the project implementation phase. The installations' teams included DPW, energy and sustainability managers, master planners, utility and O\&M managers, industrial processes specialists, USACE and NAVFAC engineers, and numerous supporting personnel.

Figure D-1. Project execution and oversight.

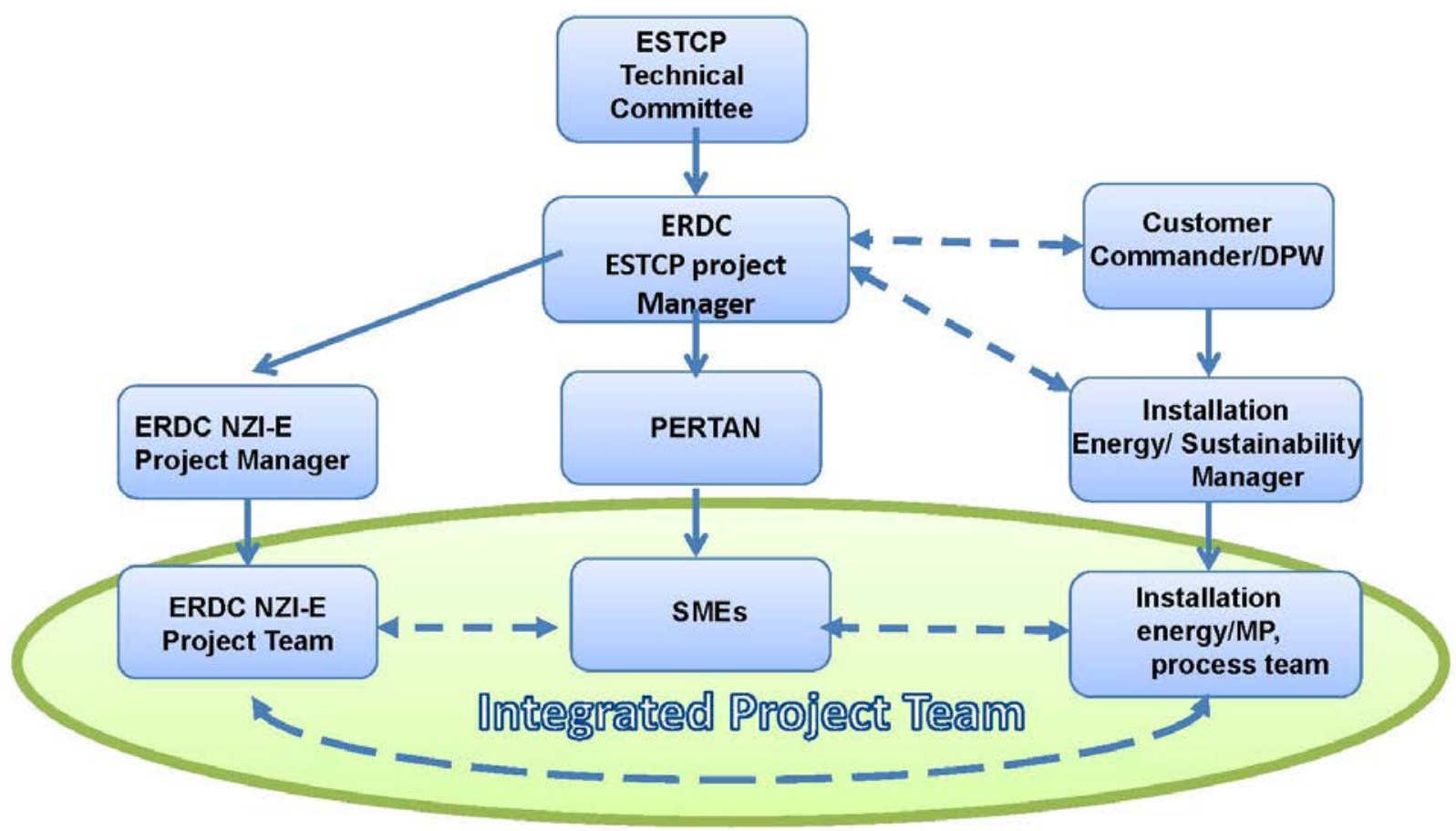




\section{REPORT DOCUMENTATION PAGE}

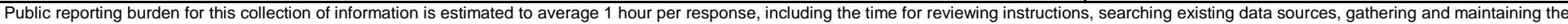

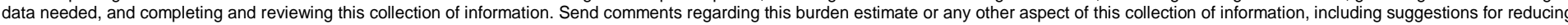

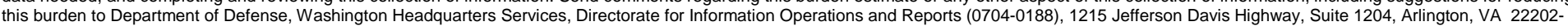

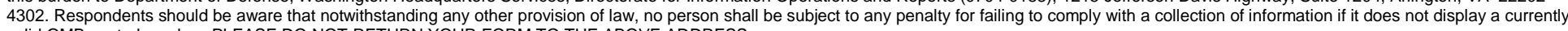
valid OMB control number. PLEASE DO NOT RETURN YOUR FORM TO THE ABOVE ADDRESS
1. REPORT DATE (DD-MM-YYYY)
07-10-2015
2. REPORT TYPE
Final

\section{DATES COVERED (From - To)}

\section{TITLE AND SUBTITLE}

Demonstration of the Energy Component of the Installation Master Plan Using the "Net Zero Energy

Planner" Tool 5a. CONTRACT NUMBER

5b. GRANT NUMBER

5c. PROGRAM ELEMENT

5d. PROJECT NUMBER

6. AUTHOR(S)

Alexander M. Zhivov, Michael. P. Case, Richard Liesen, and Matthew Swanson

\section{5e. TASK NUMBER}

\section{5f. WORK UNIT NUMBER}

8. PERFORMING ORGANIZATION REPORT NUMBER

ERDC/ CERL TR-15-28

U.S. Army Engineer Research and Development Center (ERDC)

Construction Engineering Research Laboratory (CERL)

PO Box 9005

Champaign, IL 61826-9005

\section{SPONSORING / MONITORING AGENCY NAME(S) AND ADDRESS(ES)}

SERDP/ESTCP

4800 Mark Center Drive, Suite 17D08

Alexandria, VA 22350-3605
10. SPONSOR/MONITOR'S ACRONYM(S)

11. SPONSOR/MONITOR'S REPORT NUMBER(S)

\section{DISTRIBUTION I AVAILABILITY STATEMENT}

Approved for public release; distribution is unlimited.

\section{SUPPLEMENTARY NOTES}

\section{ABSTRACT}

This work demonstrated the energy master planning (EMP) concept and automated Net Zero Planner tool (NZP) developed by the Army Engineer Research and Development Center (ERDC) at two U.S. Department of Defense (DoD) installations: United States Military Academy, West Point (USMA) and Portsmouth Navy Shipyard (PNSY). The NZP Tool incorporates the concept and various automated modules to integrate optimization across buildings, distribution, and generation systems. Results demonstrated that use of the NZP Tool reduces the time required for the analysis and the analysis cost to $\sim 35 \%$ of the time required by the alternative current best practice. Lessons learned from the project were used to make many user interface changes were made throughout the program to facilitate the process, to ease data entry, and to help determine the information required to produce useful, relevant output reports. Funding for this demonstration was provided by the Environmental Security Technology Certification Program (ESTCP) - Energy and Water Project \# EW-201240.

\section{SUBJECT TERMS}

energy master planning (EMP), Net Zero Planner (NZP), United States Military Academy, West Point (USMA), Portsmouth Navy Shipyard (PNSY), Environmental Security Technology Certification Program (ESTCP), energy efficient

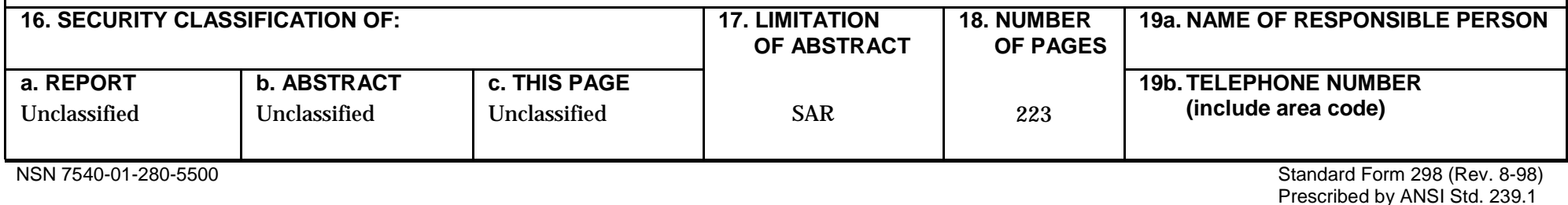

